DANIEL JOSÉ DA SILVA

APLICAÇÃO DE ESPECTROSCOPIAS VIBRACIONAIS E MÉTODOS QUIMIOMÉTRICOS AVANÇADOS NO CONTROLE DE QUALIDADE DE BLENDAS POLIMÉRICAS RECICLADAS DE PEBD/PEAD 
DANIEL JOSÉ DA SILVA

\title{
APLICAÇÃO DE ESPECTROSCOPIAS VIBRACIONAIS E MÉTODOS QUIMIOMÉTRICOS AVANÇADOS NO CONTROLE DE QUALIDADE DE BLENDAS POLIMÉRICAS RECICLADAS DE PEBD/PEAD
}

\author{
Tese apresentada a Escola Politécnica da \\ Universidade de São Paulo para obtenção \\ do título de Doutor em Ciências
}




\title{
APLICAÇÃO DE ESPECTROSCOPIAS VIBRACIONAIS E MÉTODOS QUIMIOMÉTRICOS AVANÇADOS NO CONTROLE DE QUALIDADE DE BLENDAS POLIMÉRICAS RECICLADAS DE PEBD/PEAD
}

\author{
Versão Corrigida
}

Tese apresentada a Escola Politécnica da Universidade de São Paulo para obtenção do título de Doutor em Ciências

Área de concentração:

Engenharia Metalúrgica e de Materiais

Orientador: Prof. Dr. Hélio Wiebeck

São Paulo 
Autorizo a reprodução e divulgação total ou parcial deste trabalho, por qualquer meio convencional ou eletrônico, para fins de estudo e pesquisa, desde que citada a fonte.

Este exemplar foi revisado e corrigido em relação à versão original, sob responsabilidade única do autor e com a anuência de seu orientador.

São Paulo, de de

Assinatura do autor:

Assinatura do orientador:

Catalogação-na-publicação

da Silva, Daniel José

Aplicação de espectroscopias vibracionais e métodos quimiométricos avançados no controle de qualidade de blendas poliméricas recicladas de PEBD/PEAD / D. J. da Silva -- versão corr. -- São Paulo, 2020. $126 \mathrm{p}$.

Tese (Doutorado) - Escola Politécnica da Universidade de São Paulo. Departamento de Engenharia Metalúrgica e de Materiais.

1.regressão PLS 2.misturas poliméricas 3.polietileno 4.espectroscopia ATR-FTIR 5.espectroscopia Raman confocal I.Universidade de São Paulo. Escola Politécnica. Departamento de Engenharia Metalúrgica e de Materiais II.t. 
DEDICATÓRIA

Dedico esta obra ao Tao que me guiou para o desenvolvimento da mesma... 


\section{AGRADECIMENTOS}

Ao orientador Prof. Dr. Hélio Wiebeck pela oportunidade, confiança e suporte para o desenvolvimento deste trabalho.

À professora Dra. Wang Shu Hui pelo auxílio com as análises de espectroscopia ATR-FTIR e processamento dos polímeros.

À Dra. Duclerc F. Parra e ao técnico de laboratório Eleosmar, ambos do CQMA-IPEN, pela realização das análises térmicas das amostras.

Ao técnico de laboratório Igor Yamamoto Abê do Laboratório de Microeletrônica (Poli-USP) pela realização das medidas espectroscópicas de Raman confocal.

Às empresas NZ Cooperpolymer e Drypol-Recyclean por ter gentilmente doado os polímeros reciclados usados nesta pesquisa.

À Universidade de São Paulo e ao Departamento de Engenharia Metalúrgica e de Materiais da Escola Politécnica da USP pelo apoio, pelas oportunidades e pela formação nestes últimos seis anos.

O presente trabalho foi realizado com apoio da Coordenação de Aperfeiçoamento de Pessoal de Nível Superior - Brasil (CAPES) - Código de Financiamento 001.

Obrigado! 
"O sábio não se exibe, por isso brilha.

Ele não se faz notar, e por isso é notado.

Ele não se elogia, e por isso tem mérito. E, porque não está competindo, ninguém no mundo pode competir com ele." 


\section{SUMÁRIO}

LISTA DE ABREVIATURAS E SÍMBOLOS …...............................................................

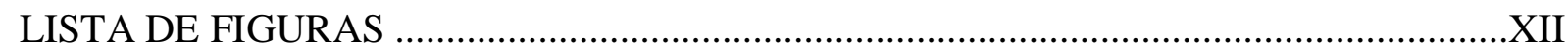

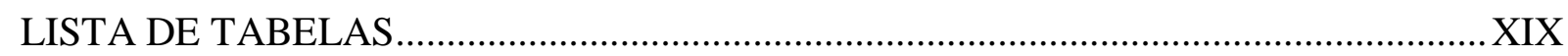

RESUMO

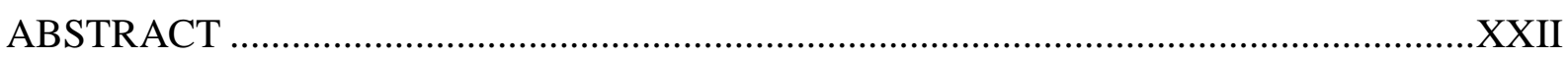

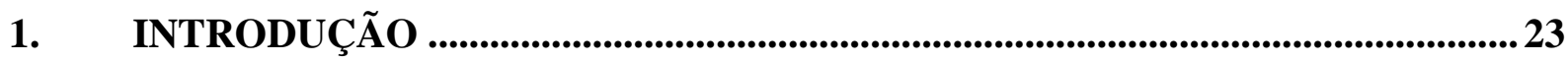

1.1. RELEVÂNCIA E JUSTIFICATIVA DA PESQUISA …......................................... 23

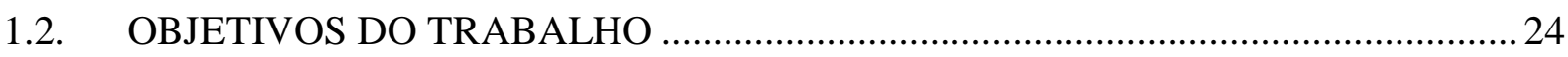

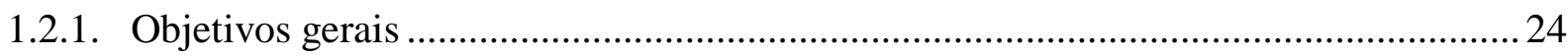

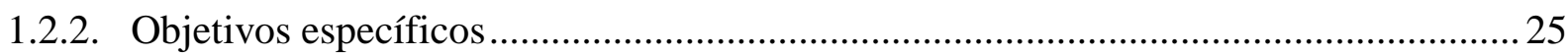

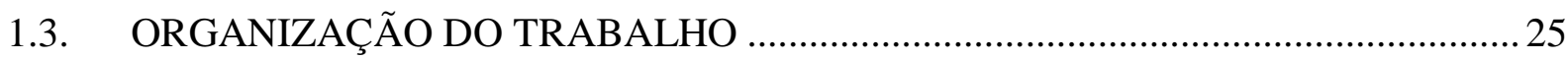

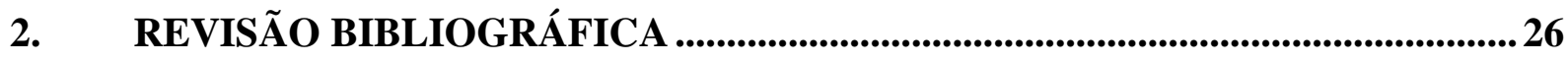

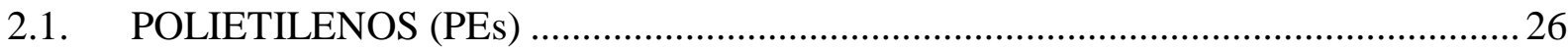

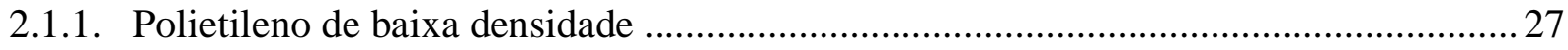

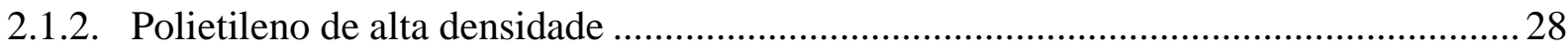

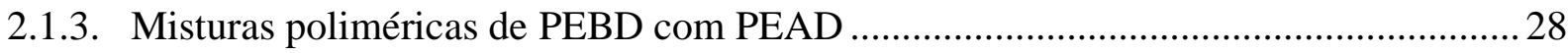

2.2. ESPECTROSCOPIA DE ABSORÇÃO NO INFRAVERMELHO ............................. 31

2.3. ESPECTROSCOPIA DE ESPALHAMENTO RAMAN ............................................. 34

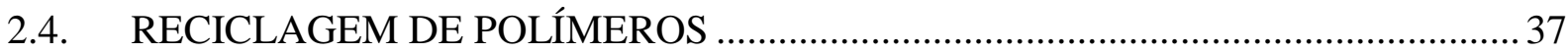

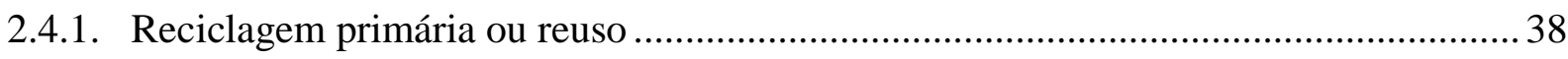

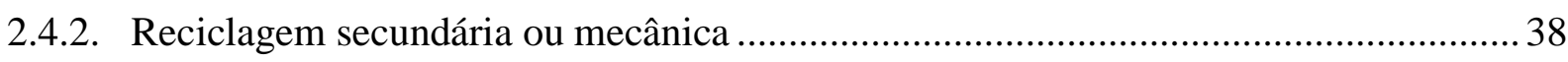

2.4.3. Controle de qualidade dos resíduos poliméricos no processo de reciclagem ............... 42

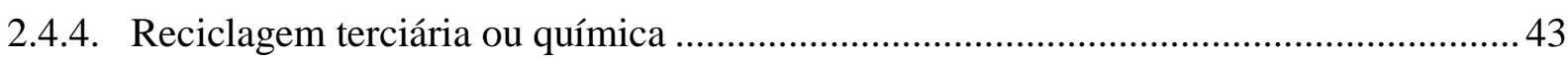

2.4.5. Reciclagem quaternária ou recuperação energética................................................ 44

2.4.6. Formas alternativas de reciclagem de resíduos plásticos ......................................... 46 
2.5. MÉTODOS DE CALIBRAÇÃO MULTIVARIADA ….......................................... 47

2.5.1. Regressão linear por mínimos quadrados parciais (PLS) …...................................... 47

2.5.2. Calibração e validação do modelo de predição ............................................................ 49

2.5.3. Regressão linear por mínimos quadrados parciais por intervalos (iPLS) ....................50

2.5.4. Regressão linear por mínimos quadrados parciais e amostragem ponderada adaptativa

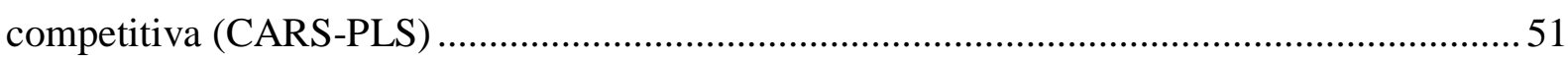

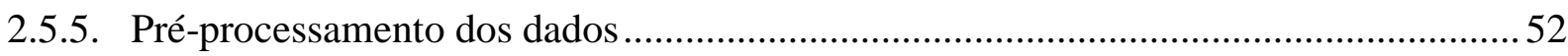

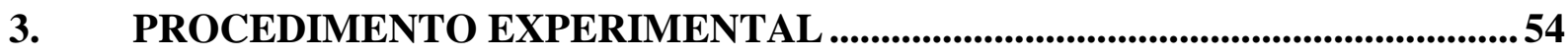

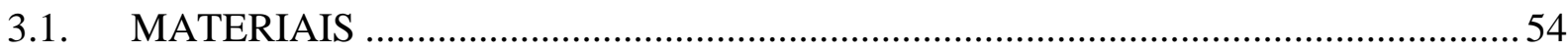

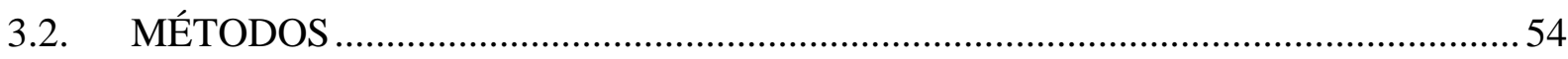

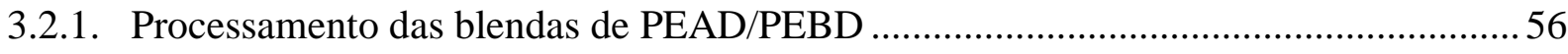

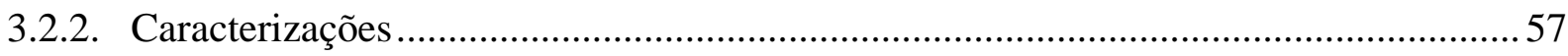

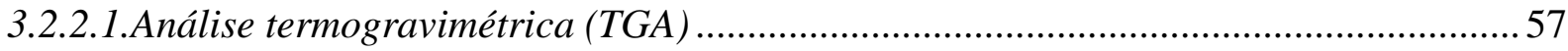

3.2.2.2. Microscopia eletrônica de varredura (MEV) e espectroscopia de energia dispersiva $(E D S)$

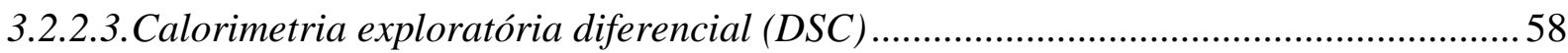

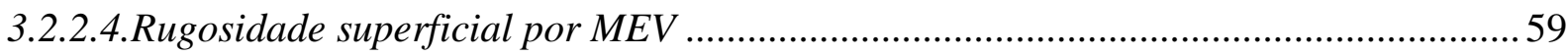

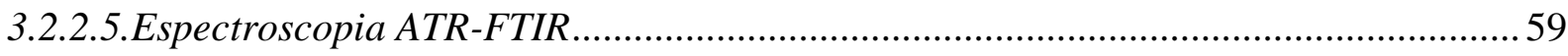

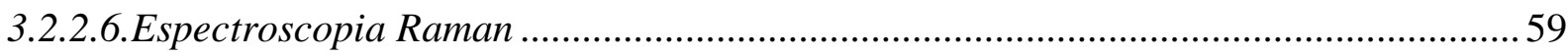

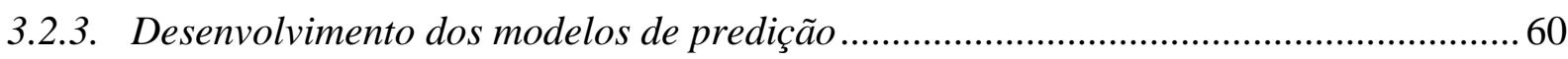

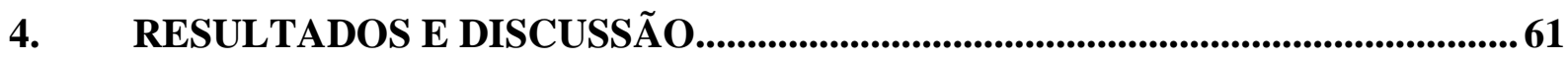

4.1. CARACTERIZAÇÃO DOS POLIETILENOS PRISTINOS E RECICLADOS ......... 61

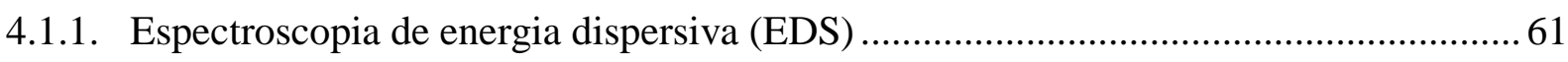

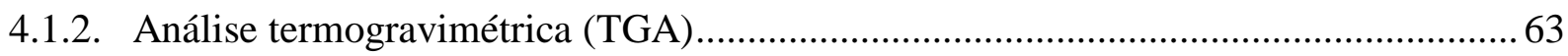

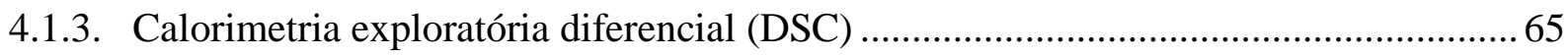

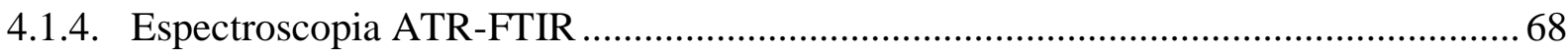




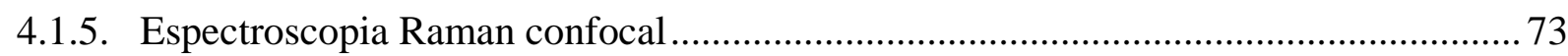

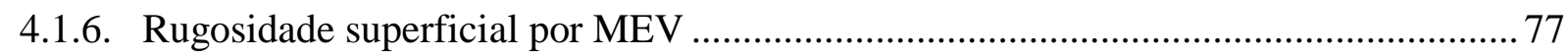

4.2. MODELOS DE PREDIÇÃO USANDO ESPECTROSCOPIA ATR-FTIR................ 79

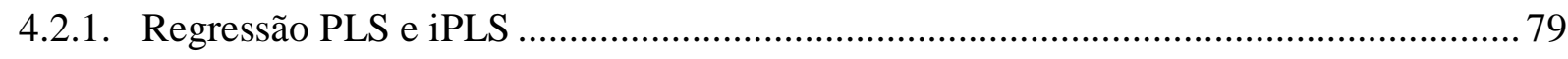

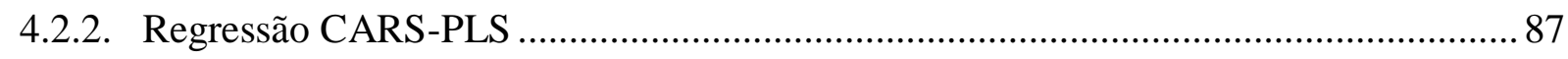

4.2.3. Desempenho do modelo preditivo para misturas poliméricas recicladas contendo

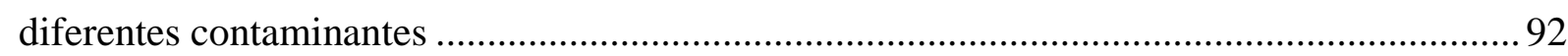

4.3. MODELOS DE PREDIÇÃO USANDO ESPECTROSCOPIA RAMAN

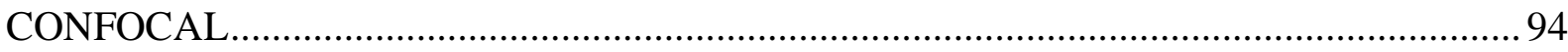

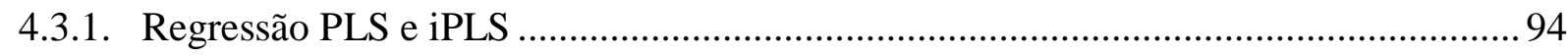

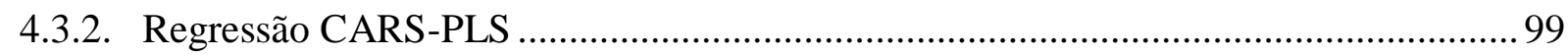

4.3.3. Desempenho do modelo preditivo para misturas poliméricas recicladas contendo

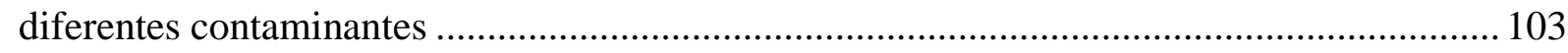

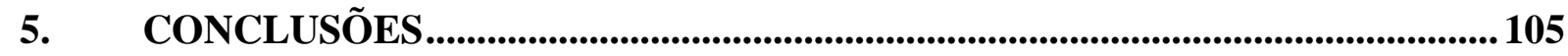

6. REFERÊNCIAS BIBLIOGRÁFICAS ................................................................... 107

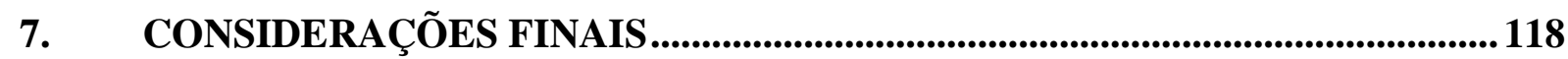

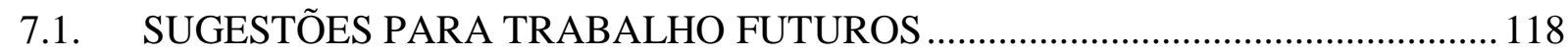

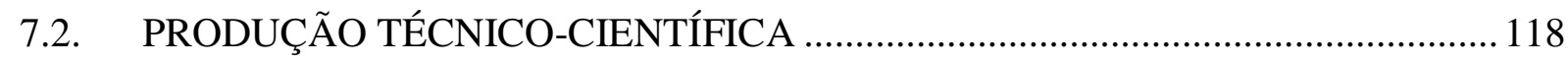

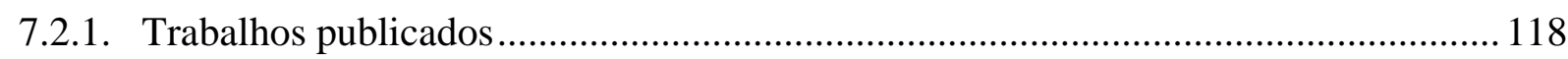

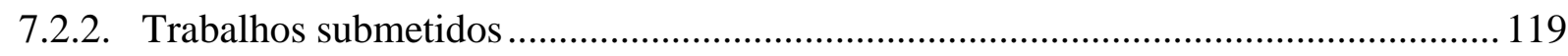

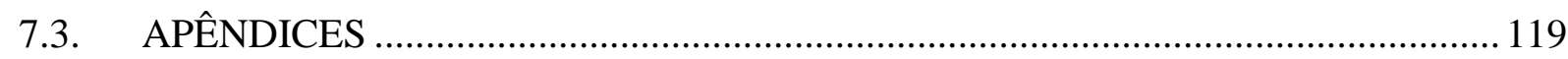

7.3.1. Apêndice A - Micrografias da superfície e imagens tridimensionais de superfície das

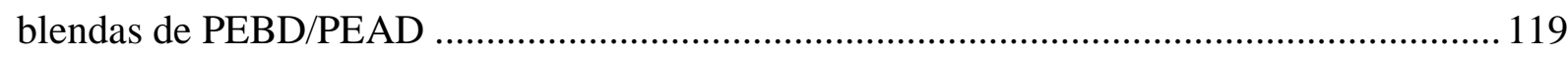

7.3.2. Apêndice B - Espectros ATR-FTIR das misturas poliméricas de PEAD/PEBD recicladas com diferentes contaminantes

7.3.3. Apêndice $\mathrm{C}$ - Espectros de Raman confocal das misturas poliméricas de PEAD/PEBD

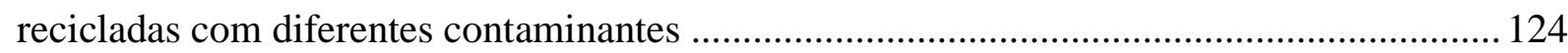




\section{LISTA DE ABREVIATURAS E SÍMBOLOS}

$\%$ p - Porcentagem em massa

$\hat{y}_{i}$ - Concentração prevista da amostra

$\hat{y}_{\text {mean }}$ - Média de concentração de referência de todas as amostras nos conjuntos de validação cruzada ou teste externo

$\mathrm{R}_{N}$ - Refletância total atenuada

$E_{0}$ - Amplitude original da radiação incidente

$f_{p}$ - Fração em peso do polímero na mistura

$n_{1}$ - Índice de refração do cristal ATR

$n_{2}$ - Índice de refração da amostra

$n_{m}$ - Índice de refração do meio de imersão

$q_{0}$ - Amplitude vibracional da ligação química

$r_{i}$ - Função exponencial EDF

$v_{0}$ - Frequência original da radiação incidente

$v_{v}$ - Frequência vibracional da ligação

$w_{C A R S}-$ Coeficiente de peso na regressão CARS-PLS

$y_{i}$ - Concentração de referência da amostra i

$\alpha_{e}$ - Polarizabilidade estática da ligação

$\theta_{C^{-}}$Ângulo de incidência crítico

$\rho_{a}$ - Densidade do polímero $100 \%$ amorfo 
$\rho_{c}-$ Densidade do polímero $100 \%$ cristalino

$\chi_{c}$ - Grau de cristalinidade (percentual de cristalinidade do polímero)

$\partial \alpha / \partial q$ - Primeira derivada parcial da polarizabilidade da ligação em função da distância internuclear

$\Delta H_{C}$ - Entalpia de cristalização secundária

$\Delta H$ - Entalpia específica de fusão cristalina da amostra

$\Delta H^{\circ}$ - Entalpia específica de fusão cristalina teórica para um polímero totalmente cristalino

$\mu \mathrm{m}$ - Micrômetro

3D - Tridimensional

Al - Alumínio

ARF - Amostragem ponderada adaptativa

ATR-FTIR - Espectroscopia de infravermelho por transformada de Fourier usando Reflexão

Total Atenuada

$B$ - Matriz de coeficientes de regressão

C - Carbono

$\mathrm{CaCO}_{3}$ - Carbonato de cálcio

CARS-PLS - Regressão linear por mínimos quadrados parciais e amostragem ponderada adaptativa competitiva

$\mathrm{cm}-$ Centímetro

$\mathrm{CO}_{2}$ - Dióxido de carbono

DMTA - Análise térmica dinâmico-mecânica 
DSC - Calorimetria exploratória diferencial

DTG - Termogravimetria derivada

$E$ - Matriz de erros residuais da matriz $X$

EDF - Função de diminuição exponencial

EDS - Espectroscopia de energia dispersiva

$F$ - Matriz de erros residuais da matriz $Y$

$\mathrm{Fe}-$ Ferro

$\mathrm{FeO}$ - Óxido de ferro

FIR - Infravermelho distante

FTIR - Espectroscopia de infravermelho por transformada de Fourier

FWHM - Largura à meia altura

g- Gramas

$G$ - Matriz de erros aleatórios

$\mathrm{g} / 10$ min - Gramas por dez minutos

$\mathrm{g} / \mathrm{cm}^{3}$ - Gramas por centímetro cúbico

Ge - Germânio

$h$ - Número de variáveis latentes (LVs)

HDPE - High density polyethylene

HSI - Imagem hiper-espectral

IF - Índice de fluidez 
iPLS - Regressão linear por mínimos quadrados parciais por intervalos

$k$ - Número de respostas medidas para uma amostra

K - Potássio

kg - Quilogramas

KRS-5 - Bromoiodeto de tálio

LDPE - Low density polyethylene

$\mathrm{LV}_{\text {ótimo }}$ - Número ótimo de variáveis latentes

LVs - Número de variáveis latentes

$m$ - Número de propriedades de interesse

MDS - Separação por densidade magnética

MEV - Microscopia eletrônica de varredura

Mg - Magnésio

$\min -$ Minuto

MIR - Infravermelho médio

$\mathrm{mL}$ - Mililitro

$\mathrm{mL} / \mathrm{min}$ - Mililitro por minuto

mm - Milímetro

mW - Milíwatts

$n$ - Número de observações da propriedade de interesse

$\mathrm{N}_{2}-$ Gás nitrogênio 
$\mathrm{Na}$ - Sódio

NIR - Infravermelho próximo

nm - Nanômetro

$\mathrm{NO}_{\mathrm{x}}$ - Óxidos de nitrogênio

$\mathrm{O}$ - Oxigênio

${ }^{\circ} \mathrm{C}$ - Graus Celsius

${ }^{\circ} \mathrm{C} / \mathrm{min}$ - Graus Celsius por minuto

$P$ - Matriz com valores de carregamento da matriz $X$

PCA - Análise por componentes principais

PEAD - Polietileno de alta densidade

PEBD - Polietileno de baixa densidade

PELBD - Polietileno linear de baixa densidade

PEs - Polietilenos

PET - Poli(tereftalato de etileno)

PEUAPM - Polietileno de ultra-alto peso molecular

PEUBD - Polietileno de ultrabaixa densidade

PLS - Regressão linear por mínimos quadrados parciais

PP - Polipropileno

PS - Poliestireno

PVC - Poli(cloreto de vinila) 
$Q$ - Matriz com valores de carregamento da matriz $Y$

$\mathrm{R}_{\mathrm{a}}$ - Rugosidade média

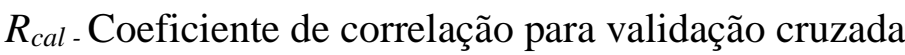

RGB - Sistema de cores aditivas constituído pelos tons de vermelho (Red), verde (Green) e azul (Blue).

RMSECV - Erro quadrático médio de validação cruzada

RMSEP - Erro quadrático médio de predição

rpm - rotações por minuto

$R_{\text {pred }}$ - Coeficiente de correlação para validação externa

$\mathrm{R}_{\mathrm{q}}$ - Rugosidade quadrática média

RSPs - Resíduos sólidos poliméricos

RSUs - Resíduos sólidos urbanos

s - Segundo

$\mathrm{Si}-$ Silício

$\mathrm{SO}_{2}$ - Dióxido de enxofre

$t$ - Escores da matriz $X$

$T$ - Matriz de pontuação para a matriz $X$

TGA - Análise termogravimétrica

$\mathrm{T}_{\mathrm{m}}$ - Temperatura de fusão cristalina

$\mathrm{T}_{\max }$ - Temperatura de máxima decomposição térmica

$\mathrm{T}_{\text {onset }}$ - Temperatura de início de decomposição térmica 
$u$ - Escores da matriz $Y$

$U$ - Matriz de pontuação para a matriz $Y$

UCST - Temperatura Crítica de Solução Superior (Upper Critical Solution Temperature)

UV - Ultravioleta

$w$ - Coeficientes de peso

WAXS - Difratometria de raios-X de alto ângulo

WPCs - Wood/plastic composites

$X$ - Conjunto de dados instrumentais

$x$ - Elementos da matriz $X$

$Y$ - Conjunto de dados de uma dada propriedade

$y$ - Elementos da matriz $Y$

ZnSe - Seleneto de zinco

$\Delta$ - Deslocamento axial do laser na superfície da amostra

$D R$ - Profundidade de campo

$M$ - Momento de dipolo elétrico induzido

$N$ - Número de reflexões

$N A$ - Abertura numérica da lente objetiva

$R$ - Coeficiente de correlação

$d p$ - Profundidade de penetração

$t-$ Tempo 
Z - Número de espectros

$\alpha$ - Coeficiente de absorção

$\theta$ - Ângulo de incidência

$\lambda$ - Comprimento de onda

$\rho$ - Densidade específica da amostra 


\section{LISTA DE FIGURAS}

FIGURA 1 - ESTRUTURA QUÍMICA DOS POLIETILENOS. 26

FIGURA 2 - CÉLULAS UNITÁRIAS OBSERVADAS NOS POLIETILENOS. FONTE: ADAPTADO DE (NEJABAT, 2018) E (YOUNG; LOVELL, 2011). .27

FiguRA 3 - REPRESENTAÇÃO DE UMA CADEIA POLIMÉRICA DO PEAD (A) E DO PEBD (B) (MOORI, 2014). 28

FIGURA 4 - REPRESENTAÇÃO ESQUEMÁTICA DA SEPARAÇÃO DE FASES EM BLENDAS POLIMÉRICAS CONTENDO DOIS COMPONENTES: A) BLENDA MISCÍVEL; B) BLENDA IMISCÍVEL; C) BLENDA PARCIALMENTE MISCÍVEL. AS LINHAS SÓLIDAS REPRESENTAM AS CADEIAS POLIMÉRICAS DO POLÍMERO A E AS LINHAS TRACEJADAS REPRESENTAM AS CADEIA POLIMÉRICAS DO POLÍMERO B (MUNARO, 2007).

FigURA 5 - DiAGRAMA DE FASE TEMPERATURA-COMPOSIÇÃO PARA UMA MISTURA IMISCÍVEL DE POLIETILENOS COM DIFERENTES QUANTIDADES DE RAMIFICAÇÕES. SENDO QUE, ESTE É UM DIAGRAMA DE TEMPERATURA CRÍTICA DE SOLUÇÃO SUPERIOR (UPPER CRITICAL SOLUTION TEMPERATURE, UCST). FONTE: ADAPTADO DE (NWABUNMA; KYU, 2008). 30

FIGURA 6 - TIPOS DE VIBRAÇÕES DE ESTIRAMENTOS E DEFORMAÇÕES MOLECULARES DETECTADOS NA ESPECTROSCOPIA DE INFRAVERMELHO. FONTE: ADAPTADO DE (COSTA, 2013).

FIGURA 7 - REPRESENTAÇÃO DA PROPAGAÇÃO DA RADIAÇÃO INFRAVERMELHA NA INTERFACE AMOSTRA/CRISTAL DE UM ACESSÓRIO ATR (VIERA, 2011) .33

FIGURA 8 - ESPALHAMENTO DE FÓTONS DO TIPO ELÁSTICO (RAYLEIGH) E INELÁSTICO (EFEITO RAMAN POR ESPALHAMENTO STOKES OU ANTI-STOKES). “G” E “I” CORRESPONDEM AO ESTADO VIBRACIONAL FUNDAMENTAL E VIRTUAL (INTERMEDIÁRIO) DA MOLÉCULA, RESPECTIVAMENTE (ANDO, 2005).

FIGURA 9 - SIMBOLOGIA PARA IDENTIFICAR POLÍMEROS SEGUNDO A NORMA ABNT 13.230 (PLASTIVIDA, 2016) 
FIGURA 10 - ESQUEMA DA CLASSIFICAÇÃO DE POLÍMEROS POR DIFERENÇAS DE DENSIDADE (SPINACÉ; DE PAOLI, 2005).

FIGURA 11 - FLUXOGRAMA DO ALGORITMO NIPALS (WOLD; SJÖSTRÖM; ERIKSSON, 2001).

FIGURA 12 - SEQUÊNCIA DE ETAPAS ADOTADAS PARA DESENVOLVIMENTO DESTE PROJETO DE PESQUISA.

FIGURA 13 - IMAGEM FOTOGRÁFICA DOS POLIETILENOS PRISTINOS E RECICLADOS, ANTES E APÓS EXTRUSÃO. 56

FIGURA 14 - IMAGENS DE MEV DO PEAD RECICLADO E SEUS RESPECTIVOS ESPECTROS DE EDS (À DIREITA). .61

FIGURA 15 - IMAGENS DE MEV DO PEBD RECICLADO E SEUS RESPECTIVOS ESPECTROS DE EDS (À DIREITA). 63

FIGURA 16 - CURVAS DE TGA E DTG PARA O PEBD PRISTINO E RECICLADO. 64

FIGURA 17 - CURVAS DE TGA E DTG PARA O PEAD PRISTINO E RECICLADO. .65

FIGURA 18 - CURVAS DSC DO PEAD PRISTINO E RECICLADO. .66

FIGURA 19 - CURVAS DSC DO PEBD PRISTINO E RECICLADO. 67

FIGURA 20 - ESPECTROS DE ATR-FTIR DO PEBD E PEAD (PRISTINOS E RECICLADOS). ORIGEM DO SINAL: (C) FASE CRISTALINA; (A) FASE AMORFA. .68

FIGURA 21 - MODIFICAÇÕES NAS BANDAS DE ABSORÇÃO IR PARA A BLENDA DE PEBD/PEAD (MISTURA DE POLÍMEROS PRISTINOS) DEVIDO À SUA COMPOSIÇÃO: $735-715 \mathrm{CM}^{-1}$ (A) E 1450-1480 $\mathrm{CM}^{-1}$ (B). OBS.: ESTES ESPECTROS DE ATR-FTIR REFEREM-SE À MÉDIA DE MEDIDAS REALIZADAS EM TRIPLICATA.

FIGURA 22 - INTENSIDADE NORMALIZADA PARA TODAS AS BANDAS DE ABSORÇÃO ATR-FTIR DE TODAS AS BLENDAS DE PEAD/PEBD OBTIDAS COM POLÍMEROS PRISTINOS. .70 
FigurA 23 - LARGURA À MEIA ALTURA (FWHM) PARA TODAS AS BANDAS DE ABSORÇÃO ATRFTIR DE TODAS AS BLENDAS DE PEAD/PEBD OBTIDAS COM POLÍMEROS PRISTINOS. .......71

FiguRA 24 - DECOMPOSIÇÃo dOS ESPECTROS ATR-FTIR DO PEBD E PEAD (PRISTINOS E RECICLADOS) NA REGIÃO DE 1340-1390 CMำ , USANDO FUNÇÃO GAUSSIANA. .72

FIGURA 25 - DECOMPOSIÇÃo GAUSSIANA DOS ESPECTROS ATR-FTIR NA REGIÃO DE 1340-1390 $\mathrm{CM}^{-1}$ PARA AS DAS BLENDAS DE PEBD/PEAD OBTIDAS COM POLIETILENOS (COMPOSIÇÃO EM \%P): PRISTINOS - (A) 75/25, (C) 50/50 E (E) 25/75; RECICLADOS - (B) 75/25, (D) 50/50 E (F) $25 / 75$

FIGURA 26 - ESPECTROS DE RAMAN CONFOCAL DO PEBD E PEAD (PRISTINOS E RECICLADOS) APÓS O PROCESSO DE EXTRUSÃO. ORIGEM DO DESLOCAMENTO: (C) FASE CRISTALINA; (A) FASE AMORFA. .74

FIGURA 27 - MODIFICAÇÕES NA INTENSIDADE DOS DESLOCAMENTOS RAMAN (GRUPO -CH $2^{-}$) PARA A BLENDA DE PEBD/PEAD (MISTURA DE POLÍMEROS PRISTINOS) DEVIDO À SUA COMPOSIÇÃO: FAIXA DE 1350 A $1500 \mathrm{CM}^{-1}$. (A): FASE AMORFA; (C): FASE CRISTALINA. ... 75

FIGURA 28 - INTENSIDADE NORMALIZADA PARA TODAS AS BANDAS DE DESLOCAMENTO RAMAN DE TODAS AS BLENDAS DE PEAD/PEBD OBTIDAS COM POLÍMEROS PRISTINOS .76

FIGURA 29 - LARGURA À MEIA ALTURA (FWHM) PARA TODAS AS BANDAS DE DESLOCAMENTO RAMAN DE TODAS AS BLENDAS DE PEAD/PEBD OBTIDAS COM POLÍMEROS PRISTINOS....77

FIGURA 30 - RUGOSIDADE DAS BLENDAS DE PEBD/PEAD OBTIDAS COM POLÍMEROS PRISTINOS.

FIGURA 31 - RUGOSIDADE DAS BLENDAS DE PEBD/PEAD OBTIDAS COM POLÍMEROS RECICLADOS. .79

FIGURA 32 - ESPECTROS ATR-FTIR DAS BLENDAS DE PEAD/PEBD (OBTIDAS COM POLÍMEROS PRISTINOS) E SUA SEGMENTAÇÃO EM 10 INTERVALOS PELO MÉTODO IPLS. 81

FIGURA 33 - VARIAÇÃO DO RMSECV EM FUNÇÃO DO NÚMERO DE VARIÁVEIS LATENTES, USANDO DIFERENTE NÚMERO DE SUBINTERVALOS (1, 10, 20, 30, 40 E 50), USANDO DADOS 
DE ATR-FTIR. O NÚMERO DE SUBINTERVALOS É 1 PARA REGRESSÃO PLS E MAIOR QUE 1 PARA REGRESSÃO IPLS

FIGURA 34 - VALORES DE RMSECV PARA CADA INTERVALO USANDO A REGRESSÃO IPLS NOS ESPECTROS DE ATR-FTIR. OS NÚMEROS DENTRO DAS BARRAS CORRESPONDEM À QUANTIDADE DE VARIÁVEIS LATENTES EM CADA SUBINTERVALO. 83

FIGURA 35 - REFERÊNCIA VS. PREVISÃO DO TEOR DE PEBD (\%P) NAS BLENDAS DE PEAD/PEBD (MATERIAL PRISTINO). DADOS OBTIDOS COM O MODELO IPLS30 (MODELO CONSTRUIIDO COM O ALGORITMO IPLS, DADOS ATR-FTIR SUBDIVIDIDOS EM 30 INTERVALOS E 11 LVS)

FIGURA 36 - REGIÃO DO ESPECTRO FTIR SELECIONADA PARA A CONSTRUÇÃO DO MODELO IPLS30. .85

FIGURA 37 - REFERÊNCIA VS. PREVISÃO DE TEOR DE PEBD (\%P) NAS BLENDAS DE PEAD/PEBD (MATERIAL RECICLADO). DADOS OBTIDOS COM O MODELO IPLS30. 86

FIGURA 38 - ESPECTROS ATR-FTIR DAS BLENDAS DE PEAD/PEBD OBTIDAS COM POLÍMEROS RECICLADOS. A REGIÃO DO ESPECTRO SELECIONADA PELO MODELO IPLS30 ESTÁ DESTACADA EM CINZA. 86

FIGURA 39 - REFERÊNCIA VS. PREDIÇÃO DO TEOR DE PEBD (\%P) NAS BLENDAS DE PEAD/PEBD (MATERIAL PRISTINO E DADOS ATR-FTIR). DADOS OBTIDOS POR REGRESSÃO CARS-PLS, USANDO VÁRIOS NÚMEROS DE CICLOS DE AMOSTRAGEM DE Monte CARlo: (A) 50, (B) 100, (C) 500, (D) 1000, (E) 5000 E (F) 10000. (PARÂMETROS CONSTANTES: MÉTODO DE PRÉ-TRATAMENTO = CENTRALIZAÇÃO MÉDIA; VALIDAÇÃO CRUZADA K-FOLD = 15; NÚMERO MÁXIMO DE LVS = 20). .90

FIGURA 40 - REFERÊNCIA VS. PREVISÃO DE TEOR DE PEBD (\%P) NAS BLENDAS DE PEAD/PEBD (MATERIAL RECICLADO). DADOS OBTIDOS COM O MODELO PLS-C20.

FIGURA 41 - REFERÊNCIA VS. PREVISÃO DO TEOR DE PEBD (\%P) NAS BLENDAS POLIMÉRICAS DE PEAD/PEBD (MATERIAL RECICLADO). DADOS OBTIDOS COM O MODELO IPLS30 E DADOS ESPECTRAIS ATR-FTIR. AS MISTURAS POLIMÉRICAS RECICLADAS CONTÊM 5 \%P DE DIFERENTES CONTAMINANTES: (A) $\mathrm{CACO}_{3}$, (B) PET, (C) PP E (D) SÍLICA GEL .93 
FiguRA 42 - VARIAÇÃo DA RUGOSIDADE R $_{\mathbf{Q}}$ NOS PÉLETES DE PEAD E PEBD RECICLADOS DEVIDO À ADIÇÃO DE DIFERENTES CONTAMINANTES.

FIGURA 43 - ESPECTROS RAMAN CONFOCAL DAS BLENDAS DE PEAD/PEBD (OBTIDAS COM POLÍMEROS PRISTINOS) E SUA SEGMENTAÇÃO EM 10 INTERVALOS PELO MÉTODO IPLS.....94

FIGURA 44 - VARIAÇÃO DO RMSECV EM FUNÇÃO DO NÚMERO DE VARIÁVEIS LATENTES, USANDO DIFERENTE NÚMERO DE SUBINTERVALOS (1, 10, 20, 30, 40 E 50), USANDO DADOS DE ESPECTROSCOPIA RAMAN CONFOCAL. O NÚMERO DE SUBINTERVALO É 1 PARA REGRESSÃO PLS E MAIOR QUE 1 PARA REGRESSÃO IPLS.

FIGURA 45 - REFERÊNCIA VS. PREVISÃO DO TEOR DE PEBD (\%P) NAS BLENDAS DE PEAD/PEBD (MATERIAL PRISTINO). DADOS OBTIDOS COM O MODELO IPLS30R (MODELO CONSTRUÍDO COM O ALGORITMO IPLS, DADOS ESPECTRAIS RAMAN SUBDIVIDIDOS EM 30 INTERVALOS E 4 LVS). .97

FIGURA 46 - REGIÃO DO ESPECTRO RAMAN SELECIONADA PARA A CONSTRUÇÃO DO MODELO IPLS30R

FIGURA 47 - REFERÊNCIA VS. PREVISÃO DE TEOR DE PEBD (\%P) NAS BLENDAS DE PEAD/PEBD (MATERIAL RECICLADO). DADOS OBTIDOS COM O MODELO IPLS30R .98

FIGURA 48 - ESPECTROS RAMAN DAS BLENDAS DE PEAD/PEBD OBTIDAS COM POLÍMEROS RECICLADOS. A REGIÃO DO ESPECTRO SELECIONADA PELO MODELO IPLS30R ESTÁ DESTACADA EM CINZA.

FIGURA 49 - REFERÊNCIA VS. PREDIÇÃO DO TEOR DE PEBD (\%P) NAS BLENDAS DE PEAD/PEBD (MATERIAL PRISTINO E DADOS DE RAMAN CONFOCAL). DADOS OBTIDOS COM REGRESSÃO CARS-PLS, USANDO VÁRIOS NÚMEROS DE CICLOS DE AMOSTRAGEM DE Monte CARlo: (A) 50, (B) 100, (C) 500, (D) 1000, (E) 5000 E (F) 10000. (PARÂMETROS CONSTANTES: MÉTODO DE PRÉ-TRATAMENTO = CENTRALIZAÇÃO MÉDIA; VALIDAÇÃO CRUZADA K-FOLD = 15; NÚMERO MÁXIMO DE LVS = 20).

FIGURA 50 - REFERÊNCIA VS. PREVISÃO DE TEOR DE PEBD (\%P) NAS BLENDAS DE PEAD/PEBD (MATERIAL RECICLADO). DADOS OBTIDOS COM O MODELO PLSR-C15. 102 
FIGURA 51 - REFERÊNCIA VS. PREVISÃO DO TEOR DE PEBD (\%P) NAS BLENDAS POLIMÉRICAS DE PEAD/PEBD (MATERIAL RECICLADO). DADOS OBTIDOS COM O MODELO IPLS30R E DADOS ESPECTRAIS RAMAN. AS MISTURAS POLIMÉRICAS RECICLADAS CONTÊM 5 \%P DE DIFERENTES CONTAMINANTE: (A) $\mathrm{CACO}_{3}$, (B) PET, (C) PP E (D) SÍLICA GEL 103

FIgURA 52 - MicRografias de MEV DAS BLENDAS DE PEBD/PEAD OBTIDAS COM POLÍMEROS PRISTINOS, NAS SEGUINTES COMPOSIÇÕES (EM \%P): 100/0 (A), 90/10 (B), 70/30 (C), 50/50 (D), 30/70 (E), 10/90 (F) E 0/100 (G). BARRAS DE ESCALA $=50 \mu \mathrm{M}$. 119

FIGURA 53 - IMAGENS SUPERFICIAIS 3D DAS BLENDAS DE PEBD/PEAD OBTIDAS COM POLÍMEROS PRISTINOS, NAS SEGUINTES COMPOSIÇÕES (EM \%P): 100/0 (A), 90/10 (B), 70/30 (C), 50/50 (D), 30/70 (E), 10/90 (F) E 0/100 (G). 120

FiguRA 54 - MicROGRAFIAS DE MEV DAS BLENDAS DE PEBD/PEAD OBTIDAS COM POLÍMEROS RECICLADOS, NAS SEGUINTES COMPOSIÇÕES (EM \%P): 100/0 (A), 90/10 (B), 70/30 (C), 50/50 (D), 30/70 (E), 10/90 (F) E 0/100 (G). BARRAS DE ESCALA $=50 \mu \mathrm{M}$.

FIGURA 55 - IMAGENS SUPERFICIAIS 3D DAS BLENDAS DE DAS BLENDAS DE PEBD/PEAD OBTIDAS COM POLÍMEROS RECICLADOS, NAS SEGUINTES COMPOSIÇÕES (EM \%P): 100/0 (A), 90/10 (B), 70/30 (C), 50/50 (D), 30/70 (E), 10/90 (F) E 0/100 (G). 122

FIGURA 56 - ESPECTROS ATR-FTIR DAS BLENDAS DE PEAD/PEBD RECICLADAS CONTENDO CARBONATO DE CÁLCIO.

FiguRA 57 - ESPECTROS ATR-FTIR DAS BLENDAS DE PEAD/PEBD RECICLADAS CONTENDO PET.

FIGURA 58 - ESPECTROS ATR-FTIR DAS BLENDAS DE PEAD/PEBD RECICLADAS CONTENDO PP.

FIGURA 59 - ESPECTROS ATR-FTIR DAS BLENDAS DE PEAD/PEBD RECICLADAS CONTENDO SÍLICA GEL.

FIGURA 60 - ESPECTROS DE RAMAN CONFOCAL DAS BLENDAS DE PEAD/PEBD RECICLADAS CONTENDO CARBONATO DE CÁLCIO. 
FIGURA 61 - ESPECTROS DE RAMAN CONFOCAL DAS BLENDAS DE PEAD/PEBD RECICLADAS CONTENDO PET.

FIGURA 62 - ESPECTROS DE RAMAN CONFOCAL DAS BLENDAS DE PEAD/PEBD RECICLADAS CONTENDO PP

FigURA 63 - ESPECTROS DE RAMAN CONFOCAL DAS BLENDAS DE PEAD/PEBD RECICLADAS

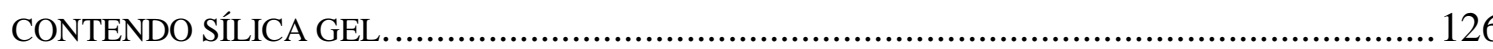




\section{LISTA DE TABELAS}

TABELA 1 - DiFERENTES TECNOLOGIAS PARA A CLASSIFICAÇÃO E SEPARAÇÃO DE RESÍDUOS POLIMÉRICOS DURANTE RECICLAGEM (RAHIMI; GARCÍA, 2017; SINGH ET AL., 2017; WANG ET AL., 2015).

TABELA 2 - DIFERENTES TECNOLOGIAS PARA CONTROLE DE QUALIDADE DOS RESÍDUOS POLIMÉRICOS APÓS A ETAPA DE CLASSIFICAÇÃO NA RECICLAGEM (RAHIMI; GARCÍA, 2017; SINGH ET AL., 2017).

TABELA 3 - DIFERENTES PROCESSOS DE RECICLAGEM QUÍMICA DE RESÍDUOS POLIMÉRICOS (ALSALEM; LETTIERI; BAEYENS, 2010; IGNATYEV; THIELEMANS; VANDER BEKE, 2014; RAGAERT; DELVA; VAN GEEM, 2017) .44

TABELA 4 - LISTA DE MATERIAIS UTILIZADOS NESTE TRABALHO. .54

TABELA 5 - DETALHES DOS PARÂMETROS USADOS NO DESENVOLVIMENTO DOS MODELOS DE PREDIÇÃO, DE ACORDO COM O ALGORITMO DE REGRESSÃO LINEAR ADOTADO.

TABEla 6 - DAdOS DE T ONSET $_{\text {E }} \mathrm{T}_{\text {MAX }}$ ORIGINADOS DAS MEDIDAS DE TGA/DTG. .64

TABELA 7 - DADOS DE $\boldsymbol{\Delta} \boldsymbol{H}, \boldsymbol{\Delta H} \boldsymbol{C}$ (ENTALPIA REFERENTE À CRISTALIZAÇÃO SECUNDÁRIA), $\boldsymbol{\chi} \boldsymbol{c}$ E DENSIDADE OBTIDOS COM AS MEDIDAS DE DSC. 66

TABELA 8 - MODELOS PREDITIVOS COM MELHOR DESEMPENHO OBTIDOS PELA REGRESSÃO PLS E IPLS PARA A QUANTIFICAÇÃO DO TEOR DE PEBD NAS BLENDAS DE PEBD/PEAD (OBTIDAS COM POLÍMEROS PRISTINOS), USANDO DADOS ESPECTRAIS DE IR (PRÉTRATAMENTO $=$ AUTOESCALADO $)$ 82

TABELA 9 - MODELOS PREDITIVOS COM MELHOR DESEMPENHO USANDO REGRESSÃO CARS-PLS E ESPECTROS ATR-FTIR, PRÉ-TRATADOS POR DIFERENTES MÉTODOS (PARÂMETROS CONSTANTES: NÚMERO MÁXIMO DE VARIÁVEIS LATENTES PARA VALIDAÇÃO CRUZADA = 20; VALIDAÇÃO CRUZADA K-FOLD = LEAVE-ONE-OUT; AMOSTRAGEM DE MONTE CARLO = 100 CICLOS).

TABELA 10 - MODELOS PREDITIVOS COM MELHOR DESEMPENHO OBTIDOS POR REGRESSÃO CARS-PLS E ESPECTROS ATR-FTIR, USANDO DIFERENTES VALORES DE K-FOLD PARA 
VALIDAÇÃO CRUZADA (PARÂMETROS CONSTANTES: PRÉ-TRATAMENTO = CENTRALIZAÇÃO MÉDIA; NÚMERO MÁXIMO DE VARIÁVEIS LATENTES PARA VALIDAÇÃO CRUZADA = 20; AMOSTRAGEM DE MONTE CARLO $=100$ CICLOS $)$

TABELA 11 - MODELOS PREDITIVOS COM MELHOR DESEMPENHO OBTIDOS POR REGRESSÃO CARS-PLS E ESPECTROS ATR-FTIR, USANDO VÁRIOS VALORES DE LVS (PARÂMETROS CONSTANTES: PRÉ-TRATAMENTO = CENTRALIZAÇÃO MÉDIA; VALIDAÇÃO CRUZADA K-FOLD $=15 ;$ AMOSTRAGEM DE MONTE CARLO $=100$ CICLOS $)$

TABELA 12 - MODELOS PREDITIVOS COM MELHOR DESEMPENHO OBTIDOS PELA REGRESSÃO PLS E IPLS PARA A QUANTIFICAÇÃO DO TEOR DE PEBD NAS BLENDAS DE PEBD/PEAD (OBTIDAS COM POLÍMEROS PRISTINOS), USANDO DADOS ESPECTRAIS RAMAN (PRÉTRATAMENTO $=$ CENTRALIZAÇÃO MÉDIA $)$ .95

TABELA 13 - MODELOS PREDITIVOS COM MELHOR DESEMPENHO USANDO REGRESSÃO CARSPLS E ESPECTROS RAMAN, PRÉ-PROCESSADOS POR DIFERENTES MÉTODOS (PARÂMETROS CONSTANTES: NÚMERO MÁXIMO DE VARIÁVEIS LATENTES PARA VALIDAÇÃO CRUZADA = 20; VALIDAÇÃO CRUZADA K-FOLD = LEAVE-ONE-OUT; AMOSTRAGEM DE MONTE CARLO = 100 CICLOS).

TABELA 14 - MODELOS PREDITIVOS COM MELHOR DESEMPENHO OBTIDOS POR REGRESSÃO CARS-PLS E ESPECTROS RAMAN, USANDO DIFERENTES VALORES DE K-FOLD PARA VALIDAÇÃO CRUZADA (PARÂMETROS CONSTANTES: PRÉ-TRATAMENTO = CENTRALIZAÇÃO MÉDIA; NÚMERO MÁXIMO DE VARIÁVEIS LATENTES PARA VALIDAÇÃO CRUZADA = 20; AMOSTRAGEM DE MONTE CARLO = 100 CICLOS)

TABELA 15 - MODELOS PREDITIVOS COM MELHOR DESEMPENHO OBTIDOS POR REGRESSÃO CARS-PLS E ESPECTROS RAMAN, USANDO VÁRIOS VALORES DE LVS (PARÂMETROS CONSTANTES: PRÉ-TRATAMENTO = CENTRALIZAÇÃO MÉDIA; VALIDAÇÃO CRUZADA K-FOLD =15; AMOSTRAGEM DE MONTE CARLO = 100 CICLOS) 100 


\section{RESUMO}

Atualmente, as indústrias e a comunidade científica se concentram na criação de novas formas de reciclagem e reutilização de resíduos poliméricos que levam a sérios riscos socioambientais. No entanto, a qualidade dos polietilenos reciclados depende fortemente do seu grau de pureza, mas a distinção entre Polietileno de Baixa Densidade (PEBD) e Polietileno de Alta Densidade (PEAD) por uma metodologia rápida e consistente é, ainda, uma questão não resolvida para os processos de reciclagem atuais. Nesta contribuição, foram aplicadas as espectroscopias Raman confocal e ATR-FTIR com diferentes métodos quimiométricos (Regressão Linear por Mínimos Quadrados Parciais - PLS, Regressão Linear por Mínimos Quadrados Parciais por Intervalos - iPLS, e Regressão Linear por Mínimos Quadrados Parciais e Amostragem Ponderada Adaptativa Competitiva - CARS-PLS) para quantificar a concentração de misturas poliméricas pristinas e recicladas de PEBD/PEAD. Os efeitos do número de subintervalos (10-50) e de vários parâmetros de regressão (método de prétratamento, ciclos de amostragem de Monte Carlo, K-fold e número máximo de variáveis latentes para validação cruzada) no desempenho de predição dos modelos preditivos construídos com regressões CARS-PLS e iPLS foram avaliados. Os modelos de predição baseados em CARS-PLS exibem o melhor desempenho preditivo para determinar o teor de PEBD em blendas pristinas de PEAD/PEBD, enquanto que os modelos baseados em iPLS são os mais adequados para quantificar a concentração de PEBD em toda a faixa de composição de blendas recicladas de PEAD/PEBD.

Palavras-chave: regressão PLS; misturas poliméricas; polietileno; espectroscopia ATR-FTIR; espectroscopia Raman confocal. 


\begin{abstract}
The industries and the scientific community currently focus on creating new ways to recycle and to reuse polymer waste that leads to serious socio-environmental risks. However, the quality of recycled polyethylenes depends strongly on their purity degree, but the distinction between Low Density Polyethylene (LDPE) and High Density Polyethylene (HDPE) by a fast and consistently good methodology is still an unsolved issue for the current recycling processes. In this contribution, confocal Raman and ATR-FTIR spectroscopies with different chemometric methods (Partial Least Squares Linear Regression - PLS, Interval Partial Least Squares Linear Regression - iPLS, and Competitive Adaptive Reweighted Sampling Linear Regression - Partial Least Squares - CARS-PLS) have been applied to quantify the concentration of LDPE/HDPE pristine and recycled blends. The effects of the number of subintervals (10-50) and several regression parameters (pretreatment method, Monte Carlo sampling runs, K-fold and maximal number of latent variables for cross-validation) on the prediction performance of CARS-PLS and iPLS-based models were evaluated. The CARS-PLS-based models display the best predictive performance to determine the LDPE content in HDPE/LDPE virgin blends, while the iPLS-based models are the most suitable for quantifying the LDPE content in the whole composition range of HDPE/LDPE recycled blend.
\end{abstract}

Keywords: PLS regression; polymer blends; polyethylene; ATR-FTIR spectroscopy; confocal Raman spectroscopy. 


\section{INTRODUÇÃO}

\subsection{RELEVÂNCIA E JUSTIFICATIVA DA PESQUISA}

Atualmente, as civilizações modernas têm enfrentado graves problemas ocasionados pelo aumento de resíduos sólidos urbanos (RSUs). A incorreta deposição de resíduos sólidos poliméricos e o aumento de espaço usado como aterro sanitário são apenas algumas das principais complicações ambientais (Kozderka et al. 2016, Al-Mulla and Gupta 2017). Diante desta problemática, a reciclagem e a reutilização de materiais pós-consumo são atualmente as alternativas mais viáveis para atenuar a geração de problemas socioambientais causadas pelos mesmos.

O polietileno de alta densidade (PEAD) e o polietileno de baixa densidade (PEBD) correspondem à principal fração de polímeros encontrada nos resíduos sólidos urbanos devido ao seu elevado consumo pela maioria dos países nos últimos anos. A razão para isto deve-se ao fato de que estes materiais poliméricos têm baixo custo de produção e apresentam grande versatilidade de suas propriedades mecânicas (GULMINE et al., 2002). Contudo, existem várias dificuldades para produzir produtos reciclados de polietilenos (PEs) com propriedades tecnologicamente atrativas e preços competitivos como, por exemplo, os processos degradativos que atuam no polímero (durante e após a sua vida útil) e a presença de contaminantes que muitas vezes inviabiliza a separação dos resíduos sólidos poliméricos (RSPs) (ACHILIAS, 2012; AL-SALEM; LETTIERI; BAEYENS, 2009). Aliado a isto, o preço relativamente baixo de polímeros pristinos, como é o caso das poliolefinas, e fatores regulatórios desestimulam a reciclagem dos RSPs (ASHTON et al., 2015; SPINACÉ; DE PAOLI, 2005).

No Brasil, os polímeros são reciclados principalmente por reciclagem mecânica que é o processo mais utilizado no mundo para reaproveitar RSPs (LUIJSTERBURG; GOOSSENS, 2014). No entanto, a completa separação das misturas de resíduos de PEAD e PEBD pelo método de diferença de densidade (em soluções água/álcool), após a separação manual, é extremamente difícil. Além disso, a presença de cargas e outros aditivos, misturas de polímeros e embalagens poliméricas multicamadas nos RSPs inviabiliza este método (ASHTON et al., 2015). Cabe destacar que este procedimento de separação é, atualmente, o mais barato e, consequentemente, é o mais utilizado para a separação de resíduos poliolefínicos no processo de reciclagem mecânica no Brasil (COUTINHO; MELLO; SANTA MARIA, 2003).

Outro agravante para a separação adequada dos resíduos poliméricos é que, no Brasil, a identificação correta das embalagens poliméricas, segundo a norma ABNT NBR 13.230, não 
ultrapassa $30 \%$ do total de produtos alimentícios e não alimentícios vendidos no mercado (COLTRO; DUARTE, 2013).

O controle de qualidade da etapa de separação, ou seja, a avaliação do grau de pureza dos diferentes polímeros separados para serem reciclados mecanicamente, desempenha um papel fundamental na obtenção de produtos reciclados de boa qualidade. No entanto, quantificar a composição de misturas de PEBD/PEAD não é uma tarefa simples porque as estruturas químicas de suas cadeias poliméricas são apenas baseadas em átomos de hidrogênio e carbono. Em relação a isto, a análise térmica dinâmico-mecânica (DMTA), a difratometria de raios-X de alto ângulo (WAXS) e a calorimetria exploratória diferencial (DSC) mostraram significativas limitações para determinar a composição das blendas de PEAD/PEBD devido a efeitos de cocristalização (MUNARO; AKCELRUD, 2008).

Em contraste com essas técnicas de caracterização, as espectroscopias de espalhamento Raman confocal e de infravermelho por transformada de Fourier usando reflexão total atenuada (ATR-FTIR) são espectroscopias vibracionais atraentes porque possibilitam realizar análises qualitativas e semiquantitativas rápidas, não destrutivas, de baixo custo e ecologicamente corretas, uma vez que não requerem insumos caros e métodos longos para preparação da amostra (FERRÃO et al., 2011; PERNA; LASALVIA; CAPOZZI, 2016).

Nesta contribuição, é avaliado o potencial do uso de espectroscopia ATR-FTIR e espectroscopia de espalhamento Raman confocal para determinar analiticamente a fração composicional das blendas de PEAD/PEBD pristinos e recicladas utilizando, como ferramenta de predição, a regressão linear por mínimos quadrados parciais (PLS) e suas versões modificadas: por intervalos (iPLS) e por amostragem ponderada adaptativa competitiva (CARS-PLS). Este tipo de análise quantitativa ainda apresenta potencial de aplicação em economia circular, sendo uma ferramenta útil para fechar o ciclo de produção (através da reutilização e reciclagem adequada) de embalagens, eletroeletrônicos e componentes automotivos baseados em misturas de polietilenos.

\subsection{OBJETIVOS DO TRABALHO}

\subsubsection{Objetivos Gerais}

Este trabalho teve como objetivo principal avaliar o desempenho dos métodos de regressão PLS, iPLS e CARS-PLS na predição da composição de blendas poliméricas de PEBD/PEAD provenientes de materiais pristinos e reciclados, usando dados de espectroscopia ATR-FTIR e Raman confocal. 


\subsubsection{Objetivos específicos}

Foram desenvolvidas as seguintes etapas para atingir o objetivo principal deste trabalho:

- Caracterização dos polietilenos por DSC, análise termogravimétrica (TGA) e índice de fluidez (IF);

- Caracterização da estrutura química e dos contaminantes dos polímeros (pristino e reciclado) através da espectroscopia ATR-FTIR, espectroscopia de energia dispersiva (EDS) e espectroscopia de espalhamento Raman confocal;

- Preparação das blendas poliméricas através de extrusão dos polietilenos pristinos e reciclados com e sem $5 \%$ p de diferentes contaminantes: poli(tereftalato de etileno) (PET) reciclado, polipropileno (PP) reciclado, sílica gel em pó e carbonato de cálcio em pó;

- Coleta de espectros vibracionais das blendas poliméricas pelas espectroscopias ATR-FTIR e Raman confocal;

- Construção dos modelos de predição por PLS, iPLS e CARS-PLS. Além de, avaliação dos diferentes parâmetros de regressão no desempenho dos modelos de predição.

\subsection{ORGANIZAÇÃO DO TRABALHO}

Esta tese de doutorado está organizada em sete sessões. Nesta primeira sessão, a pesquisa foi justificada e sua relevância foi apresentada. Além disso, foram descritos os objetivos do projeto de pesquisa. Na sessão II é apresentado o estado da arte das espectroscopias vibracionais de infravermelho e de espalhamento Raman, da reciclagem de materiais poliméricos e, por fim, da calibração multivariada por métodos de regressão linear PLS.

Dentro da sessão III, são descritos os materiais e procedimentos adotados para processamento e caracterização dos polietilenos e suas misturas. Os métodos de construção dos modelos de predição também são detalhados nesta sessão.

Na sessão IV são mostrados e discutidos os resultados obtidos. Em seguida, as conclusões estão apresentadas na sessão V. A sessão VI contém as referências bibliográficas utilizadas como fundamentação teórica desta tese. Por fim, a sessão VII apresenta sugestões para trabalhos futuros, uma lista dos trabalhos publicados e submetidos durante o período de vigência do doutorado e, ainda, os apêndices. 


\section{REVISÃO BIBLIOGRÁFICA}

\subsection{POLIETILENOS (PEs)}

Polietilenos são os materiais poliméricos mais utilizados e mais baratos do mundo, eles são obtidos industrialmente a partir da polimerização de moléculas de eteno, também conhecido como etileno. Basicamente, PEs são constituídos por longas cadeias saturadas de átomos de carbono e hidrogênio, sendo representado pela estrutura química dada na Figura 1.

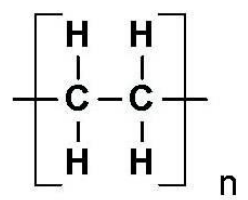

Figura 1 - Estrutura química dos polietilenos.

Os diferentes tipos de PEs dependem das condições e sistema catalítico utilizados na polimerização do etileno (COUTINHO; MELLO; SANTA MARIA, 2003). A família de polietilenos é, comumente, classificada com respeito a sua faixa de densidade: polietileno de baixa densidade (PEBD), polietileno de alta densidade (PEAD), polietileno linear de baixa densidade (PELBD), polietileno de ultra-alto peso molecular (PEUAPM) e polietileno de ultrabaixa densidade (PEUBD). Dentre os quais, o PEBD e o PEAD são o foco deste trabalho.

No estado sólido, os polietilenos apresentam diferentes estruturas cristalinas que, basicamente, podem ser representados por três células unitárias distintas contendo cadeias poliméricas numa conformação zig-zag planar com cadeias poliméricas com conformação apenas do tipo trans-trans (GANDINI; CHERADAME, 2004; PEACOCK, 2000): ortorrômbica, monoclínica e hexagonal. Os parâmetros de rede destas estruturas cristalinas estão mostrados na Figura 2.

A célula unitária mais estável é a ortorrômbica, que pode exibir diferentes parâmetros de rede devido às ramificações das cadeias poliméricas; uma vez que, elas restringem a simetria e o empacotamento dos átomos dentro da célula ortorrômbica. A célula monoclínica é observada em cristais metaestáveis nucleados sob solicitação mecânica, enquanto que a célula hexagonal é verificada em cristais de polietileno formados sob altas pressões e acima de 200 ${ }^{\circ} \mathrm{C}$ (GANDINI; CHERADAME, 2004).

Além destas diferentes células unitárias, os polietilenos são constituídos por esferulitos que apresentam cristalitos microscópicos, formados de acordo com a teoria de cadeias dobradas (CALLISTER, 2008; CANEVAROLO JR., 2006). 
Este comportamento polimórfico é característico em materiais poliméricos e resulta da anisotropia das interações entre os átomos nas cadeias poliméricas. Isto porque as interações intracadeias são muito mais fortes que as intercadeias, ocasionando uma elevada diferença tanto na cinética de cristalização quanto no(s) mínimo(s) local(is) do potencial termodinâmico de cristalização entre as diferentes fases do polímero (ZUBOVA, 2013).

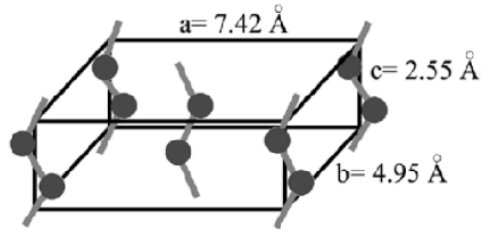

Célula unitária Ortorrômbica

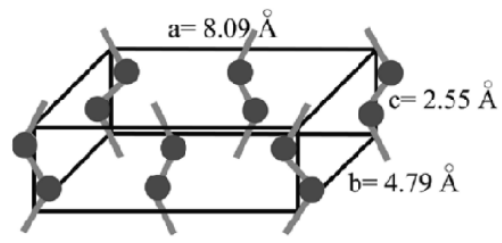

Célula unitária monoclínica

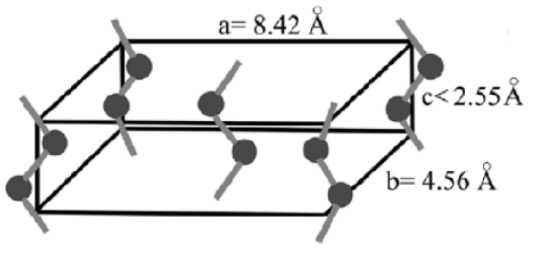

Célula unitária hexagonal

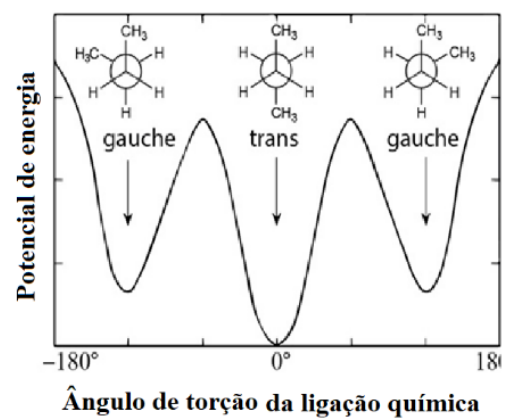

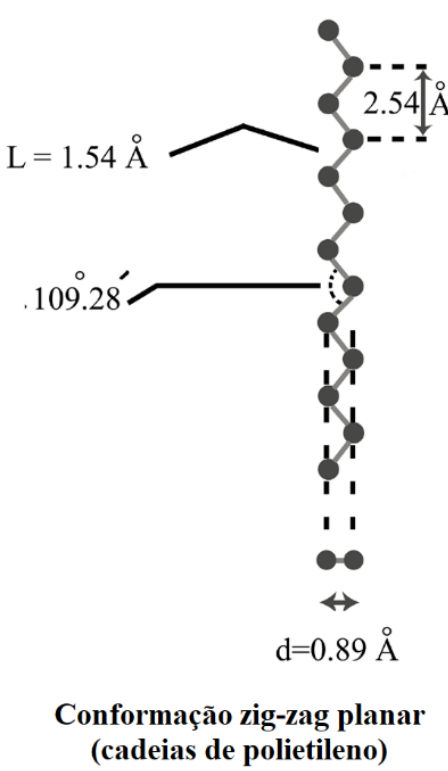

Figura 2 - Células unitárias observadas nos polietilenos. Fonte: adaptado de (NEJABAT, 2018) e (YOUNG;

LOVELL, 2011).

\subsubsection{Polietileno de baixa densidade}

O PEBD é um polímero semicristalino, em torno de 50 a $60 \%$, com densidade na faixa de 0,90 a 0,93 g/cm³ (RAHIMI; GARCÍA, 2017; SILVA; WIEBECK, 2019) e temperatura de fusão cristalina $\left(\mathrm{T}_{\mathrm{m}}\right)$ variando de 110 a $115{ }^{\circ} \mathrm{C}$. Este polímero apresenta cadeias ramificadas, que são provenientes das reações de transferência de cadeia durante a polimerização que é feita, usualmente, via radicais livres em alta pressão. Estas ramificações são, em grande parte, tão longas quanto à cadeia principal do PEBD e afetam diretamente a morfologia e propriedades deste polímero (BILLMEYER, 1984; FEL et al., 2016).

O PEBD é comumente processado por extrusão, moldagem por sopro e moldagem por injeção. Este polietileno apresenta elevada resistência ao impacto e flexibilidade, além de possuir propriedades elétricas interessantes para ser utilizado como isolante elétrico. Em relação às aplicações, PEBD é utilizado como filmes para embalagens (industriais, agrícolas, alimentos líquidos e sólidos, farmacêuticos, entre outros), discos rígidos e ópticos, bandejas (SINGH et al., 2017). 


\subsubsection{Polietileno de alta densidade}

O PEAD apresenta, geralmente, cristalinidade superior a $90 \%$ e densidade tipicamente entre 0,93 e 0,97 g/ $\mathrm{cm}^{3}$ (RAHIMI; GARCÍA, 2017; SILVA; WIEBECK, 2019), sendo estes valores superiores aos verificados no PEBD. Este fato deve-se à baixa concentração de ramificações presentes no PEAD que possibilita que o alinhamento e o empacotamento de cadeias lineares sejam mais eficientes, proporcionando aumento das interações intermoleculares entre as cadeias poliméricas. Por esta razão, a temperatura de fusão cristalina do PEAD supera a do PEBD. A Figura 3 ilustra a cadeia polimérica do PEAD (polímero com cadeias lineares) e do PEBD (polímero com cadeias com elevado grau de ramificação).

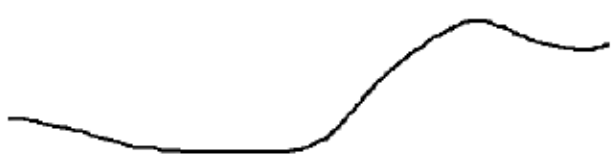

(a)

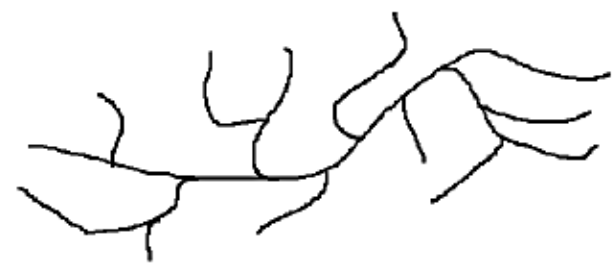

(b)

Figura 3 - Representação de uma cadeia polimérica do PEAD (a) e do PEBD (b) (MOORI, 2014).

O PEAD é obtido por processos de polimerização por coordenação, podendo ser utilizados catalisadores Ziegler-Natta, metalocenos ou Phillips (COUTINHO; MELLO; SANTA MARIA, 2003). Além disso, este polietileno é utilizado em diversos segmentos, dependendo do processamento adotado: brinquedos, utensílios, filmes, garrafas, tubos, isolamento de fios e cabos (SINGH et al., 2017).

\subsubsection{Misturas poliméricas de PEBD com PEAD}

Por definição, misturas poliméricas são sistemas poliméricos obtidos pela mistura física de pelo menos duas substâncias macromoleculares (polímeros ou copolímeros), sendo as concentrações de todos os componentes superiores a $2 \%$ p (\% em peso) (UTRACKI; WILKIE, 2014). Blenda polimérica é um termo utilizado tecnologicamente no Brasil e é um sinônimo de mistura polimérica.

As misturas poliméricas foram reconhecidas, tanto pela indústria quanto pela omunidade científica, como o método econômico mais versátil para produzir novos materiais, capazes de satisfazer as exigências de mercado porque (UTRACKI; WILKIE, 2014): (1) a 
mistura pode melhorar o desempenho do polímero ou do produto; (2) a mistura pode levar a uma melhor processabilidade do material polimérico.

Assim como qualquer mistura, as blendas poliméricas estão sujeitas à separação de fases. Por esta razão, as misturas poliméricas são classificadas em três tipos, dependendo do grau de interação termodinâmico entre os componentes (ISAYEV, 2010; UTRACKI; WILKIE, 2014): miscíveis (não há separação de fases, pois há uma mistura termodinamicamente estável a um nível molecular entre os componentes); imiscíveis (as cadeias poliméricas dos componentes separam-se, formando um sistema polimérico multifásico com fases distintas); parcialmente miscíveis (também há separação de fases, porém uma quantidade de cadeias poliméricas de um polímero fica dissolvida na fase do outro polímero e vice-versa). A Figura 4 apresenta uma representação esquemática e comparativa para o fenômeno de separação de fases destas diferentes classes de blendas poliméricas.

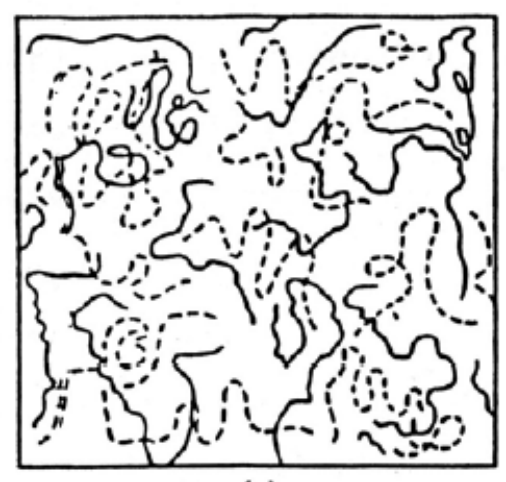

(a)

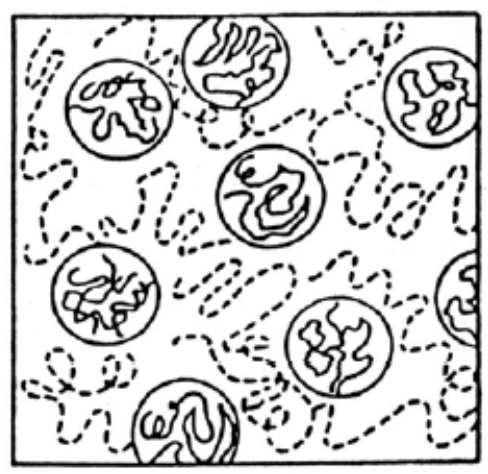

(b)

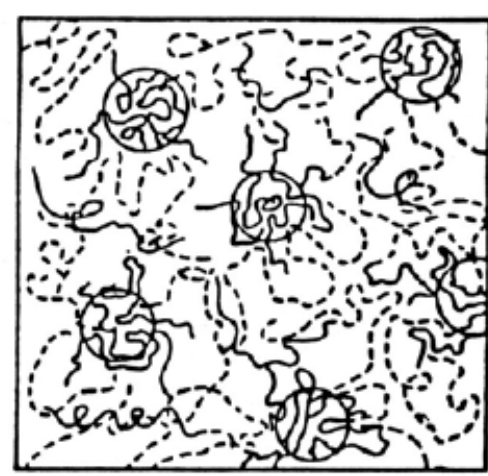

(c)

Figura 4 - Representação esquemática da separação de fases em blendas poliméricas contendo dois componentes: a)

blenda miscível; b) blenda imiscível; c) blenda parcialmente miscível. As linhas sólidas representam as cadeias poliméricas do polímero A e as linhas tracejadas representam as cadeias poliméricas do polímero B (MUNARO, 2007).

Em geral, diferentes tipos de polietilenos são misturados para atingir os requerimentos de processamento e/ou de propriedades no produto final (FAN; WILLIAMS; CHOI, 2002). No caso de blendas de PEAD/PEBD, o PEBD é adicionado ao PEAD por dois motivos principais: (1) diminuir a viscosidade do fundido, facilitando o processamento do PEAD; (2) reduzir problemas de variação dimensional da peça durante o seu resfriamento, devido à cristalização do PEAD que causa retração do polímero fundido no interior dos moldes.

Em geral, a adição do PEAD no PEBD é uma maneira utilizada pelas indústrias para aumentar a resistência do fundido, o módulo de elasticidade, o limite de escoamento e a tensão de ruptura dos produtos baseados em polietileno de baixa densidade, visto que as ramificações diminuem estas propriedades mecânicas. Lembrando que, as ramificações na cadeia polimérica 
aumentam a elasticidade, o alongamento na ruptura e a ductilidade dos polietilenos (NWABUNMA; KYU, 2008).

A regra conhecida como "semelhante dissolve semelhante" não é fator determinante de miscibilidade, sendo inadequada para misturas de poliolefinas. Algumas misturas de polietilenos sofrem separação de fases em temperaturas acima da $T_{m}$ dos componentes, de acordo com o diagrama de fase espinodal de Temperatura Crítica de Solução Superior (Upper Critical Solution Temperature, UCST) mostrado na Figura 5.

Os polietilenos têm uma ampla distribuição de temperaturas de fusão cristalina, resultantes da variação da espessura das lamelas de cadeias dobradas. Se os PEs na mistura polimérica são imiscíveis à temperatura de cristalização, cada fase deve cristalizar independentemente e normalmente haverá uma fase dispersa e uma fase contínua, exceto por frações de volume quase iguais, nas quais as fases podem ser cocontínuas. Embora as fases cristalizem independentemente, elas não cristalizarão nas mesmas temperaturas. As temperaturas de cristalização dependerão da densidade de ramificações nas cadeias poliméricas dos polietilenos (quantidade de ramificações/número de átomos de carbono na cadeia principal) (NWABUNMA; KYU, 2008). Além disso, as propriedades serão significativamente modificadas pela morfologia da blenda polimérica, como a resistência ao impacto, o alongamento máximo e o comportamento de fluência.

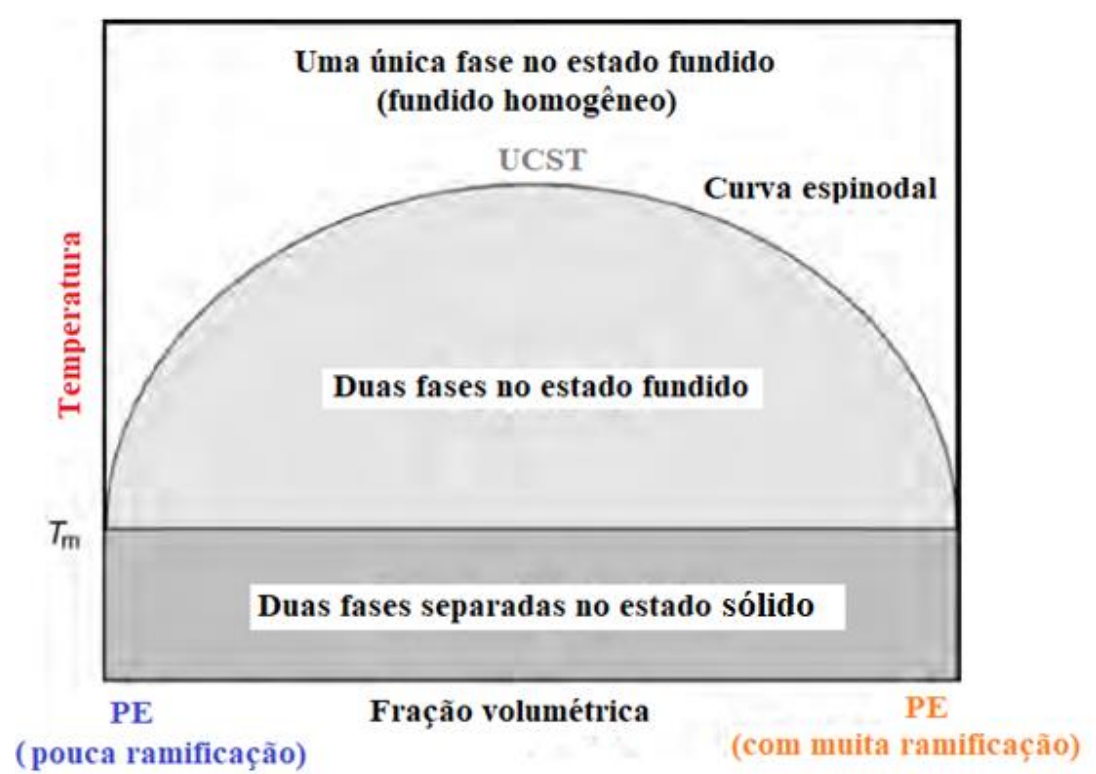

Figura 5 - Diagrama de fase temperatura-composição para uma mistura imiscível de polietilenos com diferentes concentrações de ramificações. Este é um diagrama de Temperatura Crítica de Solução Superior (Upper Critical

Solution Temperature, UCST). Fonte: adaptado de (NWABUNMA; KYU, 2008 ). 
Embora o sistema polimérico PEAD/PEBD já tenha sido investigado por muito tempo, ainda não há consenso sobre sua miscibilidade (ZHAO; CHOI, 2006). A imiscibilidade das blendas de PEBD/PEAD é atribuída às diferenças nas energias de interação dos grupos $\mathrm{CH}_{2}$, $\mathrm{CH}_{3}$ e $\mathrm{CH}$. Acredita-se que 25 ramificações por 1000 átomos de carbono na cadeia polimérica principal é o valor crítico e, acima deste valor médio, o PEBD e o PEAD se tornam imiscíveis mesmo no estado fundido (ZHAO; CHOI, 2006). Por outro lado, alguns pesquisadores acreditam que essas misturas cocristalizam, enquanto que outros pesquisadores não concordam com esta hipótese (MUNARO, 2007; MUNARO; AKCELRUD, 2008; NWABUNMA; KYU, 2008).

\subsection{ESPECTROSCOPIA DE ABSORÇÃO NO INFRA VERMELHO}

A espectroscopia de absorção no infravermelho (IR) é baseada no fato de que a absorção de energia de uma radiação infravermelha ocasiona alteração nos modos rotacionais e vibracionais dos átomos numa ligação química. A região do infravermelho do espectro eletromagnético é, frequentemente, subdividida em intervalos, de acordo com a faixa de número de onda (MEDEIROS, 2009):

- Infravermelho próximo (NIR): entre 12800 e $4000 \mathrm{~cm}^{-1}$;

- Infravermelho médio (MIR): entre 4000 e $400 \mathrm{~cm}^{-1}$;

- Infravermelho distante (FIR): entre 400 e $10 \mathrm{~cm}^{-1}$.

Embora a radiação infravermelha não tenha energia suficiente para causar rompimento de ligações químicas ou transições eletrônicas em moléculas orgânicas e inorgânicas, a sua energia é suficiente para causar transições vibracionais que requerem baixíssima energia $(2,65$ x $10^{-19}$ a 7,96 x $10^{-20} \mathrm{~J}$ ). Estas transições vibracionais são quantizadas, mas aparecem como bandas de absorção ao invés de linhas num espectro de IR. Isto ocorre porque uma mudança de nível de energia vibracional está associada a uma série de mudanças de níveis de energia rotacional (VIERA, 2011).

Existem seis modos de vibrações em que os átomos podem vibrar em ligações químicas, conforme ilustrado na Figura 6. Nas deformações, há mudanças nos ângulos das ligações químicas e, nos estiramentos (deformações axiais), ocorre variações nas distâncias entre átomos ligados.

As bandas de absorção, detectadas na espectroscopia IR, são características para cada ligação química entre os átomos na molécula, i.e., cada grupo químico absorve radiação IR com um número de onda (ou comprimento de onda) específico. Portanto, é possível identificar 
funções orgânicas, bem como interações moleculares específicas, presentes na estrutura química da molécula, basicamente, examinando o seu espectro de absorção no infravermelho. Contudo, são necessários dois requisitos básicos para que um modo vibracional possa gerar um sinal detectável na espectroscopia IR: (1) o fóton incidente precisa ter energia quântica suficiente para provocar uma transição vibracional ou rotacional dos átomos na molécula; (2) deve ocorrer variação do momento de dipolo da molécula durante a transição (COSTA, 2013).

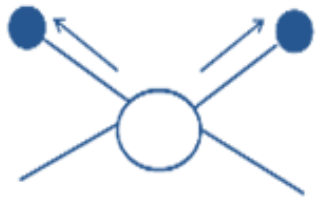

Estiramento simétrico

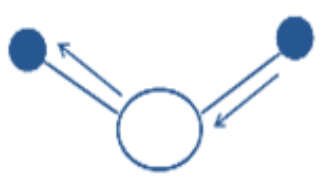

Estiramento assimétrico

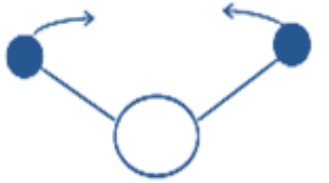

Deformação no plano tipo tesoura (dobramento angular)

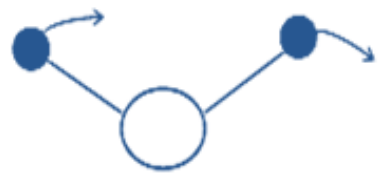

Deformação no plano tipo rotação

(Rocking)

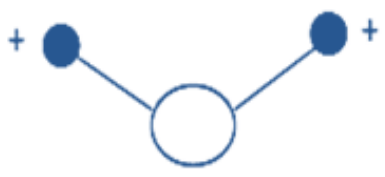

Deformação para fora do plano tipo balanço

(Wagging)

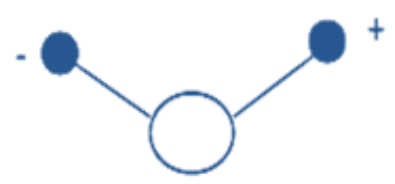

Deformação para fora do plano tipo torção

(Twisting)

Figura 6 - Tipos de vibrações de estiramentos e deformações moleculares detectados na espectroscopia de infravermelho. Fonte: adaptado de (COSTA, 2013).

A espectroscopia no infravermelho com transformada de Fourier (FTIR) foi desenvolvida após a década de 70, para agilizar as medições e melhorar a qualidade do sinal detectado pelos equipamentos (COSTA, 2013; MEDEIROS, 2009; VIERA, 2011). Para tanto, os espectrômetros com transformada de Fourier utilizam interferômetros de Michelson para aumentar a razão sinal/ruído do feixe de radiação IR medido pelos fotodiodos do equipamento (AL-SAEED; KHALIL, 2012; DENG et al., 2010; FORD et al., 2005; LACOT et al., 2010; ROCHA, 2016).

$\mathrm{Na}$ espectroscopia FTIR podem ser obtidos espectros por transmissão/absorção, emissão ou reflexão do feixe de radiação IR. Cada modo de operação exige o uso de portaamostras e acessórios característicos no espectrômetro, sendo adequados para um determinado tipo de amostra com um dado conjunto de propriedades físicas. Basicamente, na espectroscopia FTIR, um feixe de radiação IR é incidido na superfície da amostra e o sensor do equipamento detecta a parte do feixe que é transmitida (modo de transmissão/absorção), refletida (modo de reflexão) ou emitida (modo de emissão) pela amostra. 
Existem três formas de operação do modo por reflexão: reflexão especular, reflexão difusa e reflexão total atenuada (ATR). No modo ATR, a amostra é colocada em contato direto com um acessório de reflexão interna (cristal de ATR). Este acessório ATR é constituído por um material de alto índice de refração (maior que 2,2), como o seleneto de zinco ( $\mathrm{ZnSe}$ ), germânio (Ge), bromoiodeto de tálio (KRS-5) e diamante. Em seguida, o feixe de IR é incidido do cristal para a superfície da amostra num ângulo de incidência $(\theta)$, de acordo com a Figura 7. Após sofrer reflexão total na interface cristal/amostra, o feixe é redirecionado para um detector adequado no equipamento. No entanto, parte do feixe consegue penetrar na amostra, formando uma onda evanescente, no ponto em que sofreu reflexão (COSTA, 2013; MEDEIROS, 2009; VIERA, 2011). A profundidade de penetração do feixe $(d p)$ depende do comprimento de onda $(\lambda)$, ângulo de incidência $(\theta)$ e índices de refração do cristal ATR $\left(n_{2}\right)$ e da amostra $\left(n_{3}\right)$, conforme Equação 1.

$$
d p=\frac{\lambda}{2 \pi n_{2} \sqrt{\operatorname{sen}^{2} \theta-\left(\frac{n_{3}}{n_{2}}\right)^{2}}}
$$

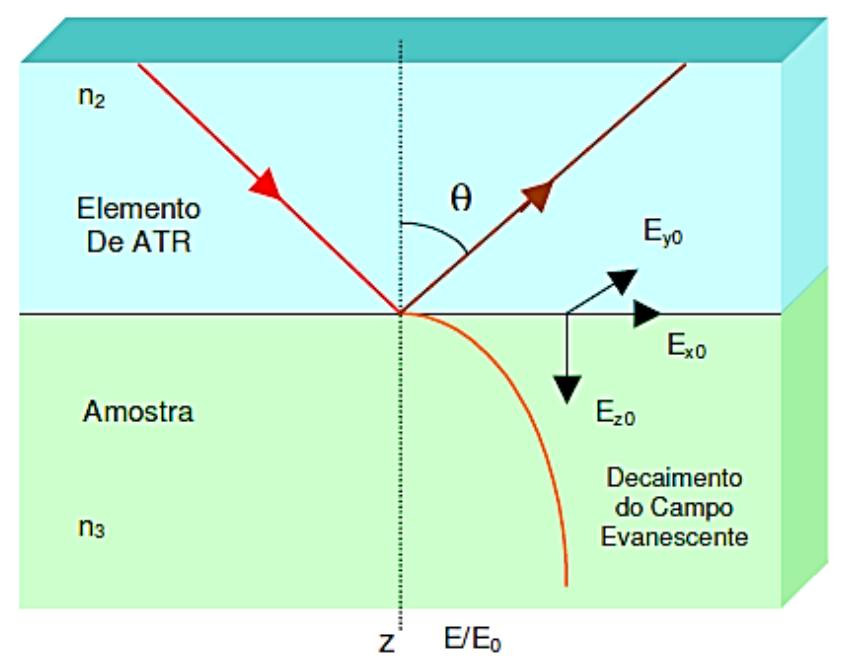

Figura 7 - Representação da propagação da radiação infravermelha na interface amostra/cristal de um acessório ATR (VIERA, 2011).

Para que ocorra reflexão total, é preciso que o ângulo de incidência do feixe de radiação IR seja maior que o ângulo de incidência crítico $\left(\theta_{C}\right)$, dado por:

$$
\theta_{C}=\operatorname{sen}^{-1}\left(\frac{n_{3}}{n_{2}}\right)
$$

Cabe destacar que, os sinais relativos às bandas de absorção no infravermelho correspondem à parte do feixe refletido que é atenuado devido à densidade específica $(\rho)$ e 
coeficiente de absorção $(\alpha)$ da amostra, ou devido à absorção dos fótons evanescentes. Matematicamente, o sinal de refletância total atenuada $\left(\mathrm{R}_{N}\right)$ para superfícies onde há múltiplas reflexões $(N)$ pode ser estimado por (HIND; BHARGAVA; MCKINNON, 2001):

$$
R_{N}=(1-\alpha \rho)^{N}
$$

A espectroscopia ATR-FTIR permite a realização de medidas de superfícies de amostras sólidas e liquidas, sem a necessidade de métodos sofisticados ou demorados para preparação. Contudo, este modo de operação requer um manuseio cuidadoso de amostras porque ele é altamente sensível à contaminação superficial (GULMINE et al., 2002).

Alguns estudos mostraram a possibilidade de distinguir PEAD e PEBD por espectroscopia FTIR (GULMINE et al., 2002; MILLER, 1993). O sucesso dessa técnica está relacionado às sutis diferenças nos níveis de energia vibracionais permitidos para os átomos presentes nas cadeias poliméricas ocasionadas pelos seus diferentes estados conformacionais que, por sua vez, são afetados diretamente pelo grau de ramificações das macromoléculas do polietileno.

\subsection{ESPECTROSCOPIA DE ESPALHAMENTO RAMAN}

A espectroscopia de espalhamento Raman é uma espectroscopia vibracional que é baseada no espalhamento inelástico de fótons devido à sua interação com uma molécula (LOPES, 2005). A amostra, ao ser irradiada por um feixe de luz monocromática de frequência original $\left(v_{0}\right)$, espalha elasticamente os fótons (espalhamento Rayleigh), mas também dá origem a fótons espalhados com frequências diferentes $v_{0}+v_{v}$ e $v_{0}-v_{v}$ (radiações inelásticas) (BUMBRAH; SHARMA, 2016). Sendo que, $v_{v}$ é uma das frequências vibracionais da molécula presente na amostra e estas vibrações moleculares são características da molécula, assim como na espectroscopia de infravermelho. Como consequência, o espectro Raman possibilita obter informações sobre grupos funcionais e orientação da molécula (FREDERICCI et al., 2016).

A origem da radiação inelástica (i.e., efeito ou espalhamento Raman) está diretamente associada com a polarização eletrônica da molécula (deformação da nuvem eletrônica molecular) devido à sua interação com o campo elétrico de uma radiação eletromagnética. Conforme Equação 4, este momento de dipolo elétrico induzido $(M)$ é, matematicamente, representado por três componentes de polarizabilidade estática da ligação $\left(\alpha_{e}\right)$ : uma que oscila com a mesma frequência do campo elétrico (espalhamento Rayleigh) e duas que estão correlacionadas com as frequências vibracionais das ligações químicas presentes na molécula (espalhamento Stokes e anti-Stokes) (SKOOG; HOLLER; CROUCH, 2007). 


$$
\begin{array}{r}
M=\underbrace{\alpha_{e} E_{0} \cos \left(2 \pi v_{0} t\right)}_{\text {Rayleigh }}+\underbrace{\frac{E_{0}}{2} q_{0}\left(\frac{\partial \alpha_{e}}{\partial q}\right) \cos \left[2 \pi t\left(v_{0}-v_{v}\right)\right]}_{\text {Stokes }}+ \\
\underbrace{\frac{E_{0}}{2} q_{0}\left(\frac{\partial \alpha_{e}}{\partial q}\right) \cos \left[2 \pi t\left(v_{0}+v_{v}\right)\right]}_{\text {Anti-Stokes }}
\end{array}
$$

onde, $q_{0}$ é a amplitude vibracional da ligação química, $v_{v}$ é a frequência vibracional da ligação, $t$ é o tempo, $\partial \alpha / \partial q$ é a primeira derivada parcial da polarizabilidade da ligação em função da distância internuclear, $E_{0}$ e $v_{0}$ são amplitude e frequência da radiação incidente, respectivamente.

No espalhamento Raman Stokes, parte da energia do fóton incidente é transferida para a molécula, ocorrendo uma transição quântica vibracional ou rotacional na mesma e, como consequência, o fóton espalhado pela amostra apresenta redução de energia, frequência e número de onda. Por outro lado, no espalhamento Raman anti-Stokes há uma transferência de energia da molécula para o fóton incidido na amostra, ocorrendo aumento da frequência e número de onda do fóton espalhado, devido às moléculas estarem, termicamente, em um estado energético inicial superior ao do fóton incidido (i.e., a molécula está num estado vibracional excitado).

O espalhamento Raman anti-Stokes ocorre em uma menor proporção que o espalhamento de Stokes que, por sua vez, é menos intenso que o fenômeno de espalhamento Rayleigh. As transições envolvidas e intensidade dos sinais, destes três tipos de espalhamento, estão representadas, esquematicamente, na Figura 8. Cabe ressaltar que, os equipamentos convencionais geralmente medem o feixe espalhado a um ângulo de $90^{\circ}$ em relação ao feixe de luz incidido, isto porque, nesta configuração, os sinais de espalhamento inelástico são mais intensos.

Várias técnicas de espectroscopia Raman foram desenvolvidas, cada uma delas com seu próprio conjunto de aplicações, vantagens e desvantagens (EMBER et al., 2017): microscopia ou espectroscopia Raman confocal, espectroscopia de ressonância Raman, espectroscopia Raman intensificada com superfície, espectroscopia Raman compensada espacialmente, espectroscopia Raman anti-Stokes coerente e espalhamento Raman estimulado.

A espectroscopia Raman confocal é um modo de operação que permite reconhecer as ligações químicas de amostras orgânicas, inorgânicas e biológicas em diferentes estados físicos, sendo uma técnica poderosa e relativamente rápida, assim como a espectroscopia ATR-FTIR (BRUNEEL; LASSÈGUES; SOURISSEAU, 2002; EVERALL, 2004a, 2004b; MUJICA ASCENCIO et al., 2016). 


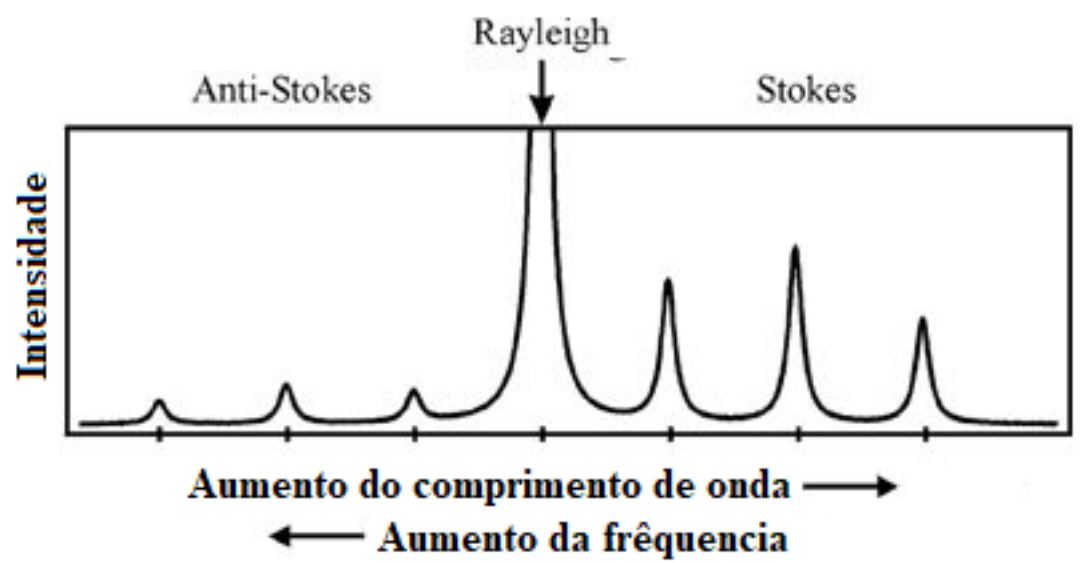

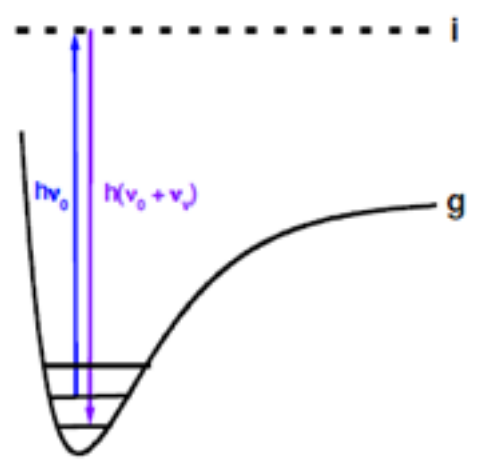

anti-Stokes

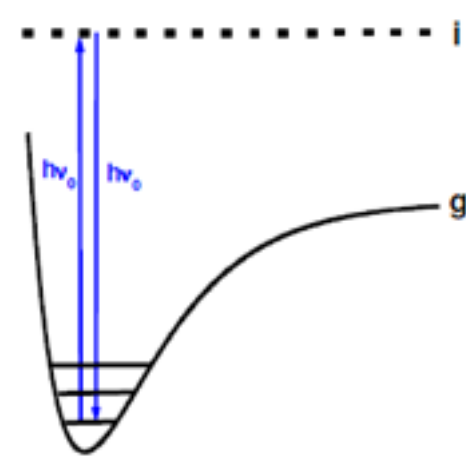

Rayleigh

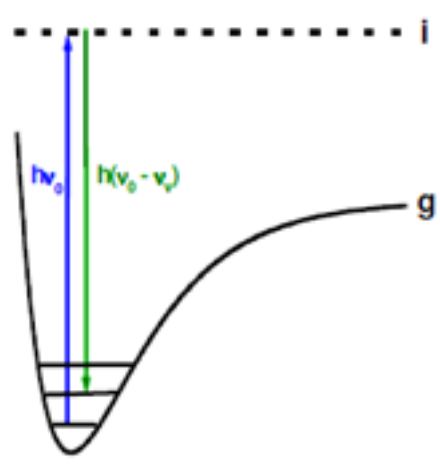

Stokes

Figura 8 - Espalhamento de fótons do tipo elástico (Rayleigh) e inelástico (efeito Raman por espalhamento Stokes ou anti-Stokes). "g" e "ij" correspondem ao estado vibracional fundamental e virtual (intermediário) da molécula, respectivamente (ANDO, 2005).

Na espectroscopia Raman confocal, um microscópio é acoplado a um espectrômetro convencional de espalhamento Raman com um detector de alta sensibilidade. Neste equipamento, é utilizado um laser como fonte de luz monocromática e este é incidido na amostra pela objetiva do próprio microscópio que, ao mesmo tempo, é responsável por detectar a parte da radiação espalhada inelasticamente pela amostra (LOPES, 2005). O feixe do laser é focalizado em uma pequena área da superfície da amostra (ordem de mícrons) e o microscópio opera em um modo confocal, i.e., há uma abertura em um plano focal traseiro do microscópio (também conhecida como abertura confocal). Esta abertura melhora a resolução espacial lateral e axial do microscópio, permitindo criar imagens tridimensionais de maneira não destrutiva e com aquisição de espectros Raman ponto-a-ponto, à medida que o foco do laser é movido gradualmente sobre a superfície da amostra (EVERALL, 2004a). Desta forma, a microscopia Raman confocal pode ser aplicada de duas maneiras: (1) simples aquisição do espectro Raman característico da amostra, a partir da superfície e em diferentes profundidades; (2) mapear a 
intensidade de uma banda ou pico de espalhamento Raman específica na superfície da amostra, permitindo produzir uma imagem com informação morfológica da superfície.

Em um microscópio Raman confocal, a profundidade de campo $(D R)$ ou resolução máxima axial (eixo z) pode ser determinada por (EVERALL, 2004a):

$$
D R=\Delta\left\{\left[\frac{N A^{2}\left(n_{m}^{2}-1\right)}{1-N A^{2}}+n_{m}^{2}\right]^{\frac{1}{2}}-n_{m}\right\}
$$

onde $n_{m}$ é o índice de refração do meio de imersão (geralmente o ar), $N A$ é a abertura numérica da lente objetiva e $\Delta$ refere-se ao deslocamento axial do laser na superfície da $\operatorname{amostra}(\Delta=0$ $\mu \mathrm{m}$, quando o feixe do laser está focalizado exatamente na superfície superior).

Efeitos inevitáveis de refração e aberração esférica da lente causam variações no perfil de profundidade da intensidade do sinal na espectroscopia de Raman confocal. Como consequência disto, pode ocorrer alargamento da bandas de espalhamento Raman, que tendem a variar de acordo com o valor de $\Delta$ (EVERALL, 2004b).

Allen et al. (ALLEN; KALIVAS; RODRIGUEZ, 1999) mostraram que é possível distinguir PEAD de PEBD usando dados espectrais Raman processados por regressões multivariadas lineares, como regressão por componentes principais (PCR) e regressão de mínimos quadrados parciais (PLS). Em um estudo posterior (SATO et al., 2002), foi mostrado que a espectroscopia Raman e métodos PLS podem ser aplicados na predição da cristalinidade e ponto de fusão destes polietilenos.

\subsection{RECICLAGEM DE POLÍMEROS}

De modo geral, a reciclagem de polímeros é classificada em quatro categorias, que estão relacionadas com o grau de gerenciamento de recursos e redução de custos de processamento. Desta forma, os métodos de reciclagem apresentam uma hierarquia de preferência, de ordem ascendente, que vai do primário ao quaternário (AL-SALEM et al., 2017; HAMAD; KASEEM; DERI, 2013; SPINACÉ; DE PAOLI, 2005): reciclagem primária ou reuso; reciclagem secundária ou mecânica; reciclagem terciária ou química; reciclagem quaternária ou recuperação energética. 


\subsubsection{Reciclagem primária ou reuso}

A reciclagem primária é viável apenas em resíduos poliméricos semilimpos e com alto grau de pureza, consequentemente, é uma opção pouco recorrente aos recicladores. No entanto, este método de reciclagem é frequentemente adotado pelas indústrias para reciclar resíduos poliméricos provenientes dos seus próprios processos produtivos. Isto devido ao elevado grau de pureza e fácil identificação do resíduo, o que contribui para a redução de geração de resíduos no processo industrial. Além disso, reutilizar o resíduo plástico é sempre a escolha preferencial para a reciclagem devido a uma série de vantagens: (1) reduz o consumo de energia e de recursos; (2) contribui para a conservação de combustíveis fósseis, uma vez que a produção de polímeros sintéticos consome de 4 a $8 \%$ da produção mundial de petróleo; (3) reduz a emissão de diversos gases tóxicos, como óxidos de nitrogênio $\left(\mathrm{NO}_{\mathrm{x}}\right)$ e dióxido de enxofre $\left(\mathrm{SO}_{2}\right)$, além do dióxido de carbono $\left(\mathrm{CO}_{2}\right)$ que é um dos gases responsáveis pelo efeito estufa (AL-SALEM; LETTIERI; BAEYENS, 2009, 2010).

\subsubsection{Reciclagem secundária ou mecânica}

A reciclagem mecânica é o tipo de reciclagem mais utilizado no Brasil, porém é limitada à reciclagem de termoplásticos. A presença de contaminantes e misturas de polímeros no resíduo dificulta este método de reciclagem e, desta forma, a separação do material polimérico pós-consumo no momento da coleta tem papel essencial (AL-SALEM; LETTIERI; BAEYENS, 2009).

Os contaminantes (como tintas e particulados) limitam a obtenção de produtos finais de alta qualidade e homogêneos, uma vez que eles atuam como concentradores de tensão e, assim, reduzem significativamente o desempenho mecânico do produto reciclado. Já a presença de misturas poliméricas no resíduo gera separação de fases e, consequentemente, surgimento de problemas de compatibilidade que comprometem o desempenho do produto final; além de ocasionar maiores dificuldades durante o reprocessamento do reciclado polimérico no estado fundido (AL-SALEM; LETTIERI; BAEYENS, 2009). Diante disto, programas de coleta seletiva são necessários para que a maior quantidade possível de polímeros descartados seja separada de forma adequada, evitando ou reduzindo a contaminação dos mesmos com outros materiais.

Visando facilitar a identificação dos diferentes tipos de resíduos poliméricos, a ABNT (Associação Brasileira de Normas Técnicas) estabeleceu no Brasil, pela na Norma NBR 13.230, um sistema de codificação de produtos plásticos. Basicamente, este sistema é baseado em um 
código numérico para cada polímero, conforme mostrado na Figura 9, que obrigatoriamente deve estar identificado no produto polimérico acabado.

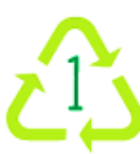

PET

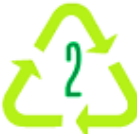

PEAD

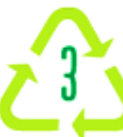

PVC

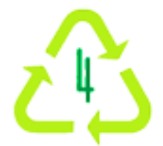

PEBD
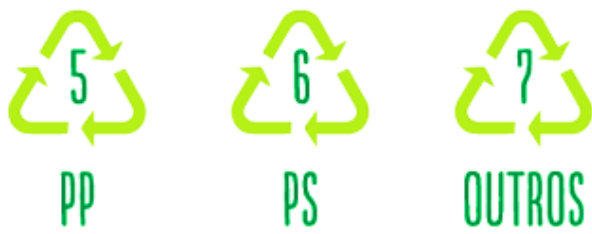

Figura 9 - Simbologia para identificar polímeros segundo a norma ABNT 13.230 (PLASTIVIDA, 2016).

Outro desafio para reciclagem secundária é a degradação termomecânica, que é causada pelo aquecimento e cisalhamento mecânico do polímero durante o seu ciclo de reprocessamento. Desta forma, a reciclagem mecânica de um dado polímero fica limitada pelo número de ciclos que um dado polímero pode suportar, mantendo um desempenho satisfatório para uma dada propriedade de interesse tecnológico (RAHIMI; GARCÍA, 2017). A degradação é ainda mais crítica ao reprocessar misturas poliméricas, visto que o reciclador é forçado a reprocessar o resíduo na temperatura de processamento do polímero com maior temperatura de fusão. Isso ocasiona um superaquecimento e degradação dos componentes da blenda polimérica com menor temperatura de processamento (RAGAERT; DELVA; VAN GEEM, 2017).

Em sumário, a reciclagem secundária ou mecânica, em escala industrial, é realizada por um conjunto de etapas de preparação e tratamento do resíduo polimérico pós-consumo (ALSALEM; LETTIERI; BAEYENS, 2009; RAGAERT; DELVA; VAN GEEM, 2017; SPINACÉ; DE PAOLI, 2005):

- Separação e classificação dos resíduos poliméricos: primeiramente, os materiais não poliméricos são separados dos RSPs (etapa de separação). Na segunda etapa (etapa de classificação), os diferentes tipos polímeros são separados entre si com base nas suas densidades, cores ou composições químicas. Para tanto, são usados diferentes métodos, como detalhado na Tabela 1. Contudo, no Brasil, a maior parte das empresas recicladoras faz a separação manualmente e a classificação por diferença de densidade em água (como ilustrado na Figura 10). No entanto, a classificação dos polímeros que possuem densidades próximas não é completamente efetiva e a eficiência de separação é altamente dependente da experiência do operador; 
Tabela 1 - Diferentes tecnologias para a classificação e separação de resíduos poliméricos durante reciclagem (RAHIMI; GARCÍA, 2017; SINGH et al., 2017; WANG et al., 2015).

\begin{tabular}{|c|c|c|}
\hline Processo & Descrição & Aplicação \\
\hline Manual & $\begin{array}{l}\text { Usa-se mão de obra treinada para separar e classificar } \\
\text { manualmente os resíduos poliméricos, baseando-se na } \\
\text { densidade, cor e pictogramas (NBR 13.230). Processo } \\
\text { considerado pouco produtivo e altamente dependente da } \\
\text { experiência do operador }\end{array}$ & $\begin{array}{l}\text { Classificação } \\
\text { e separação }\end{array}$ \\
\hline $\begin{array}{l}\text { Separação por } \\
\text { diferença de } \\
\text { densidade }\end{array}$ & $\begin{array}{l}\text { Usam-se tanques de água, ou de soluções aquosas de sal } \\
\text { inorgânico ou de álcool, para separar diferentes polímeros } \\
\text { ou materiais que irão flutuar ou afundar no tanque de } \\
\text { acordo com suas densidades e a do meio líquido }\end{array}$ & $\begin{array}{l}\text { Classificação } \\
\text { e separação }\end{array}$ \\
\hline $\begin{array}{l}\text { Separação por } \\
\text { densidade } \\
\text { magnética } \\
\text { (MDS) }\end{array}$ & $\begin{array}{l}\text { Usa-se uma mistura magnética (partículas de FeO de } \\
\text { tamanho nanométrico suspensas em água), cuja densidade } \\
\text { efetiva varia verticalmente em um campo magnético, } \\
\text { permitindo classificar partículas de polímeros com } \\
\text { densidade muito semelhante e, também, separar os } \\
\text { polímeros de diferentes materiais }\end{array}$ & $\begin{array}{l}\text { Classificação } \\
\text { e separação }\end{array}$ \\
\hline $\begin{array}{l}\text { Separação } \\
\text { tribo- } \\
\text { eletrostática }\end{array}$ & $\begin{array}{l}\text { Usa-se fricção para carregar as superfícies das partículas } \\
\text { poliméricas e elas são separadas de acordo com natureza } \\
\text { aniônica ou catiônica }\end{array}$ & Classificação \\
\hline $\begin{array}{l}\text { Flotação Froth } \\
\text { (flotação } \\
\text { seletiva) }\end{array}$ & $\begin{array}{c}\text { Classifica-se o polímero baseando-se no seu caráter } \\
\text { hidrofóbico ou hidrofílico }\end{array}$ & Classificação \\
\hline $\begin{array}{l}\text { Aceleradores } \\
\text { de velocidade }\end{array}$ & $\begin{array}{l}\text { Delaminam-se embalagens multicamadas de polímeros e } \\
\text { de outros materiais usando alta velocidade rotacional }\end{array}$ & Separação \\
\hline $\begin{array}{l}\text { Dissolução } \\
\text { seletiva }\end{array}$ & $\begin{array}{l}\text { Usa-se um solvente especifico para separar um polímero } \\
\text { dos demais materiais que são insolúveis }\end{array}$ & $\begin{array}{l}\text { Separação e } \\
\text { classificação }\end{array}$ \\
\hline
\end{tabular}




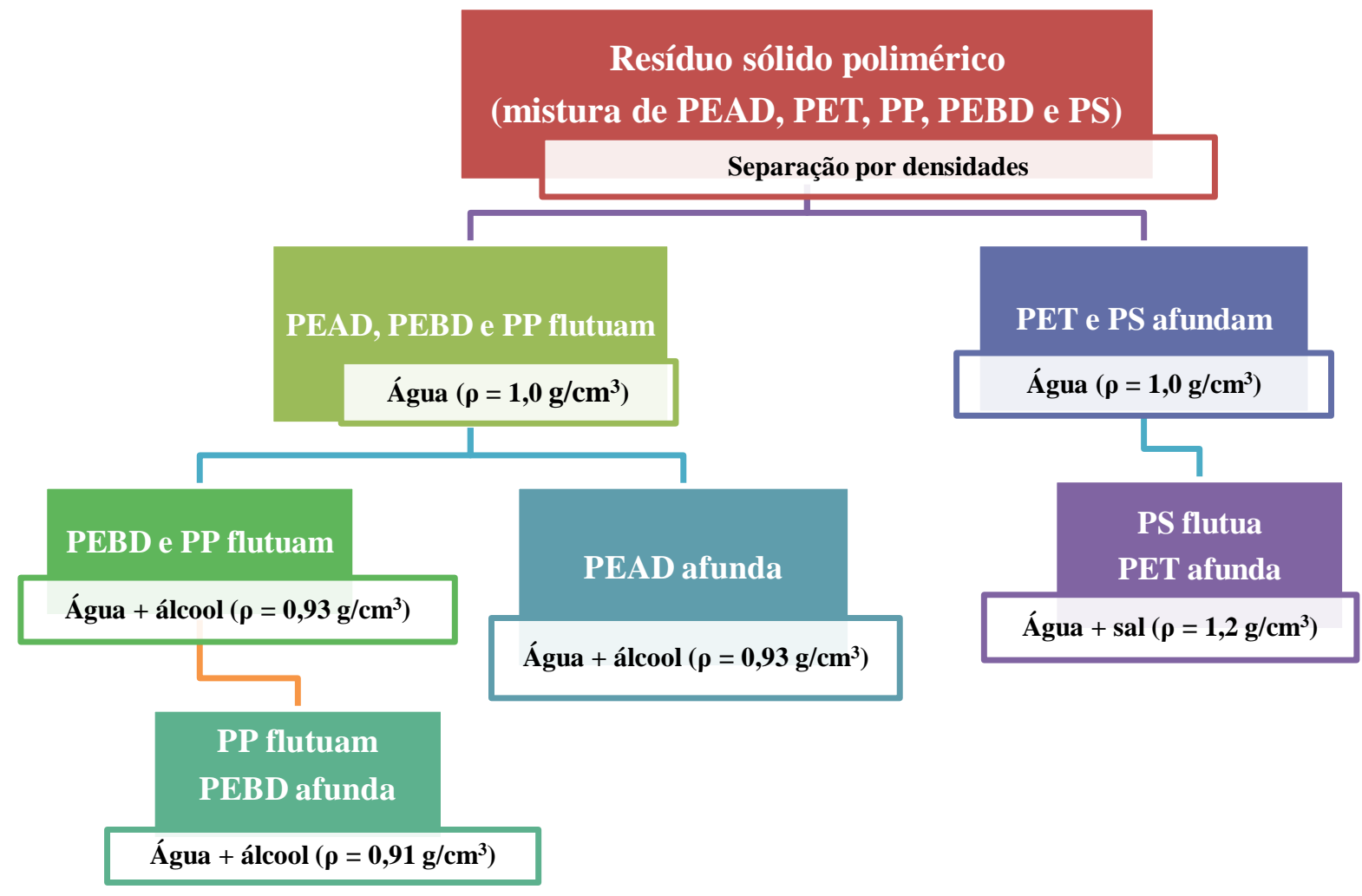

Figura 10 - Esquema da classificação de polímeros por diferenças de densidade (SPINACÉ; DE PAOLI, 2005).

- Moagem ou trituração: os resíduos poliméricos, depois de separados e classificados, são transformados em fragmentos menores por meio de moinhos de facas rotativas. Esta etapa leva a obtenção de resíduos na forma de grânulos, pó ou flocos;

- Lavagem: os contaminantes orgânicos e inorgânicos, que não foram removidos na etapa de separação, são retirados do resíduo polimérico através da lavagem com água em tanques ou ciclones. A água residual é submetida a um tratamento para ser reutilizada ou descartada. A lavagem química também é importante em certos casos, como remoção de adesivos e cola do plástico (soda cáustica e surfactantes são comumente utilizados para este fim);

- Secagem: a secagem do material é necessária, principalmente, em polímeros obtidos por policondensação (ou polimerização em etapas) que são susceptíveis à hidrólise durante o reprocessamento, como os poliésteres ou as poliamidas;

- Aglutinação: após lavado e seco, o resíduo polimérico moído é compactado em um aglutinador, com a finalidade de reduzir o volume e homogeneizar o reciclado. Isto facilita o processo final que, normalmente, é realizado em uma extrusora. $\mathrm{Na}$ aglutinação, é formada uma massa polimérica devido à elevação da temperatura 
do material, que é provocada pelo atrito dos fragmentos poliméricos com as paredes do aglutinador;

- Reprocessamento: nesta última etapa, o resíduo polimérico é transformado em grãos de polímero (péletes), que por sua vez serão mandados para as indústrias transformadoras. Geralmente, este processo é realizado em uma extrusora, na qual o resíduo polimérico, previamente aglutinado, é fundido e homogeneizado com aditivos (oxidantes e pigmentos). Na saída da extrusora são ejetados filamentos contínuos de polímero fundido que, após resfriados, são granulados no formato de péletes.

\subsubsection{Controle de qualidade dos resíduos poliméricos no processo de reciclagem}

Embora os termos separação e classificação sejam geralmente adotados como sinônimos na literatura sobre reciclagem de resíduos poliméricos (DAHLBO et al., 2018; HORODYTSKA; VALDÉS; FULLANA, 2018; WANG; WANG; HUANG, 2017), nesta tese, eles são tratados como processos distintos como descrito anteriormente: a separação envolve distinguir e separar polímeros de materiais não poliméricos misturados no RSP; a classificação corresponde a identificação e isolamento de um tipo de polímero dentre outros polímeros com estruturas químicas diferentes no RSP. Cabe ressaltar que, ambos podem ser realizados simultaneamente, numa única etapa, em um processo de reciclagem.

Além da separação e classificação manual e por diferença de densidades, existem outras tecnologias, já bem estabelecidos, que podem ser utilizadas para o pré-tratamento dos RSPs: tribo-eletrostática, flotação seletiva, dissolução seletiva, dentre outras (conforme Tabela 1). A separação por densidade magnética (MDS) é uma nova tecnologia proposta para melhorar a qualidade da etapa de separação de poliolefinas (HU et al., 2013; SERRANTI et al., 2015).

MDS é um método de separação física e, também, de classificação baseado nas diferenças em densidade dos materiais utilizando um campo magnético, porém é utilizada uma suspensão aquosa com partículas nanométricas de óxido de ferro magnético como meio líquido.

Na Tabela 2, são listados os principais métodos de controle de qualidade dos resíduos poliméricos após as etapas de separação e classificação. Frequentemente, a espectroscopia de absorção no infravermelho próximo (NIR) e espectroscopia de espalhamento Raman são usadas com esta finalidade. Aliadas a estas caracterizações, ferramentas estatísticas, como a análise por componentes principais (PCA) e imagem hiperespectral (HSI) são, geralmente, utilizadas 
para classificação do resíduo polimérico, a partir de seus dados espectrais NIR ou Raman (HU et al., 2013; SERRANTI et al., 2015; SERRANTI; GARGIULO; BONIFAZI, 2012).

Tabela 2 - Diferentes tecnologias para controle de qualidade dos resíduos poliméricos após a etapa de classificação na reciclagem (RAHIMI; GARCÍA, 2017; SINGH et al., 2017).

\begin{tabular}{cc}
\hline Processo & Descrição \\
\hline $\begin{array}{c}\text { Espectroscopia de } \\
\text { fluorescência de } \\
\text { raios-X, }\end{array}$ & $\begin{array}{c}\text { Usam-se estes métodos espectroscópicos para classificação de acordo } \\
\text { com a composição química do polímero. Além disso, usa-se estes } \\
\text { métodos para avaliar a etapa de separação e classificação dos RSPs } \\
\text { através de ferramentas estatísticas } \\
\text { Raman }\end{array}$ \\
$\begin{array}{c}\text { Imagem hiper- } \\
\text { espectral }\end{array}$ & $\begin{array}{c}\text { Usa-se uma tecnologia de sensores em linha de produção que } \\
\text { combina análise espacial (imagem 3D) e espectral (tipicamente no } \\
\text { infravermelho) de sólidos. Imagem hiper-espectral é uma técnica de } \\
\text { controle de qualidade para monitorar continuamente os processos de } \\
\text { classificação de poliolefinas por métodos mecânicos }\end{array}$ \\
$\begin{array}{c}\text { Tecnologia de } \\
\text { ultrassom }\end{array}$ & $\begin{array}{c}\text { Usam-se imagens de ultrassom para monitoramento e identificação de } \\
\text { contaminantes nos resíduos poliméricos }\end{array}$ \\
$\begin{array}{c}\text { Espectroscopia de } \\
\text { plasma induzida } \\
\text { por laser (LIBS) }\end{array}$ & $\begin{array}{c}\text { Usam-se fontes laser pulsadas para gerar um plasma do resíduo } \\
\text { plástico e detecta-se os elementos presentes neste plasma usando } \\
\text { sensores ópticos. A classificação dos polímeros é baseada na } \\
\text { comparação dos elementos detectados e de uma referência }\end{array}$ \\
\hline
\end{tabular}

Embora o HSI possibilite detectar e mapear a presença de contaminantes (cargas e misturas de diferentes polímeros) na amostra, esta técnica permite apenas avaliar qualitativamente os diferentes polímeros no resíduo polimérico. Sendo esta, também, a principal limitação do método PCA (SERRANTI; GARGIULO; BONIFAZI, 2011).

A partir da primeira década do século XXI, os resíduos eletrônicos têm crescido desenfreadamente com o desenvolvimento e comercialização de equipamentos eletroeletrônicos. Contudo, os processos para separação e classificação da fração polimérica neste tipo de resíduo ainda carecem de desenvolvimento tecnológico. Experimentalmente, a moagem criogênica tem mostrado resultados promissores neste âmbito (TIWARY et al., 2017).

\subsubsection{Reciclagem terciária ou química}

Na reciclagem química, os polímeros pós-consumo são tratados através de diferentes processos térmicos (gaseificação, pirólise e hidrocraqueamento) e químicos (quimólise). Alguns pesquisadores consideram que a degradação biológica também é um tipo de reciclagem química (IGNATYEV; THIELEMANS; VANDER BEKE, 2014). Estas rotas químicas, que 
estão detalhadas na Tabela 3, possibilitam a obtenção de insumos químicos (petroquímicos ou monômeros) que podem ser reinseridos na cadeia produtiva de novos produtos.

Tabela 3 - Diferentes processos de reciclagem química de resíduos poliméricos (AL-SALEM; LETTIERI; BAEYENS, 2010; IGNATYEV; THIELEMANS; VANDER BEKE, 2014; RAGAERT; DELVA; VAN GEEM, 2017).

\begin{tabular}{|c|c|c|}
\hline Processo & Descriçãa & Vantagens \\
\hline Quimólise & $\begin{array}{l}\text { Despolimerização usando solventes e } \\
\text { temperaturas relativamente baixas para obtenção } \\
\text { de monômeros ou oligômeros. Podem ser feitos } \\
\text { por hidrólise, glicólise, aminólise, entre outros. } \\
\text { Fluidos sub- e supercríticos, como água e álcool, } \\
\text { também podem ser usados como meio reacional } \\
\text { e tem mostrado resultados promissores para } \\
\text { reciclagem química de resíduos poliméricos }\end{array}$ & $\begin{array}{l}\text { Gera produtos } \\
\text { puros de valor } \\
\text { agregado }\end{array}$ \\
\hline $\begin{array}{l}\text { Degradação } \\
\text { biológica }\end{array}$ & $\begin{array}{l}\text { Quebra das cadeias poliméricas, na presença de } \\
\text { ar e água, em moléculas menores por bactérias, } \\
\text { fungo, ou outros microrganismos }\end{array}$ & $\begin{array}{c}\text { Ecologicamente } \\
\text { correta }\end{array}$ \\
\hline Pirólise & $\begin{array}{c}\text { Quebra das cadeias poliméricas (craqueamento), } \\
\text { em atmosfera sem oxigênio, usando calor e } \\
\text { pressões de } 1 \text { a } 2 \text { atm. Os produtos obtidos são } \\
\text { basicamente uma mistura de hidrocarbonetos } \\
\text { (líquidos e gases combustíveis) e resíduos } \\
\text { carbonáceos }\end{array}$ & $\begin{array}{l}\text { Adequado para } \\
\text { misturas altamente } \\
\text { heterogêneas de } \\
\text { polímeros } \\
\text { Tecnologia } \\
\text { relativamente } \\
\text { simples }\end{array}$ \\
\hline $\begin{array}{l}\text { Hidrocraqueamento } \\
\text { ou hidrogenação }\end{array}$ & $\begin{array}{l}\text { Craqueamento catalítico em elevada pressão de } \\
\text { hidrogênio (aproximadamente } 70 \mathrm{~atm} \text { ) e } \\
\text { temperaturas na faixa de } 375 \mathrm{a} 400{ }^{\circ} \mathrm{C} \text {. } \\
\text { Catalisadores suportados (Ni/S ou NiMo/S) são } \\
\text { os mais utilizados nesse processo }\end{array}$ & $\begin{array}{l}\text { Alta qualidade da } \\
\text { nafta produzida } \\
\text { Adequado para } \\
\text { misturas de } \\
\text { plásticos }\end{array}$ \\
\hline Processo KDV & $\begin{array}{l}\text { Despolimerização usando catalisador, calor e } \\
\text { pressão (quase atmosférica), tendo como } \\
\text { produtos principais combustíveis líquidos com } \\
\text { baixa concentração de oxigênio }\end{array}$ & $\begin{array}{l}\text { Adequado para } \\
\text { polímeros } \\
\text { halogenados }\end{array}$ \\
\hline Gaseificação & $\begin{array}{l}\text { Conversão de material orgânico numa mistura } \\
\text { gasosa de } \mathrm{CO}_{2}, \mathrm{CO}, \mathrm{H}_{2}, \mathrm{CH}_{4} \text { e outros } \\
\text { hidrocarbonetos leves por oxidação parcial do } \\
\text { resíduo, usando calor e ar (ou uma mistura de } \\
\text { vapor e oxigênio) }\end{array}$ & $\begin{array}{l}\text { Baixo custo e } \\
\text { tecnologia bem } \\
\text { estabelecida }\end{array}$ \\
\hline
\end{tabular}

Embora as rotas de reciclagem química possam ser aplicadas em resíduos formados por misturas de diversos materiais poliméricos, é de vital importância que o resíduo esteja limpo e com baixo teor de contaminantes inorgânicos. Isto porque estas condições facilitam o processo 
e contribuem para a melhor qualidade do produto final. Por esta razão, é necessário um prétratamento (separação e lavagem) do resíduo, assim como na reciclagem mecânica, para que o resíduo pós-consumo alcance as especificações de limpeza necessárias ao processo de reciclagem adotado.

\subsubsection{Reciclagem quaternária ou recuperação energética}

A reciclagem energética é uma alternativa aplicada aos resíduos poliméricos mistos e altamente contaminados, que não podem ser facilmente e/ou economicamente reciclados pelas outras formas de reciclagem. Sendo assim, é uma tecnologia ideal para a reciclagem de resíduos provenientes de aplicações médicas e embalagens de produtos perigosos (IGNATYEV; THIELEMANS; VANDER BEKE, 2014).

Na reciclagem quaternária, os resíduos são incinerados, i.e., queimados, produzindo majoritariamente dióxido de carbono, água e energia na forma de vapor, calor e/ou eletricidade (AL-SALEM; LETTIERI; BAEYENS, 2010). Os sistemas de incineração operam em temperaturas elevadas e apresentam sistemas para controle de emissão de gases e de mistura dos resíduos, facilitando a incineração de resíduos com diferentes características físicas e químicas (OLIVEIRA, 2012).

Embora haja emissão de gases poluentes e geração de substâncias perigosas, a incineração é o método mais utilizado na Europa para reciclagem de polímeros descartados. Sendo este fato justificado pelos benefícios envolvidos neste tipo de operação (AL-SALEM; LETTIERI; BAEYENS, 2009; MEKHZOUM et al., 2017; SINGH et al., 2017):

- Redução/eliminação imediata de 90 a 99 \% (em volume) dos resíduos poliméricos, reduzindo a necessidade de aterros sanitários;

- Elevado poder calorífico dos polímeros, o que torna os seus resíduos convenientes fontes de energia através da incineração;

- Possibilidade de implantação da planta de incineração próxima às fontes geradoras dos resíduos, o que acarreta em diminuição dos custos referente a transportes;

- A venda de energia gerada pode compensar o custo de implantação e operação da instalação;

- Possiblidade de controle das emissões gasosas provenientes do processo de incineração, de acordo com as exigências da legislação regional. 


\subsubsection{Formas alternativas de reciclagem de resíduos plásticos}

Segundo o Plano Nacional de Resíduos Sólidos, é de vital importância adotar o conceito dos 3Rs (reduzir, reutilizar e reciclar) em todas as etapas do desenvolvimento de um produto para evitar e amenizar os problemas envolvendo a geração de resíduos (BARROS, 2013). Para o gerenciamento de resíduos, deve ser seguida a seguinte ordem de prioridade (CEMPRE, 2015): ( $\left(1^{\circ}\right)$ a não-geração de resíduos; $\left(2^{\circ}\right)$ a redução; $\left(3^{\circ}\right)$ o reuso; $\left(3^{\circ}\right)$ a reciclagem; $\left(4^{\circ}\right)$ o tratamento dos resíduos sólidos, se nenhuma das opções anteriores forem possíveis de serem adotadas.

Em respeito aos 3Rs, a inserção de resíduos sólidos poliméricos em concreto (na forma de particulado, flake ou fibras) tem sido uma forma alternativa de reutilizar este tipo de resíduo na indústria civil. Este procedimento mostra-se viável para o reuso de RSPs com alto teor de contaminantes, sendo necessário um número pequeno de etapas prévias para tratamento destes resíduos. Além disso, é aplicável para resíduos de termoplásticos ou termofixos, que podem ser apenas moídos e diretamente introduzidos na composição do concreto. Este método tem sido reportado na literatura como uma forma de descarte seguro de resíduos poliméricos pósconsumo, visto que o concreto detém um tempo de vida útil muito maior do que os polímeros. Desta forma, eles são removidos do fluxo de resíduos por um longo período, contribuindo para a redução do consumo de energia e recursos naturais (JASSIM, 2017; SHARMA; BANSAL, 2016). Além deste aspecto ecológico, a adição de resíduos poliméricos pode melhorar as propriedades do concreto, como por exemplo, aumento da resistência à tração e resistência química, menor retração de secagem e, ainda, possibilidade de redução de gastos com matériaprima (JASSIM, 2017; SAFINIA; ALKALBANI, 2016).

A produção de madeiras termoplásticas, que são geralmente chamadas na literatura cientifica por WPCs (wood/plastic composites), são compósitos obtidos basicamente através da reciclagem mecânica de resíduos de termoplásticos e resíduos oriundos das indústrias de transformação de madeira, como a lixa e a serragem (POLETTO, 2017). Este método de reciclagem de polímeros termoplásticos é uma forma alternativa de contornar problemas de perda de propriedades mecânicas do polímero reciclado que ocorre, intrinsecamente, durante a reciclagem mecânica do mesmo.

Diferentes segmentos da indústria, como moveleira e automotiva, têm atualmente um grande interesse em WPCs para a confecção de produtos devido aos seus menores custos, possibilidade de serem reciclados, e facilidade de processamento com técnicas convencionais de processamento de polímeros (extrusão, injeção e moldagem) (BORAH; KIM, 2016). No 
entanto, este método alternativo de reciclagem mecânica é limitado a poucos termoplásticos (PEAD, PEBD, PELBD, PP e PET), que possuem temperatura de processamento inferior a 200 ${ }^{\circ} \mathrm{C}$; uma vez que, acima desta temperatura, ocorre degradação dos materiais lignocelulósicos que compromete a qualidade do produto reciclado (KAZEMI NAJAFI, 2013).

\subsection{MÉTODOS DE CALIBRAÇÃO MULTIVARIADA}

A regressão linear por mínimos quadrados parciais (regressão PLS) é um dos métodos de regressão mais empregados na quimiometria, sendo uma ferramenta matemática extremamente eficaz para a construção de modelos de calibração multivariada (COSTA, 2013).

Por definição, a calibração multivariada é um método matemático-estatístico utilizado para correlacionar a concentração de um analito com uma propriedade mensurável dentro de um sistema complexo, cujas respostas ou sinais analíticos mensurados sofrem ação direta ou indireta de diferentes efeitos de interferência, que são intrínsecos do equipamento ou do método de medições, ou de outras variáveis físico-químicas do próprio sistema (GOMES, 2012; MEDEIROS, 2009).

A principal vantagem da regressão PLS é o fácil tratamento e interpretação de dados altamente correlacionados, com ruídos, com interferências físico-químicas e com sobreposição de sinais, que são comumente observados em espectros vibracionais (COSTA, 2013; MEDEIROS, 2009).

\subsubsection{Regressão linear por mínimos quadrados parciais (PLS)}

Em resumo, a regressão PLS é um método interativo que encontra um conjunto de escores $t$ e $u$ para uma matriz $X$ (conjunto de dados instrumentais) e uma matriz $Y$ (conjunto de dados de uma dada propriedade), respectivamente. Para tanto, essas matrizes são externamente correlacionadas pelas equações (BURNHAM; VIVEROS; MACGREGOR, 1996; ROCHA et al., 2016; WOLD; SJÖSTRÖM; ERIKSSON, 2001):

$$
\begin{array}{ll}
X_{(n \times k)}=T_{(n \times h)} * P_{(h \times k)}^{T}+E_{(n \times k)} ; & x_{n k}=\sum_{h} t_{n h} p_{h k}+e_{n k} \\
Y_{(n \times m)}=U_{(n \times h)} * Q_{(h \times m)}^{T}+F_{(n \times m)} ; & y_{n m}=\sum_{h} u_{n h} q_{h m}+f_{n m}
\end{array}
$$

onde $n$ é o número de observações da propriedade de interesse (por exemplo, número de espectros medidos), $k$ é o número de respostas medidas para uma amostra (por exemplo, número de pontos em um espectro vibracional), $m$ é o número de propriedades de interesse para ser 
predito pela regressão PLS (por exemplo, concentração ou densidade), $h$ é o número de variáveis latentes (LVs), $T$ e $U$ são as matrizes de pontuação para matrizes de dados $X$ e $Y$, respectivamente; $x$ e $y$ são elementos das matrizes $X$ e $Y$, respectivamente. As matrizes $P$ e $Q$ contêm os valores de carregamento para $X$ e $Y$, nesta ordem. As matrizes $E$ e $F$ apresentam os erros residuais.

Os escores são estimadas a partir de combinações lineares das variáveis originais das matrizes $X$ e $Y$, usando coeficientes de peso $(w)$ e um número determinado de LVs, com a finalidade de maximizar a covariância entre essas matrizes de dados (MEHMOOD et al., 2012). Para a matriz $X$, os escores são obtidos por:

$$
T_{(n \times h)} ; \quad t_{n h}=\sum_{k} x_{n k} w_{k h}
$$

O algoritmo PLS mantém o módulo mínimo para os elementos de $F$ e correlaciona internamente as matrizes de escores $T$ e $U$, admitindo que os escores de $X$ são bons preditores para a matriz de dados $Y$ (ou seja, $U=T$ ) (WOLD; SJÖSTRÖM; ERIKSSON, 2001). Então, a Equação 7 pode ser reescrita como:

$$
Y_{(n \times m)}=T_{(n \times h)} * Q_{(h \times m)}^{T}+G_{(n \times m)} ; \quad y_{n m}=\sum_{h} q_{h m} \sum_{k} w_{k h} x_{n k}+g_{n m}
$$

onde $G$ é a matriz de erros aleatórios. Rearranjando a Equação 9, a regressão PLS permite prever os valores de $Y$ a partir da matriz $X$ usando a equação (10).

$$
Y_{(n \times m)}=X_{(n \times k)} * B_{(k \times m)}+G_{(n \times m)} ; \quad y_{n m}=\sum_{k} x_{n k} b_{k m}+g_{n m}
$$

onde $B$ é a matriz de coeficientes de regressão.

A equação (10) é denominada modelo preditivo ou modelo de predição quando são estabelecidos os valores de $B$ e $G$ para um conjunto de dados em $X$ e $Y$.

Computacionalmente, o modelo linear PLS é implementado pelo algoritmo NIPALS detalhado na Figura 11. Existem regressões PLS não lineares, mas estão fora do escopo desta tese e podem ser encontradas em literatura específica (HASSEL, 2003; ROSIPAL, 2011). 


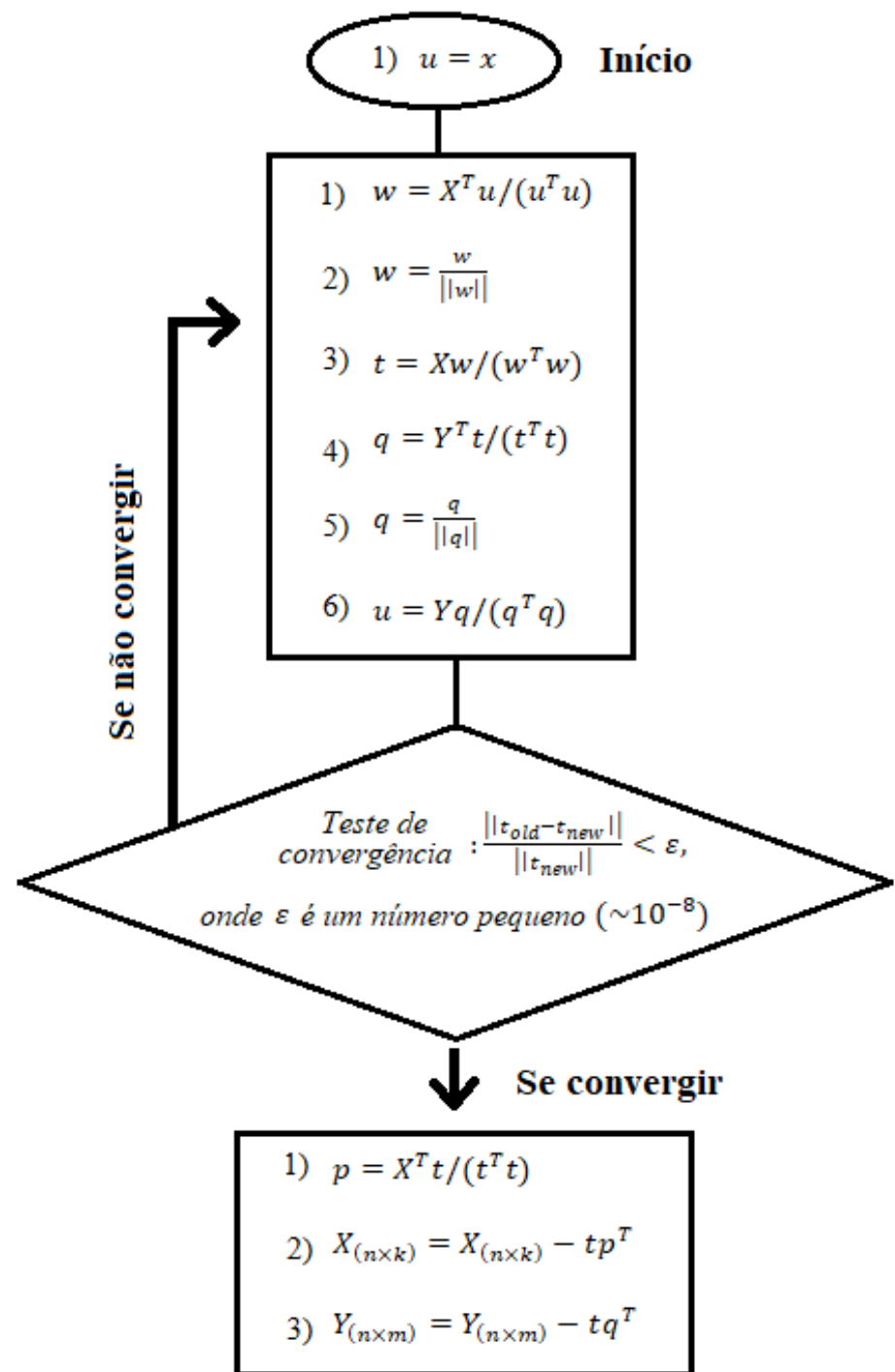

Figura 11 - Fluxograma do algoritmo NIPALS (WOLD; SJÖSTRÖM; ERIKSSON, 2001).

\subsubsection{Calibração e validação do modelo de predição}

A construção do modelo de predição é feita através do método de validação cruzada, que consiste em retirar aleatoriamente uma ou mais amostras dos dados de calibração (subconjunto de teste) e, em seguida, é construído o modelo com as amostras restantes (subconjunto de calibração); então, é realizada a previsão da propriedade de interesse para as amostras do subconjunto de teste (variáveis latentes). Desta forma, a capacidade de predição do modelo é quantificada através do cálculo de erro relativo entre os resultados preditos e os valores reais, para a propriedade mensurada de interesse, das amostras no subconjunto de teste (MEDEIROS, 2009). Posteriormente, as variáveis latentes são incluídas novamente no conjunto de calibração e o algoritmo de validação é repetido, seguidamente, até que o erro seja igual ou 
inferior a um valor predeterminado. Este processo cíclico é conhecido como calibração ou treinamento (training) do algoritmo PLS.

Após a etapa de calibração, é de vital importância validar o modelo proposto através da comparação entre os valores experimentais e preditos de um conjunto de dados independentes. Nesta validação independente, ou validação externa, o modelo de predição construído é utilizado para prever a propriedade de interesse de um conjunto de dados que não foram utilizados na calibração.

Como forma de avaliar o desempenho e generalidade de predição dos modelos, são utilizados parâmetros estatísticos de erro quadrático médio de validação cruzada (RMSECV) e erro quadrático médio de predição (RMSEP):

$$
R M S E C V / P=\sqrt{\frac{\sum_{i=1}^{z}\left(y_{i}-\hat{y}_{i}\right)^{2}}{z}}
$$

onde $z$ é o número de espectros, $y_{i}$ é a medida de referência (medida experimental da propriedade de interesse) para a amostra $\mathrm{i}$, e $\hat{y}_{i}$ é a medida prevista da amostra no conjunto de calibração (RMSECV) ou no conjunto de teste de validação independente (RMSEP).

O grau de ajuste entre os valores previstos e os valores de referência é avaliado pelo coeficiente de correlação $(R)$, dado por:

$$
R=\sqrt{1-\frac{\sum_{i=1}^{Z}\left(y_{i}-\hat{y}_{i}\right)^{2}}{\sum_{i=1}^{Z}\left(y_{i}-\hat{y}_{\text {mean }}\right)^{2}}}
$$

onde $\hat{y}_{\text {mean }}$ é a média da medida de referência de todas as amostras (no caso desta tese, é a concentração do analito) no conjunto de validação cruzada $\left(R_{c a l}\right)$ ou conjunto de validação externa $\left(R_{\text {pred }}\right)$.

\subsubsection{Regressão linear por mínimos quadrados parciais por intervalos (iPLS)}

A regressão linear por mínimos quadrados parciais por intervalos (regressão iPLS) é um tipo de regressão PLS modificada, onde o espectro da amostra é previamente subdividido em intervalos equidistantes menores e, subsequentemente, a regressão PLS é aplicada em cada um deles. Desta forma, é possível otimizar modelos de predição porque os subintervalos sem informações relevantes ou com significante interferência podem ser desconsiderados (ROCHA et al., 2016). Geralmente, regressões iPLS fornecem modelos de predição mais robustos com 
erros de predição mais baixos (SILVA; FLORES; PARISOTTO, 2016; ZUO; FANG; LIANG, 2014).

\subsubsection{Regressão linear por mínimos quadrados parciais e amostragem ponderada adaptativa competitiva (CARS-PLS)}

$\mathrm{O}$ algoritmo de amostragem ponderada adaptativa competitiva (algoritmo CARS) foi projetado para encontrar, de forma interativa, o menor subconjunto "ótimo" de dados experimentais, dentro da matriz $X$, que leva à obtenção do modelo preditivo baseado na regressão PLS com o menor valor de RMSECV (LI et al., 2009). Em cada corrida de calibração, o algoritmo CARS constrói um modelo preditivo PLS com um subconjunto variável de dados, selecionados aleatoriamente do conjunto de calibração (método de amostragem de Monte Carlo). A função de diminuição exponencial (EDF) e a amostragem ponderada adaptativa (ARF) são, em seguida, aplicadas como um método de duas etapas para a seleção dos elementos $x$, removendo os elementos na matriz $X$ que apresentam os coeficientes de peso $(w)$ mais pobres por uma simulação de o princípio da "sobrevivência do mais apto" (LI et al., 2009).

Na regressão CARS-PLS, a importância de cada elemento $x$ é avaliada por um peso normalizado calculado por:

$$
w_{C A R S}=\left|b_{i}\right| / \sum_{i=1}^{k}\left|b_{i}\right|
$$

Enquanto que o método ARF mantém o elemento $x$ com os maiores pesos, o método EDF causa a redução do número de elementos na matriz $X$. Desta forma, são construídos, forçadamente, modelos de predição PLS com a menor quantidade de coeficientes de regressão na matriz $B$, promovendo significativa redução de "custo computacional", ou seja, diminuição no tempo de processamento dos ciclos de calibração no algoritmo PLS. Em cada corrida de calibração, a função EDF usa a equação exponencial:

$$
r_{i}=\alpha e^{-\beta i}
$$

sendo $\alpha$ e $\beta$ dados por:

$$
\alpha=\left(\frac{k}{2}\right)^{1 /(N-1)}
$$




$$
\beta=\ln (k / 2) /(N-1)
$$

\subsubsection{Pré-processamento dos dados}

Antes de iniciar a construção dos modelos de predição, é de suma importância que os dados passem por uma etapa de pré-processamento. Este procedimento consiste em manipular matematicamente os dados antes de aplicar o método de regressão neles, visando reduzir e/ou remover informações irrelevantes e ruídos que podem ter efeitos negativos na calibração multivariada. Em métodos espectroscópicos, a presença de ruídos é sempre observada nos espectros devido à instabilidade do laser, vibrações mecânicas ou campos elétricos ambientais durante as medições.

Existem, atualmente, diversos algoritmos de pré-tratamento de dados que devem ser escolhidos de acordo com a finalidade do método. Contudo, a escolha nem sempre é simples e direta e, em muitos casos, o analista precisa testar e utilizar mais de um tipo de algoritmo para tratar os dados.

No caso de dados espectrais infravermelho e Raman, o alisamento ou suavização (smoothing) é uma das primeiras operações necessárias no pré-tratamento para eliminar ou reduzir ao máximo o ruído, sem que haja modificações significativas nos espectros. O alisamento proposto por Savitzky-Golay é um dos mais utilizados para este fim. Sendo que, este é um método matemático de suavização baseado em uma regressão polinomial $\left(1^{\mathrm{a}}, 2^{\mathrm{a}} \mathrm{e}\right.$ ordem superior), usando métodos de mínimos quadrados e o conceito de janela de comprimento “n” entre pontos (COSTA, 2013; SAVITZKY; GOLAY, 1964).

O pré-processamento de dados por centralização média consiste em reduzir os desvios anômalos nos dados espectrais, causados por instabilidade do sinal no equipamento (ruídos), através da equação (VAN DEN BERG et al., 2006):

$$
\dot{x}_{n k}=x_{n k}-\bar{x}_{n}
$$

onde $\dot{x}$ é o substituto para o elemento $x$ na matriz $X$ e $\bar{x}_{n}$ é a média aritmética dos elementos na linha $n$ da matriz $X$.

No método autoescalado, todos os dados espectrais têm igual importância, mas os erros de medição podem ser reduzidos pela correlação entre os elementos $x$ e seus substitutos, conforme equação: 


$$
\ddot{x}_{n k}=\frac{x_{n k}-\bar{x}_{n}}{s_{n}}
$$

onde $s_{n}$ é o fator scaling, dado por:

$$
s_{n}=\sqrt{\frac{\sum_{j=1}^{k}\left(x_{n j}-\bar{x}_{n}\right)^{2}}{k-1}}
$$

No pré-processamento Pareto, o objetivo é minimizar a importância relativa dos dados anômalos (outliers) com valores grandes, sem causar mudanças significativas nos dados espectrais originais. Para este fim, os elementos $x$ são substituídos por:

$$
\dddot{x}_{n k}=\frac{x_{n k}-\bar{x}_{n}}{\sqrt{s_{n}}}
$$




\section{PROCEDIMENTO EXPERIMENTAL}

\subsection{MATERIAIS}

Os materiais utilizados neste trabalho estão detalhados na Tabela 4.

Tabela 4 - Lista de materiais utilizados neste trabalho.

\begin{tabular}{|c|c|c|}
\hline Material & $\begin{array}{c}\text { IF }(\mathrm{g} / 10 \mathrm{~min})-\mathrm{ASTM} \\
\mathrm{D-1238}\end{array}$ & Fornecedor \\
\hline PEAD pristino & $0,3\left(190{ }^{\circ} \mathrm{C}-5 \mathrm{~kg}\right)$ & Petroquímica Triunfo S.A. \\
\hline PEBD pristino & $2,6\left(190{ }^{\circ} \mathrm{C}-2,16 \mathrm{~kg}\right)$ & Braskem \\
\hline PEAD reciclado & $0,8\left(300^{\circ} \mathrm{C}-1,2 \mathrm{~kg}\right)$ & NZ Cooperpolymer \\
\hline PEBD reciclado & $9,5\left(190{ }^{\circ} \mathrm{C}-2,16 \mathrm{~kg}\right)$ & NZ Cooperpolymer \\
\hline PET reciclado & $14\left(255^{\circ} \mathrm{C}-2,16 \mathrm{~kg}\right)$ & NZ Cooperpolymer \\
\hline PP reciclado & $0,5\left(230{ }^{\circ} \mathrm{C}-2,16 \mathrm{~kg}\right)$ & NZ Cooperpolymer \\
\hline $\begin{array}{l}\text { Carbonato de cálcio (malha } 400 \\
\qquad- \text { abertura } 37 \mu \mathrm{m} \text { ) }\end{array}$ & - & Brasilminas \\
\hline $\begin{array}{l}\text { Sílica gel (diâmetro de partícula } \\
\text { na faixa de } 40-60 \mu \mathrm{m} \text { ) }\end{array}$ & - & Merck \\
\hline
\end{tabular}

\subsection{MÉTODOS}

Os procedimentos adotados para o desenvolvimento desta pesquisa estão, esquematicamente, apresentados na Figura 12.

O início do trabalho consistiu em caracterizar as matérias-primas utilizadas na preparação das blendas de PEAD/PEBD por extrusão. Após processadas, foram coletados os espectros vibracionais das misturas poliméricas. Sendo que, não houve nenhum preparo específico para as amostras na forma de péletes antes das medições de espectroscopia ATRFTIR e Raman confocal. Após a aquisição dos dados espectrais, foi iniciada a etapa de prétratamento dos dados e, em seguida, a construção dos modelos preditivos usando os métodos de regressão PLS, iPLS e CARS-PLS e o programa Matlab. 


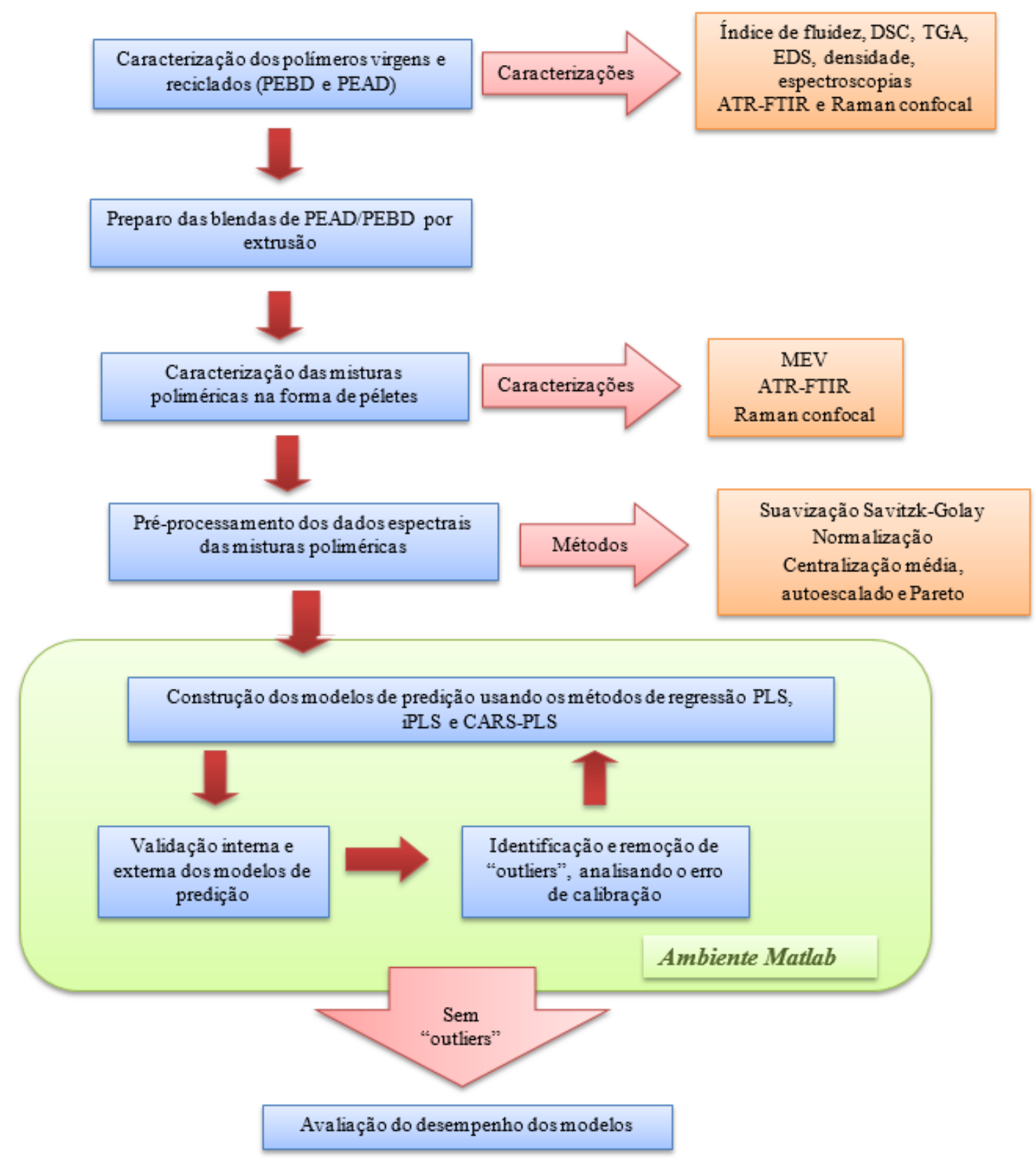

Figura 12 - Sequência de etapas adotadas para desenvolvimento deste projeto de pesquisa.

A etapa de construção dos modelos de predição foi repetida diversas vezes, até que não fossem mais detectados dados outliers após cada passo de validação interna (validação cruzada) e validação externa (teste/validação independente) dos modelos. Por fim, os modelos preditivos com maior desempenho de predição das concentrações das blendas de PEBD/PEAD foram analisados e apresentados na sessão de resultados desta tese.

Por fim, o grau de generalidade e aplicabilidade dos modelos preditivos foi feito avaliando a incerteza de predição da composição das blendas poliméricas obtidas com 
polietilenos reciclados e com a presença de quatro diferentes contaminantes (PET reciclado, PP reciclado, sílica e carbonato de cálcio).

\subsubsection{Processamento das blendas de PEAD/PEBD}

Vinte e uma misturas poliméricas de PEAD/PEBD pristinos (100/0, 95/5, 90/10, $85 / 15,80 / 20,75 / 25,70 / 30,65 / 35$ e assim por diante, até a concentração de 0/100 \%p) foram preparadas usando extrusora (Dynisco Laboratory Mixing Extruder com diâmetro do cilindro $=19 \mathrm{~mm}$; diâmetro da matriz $=3,12 \mathrm{~mm})$, com duas zonas de aquecimento $\left(180\right.$ e $\left.190{ }^{\circ} \mathrm{C}\right)$. A velocidade de rotação da rosca utilizada foi de $220 \mathrm{rpm}$. Para simular um processo de reciclagem mecânica e, para assegurar uma mistura completa, todas as amostras foram extrusadas três vezes antes das análises espectroscópicas. A aparência dos polietilenos pristinos e reciclados, antes e após extrusão, pode ser observada na Figura 13.

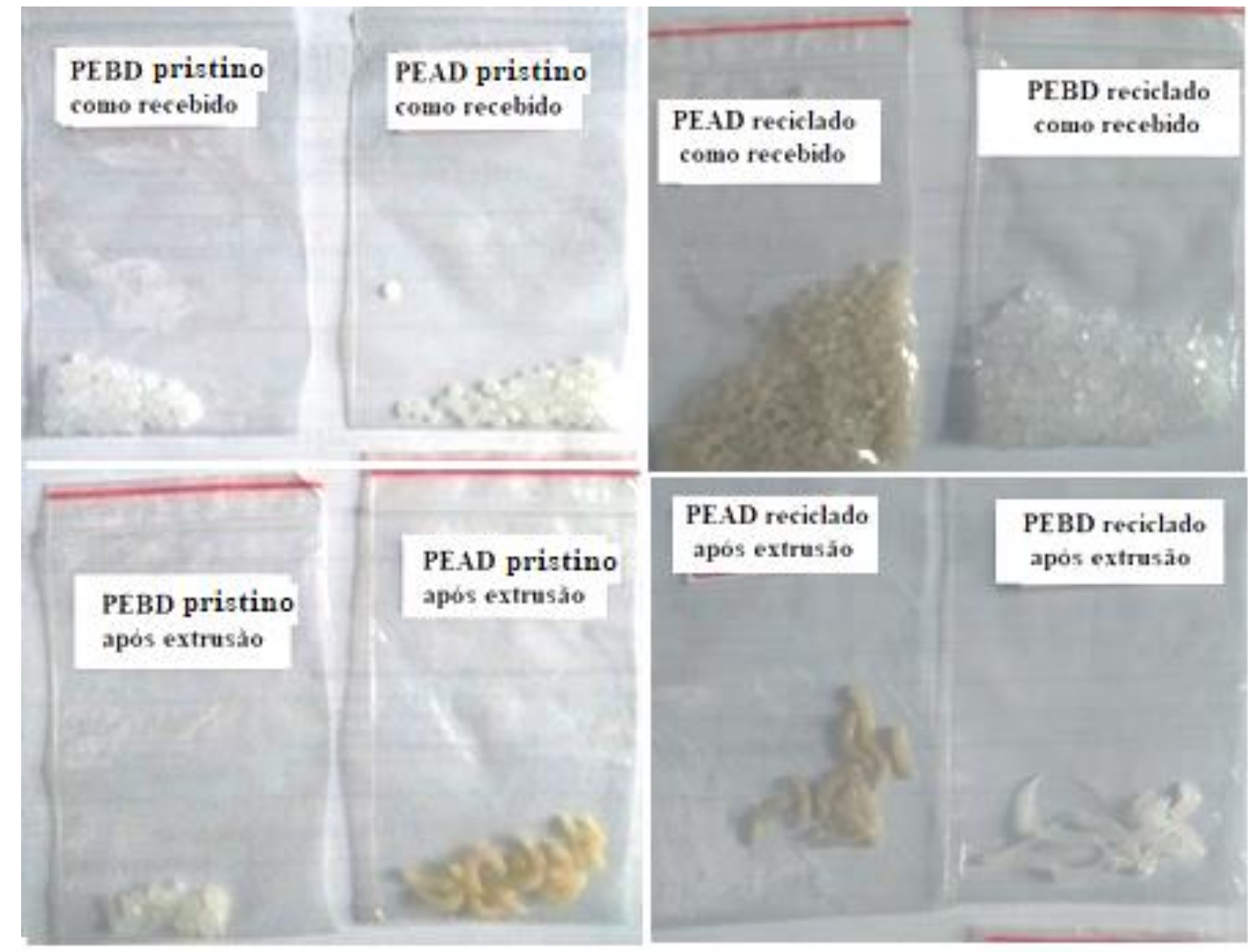

Figura 13 - Imagem fotográfica dos polietilenos pristinos e reciclados, antes e após extrusão.

As misturas poliméricas de PEAD/PEBD reciclados (sem e com contaminante) foram preparadas na extrusora Dynisco (zonas de aquecimento operando em 190 e $200{ }^{\circ} \mathrm{C}$; velocidade de rotação da rosca igual a 220 rpm), usando as composições análogas aos polietilenos pristinos. 
Poli(tereftalato de etileno) (PET) reciclado, polipropileno (PP) reciclado, sílica gel em pó e carbonato de cálcio em pó foram usados como contaminantes neste trabalho de pesquisa. Para tanto, estes materiais foram adicionados nas misturas poliméricas de polietilenos reciclados num teor de $5 \%$ p. Apenas as misturas poliméricas recicladas com PET foram extrusadas com zonas de aquecimento operando em 220 e $230{ }^{\circ} \mathrm{C}$, que corresponde à faixa de temperatura mínima para plastificar e processar o PET.

\subsubsection{Caracterizações}

\subsubsection{Análise termogravimétrica (TGA)}

Os perfis de decomposição térmica dos polímeros foram identificados por análises termogravimétricas (TGA), utilizando o equipamento TGA/SDTA MODELO 851e, Mettler Toledo (equipamento do Centro de Química e Meio Ambiente do IPEN). Os materiais não foram secados previamente, sendo submetidos a análise TGA na faixa de temperatura entre 25 a $600{ }^{\circ} \mathrm{C}$, com taxas de aquecimento e resfriamento de $10{ }^{\circ} \mathrm{C} / \mathrm{min}$, sob fluxo contínuo de gás nitrogênio $(50 \mathrm{~mL} / \mathrm{min})$. Neste trabalho, são apresentados os resultados de decomposição térmica relativos à segunda rampa de aquecimento.

A temperatura de início de decomposição térmica ( $\mathrm{T}_{\text {onset }}$ ) foi determinada pela interseção de uma linha tangente à linha de base com uma linha tangente à região mais inclinada na curva TGA. Enquanto que, a temperatura de máxima decomposição térmica $\left(\mathrm{T}_{\max }\right)$, ou seja, a temperatura na qual a taxa de decomposição é máxima, foi determinada pelo pico das curvas de termogravimétrica derivada (DTG) (DA SILVA et al., 2018). As curvas DTG correspondem à derivada primeira dos termogramas de TGA.

\subsubsection{Microscopia eletrônica de varredura (MEV) e espectroscopia de energia dispersiva (EDS)}

As micrografias de MEV e as análises elementares por espectroscopia EDS foram obtidas no microscópio eletrônico de varredura da FEI Company, modelo FEG - Inspect F50 (equipamento do departamento de Engenharia Metalúrgica e de Materiais da Escola Politécnica da USP). Para tanto, os polímeros foram recobertos com ouro (espessura de 5 a $10 \mathrm{~nm}$ ) e fixados ao porta-amostra com o auxílio de fita de carbono. 


\subsubsection{Calorimetria exploratória diferencial (DSC)}

Os ensaios de DSC foram realizados no calorímetro exploratório diferencial da Mettler Toledo, modelo 822e (equipamento do Centro de Química e Meio Ambiente do IPEN). Para eliminar a história térmica, foram realizados dois ciclos de aquecimento consecutivos nas seguintes condições: faixa de temperatura de 25 a $200{ }^{\circ} \mathrm{C}$, taxa de aquecimento de $10{ }^{\circ} \mathrm{C} / \mathrm{min}$ e fluxo de $\mathrm{N}_{2}(50 \mathrm{~mL} / \mathrm{min})$. Neste trabalho, são apresentados apenas a segunda rampa de aquecimento.

O grau de cristalinidade $\left(\chi_{c}\right)$ foi determinado a partir da entalpia específica de fusão cristalina da amostra $(\Delta H)$, entalpia específica de fusão cristalina teórica para um polímero totalmente cristalino $\left(\Delta H^{\circ}\right)$ e a fração em peso do polímero na mistura $\left(f_{p}\right)$, usando a Equação 21 (PERSICO et al., 2009; YOUSFI; LIVI; DUCHET-RUMEAU, 2014). Sendo que, o valor de $f_{p}$ foi obtido pelas análises de TGA de cada amostra.

$$
\chi_{c}(\% \mathrm{p})=\frac{|\Delta H|}{f_{p} \Delta H^{\circ}} \times 100
$$

No caso dos polietilenos com cristalização secundária (cristalização no segundo ciclo de aquecimento), é necessário considerar a entalpia de cristalização secundária $\left(\Delta H_{C}\right)$, que é um evento exotérmico. Desta forma, o grau de cristalinidade destes polímeros é dado por:

$$
\chi_{c}(\% \mathrm{p})=\frac{|\Delta H|+\left|\Delta H_{C}\right|}{f_{p} \Delta H^{\circ}} \times 100
$$

Para os polietilenos pristinos e reciclados com baixa concentração de impurezas $\left(f_{p}>\right.$ $99 \%$ p), a densidade da amostra ( $\rho$ ) foi estimada com base no grau de cristalinidade $\left(\chi_{c}\right)$, de acordo com a seguinte equação (MUNARO; AKCELRUD, 2008):

$$
\rho=\frac{\rho_{c} \rho_{a}}{\left(1-\chi_{c}\right) \rho_{c}+\chi_{c} \rho_{a}}
$$

onde $\rho_{c}$ e $\rho_{a}$ são a densidade do polímero $100 \%$ cristalino e $100 \%$ amorfo, respectivamente. No caso do polietileno puramente ortorrômbico, $\Delta H^{\circ}=290 \mathrm{~J} / \mathrm{g}, \rho_{c}=1 \mathrm{~g} / \mathrm{cm}^{3}$ e $\rho_{a}=0,852 \mathrm{~g} / \mathrm{cm}^{3}$ (MUNARO; AKCELRUD, 2008). 


\subsubsection{Rugosidade superficial por MEV}

As micrografias da superfície das amostras, na forma de péletes, foram realizadas no microscópio eletrônico de varredura da FEI Company, modelo FEG - Inspect F50. O recobrimento das amostras foi realizado com ouro (filme com espessura de 5 a $10 \mathrm{~nm}$ ), usando um pulverizador de mesa BALZERS - SCD050 (BALTEC) com um tempo de deposição de 25 segundos. As micrografias de MEV (aumento de 2000 vezes) foram feitas com os elétrons secundários, usando uma distância de trabalho de $11,14 \mathrm{~mm}$ e um ângulo de $90^{\circ}$ entre o feixe de elétrons e a amostra.

A imagem superficial 3D foi construída digitalizando as micrografias de MEV em imagens RGB no software ImageJ, usando o recurso Interative $3 D$ Surface plot com os seguintes parâmetros: "grid size" = 128; "smoothing" = 4; "perspective" = 0; "lightning" =0,5; "scale" $=1 ; "$ z-scale" = 0,$2 ; " \max "=100 \% ; " \min "=0 \%$.

A rugosidade quadrática média $\left(R_{q}\right)$ e rugosidade média $\left(R_{a}\right)$ foram obtidas também com o programa ImageJ, mas as micrografias foram digitalizadas em escala de cinza de 32 bits e as rugosidades foram determinadas pelo SurfCharJ plugin desenvolvido por Chinga e colaboradores (CHINGA et al., 2007).

\subsubsection{Espectroscopia ATR-FTIR}

Os espectros de FTIR dos polietilenos e das suas blendas poliméricas foram adquiridos através do espectrômetro Thermo IS5 Nicolet com acessório ATR (cristal de ZnSe). As amostras foram analisadas na faixa de 600 a $4000 \mathrm{~cm}^{-1}$, em temperatura ambiente, usando 16 varreduras e resolução espectral de $4 \mathrm{~cm}^{-1}$. $\mathrm{O}$ número de varreduras foi selecionado após testes preliminares, nos quais foi identificado que o aumento do número de varreduras não melhora a qualidade do sinal/ruído dos espectros de ATR-FTIR medidos.

\subsubsection{Espectroscopia Raman}

Os espectros Raman dos polietilenos e das suas misturas foram obtidos em um microscópio de Raman confocal Alpha300R (WITEC, laser de 532 nm e 45 mW). Os espectros foram coletados de 210 a $3785 \mathrm{~cm}^{-1}$, em temperatura ambiente e sala escura, usando uma resolução espectral de $3 \mathrm{~cm}^{-1}$. Foram coletados espectros em regiões diferentes e aleatórias da superfície de cada amostra, mantendo sempre a lente objetiva do microscópio em foco com a superfície analisada. 


\subsubsection{Desenvolvimento dos modelos de predição}

Todos os espectros Raman e ATR-FTIR foram suavizados usando o método SavitzkyGolay $($ ordem polinomial $=5$ e pontos de janela $=10)$ e, em seguida, normalizados usando o programa Origin 2016. Os métodos de regressão PLS e iPLS foram realizados com o software Matlab (versão R2015a) usando pacote iToolbox (NØRGAARD et al., 2005). Em contrapartida, a regressão CARS-PLS foi realizada através do pacote libPLS 1.95 (LI; XU; LIANG, 2014).

Usando os algoritmos iPLS, todos os espectros foram segmentados em intervalos de PLS equidistantes $(10,20,30,40,50)$. Além de suavização e normalização, foi implementado mais um método de pré-processamento nos espectros vibracionais (autoescalado, centralização média ou Pareto), dependendo do tipo espectroscopia e algoritmo PLS utilizados, conforme descrito na Tabela 5.

Tabela 5 - Detalhes dos parâmetros usados no desenvolvimento dos modelos de predição, de acordo com o algoritmo de regressão linear adotado.

\begin{tabular}{ccccc}
\hline Espectroscopia & Algoritmo & $\begin{array}{c}\text { Método de pré- } \\
\text { processamento }\end{array}$ & $\begin{array}{c}\mathbf{N}^{\circ} \text { de } \\
\text { espectros } \\
\text { (calibração) }\end{array}$ & $\begin{array}{c}\mathbf{N}^{\circ} \text { de } \\
\text { espectros } \\
\text { (teste } \\
\text { independente) }\end{array}$ \\
\hline ATR-FTIR & PLS e iPLS & Autoescalado & 62 & 18 \\
& CARS-PLS & Centralização média & 62 & 18 \\
\hline & PLS e iPLS & Centralização média & 42 & 16 \\
\hline & & & & \\
\hline
\end{tabular}

A seleção do método foi baseada nos modelos preditivos que melhor se ajustaram ao conjunto de validação externa (i.e., teste independente). Além disso, o número de espectros usados como conjunto de validação cruzada e como conjunto de teste independente está detalhado na Tabela 5 . 


\section{RESULTADOS E DISCUSSÃO}

\subsection{CARACTERIZAÇÃO DOS POLIETILENOS PRISTINOS E RECICLADOS}

\subsubsection{Espectroscopia de energia dispersiva (EDS)}

Para avaliar o grau de pureza e identificar os possíveis contaminantes nos polietilenos reciclados, foi avaliada a composição química destes polímeros pela técnica EDS. Nas micrografias de MEV do PEAD reciclado (Figura 14), é possível identificar nitidamente a presença de impurezas na superfície deste polímero.
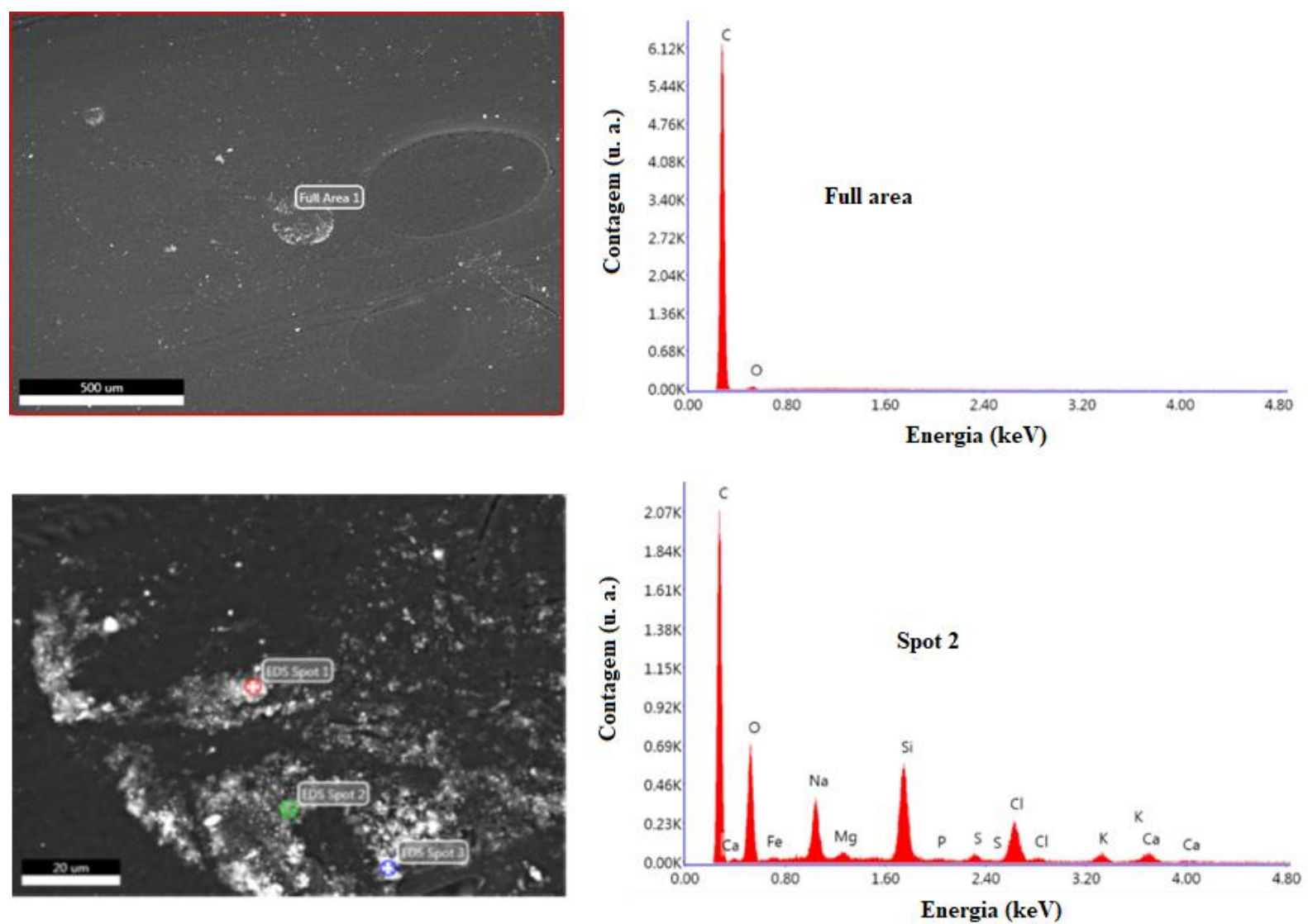

Figura 14 - Imagens de MEV do PEAD reciclado e seus respectivos espectros de EDS (à direita).

Os espectros de EDS da Figura 14 revelaram que estes contaminantes são constituídos pelos elementos: $\mathrm{K}, \mathrm{O}, \mathrm{Si}, \mathrm{Na}, \mathrm{Mg}, \mathrm{Fe}, \mathrm{S}, \mathrm{Cl}, \mathrm{Ca}$ e P. Estes elementos químicos podem estar relacionados a diferentes aditivos presentes no PEAD (DE PAOLI, 2008; HAHLADAKIS et al., 2018; MITROKA et al., 2013; PONTES; ALMEIDA, 2005):

- P, O e S: fosfatos, fosfitos e sulfitos que são antioxidantes secundários, atuando na decomposição de hidroperóxidos que se formam na matriz polimérica;

- Mg, O e Si: talco (carga de enchimento) que apresenta em sua composição oxido de magnésio $(\mathrm{MgO})$, dióxido de silício $\left(\mathrm{SiO}_{2}\right)$ e água; 
- $\mathrm{Ca}, \mathrm{C}$ e O: carbonato de cálcio $\left(\mathrm{CaCO}_{3}\right)$, que é uma carga tipicamente utilizada como enchimento em polímeros, para baratear o preço do produto;

- Si e O: dióxido de silício e vidro que são usados como cargas de enchimento e de reforço em termoplásticos;

- Cl: pode ser devido à presença de retardante de chamas clorados ou presença de compostos clorados no PEAD devido ao seu contato direto com água potável clorada, quando este polímero é utilizado como tubos;

- Fe, Na, K, Si, Mg e O: mica e argilas (silicatos) que são comumente utilizadas como cargas de enchimento nas dimensões (granulometria) observadas na micrografia de MEV do PEAD reciclado.

A presença, em maior concentração, de carbono deve-se à composição química das cadeias poliméricas do polietileno. O elemento oxigênio, além de estar associados aos aditivos mencionados anteriormente, também podem estar associados à degradação oxidativa do polímero durante o seu processamento e vida útil.

O PEBD reciclado também apresenta impurezas, como pode ser verificado na Figura 15, que são constituídas por átomos de Alumínio, Ferro, Magnésio, Oxigênio e Silício. Estes elementos são típicos da composição química de silicatos (PEREIRA, 2008). Devido ao tamanho das partículas serem da ordem de micrômetros, estes silicatos foram aplicados, provavelmente, como carga de enchimento ou são provenientes de contaminação após o descarte do produto à base de PEBD.

No entanto, polietilenos de baixa densidade são tipicamente utilizados para a confecção de embalagens alimentícias e argilas nanométricas podem ser empregadas em filmes poliméricos para diminuir a difusão de gás oxigênio para o interior do produto por efeito de barreira (ALVES, 2008), reduzindo a velocidade de oxidação do alimento embalado. Além disso, nanoargilas são utilizadas como cargas de reforço em polímeros, sendo amplamente aplicados no desenvolvimento de nanocompósitos de matriz polimérica (DE PAIVA; MORALES; VALENZUELA DÍAZ, 2008; ZARE, 2013). 

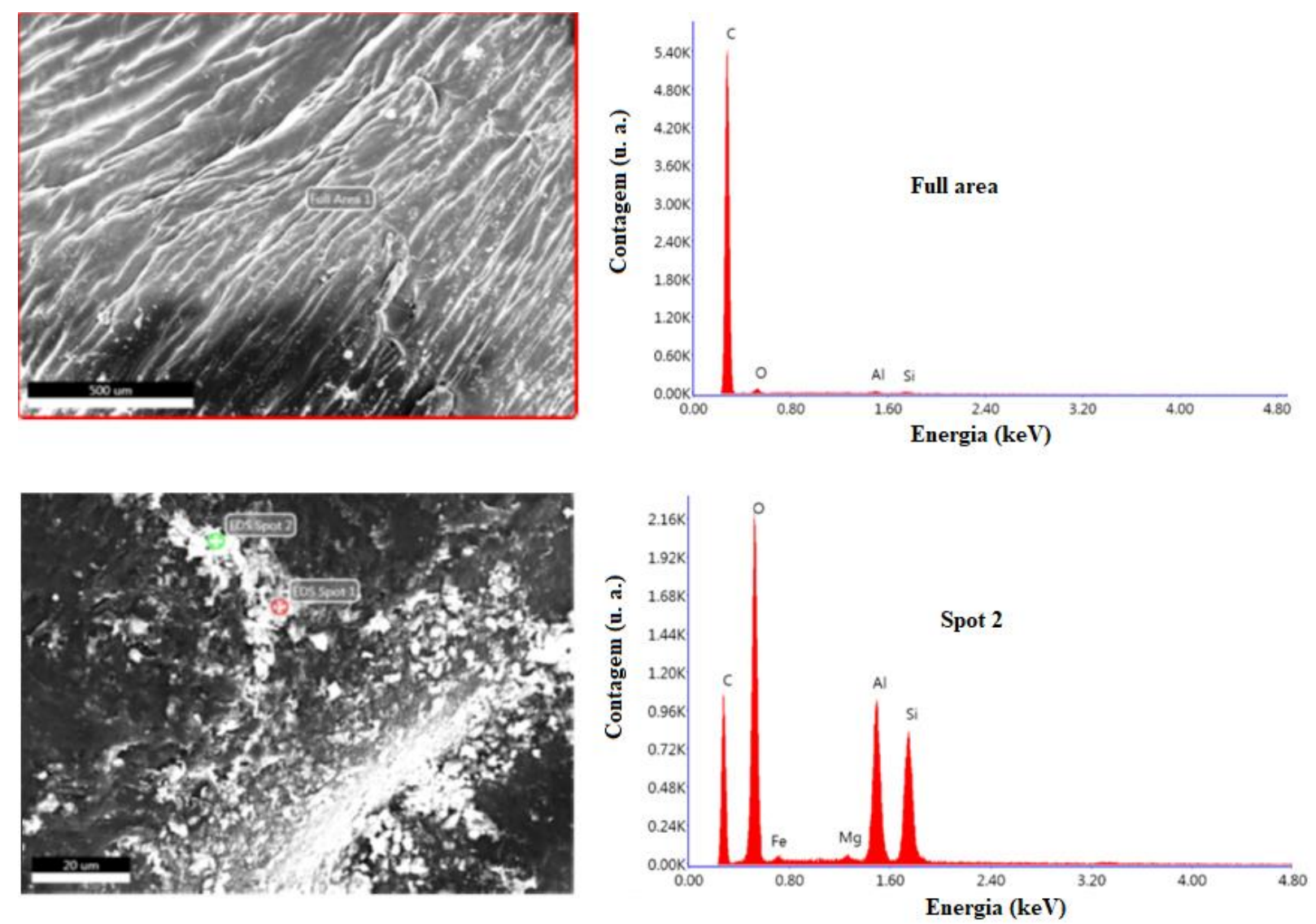

Figura 15 - Imagens de MEV do PEBD reciclado e seus respectivos espectros de EDS (à direita).

\subsubsection{Análise termogravimétrica (TGA)}

Foram feitas análises de TGA para avaliar a estabilidade térmica e o teor de impurezas nos polietilenos, principalmente nos reciclados. As curvas de TGA e DTG do PEBD reciclado e pristino estão apresentados na Figura 16. Como pode ser observado, estes materiais apresentam curva de perda de massa semelhante, com $\mathrm{T}_{\text {onset }}$ igual a $432 \pm 2{ }^{\circ} \mathrm{C}$, envolvendo um único processo de termodecomposição com taxa máxima a $458 \pm 2{ }^{\circ} \mathrm{C}$ (Tabela 6). $\mathrm{O}$ teor de resíduos da decomposição térmica (carbonáceos e/ou óxidos) foi igual a 0,72\%p e 0,78\%p para o PEBD pristino e reciclado, respectivamente. Este resultado indica um elevado grau de pureza do PEBD reciclado.

Conforme detalhado na Tabela 6, a temperatura de início de decomposição térmica é de $447 \pm 2{ }^{\circ} \mathrm{C}$ para o PEAD pristino e é igual a $438 \pm 3{ }^{\circ} \mathrm{C}$ para o mesmo polímero reciclado, o que sugere uma menor estabilidade térmica para o PEAD reciclado. Este resultado é justificado pela presença significante de oxigênio nos espectros de EDS dos polímeros reciclados, visto que o polietileno reciclado é mais susceptível à degradação oxidativa devido a dois fatores: (1) foi submetido a um maior número de processamentos termomecânicos que um material pristino; 
(2) ficou um maior tempo exposto a diferentes intempéries (radiação UV, temperatura, chuva), contato com fluídos e íons metálicos durante o seu ciclo de vida, que ocasionam formação de radicais livres no polímero. De acordo com De Paoli (DE PAOLI, 2008), uma vez que radicais livres são gerados na superfície ou no interior de um polímero em uma atmosfera contendo oxigênio, sempre ocorrerá um processo autocatalítico de oxidação das cadeias poliméricas. No caso de polietilenos, esses processos fotoquímicos dão origem, principalmente, a grupos contendo a ligação $\mathrm{C}=\mathrm{O}$ (carbonilas) e ligações duplas $\mathrm{C}=\mathrm{C}$.

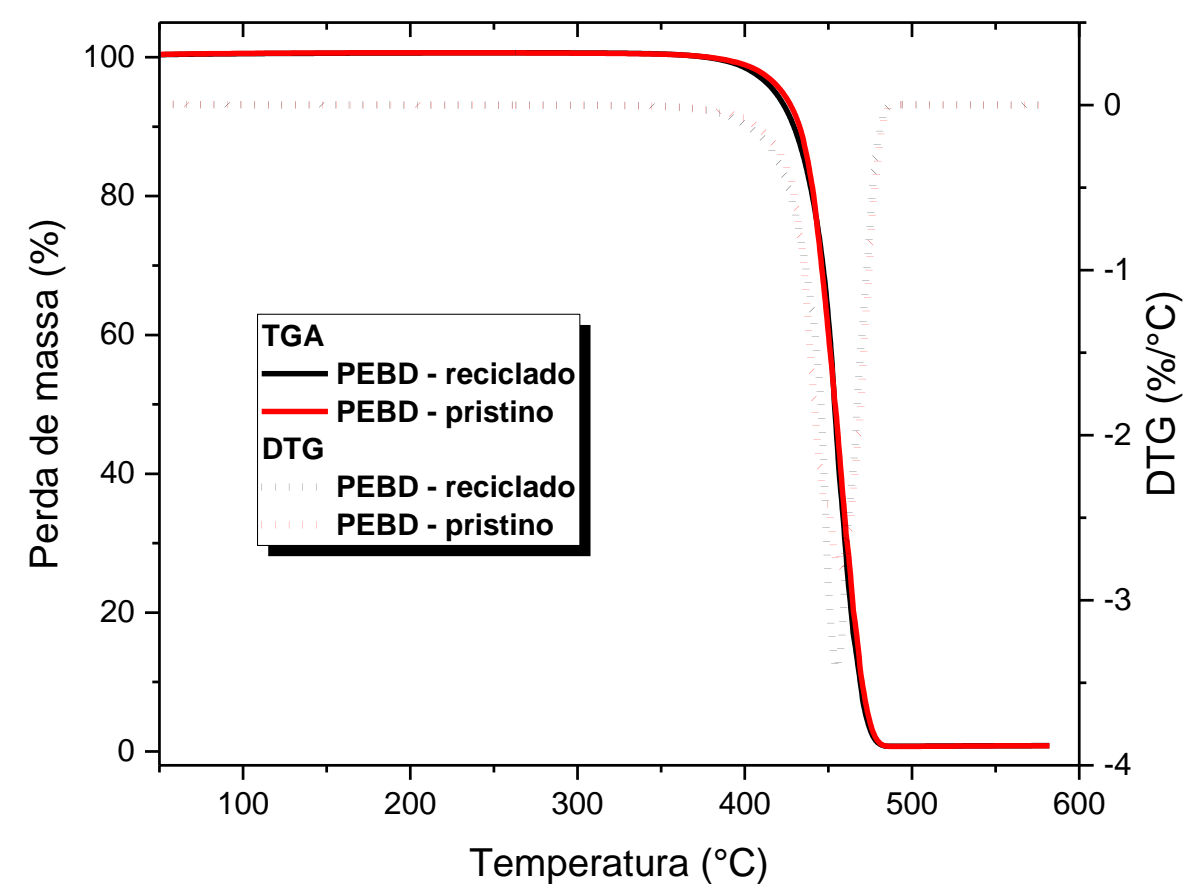

Figura 16 - Curvas de TGA e DTG para o PEBD pristino e reciclado.

Tabela 6 - Dados de $T_{\text {onset }} \mathbf{e} \mathbf{T}_{\max }$ originados das medidas de TGA/DTG.

\begin{tabular}{ccc}
\hline Material & $\mathbf{T}_{\text {onset }}\left({ }^{\circ} \mathbf{C}\right)$ & $\mathbf{T}_{\max }\left({ }^{\circ} \mathbf{C}\right)$ \\
\hline PEAD pristino & $447 \pm 2$ & $471 \pm 2$ \\
\hline PEBD pristino & $431 \pm 2$ & $458 \pm 2$ \\
\hline PEAD reciclado & $438 \pm 3$ & $459 \pm 2$ \\
PEBD reciclado & $432 \pm 2$ & $455 \pm 2$ \\
\hline
\end{tabular}

Segundo os termogramas de TGA presentes na Figura 17, a massa residual é de 0,68 $\%$ p para o PEAD pristino e de $0,98 \%$ p para o PEAD reciclado. Em relação às taxas de 
termodecomposição máxima, PEAD pristino apresenta $\mathrm{T}_{\max }$ igual a $471 \pm 2{ }^{\circ} \mathrm{C}$ que é, aproximadamente, $10{ }^{\circ} \mathrm{C}$ maior que a $\mathrm{T}_{\max }$ do PEAD reciclado.

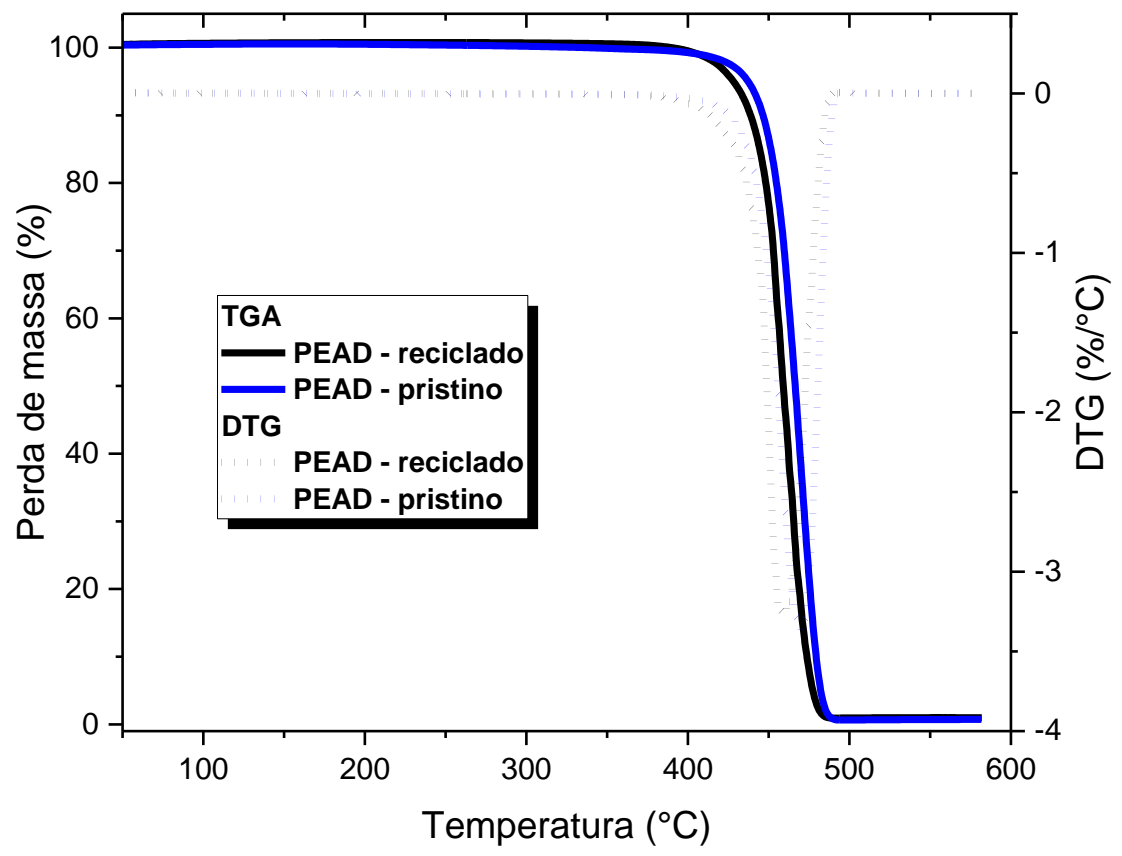

Figura 17 - Curvas de TGA e DTG para o PEAD pristino e reciclado.

\subsubsection{Calorimetria exploratória diferencial (DSC)}

Na Figura 18, estão apresentadas as curvas de DSC do PEAD pristino e reciclado. A temperatura de transição vítrea $\left(\mathrm{T}_{\mathrm{g}}\right)$ não foi detectada, visto que os polietilenos apresentam $\mathrm{T}_{\mathrm{g}}$ subambiente, entre -130 e $-100{ }^{\circ} \mathrm{C}$ (PEACOCK, 2000), que é uma faixa de temperatura fora da capacidade de varredura do equipamento utilizado. Para o PEAD pristino, a fusão da fase cristalina possui faixa de temperatura estreita e ocorre dentro do intervalo de 110 a $138{ }^{\circ} \mathrm{C}$, com pico endotérmico em $132{ }^{\circ} \mathrm{C}$. Em contraste, para o PEAD reciclado, a faixa de temperatura de fusão cristalina é mais larga $\left(110-160^{\circ} \mathrm{C}\right)$, com pico endotérmico a $134{ }^{\circ} \mathrm{C}$.

Alguns autores relatam que um alargamento no intervalo de temperatura desta transição termodinâmica (de primeira ordem) é um indicativo de uma distribuição pouco uniforme de tamanho dos cristais no polímero (POTEKAEV et al., 2016), o que pode ser justificado pela maior heterogeneidade de distribuição de massa molar do PEAD reciclado inerente ao processo de reciclagem mecânica.

Ainda, é possível identificar, na Figura 18, que ambos polietilenos de alta densidade apresentam evento de cristalização secundária na faixa de 93-110 ${ }^{\circ} \mathrm{C}$. Este fenômeno deve-se à incompleta cristalização do polímero durante o primeiro ciclo de resfriamento controlado e 
ocorre devido ao elevado tamanho das cadeias poliméricas dos PEADs que dificulta a formação dos cristalitos de cadeias dobradas, tornando o evento cinético de cristalização muito lento.

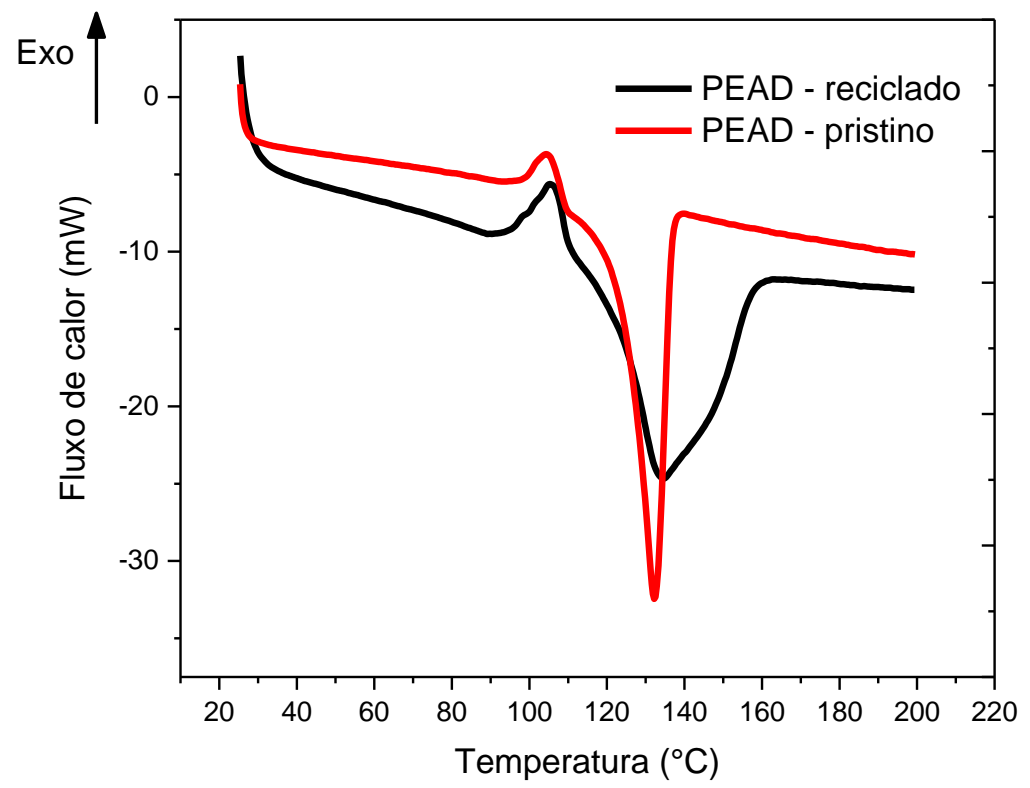

Figura 18 - Curvas DSC do PEAD pristino e reciclado.

Como a presença de contaminantes no PEAD reciclado é muito baixa, a sua densidade sofre efeito negligenciável das densidades de possíveis materiais residuais presentes no mesmo. Assim, a densidade do PEAD reciclado pode ser estimada, com boa precisão, pela Equação 23. De acordo com os resultados detalhados na Tabela 7, o PEAD reciclado apresenta possui grau de cristalinidade igual a 44,2 $\pm 0,1 \%$ e densidade similar à do PEAD pristino $(0,92 \pm 0,01$ $\left.\mathrm{g} / \mathrm{cm}^{3}\right)$.

Tabela 7 - Dados de $\Delta H, \Delta H_{C}$ (entalpia referente à cristalização secundária), $\chi_{c}$ e densidade obtidos com as medidas de DSC.

\begin{tabular}{ccccc}
\hline Material & $\Delta \boldsymbol{H}(\mathbf{J} / \mathbf{g})$ & $\Delta \boldsymbol{H}_{\boldsymbol{C}}(\mathbf{J} / \mathbf{g})$ & $\chi_{\boldsymbol{c}}(\boldsymbol{\%})$ & $\begin{array}{c}\text { Densidade } \\
\left(\mathbf{g} / \mathbf{c m}^{\mathbf{3}}\right)\end{array}$ \\
\hline PEBD pristino & 71,6 & - & $24,7 \pm 0,1$ & $0,88 \pm 0,01$ \\
PEBD reciclado & 59,1 & - & $20,4 \pm 0,1$ & $0,88 \pm 0,01$ \\
PEAD pristino & 123,0 & $-11,4$ & $46,4 \pm 0,1$ & $0,92 \pm 0,01$ \\
PEAD reciclado & 91,8 & $-35,9$ & $44,2 \pm 0,1$ & $0,91 \pm 0,01$ \\
\hline
\end{tabular}


Conforme mostrado na Figura 19, o PEBD pristino apresenta fusão cristalina na faixa de $74-126^{\circ} \mathrm{C}$, com pico endotérmico a $113{ }^{\circ} \mathrm{C}$. Enquanto que, o PEBD reciclado possui fusão cristalina na faixa de $74-113^{\circ} \mathrm{C}$, com pico endotérmico máximo em $107^{\circ} \mathrm{C}$ e um ombro a 95 ${ }^{\circ} \mathrm{C}$ sobrebosto a este pico. Os polietilenos de baixa densidade não apresentaram evento de cristalização secundária, como foi detectado nos PEADs. Em relação à densidade, os resultados de DSC sugerem que os PEBDs possuem densidade similar $\left(0,88 \pm 0,01 \mathrm{~g} / \mathrm{cm}^{3}\right)$. O grau de cristalinidade do PEBD pristino é $24,7 \pm 0,1 \%$, enquanto que o PEBD reciclado apresenta $\chi_{c}$ igual a $20,4 \pm 0,1 \%$.

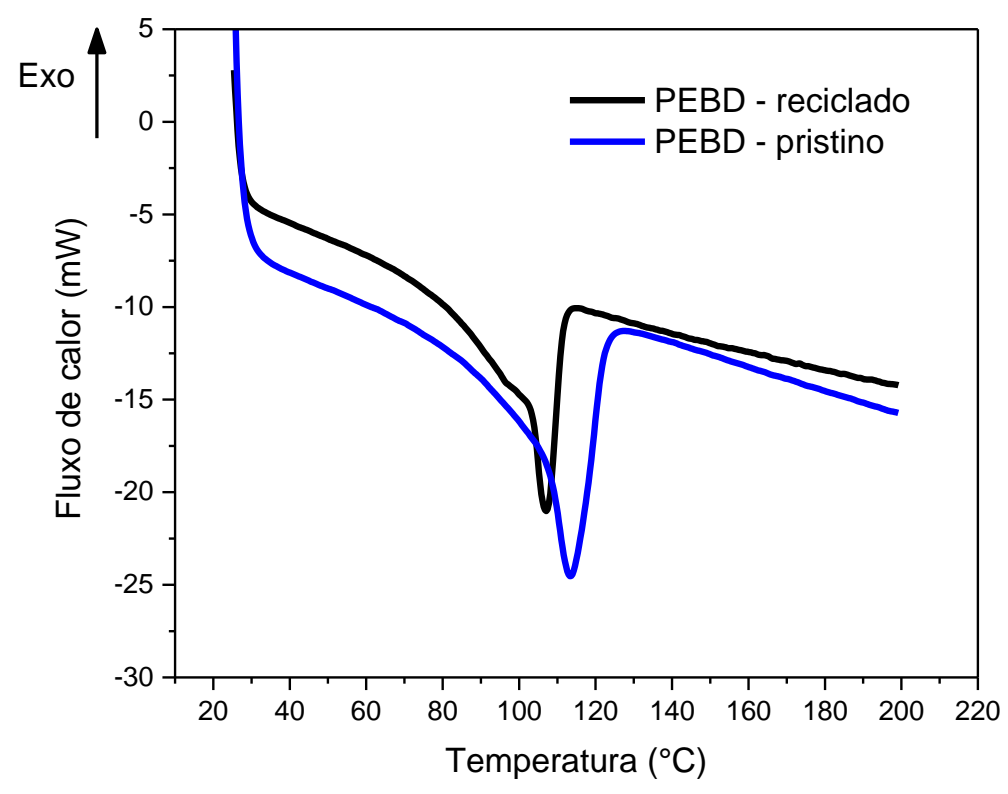

Figura 19 - Curvas DSC do PEBD pristino e reciclado.

Os PEBDs apresentam uma larga faixa de temperatura associada a fusão da fase cristalina. A presença de um ombro na banda associada ao evento endotérmico na curva de DSC do PEBD reciclado sugere que este polímero pode: (1) estar contaminado (embora a contaminação seja extremamente baixa) com resíduos de outros polímeros semicristalinos do tipo commodity, uma vez que eles apresentam temperatura de fusão cristalina $\left(\mathrm{T}_{\mathrm{m}}\right)$ na faixa de 60-200 ㄷ (PEACOCK, 2000); (2) apresentar uma distribuição de massa molar do tipo bimodal ou muito larga (BOROVANSKA et al., 2012). À primeira vista, a presença de PET poderia ser descartada devido à ausência de $\mathrm{T}_{\mathrm{g}}$ entre 75-80 ${ }^{\circ} \mathrm{C}$ (BANNACH et al., 2011), que é caracterizada por uma mudança abrupta na linha base de uma curva DSC. No entanto, é importante ressaltar que equipamentos DSC raramente conseguem detectar a $\mathrm{T}_{\mathrm{g}}$ de um polímero semicristalino numa mistura polimérica quando a sua concentração é inferior a $10 \%$ p. 


\subsubsection{Espectroscopia ATR-FTIR}

Os espectros ATR-FTIR do PEAD e PEBD, pristinos e reciclados, estão mostrados na Figura 20. A banda de vibração localizada em: 705-735 $\mathrm{cm}^{-1}$ corresponde à deformação no plano (por rotação) das ligações no grupo metileno (fase amorfa e cristalina); $1450-1480 \mathrm{~cm}^{-1}$ é devido às deformações tipo balanço das ligações C-H nas fases amorfas e cristalinas; 2875$2770 \mathrm{~cm}^{-1}$ é relativa ao estiramento simétrico do $\mathrm{CH}_{2}$ (fases amorfas e cristalinas); 2980-2875 $\mathrm{cm}^{-1}$ é referente ao estiramento assimétrico do $\mathrm{CH}_{2}$ (fase amorfa). Ainda, foram observadas bandas de absorção com intensidade muito fraca de 1306 a $1351 \mathrm{~cm}^{-1}$, que estão conectadas com as deformações fora do plano (tipo torção e balanço) dos grupos $\mathrm{CH}_{3}$. É observada uma absorção fraca a $1367 \mathrm{~cm}^{-1}$ nos espectros dos polietilenos devido, também, à deformação tipo balanço dos grupos $\mathrm{CH}_{3}$ (BABAGHAYOU et al., 2016; CARO; COMAS, 2017; GULMINE et al., 2002; LUIJSTERBURG; GOOSSENS, 2014; MARTÍNEZ-ROMO et al., 2015). No entanto, não é possível distinguir as fases cristalinas presentes nas blendas de PEBD/PEAD por espectroscopia infravermelho.

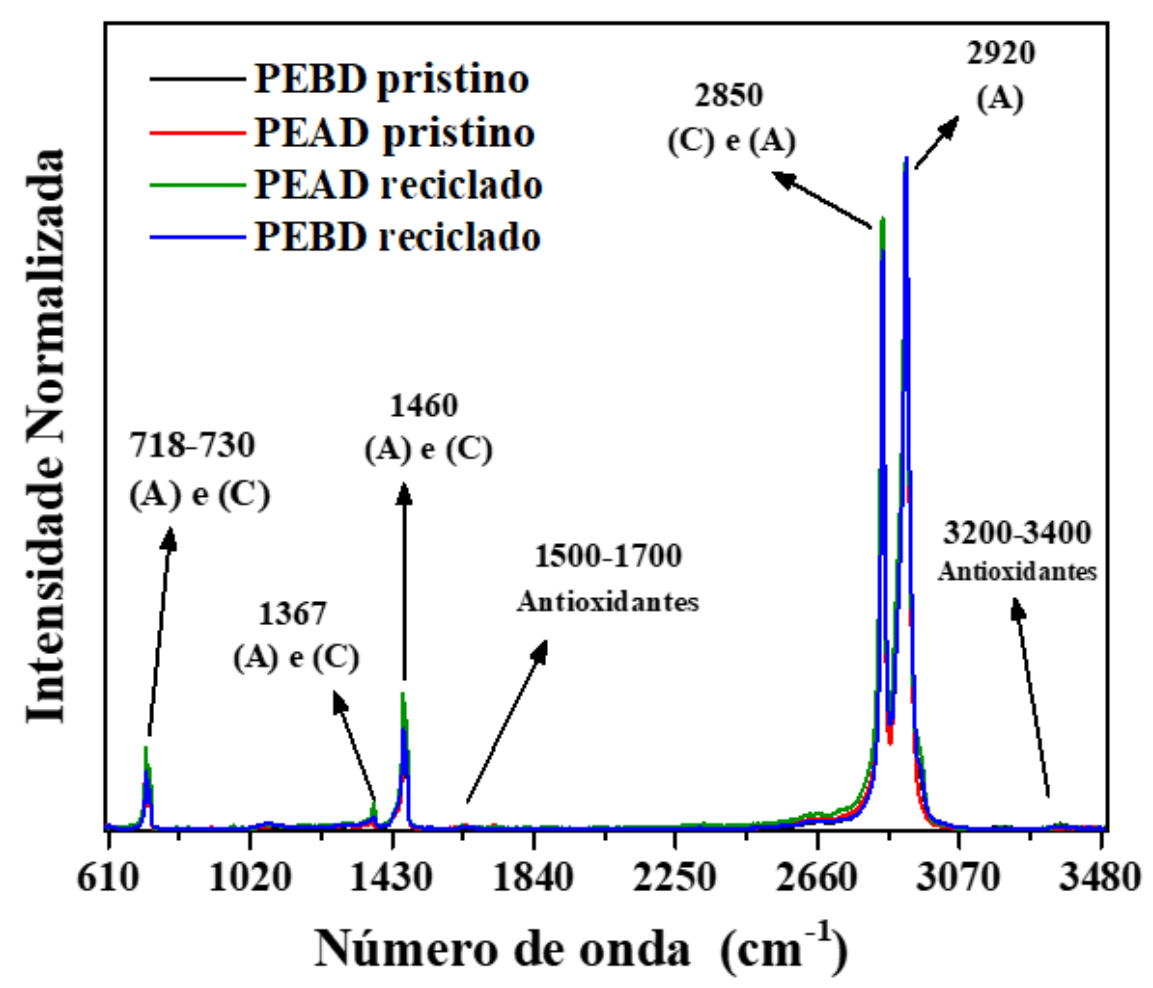

Figura 20 - Espectros de ATR-FTIR do PEBD e PEAD (pristinos e reciclados). Origem do sinal: (C) Fase cristalina; (A) Fase amorfa.

De acordo com a Figura 20, o PEBD pristino e suas misturas poliméricas apresentam banda de absorção na faixa de: $3200-3400 \mathrm{~cm}^{-1}$, que pode ser atribuída à absorção de grupos 
fenólicos do antioxidante Irganox; $1500-1700 \mathrm{~cm}^{-1}$, que está associada a ligações $\mathrm{C}=\mathrm{C}$ de anéis aromáticos de antioxidantes tipo Irganox e Weston 399 (GULMINE et al., 2003). Estes aditivos poliméricos estão presentes no PEBD pristino, mas a concentração não é especificada pelo fabricante. As bandas de absorção IR destes aditivos tendem a ser evidentes nos espectros ATRFTIR devido à migração dos mesmos para a superfície do polímero, já que este processo migratório é acelerado pela temperatura, relativamente alta, utilizada no processamento das blendas poliméricas (DA SILVA; WIEBECK, 2017).

Está bem estabelecido que a intensidade e a largura à meia altura (FWHM) das bandas de absorção em espectros IR estão diretamente conectadas com a quantidade de grupos químicos no polímero e, também, são influenciadas pela organização macromolecular das cadeias poliméricas. Isso ocorre porque as conformações das macromoléculas afetam as rotações e as vibrações moleculares responsáveis pelo sinal detectado pela espectroscopia IR. Os espectros ATR-FTIR da Figura 21 mostram claramente estes efeitos sobre as deformações dos grupos metileno, visto que o aumento do teor de PEAD na blenda de PEAD/PEBD pristino provoca um alargamento de FWHM da banda de absorção em 735-715 $\mathrm{cm}^{-1}$ (Figura 21a) e, também, uma diminuição da intensidade de absorção em $1472 \mathrm{~cm}^{-1}$ (Figura 21b).
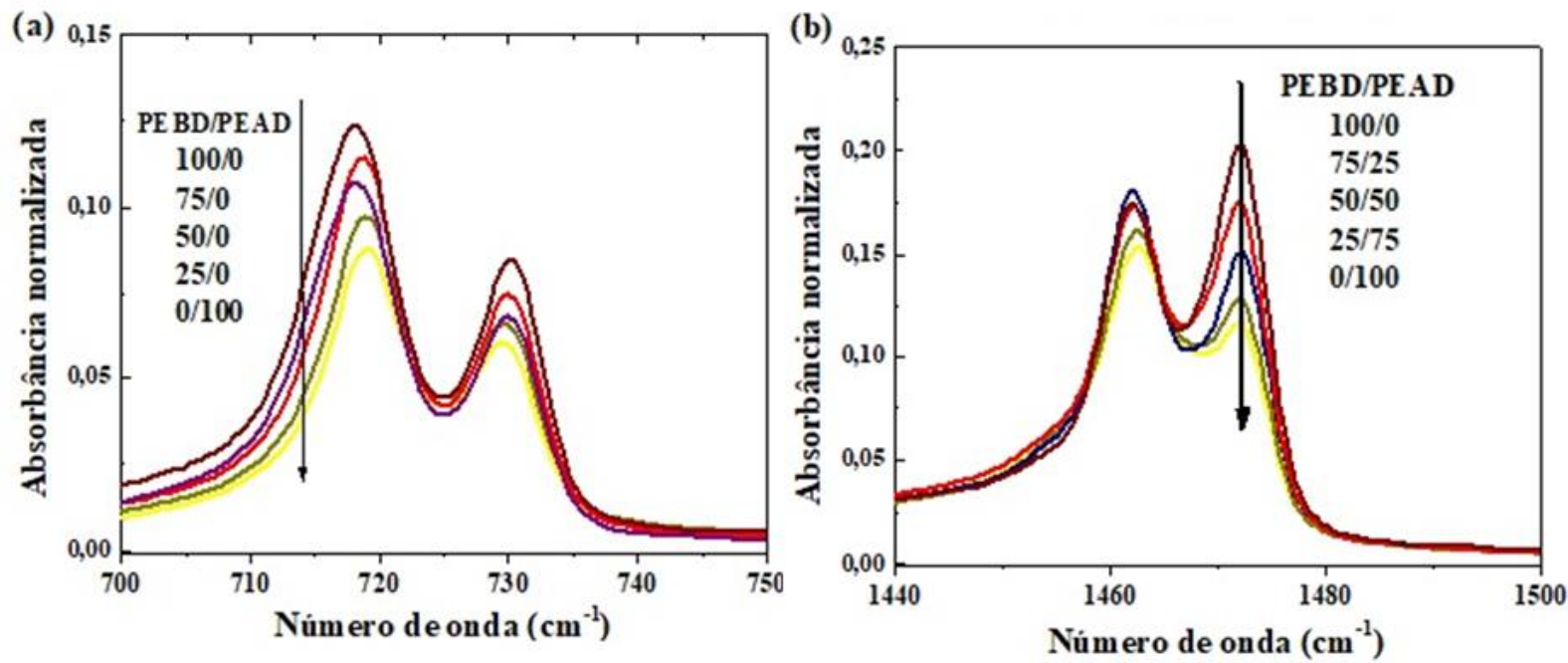

Figura 21 - Modificações nas bandas de absorção IR para a blenda de PEBD/PEAD (mistura de polímeros pristinos) devido à sua composição: $735-715 \mathrm{~cm}^{-1}$ (a) e 1450-1480 $\mathrm{cm}^{-1}$ (b). Obs.: Estes espectros de ATR-FTIR referem-se à média de medidas realizadas em triplicata.

Essas duas mudanças no espectro ATR-FTIR mostradas na Figura 21 estão intimamente associadas à elevação do grau de cristalinidade causado pelo aumento do teor de PEAD nas suas misturas poliméricas com PEBD, conforme relatado por Hagemann e colaboradores (HAGEMANN et al., 1989). Tal comportamento na cristalinidade é esperado, 
devido à maior facilidade para ocorrer cristalização de polietilenos lineares, como o PEAD, contra aqueles com alto grau de ramificação (MARTÍNEZ-ROMO et al., 2015), como é o caso do PEBD.

No entanto, a baixa intensidade do sinal destas vibrações $\left(735-715 \mathrm{~cm}^{-1}\right.$ e $1450-1480$ $\mathrm{cm}^{-1}$ ) impede determinar, com precisão e reprodutividade, a fração mássica dos constituintes na blenda PEBD/PEAD, em toda a faixa de composição (0-100 \% p de PEBD), através de métodos lineares simples (calibração univariada). Neste caso, a calibração multivariada por regressões do tipo PLS pode superar estes problemas, visto que também há mudanças em outras bandas de absorção IR, embora pouco significativas, como mostrado nas Figuras 22 e 23 (os valores de FWHM foram determinados por regressão Gaussiana).

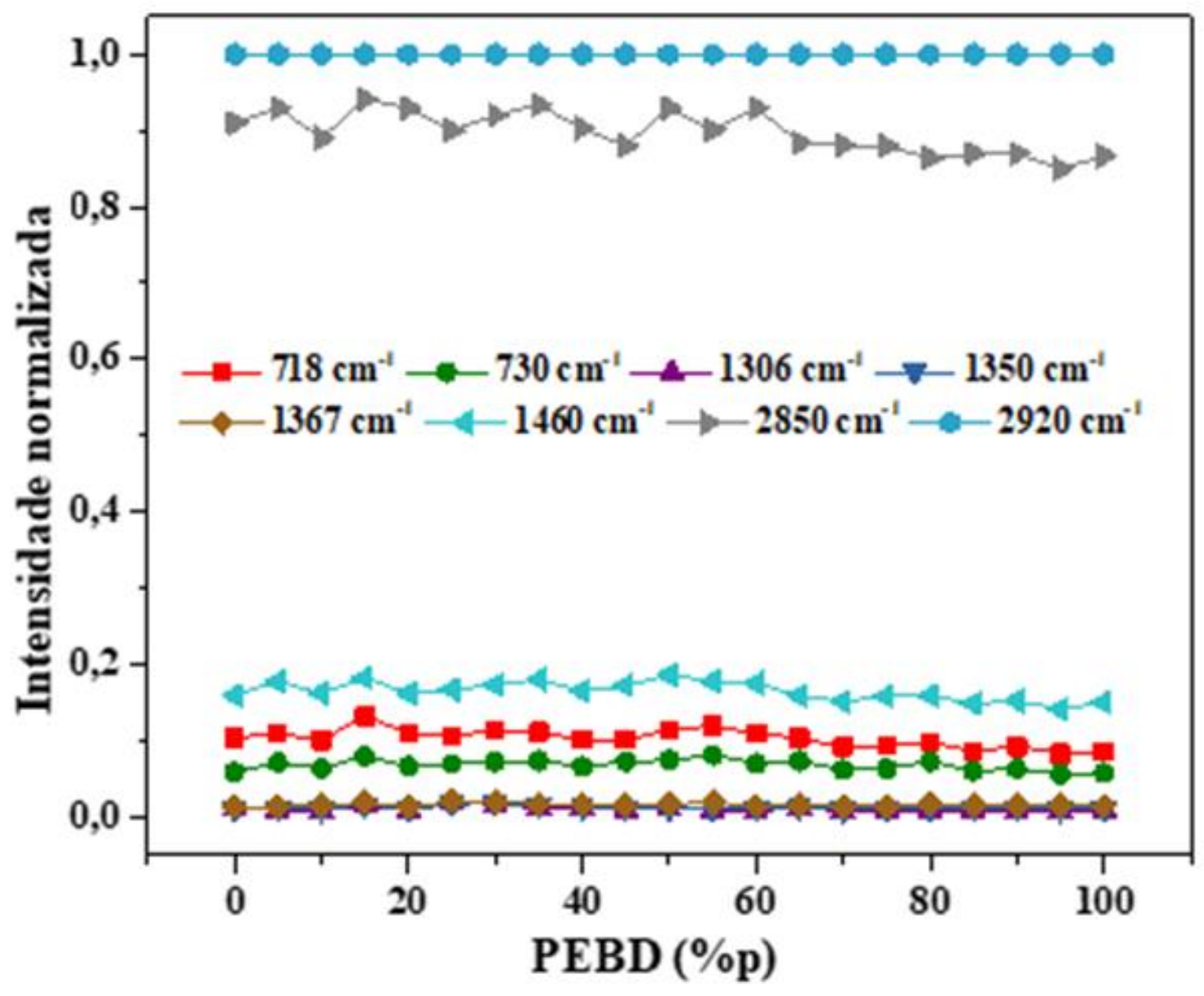

Figura 22 - Intensidade normalizada para todas as bandas de absorção ATR-FTIR de todas as blendas de PEAD/PEBD obtidas com polímeros pristinos. 


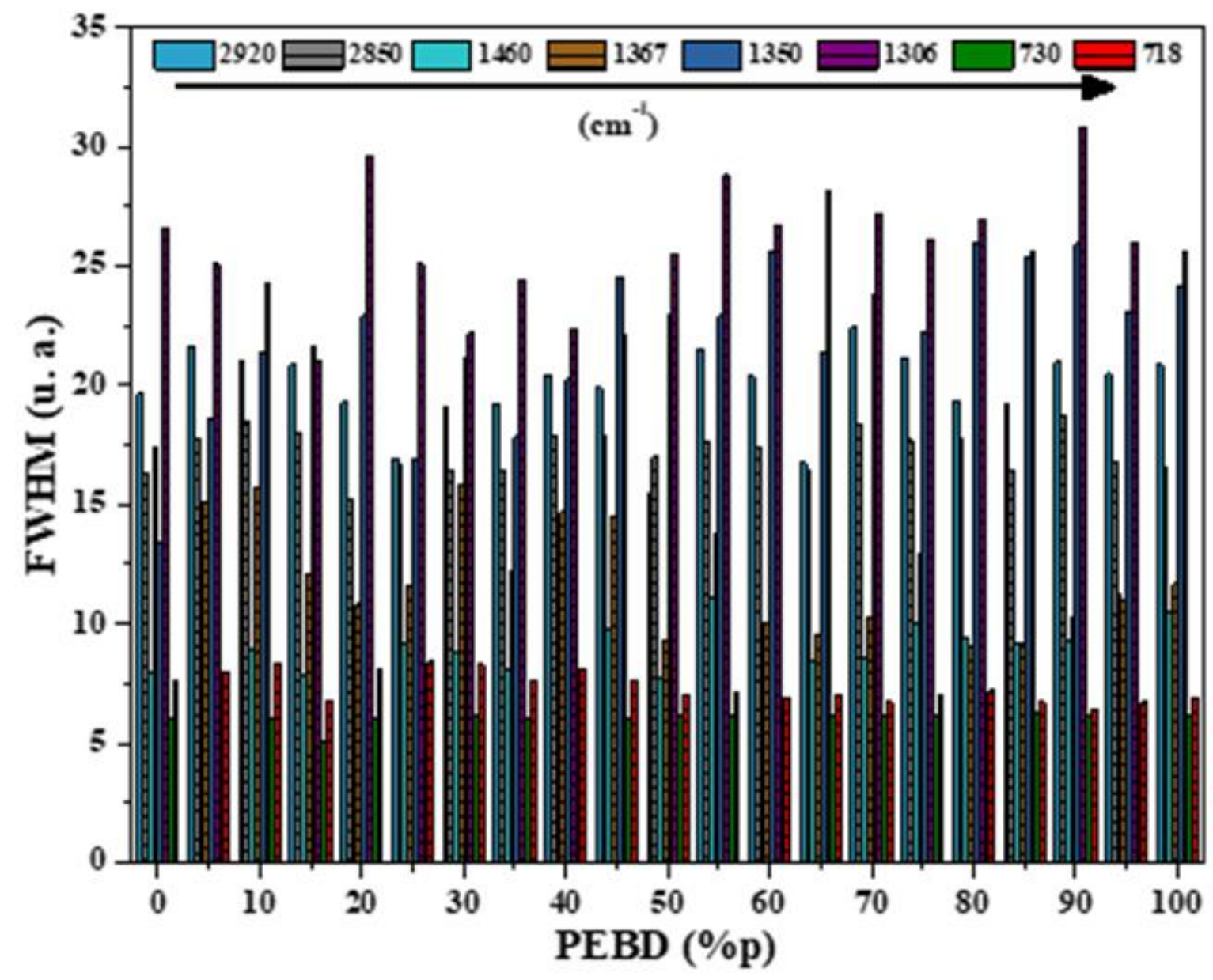

Figura 23 - Largura à meia altura (FWHM) para todas as bandas de absorção ATR-FTIR de todas as blendas de PEAD/PEBD obtidas com polímeros pristinos.

Outra vantagem da calibração por regressão PLS, é a possibilidade de tornar as análises espectrais automáticas pelo uso de programas e, assim, não há necessidade de gastar muito tempo processando e analisando todas as bandas de absorção do espectro vibracional, o que é ideal para o monitoramento de processos de produção industriais.

Uma outra dificuldade, é distinguir PEBD e PEAD por espectroscopias vibracionais. Diferentes autores têm identificado mudanças na intensidade das bandas de absorção em diferentes faixas dos espectro IR (GULMINE et al., 2002; HAGEMANN et al., 1989; MARTÍNEZ-ROMO et al., 2015). Neste trabalho, é proposto o uso de ajuste de curva não linear para decompor a banda de absorção na região de 1340-1390 $\mathrm{cm}^{-1}$ do espectro ATR-FTIR usando uma função Gaussiana, conforme ilustrado na Figura 24. No caso do PEAD pristino e reciclado, esta banda de absorção IR é formada por seis curvas Gaussianas; enquanto que no caso do PEBD pristino e reciclado, são cinco o número de curvas de decomposição espectral. 

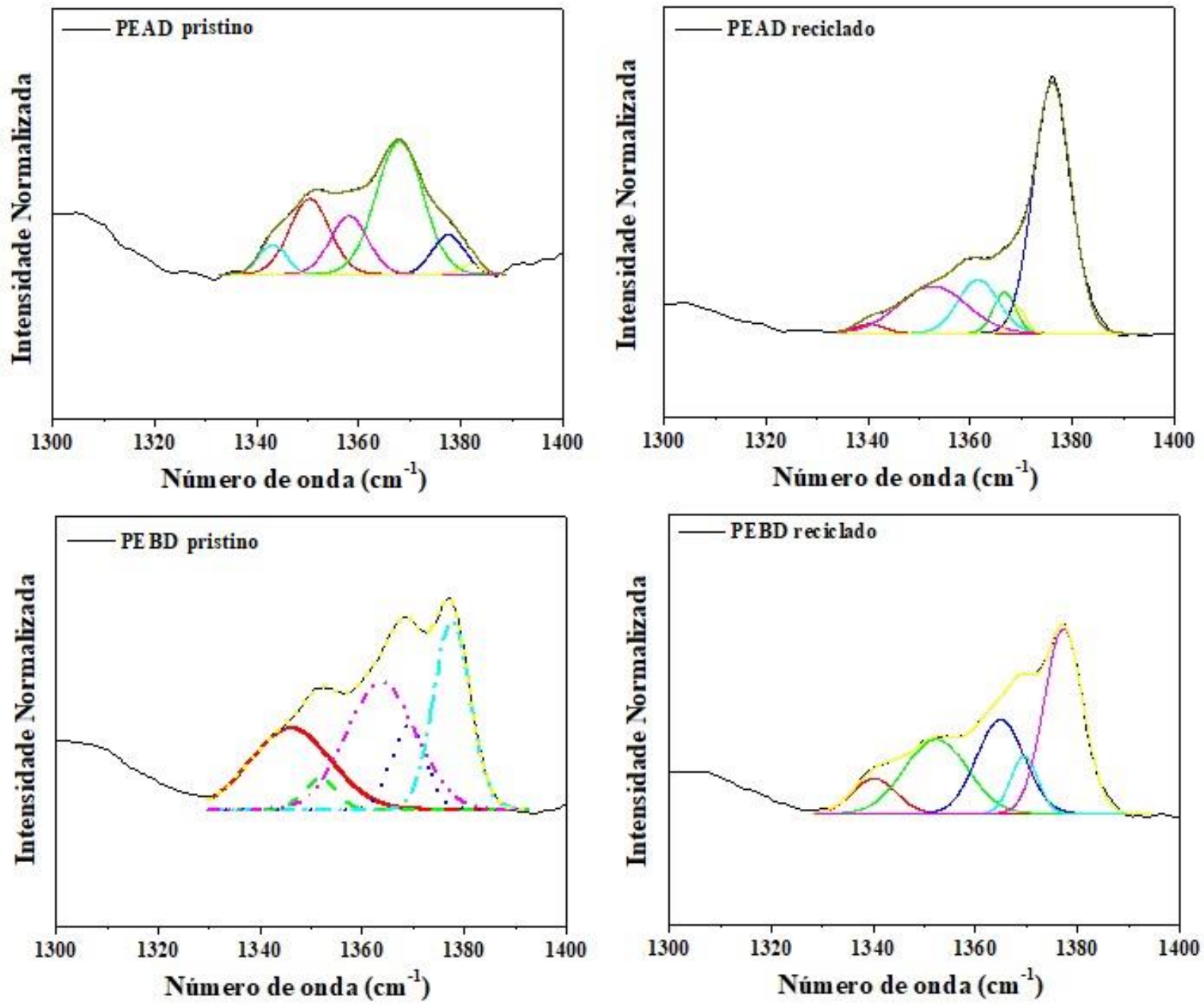

Figura 24 - Decomposição dos espectros ATR-FTIR do PEBD e PEAD (pristinos e reciclados) na região de 1340-1390 $\mathrm{cm}^{-1}$, usando função Gaussiana.

Em relação às misturas poliméricas de PEAD/PEBD, a Figura 25 mostra que a banda de absorção de 1340 a $1390 \mathrm{~cm}^{-1}$ é constituída por quatro ou sete curvas Gaussianas, dependendo da composição da mistura polimérica e da origem dos polietilenos (reciclagem mecânica ou pristino). Estes diferentes números de curvas de ajuste Gaussiano estão associados à quantidade de modos ou estados conformacionais das cadeias poliméricas dos polietilenos, tanto na fase amorfa quanto na fase cristalina. 

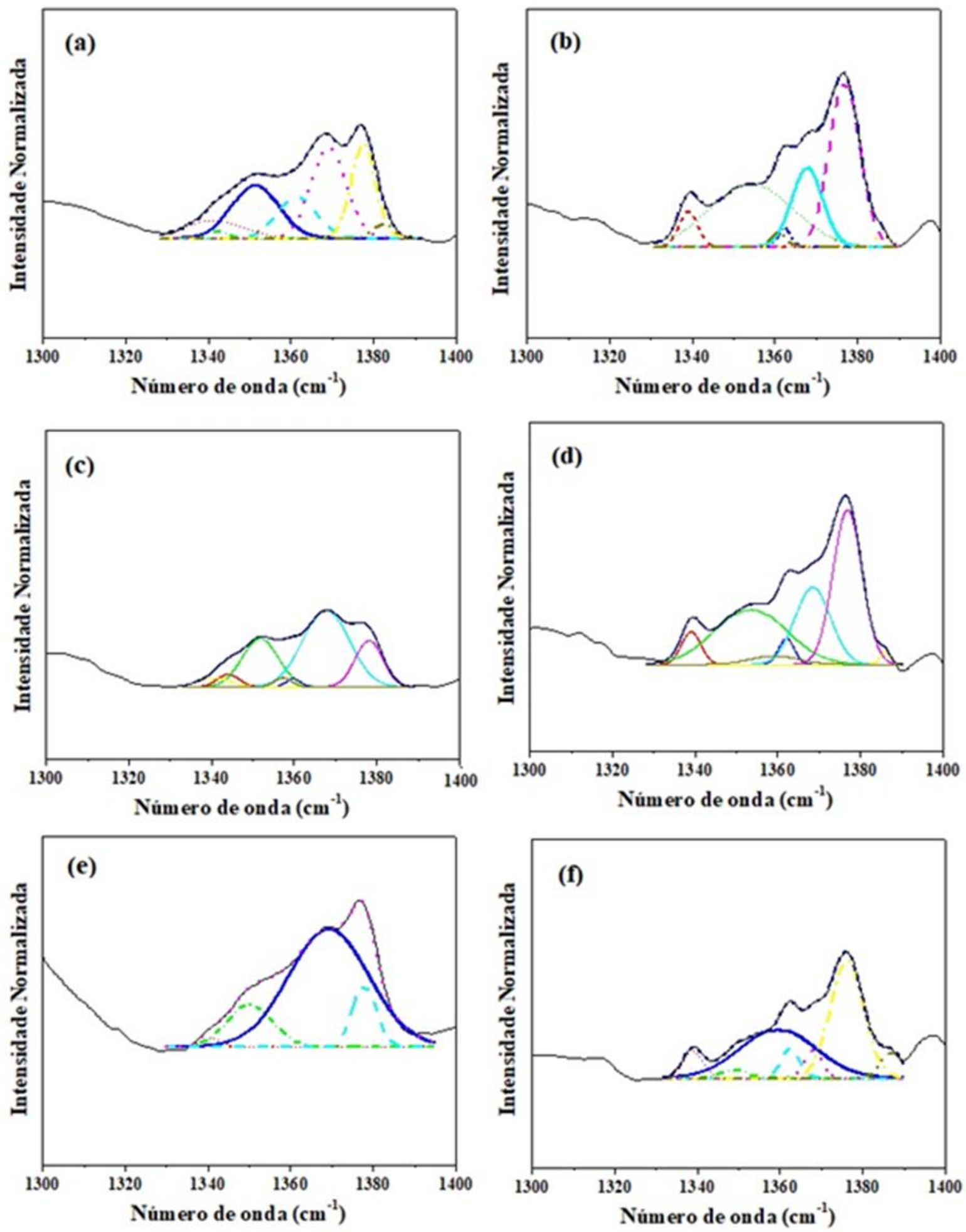

Figura 25 - Decomposição Gaussiana dos espectros ATR-FTIR na região de 1340-1390 $\mathrm{cm}^{-1}$ para as das blendas de PEBD/PEAD obtidas com polietilenos (composição em \% p): pristinos - (a) 75/25, (c) 50/50 e (e) 25/75; reciclados - (b) $75 / 25$, (d) $50 / 50$ e (f) $25 / 75$.

\subsubsection{Espectroscopia Raman confocal}

Os espectros Raman dos polietilenos estão apresentados na Figura 26. Os deslocamentos Raman com intensidades máximas a 1060, 1135 e $1300 \mathrm{~cm}^{-1}$ correspondem ao 
estiramento $\mathrm{C}-\mathrm{C}$, estiramento $\mathrm{C}-\mathrm{C}$ e torção de grupos $-\mathrm{CH}_{2}$ na fase cristalina dos PEs, nesta ordem. Já as bandas de deslocamento Raman de baixa intensidade e com valores máximos em 1175 e $1372 \mathrm{~cm}^{-1}$ são relativas à rotação (fase cristalina) e balanço (fase amorfa) de unidades $\mathrm{CH}_{2}$, respectivamente (SATO et al., 2002). Uma larga banda de deslocamento Raman também é observada a $1400-1500 \mathrm{~cm}^{-1}$, que pode ser atribuída a três modos de vibração do grupo $-\mathrm{CH}_{2}$ dentro da estrutura cristalina dos polietilenos (um modo vibracional do tipo balanço e dois modos de dobramento angular) (ALLEN; KALIVAS; RODRIGUEZ, 1999). Além disso, estão presentes outras bandas Raman nos espectros dos PEs: $2400-2465 \mathrm{~cm}^{-1}$ e $2695-2747 \mathrm{~cm}^{-1}$ são sobretons e combinações de números de onda na faixa de 1400-1492 cm ch $^{-1}$ (deformações do grupo - $\left.\mathrm{CH}_{2-}\right)$ (GALL et al., 1972); 2815-2864 $\mathrm{cm}^{-1}$ é originada do estiramento assimétrico dos grupos $\mathrm{CH}_{2}$ (na fase amorfa e cristalina); e $2865-2970 \mathrm{~cm}^{-1}$ é relativa ao estiramento simétrico de grupos metileno (fase amorfa e cristalina) (BENTLEY; HENDRA, 1995).

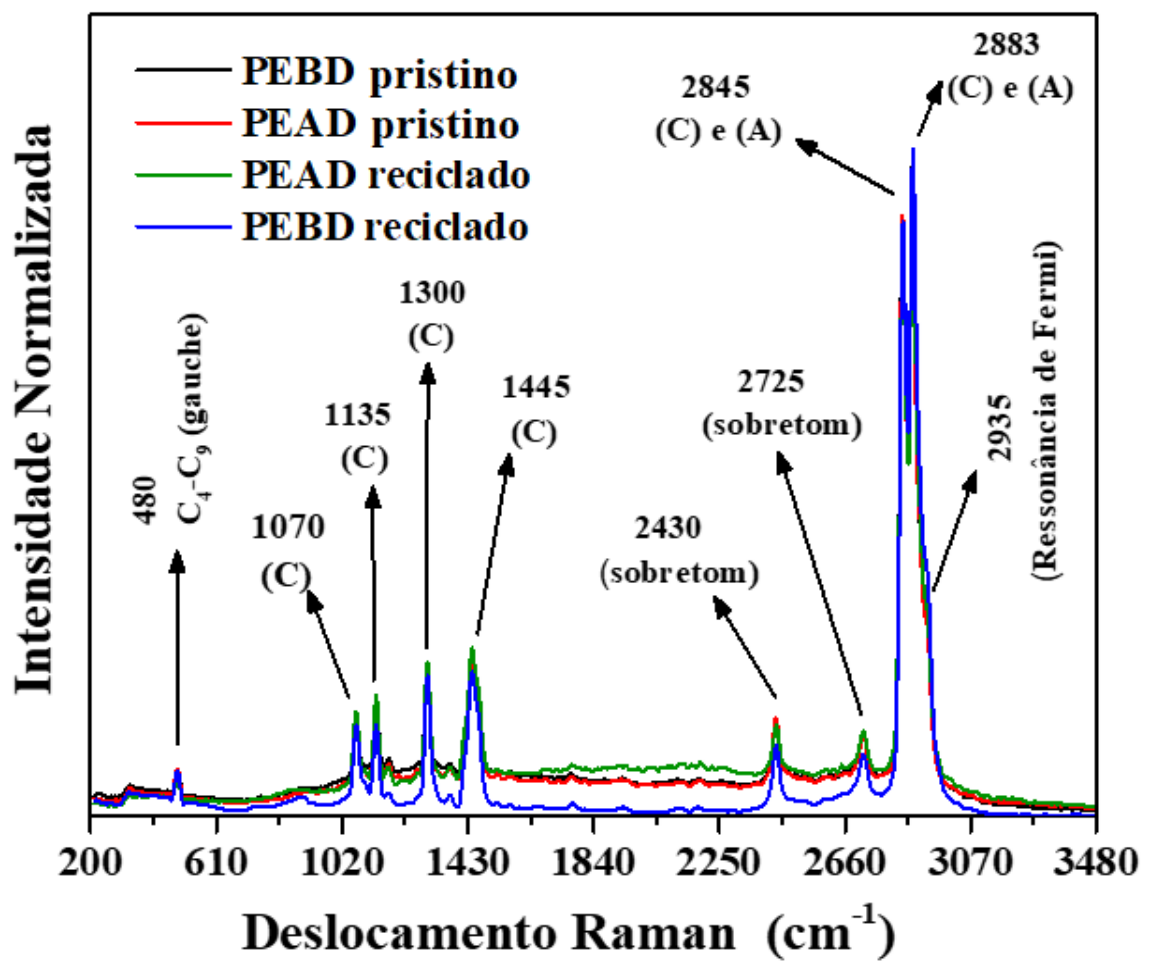

Figura 26 - Espectros de Raman confocal do PEBD e PEAD (pristinos e reciclados) após o processo de extrusão.

Origem do deslocamento: (C) Fase cristalina; (A) Fase amorfa.

A presença de um "ombro" de fraca intensidade a $2935 \mathrm{~cm}^{-1}$ (Figura 26) pode ser atribuída à ressonância de Fermi entre o estiramento simétrico e o sobretom de deformação dos grupos $\mathrm{CH}_{2}$ (ZHANG; SHEN; SOMORJAI, 1997). Somente nos espectros dos PEBDs (pristino e reciclado) foi identificada uma larga banda de deslocamento Raman a $890 \mathrm{~cm}^{-1}$, com intensidade muito fraca, que está conectada com a existência de ramificações poliméricas curtas 
(SATO et al., 2002). Outro deslocamento Raman de baixa intensidade é verificado a 460-501 $\mathrm{cm}^{-1}$ nos espectros destes polietilenos, que pode estar associado a segmentos $\mathrm{C}-\mathrm{C}$ curtos $\left(\mathrm{C}_{4-}\right.$ C9) com conformação molecular do tipo gauche (SNYDER; KIM, 1991).

Conforme mostrado na Figura 27, as intensidades máximas dos deslocamentos Raman em 1370 e $1416 \mathrm{~cm}^{-1}$ reduzem com o aumento de PEBD na mistura polimérica. Enquanto que, é observado um comportamento contrário no deslocamento Raman a $1460 \mathrm{~cm}^{-1}$, sem que haja nenhuma mudança no deslocamento Raman a $1400 \mathrm{~cm}^{-1}$ nos espectros de PEAD puro, de PEBD puro e da mistura de PEBD/PEAD (50/50 \%p). Todas essas bandas de espalhamento Raman (na faixa de 1400-1500 $\mathrm{cm}^{-1}$ ) são relativas à fase cristalina de PE, sendo o deslocamento Raman a $1416 \mathrm{~cm}^{-1}$ relatado na literatura como sendo exclusivamente da vibração de metilenos em células ortorrômbicas do PE (ALLEN; KALIVAS; RODRIGUEZ, 1999; STUART, 1996).

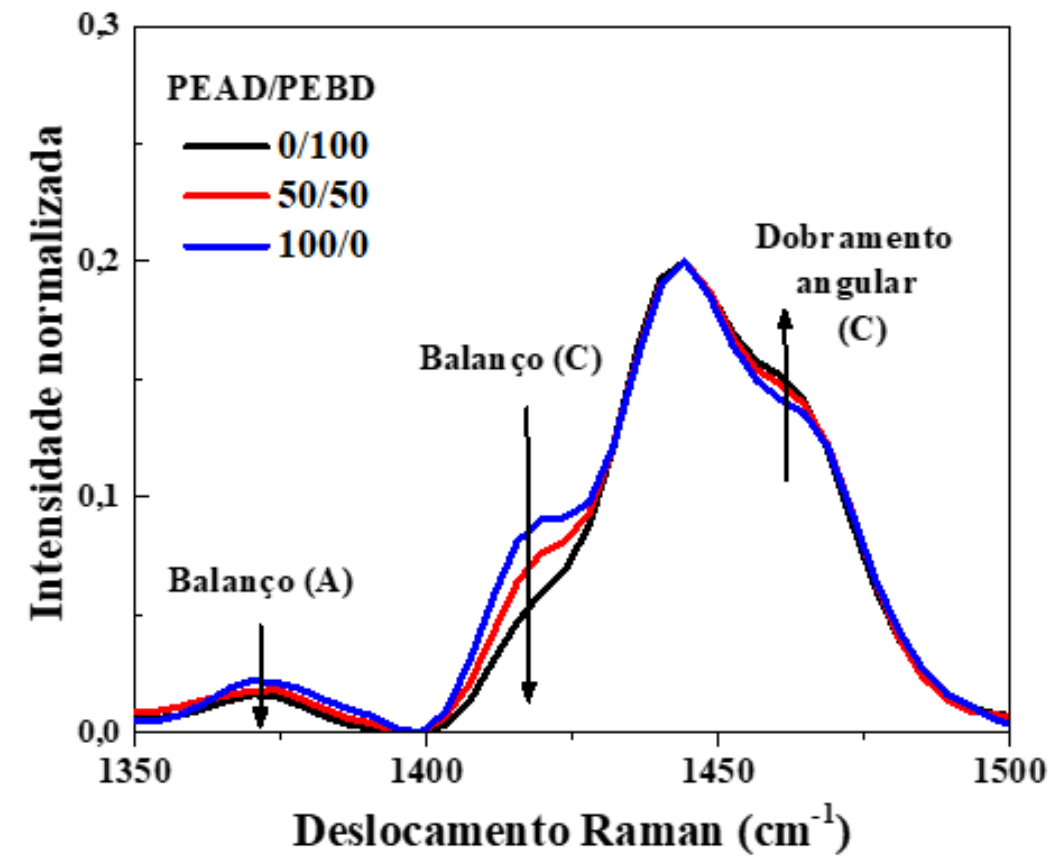

Figura 27 - Modificações na intensidade dos deslocamentos Raman (grupo - $\mathrm{CH}_{2}$-) para a blenda de PEBD/PEAD (mistura de polímeros pristinos) devido à sua composição: faixa de 1350 a $1500 \mathrm{~cm}^{-1}$. (A): fase amorfa; (C): fase cristalina.

Estas variações evidentes na região de $1350-1500 \mathrm{~cm}^{-1}$ no espectro Raman dos PEs pristinos (Figura 27) são explicadas pela diminuição do grau de cristalinidade da blenda de PEAD/PEBD com a redução do teor de PEAD, assim como ocorre no espectro de ATR-FTIR destes materiais. Porém, o uso apenas das variações nestas bandas de espalhamento Raman, que são de baixa intensidade, é impraticável para a construção de uma curva de calibração analítica 
simples para quantificar a composição da blenda de PEAD/PEBD em toda sua faixa de composição.

Analogamente ao observado nas curvas de intensidade normalizada de ATR-FTIR das blendas poliméricas de PEBD/PEAD obtidas com polímeros pristinos (Figuras 22 e 23), há variações na intensidade dos sinais das bandas característica de espalhamento Raman, conforme mostrado na Figura 28. Além disso, há uma leve redução da intensidade máxima do deslocamento Raman em $1070 \mathrm{~cm}^{-1}$ e, também, sútil aumento do sinal em $2845 \mathrm{~cm}^{-1}$, devido ao aumento na concentração de PEBD pristino. Embora haja significativas variações nos valores de FWHM (Figura 29), não foi detectada nenhuma tendência nítida relacionada com o aumento do teor de PEAD pristino na mistura polimérica.

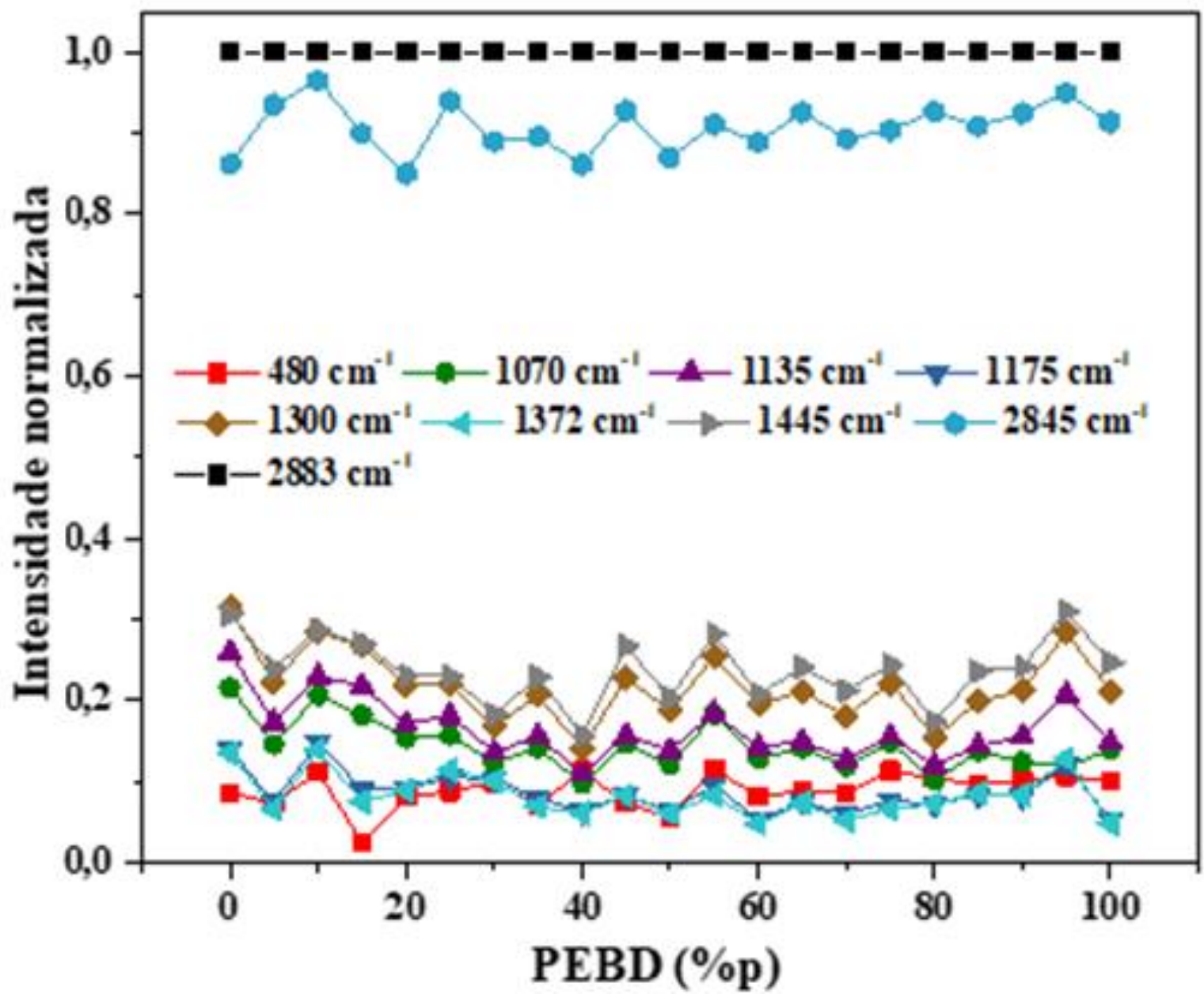

Figura 28 - Intensidade normalizada para todas as bandas de deslocamento Raman de todas as blendas de PEAD/PEBD obtidas com polímeros pristinos. 


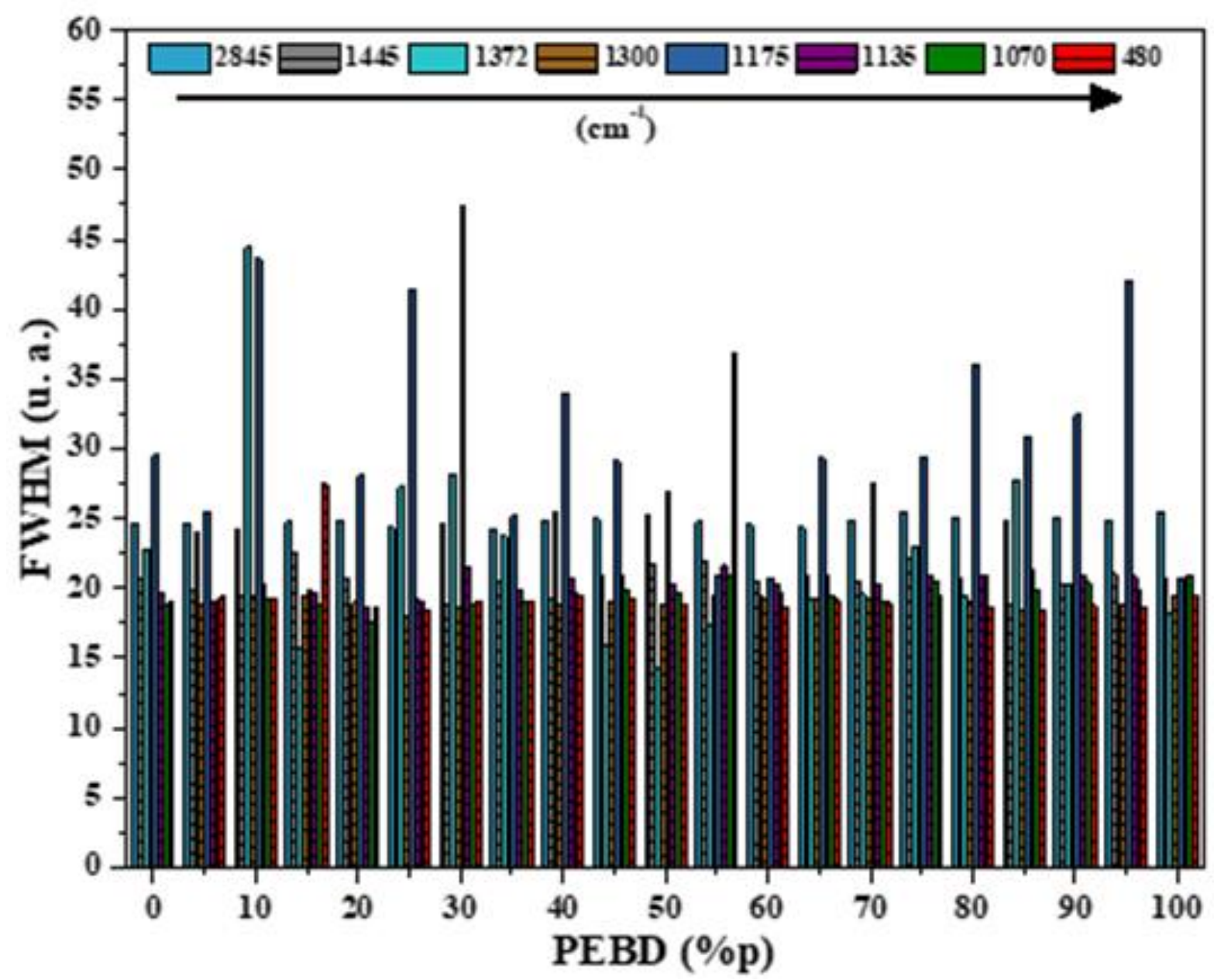

Figura 29 - Largura à meia altura (FWHM) para todas as bandas de deslocamento Raman de todas as blendas de PEAD/PEBD obtidas com polímeros pristinos.

\subsubsection{Rugosidade superficial por MEV}

As micrografias da superfície dos péletes das blendas de PEBD/PEAD, com diferentes composições de polietilenos pristinos, as imagens tridimensionais de superfície, que foram construídas por simulação computacional, estão apresentadas no Apêndice A. Estes resultados mostram que ocorre ampliação da irregularidade superficial dos péletes devido ao incremento de PEAD na mistura polimérica. Este fenômeno é justificado pelo fato de que o PEAD aumenta a viscosidade da blenda no estado fundido porque este apresentar maior índice de fluidez que o PEBD. Além disso, a mistura de PEAD com PEBD forma um sistema multifásico imiscível no qual há efeitos associados a mudanças morfológicas (e.g., deformação, ruptura e coalescência) e processos interfaciais (e.g., relaxação e deslizamento interfacial) das gotículas dispersas de um polímero na matriz do outro, que influenciam significativamente no fluxo da mistura polimérica de PEBD/PEAD no estado fundido dentro da matriz da extrusora (ILYIN et al., 2020; LIU; WANG; HE, 2002; UTRACKI; WILKIE, 2014; VAN PUYVELDE et al., 2008). 
O aumento da viscosidade do fundido na blenda polimérica de PEBD/PEAD intensifica a taxa de cisalhamento na superfície do material fundido durante a sua passagem na matriz da extrusora e, consequentemente, há formação de defeitos superficiais por deformação plástica no polímero extrusado. Se a tensão de cisalhamento na matriz da extrusora for muito maior que a resistência do polímero fundido, os defeitos não são mais superficiais e passa a ocorrer a fratura do fundido, que é um defeito macroscópico. Além disso, o aumento da viscosidade do fundido acarreta em uma maior adesão do mesmo com o maquinário que, também, intensifica a ocorrência de defeitos superficiais e fratura do fundido do perfil extrusado.

Como as análises pelas espectroscopias ATR-FTIR e Raman confocal são realizadas na superfície das amostras, é de grande importância avaliar a rugosidade superficial das mesmas. Para tanto, as rugosidades $\mathrm{R}_{\mathrm{a}}$ e $\mathrm{R}_{\mathrm{q}}$ das blendas de PEBD/PEAD foram determinadas a partir de análise computacional das micrografias de MEV. Este tipo de ensaio baseia-se nas variações locais do brilho na micrografia de MEV (i.e., mudanças na uniformidade na escala de cinza) que estão, diretamente, associados com a topografia da amostra (BANERJEE et al., 2009; CHINGA et al., 2007).

De acordo com a Figura 30, os valores de rugosidade $\mathrm{R}_{\mathrm{q}}$ tendem a ser de 27 a $32 \%$ maiores que $\mathrm{R}_{\mathrm{a}}$, que é um efeito ocasionado por elevar ao quadrado as variações superficiais e, consequentemente, enfatizando o peso dos picos e vales topográficos da superfície nos resultados de rugosidade superficial. Além disso, é observado que as rugosidades superficiais do PEAD pristino $\left(\mathrm{R}_{\mathrm{q}}=35\right.$ e $\left.\mathrm{R}_{\mathrm{a}}=26,3\right)$ são o dobro do valor observado do PEBD pristino, quando estes polímeros são extrusados em condições semelhantes.

Assim como observado nas blendas com polietilenos pristinos, os péletes extrusados das blendas recicladas também apresentam defeitos nas suas superfícies, como pode ser identificado nas micrografias de MEV e imagens tridimensionais de superfície simuladas presentes no Apêndice A. De acordo com os resultados de rugosidade $R_{a}$ e $R_{q}$ (Figura 31), há um significativo aumento da rugosidade do extrusado quando o teor de PEAD reciclado na mistura polimérica é maior ou igual a $50 \%$ p. Ainda, é observado que a rugosidade média dos péletes de PEAD reciclado $\left(\mathrm{R}_{\mathrm{a}}=14,04\right)$ é inferior àquela observada para os péletes de PEAD pristino $\left(\mathrm{R}_{\mathrm{a}}=26,34\right)$. Isto está diretamente associado ao fato de que o PEAD reciclado possui um maior índice de fluidez (Tabela 4), i.e., apresenta menor viscosidade do fundido. 


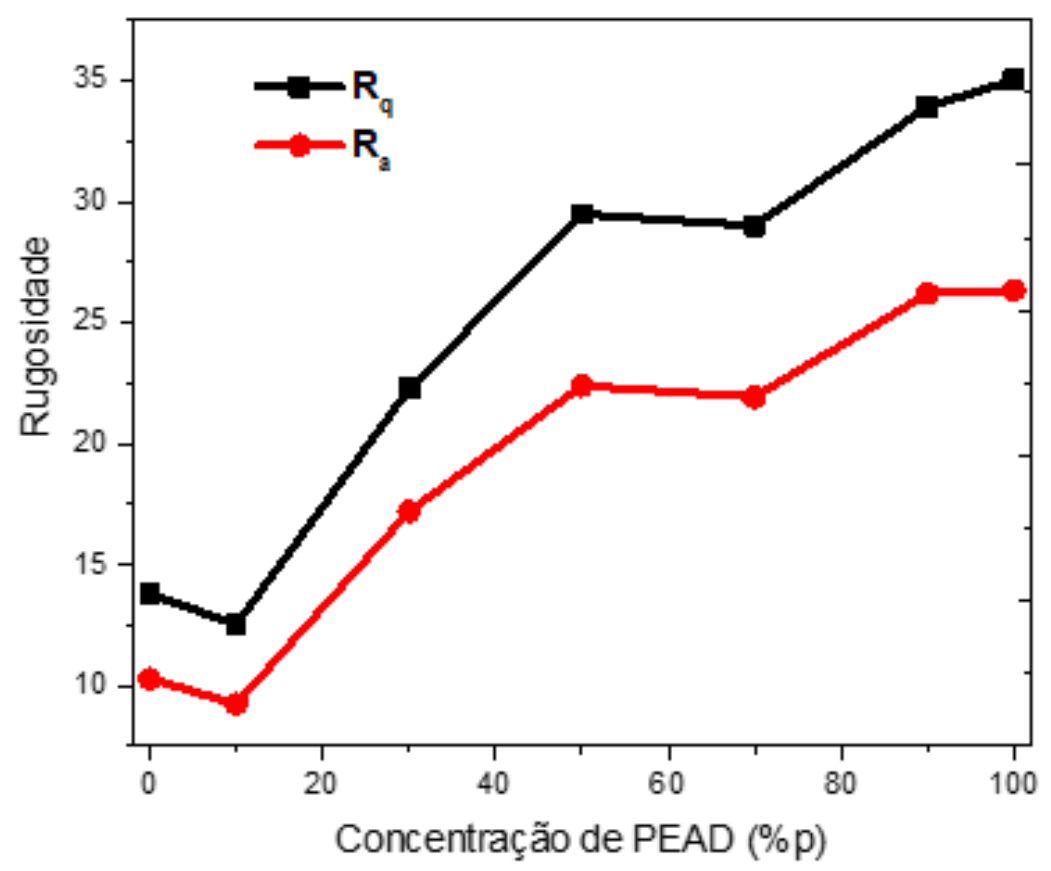

Figura 30 - Rugosidade das blendas de PEBD/PEAD obtidas com polímeros pristinos.

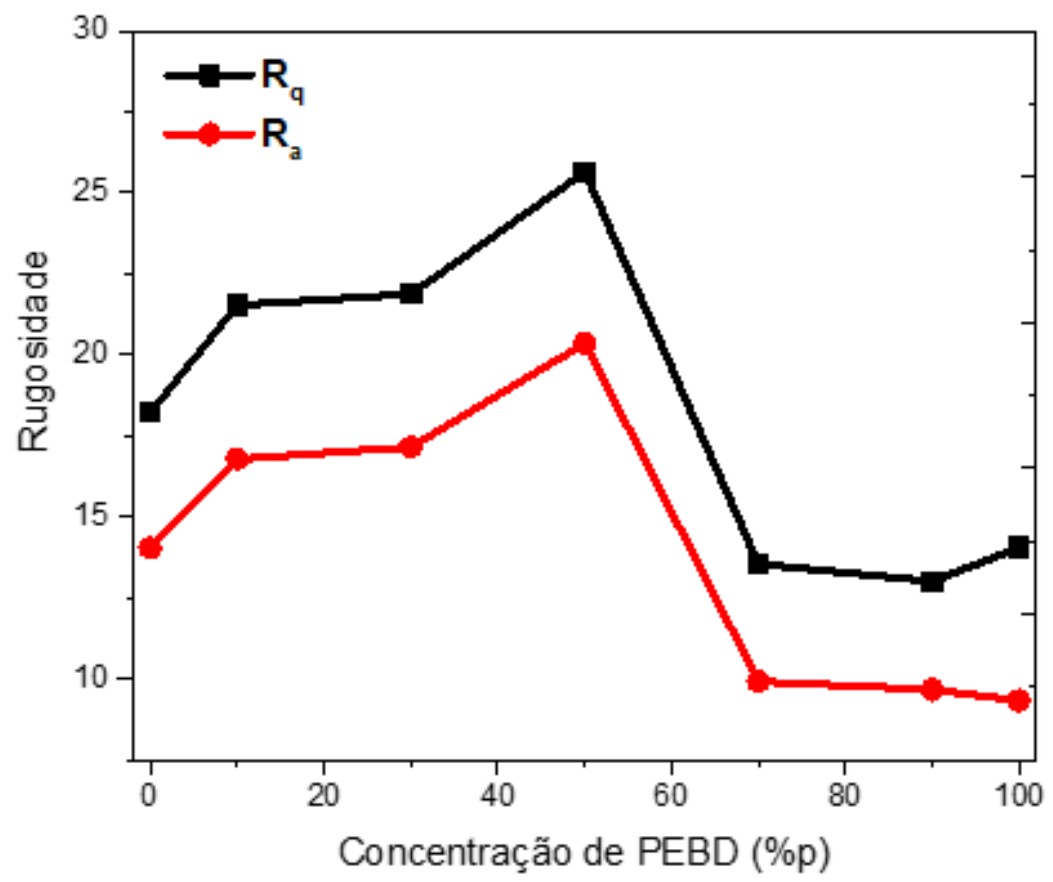

Figura 31 - Rugosidade das blendas de PEBD/PEAD obtidas com polímeros reciclados.

\subsection{MODELOS DE PREDIÇÃO USANDO ESPECTROSCOPIA ATR-FTIR}

\subsubsection{Regressão PLS e iPLS}

A partir dos dados espectrais ATR-FTIR das blendas de PEAD/PEBD, obtidas com polímeros pristinos, foram construídos modelos de predição do teor de PEBD nas misturas 
poliméricas. Para isto, primeiramente, todos os espectros foram suavizados e normalizados e, em seguida, foi utilizado outro pré-tratamento nos espectros, durante a construção dos modelos de predição. Uma vez que, o pacote iToolbox permite adicionar uma etapa prévia de tratamento de dados por um dos seguintes métodos: autoescalado ou centralização média.

É importante ressaltar que, não foi adotado nenhum método específico para correção na linha base dos espectros obtidos pelas espectroscopias ATR-FTIR e Raman Confocal, isto porque: (1) seria mais uma variável a ser analisada nesta tese porque existem vários métodos de correção (SHEN et al., 2018a, 2018b), exigindo uma investigação profunda uma vez que o tipo de método influenciaria tanto na calibração quanto no desempenho de predição dos modelos; (2) a composição das misturas poliméricas influenciam na sua rugosidade superficial que, por sua vez, afetam a intensidade de fluorescência da amostra na espectroscopia Raman; (3) a composição e dimensões das partículas contaminantes também influenciam na fluorescência das misturas poliméricas de PEBD/PEAD. Diante dos itens (1) e (2), a remoção do background de fluorescência na linha base dos espectros Raman estão intimamente associados a perdas de informações características da morfologia e composição das blendas nos dados espectrais e, desta forma, podem acarretar em efeitos negativos quanto ao desempenho de predição dos modelos. Portanto, seria necessária uma análise aprofundada sobre estes parâmetros que fojem do escopo desta tese.

No caso dos dados espectrais ATR-FTIR, o método autoescalado apresentou melhor desempenho nas etapas de calibração e teste de predição. Enquanto que no método linear PLS tradicional, os espectros são analisados em toda sua extensão de varredura $\left(600\right.$ a $\left.4000 \mathrm{~cm}^{-1}\right)$, no iPLS, os espectros ATR-FTIR foram divididos em 10 a 50 subintervalos, igualmente espaçados, e a numeração de cada intervalo foi iniciada em $600 \mathrm{~cm}^{-1}$.

Como exemplificação do processo de divisão dos espectros por iPLS, a Figura 32 mostra os espectros ATR-FTIR de todas as blendas subdivididos em 10 intervalos. O mesmo procedimento foi adotado para a divisão espectral em mais segmentos. 
Número do intervalo

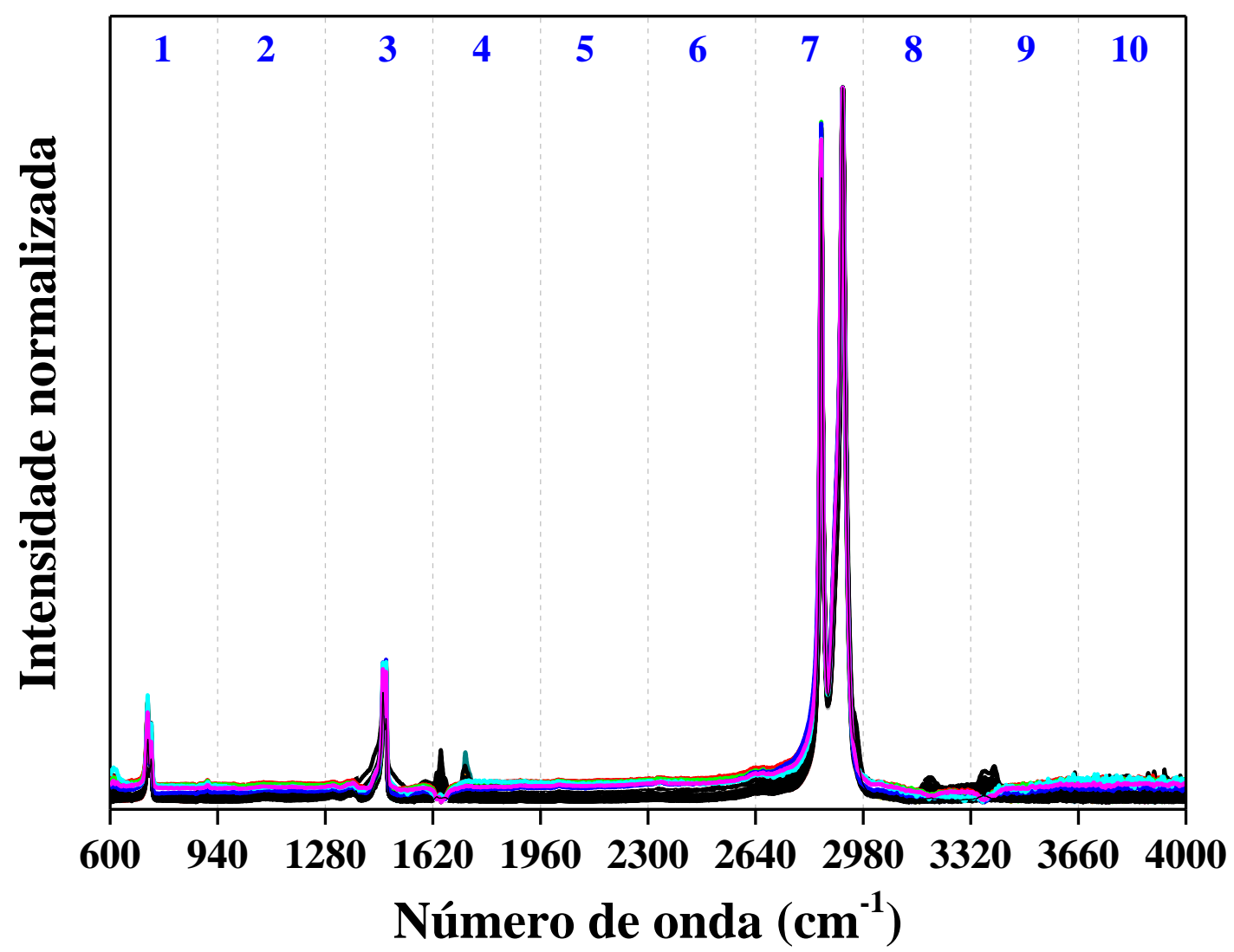

Figura 32 - Espectros ATR-FTIR das blendas de PEAD/PEBD (obtidas com polímeros pristinos) e sua segmentação em 10 intervalos pelo método iPLS.

A Tabela 8 mostra os modelos preditivos obtidos com os valores mais baixos de RMSECV e RMSEP, usando os espectros de ATR-FTIR das amostras. O número de variáveis latentes (LVs) e seus coeficientes de correlação de predição $\left(R_{\text {pred }}\right)$ e calibração $\left(R_{\text {calib }}\right)$ também foram detalhados. O desempenho do modelo de previsão aumenta com a diminuição do RMSEP, enquanto que os coeficientes de correlação fornecem informações sobre o ajuste estatístico entre valores de referência e: (1) conjunto de calibração ( $\left.R_{\text {calib}}\right)$; (2) resultados previstos num conjunto de testes independentes $\left(\mathrm{R}_{\text {pred }}\right)$. Todos os modelos de predição, baseados no algoritmo PLS ou iPLS, apresentaram número ótimo de variáveis latentes ( $\mathrm{LV}_{\text {ótimo}}$ ) igual a 11. A escolha do número de LVs foi feita de acordo com o valor mínimo de erro de calibração (RMSECV) sugerido pelo próprio algoritmo iPLS, conforme mostrado na Figura 33. 
Tabela 8 - Modelos preditivos com melhor desempenho obtidos pela regressão PLS e iPLS para a quantificação do teor de PEBD nas blendas de PEBD/PEAD (obtidas com polímeros pristinos), usando dados espectrais de IR (prétratamento $=$ autoescalado $)$.

\begin{tabular}{|c|c|c|c|c|c|c|c|}
\hline $\begin{array}{l}\text { Modelo } \\
\text { de } \\
\text { predição }\end{array}$ & $\begin{array}{c}\text { Número de } \\
\text { subintervalos }\end{array}$ & $\begin{array}{c}\text { Intervalo } \\
\text { selecionado }\end{array}$ & $\mathrm{LV}_{\text {ótimo }}$ & $\begin{array}{l}\text { RMSECV } \\
\text { (\%p de } \\
\text { PEBD) }\end{array}$ & $\mathrm{R}_{\text {calib }}$ & $\begin{array}{l}\text { RMSEP } \\
\text { (\%p de } \\
\text { PEBD) }\end{array}$ & $\mathrm{R}_{\text {pred }}$ \\
\hline PLS-IR & - & - & 11 & 6,993 & 0,976 & 8,262 & 0,958 \\
\hline iPLS10 & 10 & 7 & 11 & 6,104 & 0,981 & 7,091 & 0,968 \\
\hline iPLS20 & 20 & 14 & 11 & 4,553 & 0,989 & 5,738 & 0,978 \\
\hline iPLS30 & 30 & 21 & 11 & 8,829 & 0,964 & 5,638 & 0,979 \\
\hline iPLS40 & 40 & 28 & 11 & 9,106 & 0,961 & 6,754 & 0,974 \\
\hline iPLS50 & 50 & 35 & 11 & 7,253 & 0,973 & 6,891 & 0,970 \\
\hline
\end{tabular}

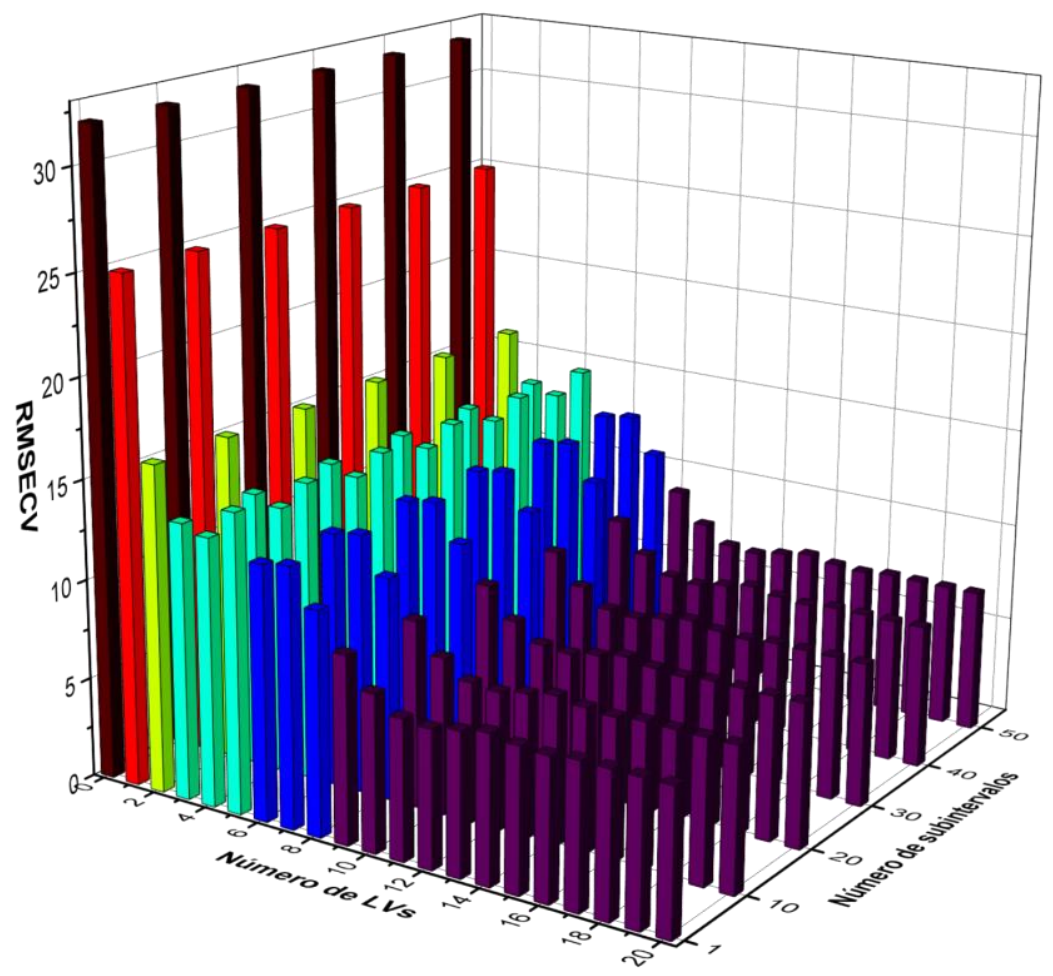

Figura 33 - Variação do RMSECV em função do número de variáveis latentes, usando diferente número de subintervalos (1, 10, 20, 30, 40 e 50), usando dados de ATR-FTIR. O número de subintervalos é 1 para regressão PLS e maior que 1 para regressão iPLS. 
Resumindo a Tabela 8, o RMSECV é sempre um pouco menor do que RMSEP quando o número de subintervalos usado é menor ou igual a 20, e este comportamento inverte-se quando o número de intervalos é maior do que 20. Todos os modelos baseados em iPLS têm seu melhor desempenho de calibração quando é utilizado o intervalo que contém a faixa do espectro associada aos estiramentos simétricos e/ou assimétricos de $\mathrm{CH}_{2}$ (faixas espectrais de 2770-2875 e 2875-2980 $\mathrm{cm}^{-1}$ ), conforme mostrado no gráfico da Figura 34. Lembrando que, foram identificadas modificações evidentes em outras bandas de absorção, localizadas em números mais baixos do ATR-FTIR espectros, como discutido na sessão 4.1 .4 desta tese.

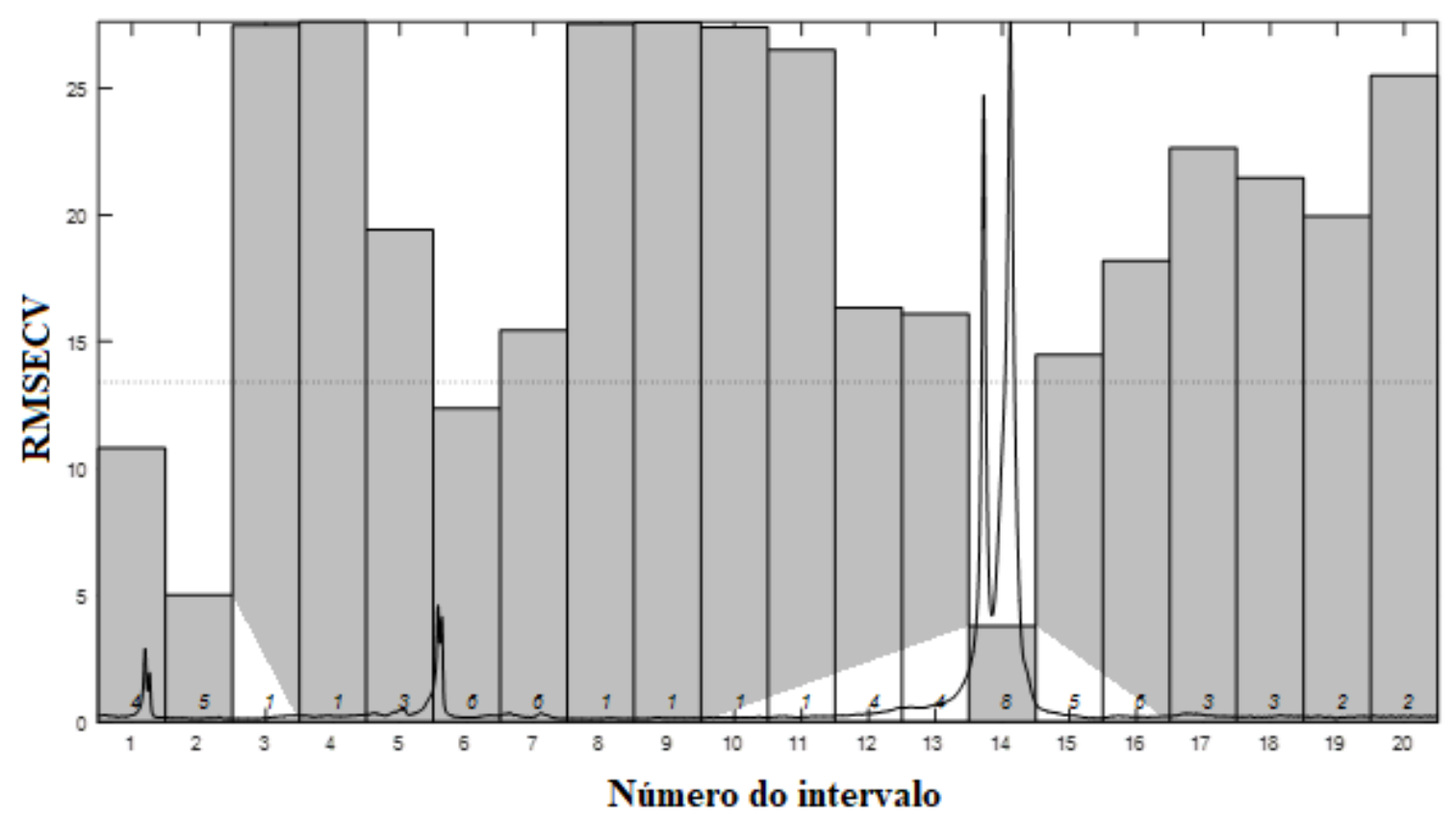

Figura 34 - Valores de RMSECV para cada intervalo usando a regressão iPLS nos espectros de ATR-FTIR. Os números dentro das barras correspondem à quantidade de variáveis latentes em cada subintervalo.

Ainda, de acordo com a Tabela 8, o resultado máximo para $\mathrm{R}_{\text {pred }}$ é 0,979 e o mínimo é de 0,958 para modelos iPLS30 e PLS-IR, respectivamente. O RMSEP mais baixo é 5,638 \%p de PEBD, que é observado para o modelo de predição com 30 subintervalos (iPLS30). O modelo iPLS40, que contém 40 segmentos, possui o RMSECV mais alto (9,106 \% p de PEBD), seguido pelos modelos iPLS30 e iPLS50 com erros de calibração iguais a 8,829 e 7,253 \%p de PEBD. Os resultados de RMSEP sugerem que o uso de 40 ou mais intervalos PLS tem um efeito negativo na capacidade preditiva dos modelos baseados em iPLS com dados ATR-FTIR.

Usando dados espectrais de ATR-FTIR, o modelo baseado em PLS (PLS-IR) apresentou desempenho baixo em relação àqueles obtidos pelo método iPLS. Dentre eles, o modelo preditivo iPLS30 foi o mais robusto e seu elevado coeficiente de correlação para as 
concentrações de PEBD, que foi previsto no conjunto de teste externo $\left(\mathrm{R}_{\text {pred }}=0,979\right)$, está ilustrado na Figura 35. Nesta figura, é evidente que há um maior erro de calibração e predição para as amostras contendo $50 \%$ p ou menos de PEBD, o que pode ser justificado pelos resultados de rugosidade; visto que, o aumento de PEAD na blenda polimérica acentua a rugosidade superficial dos péletes, o que ocasiona aumento no ruído dos espectros ATR-FTIR devido a efeitos de espalhamento do laser na superfície da amostra.

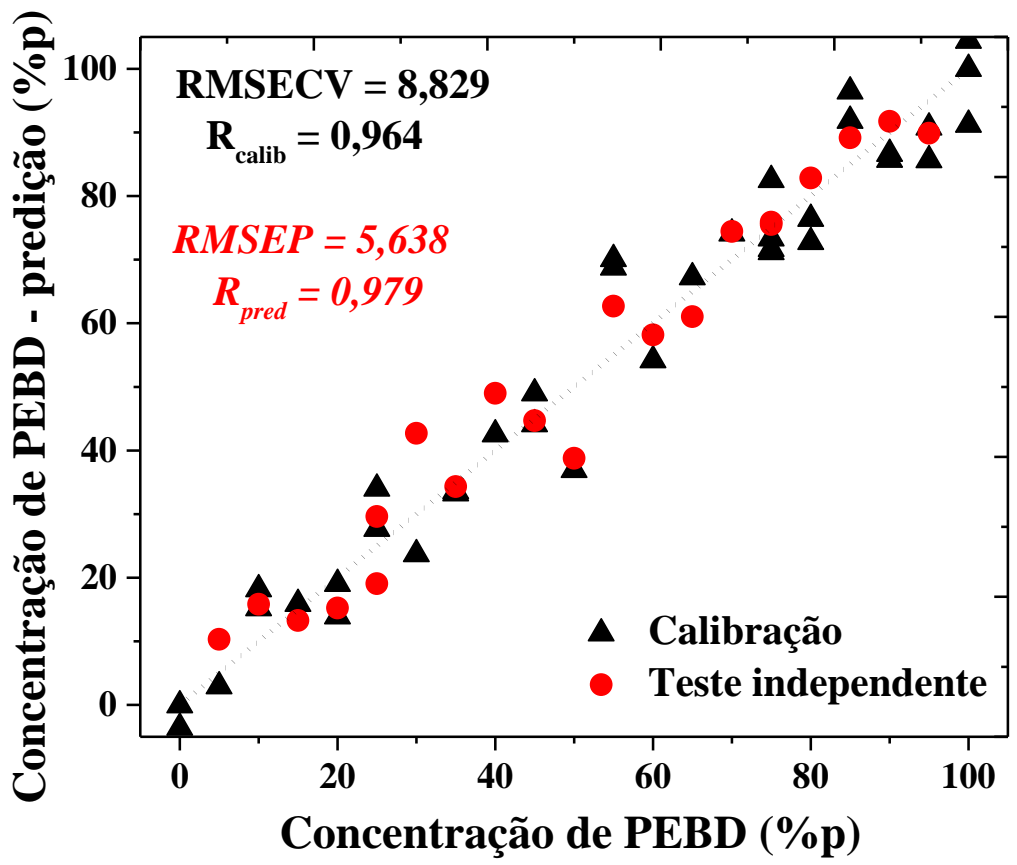

Figura 35 - Referência vs. previsão do teor de PEBD (\% p) nas blendas de PEAD/PEBD (material pristino). Dados obtidos com o modelo iPLS30 (modelo construído com o algoritmo iPLS, dados ATR-FTIR subdivididos em 30 intervalos e 11 LVs).

Vale destacar que, era esperado que houvesse maior incerteza de calibração/predição nos modelos PLS na faixa de baixa concentração de PEAD (menor do que $50 \%$ p), devido a erros significativos ocasionado por dois fatores: (1) efeitos de cocristalização das blendas de PEAD/PEBD, ou seja, formação de regiões altamente ordenadas com cadeias de polímero de PEAD dentro dos cristalitos de PEBD, principalmente para blendas com altos teores de PEBD (ESLAMIAN; BAGHERI; PIRCHERAGHI, 2016; PUIG, 1997); (2) efeitos de segregação de fase nas misturas poliméricas com concentrações de PEBD acima de 60 \%p (BARHAM et al., 1988; MILLER, 1993).

A região selecionada pelo algoritmo de seleção iPLS para a construção do modelo iPLS30 está apresentada na Figura 36. De acordo com a mesma, o algoritmo iPLS encontrou o 
menor erro de calibração e predição na faixa de $2875-2980 \mathrm{~cm}^{-1}$, o que sugere uma estreita relação entre composição e fração amorfa das blendas de PEBD/PEAD.

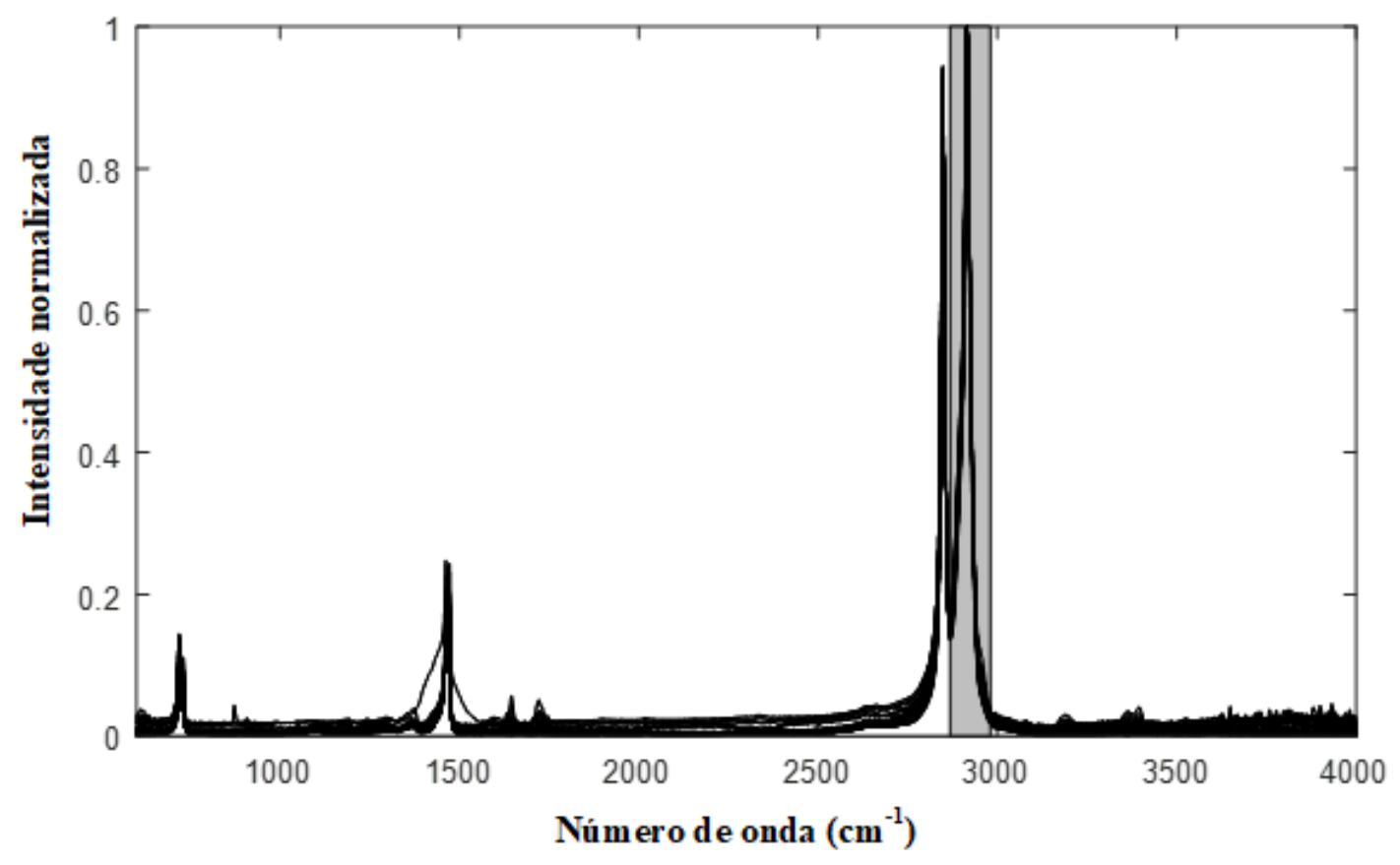

Figura 36 - Região do espectro FTIR selecionada para a construção do modelo iPLS30.

Para avaliar o grau de generalidade do modelo iPLS30, foi realizado um teste de predição usando um conjunto de espectros ATR-FTIR de blendas de PEBD/PEAD obtidas com os polietilenos reciclados. Os resultados de predição do teor de PEBD estão apresentados na Figura 37. Como pode ser identificado, o erro RMSEP é igual a 6,479 e o $R_{\text {pred }}$ é de 0,995; sendo que, há um baixo fator de ajuste para as blendas recicladas contendo menos que $10 \% \mathrm{p}$ de PEBD. Os espectros de infravermelho das blendas recicladas e a região selecionada pelo modelo de previsão iPLS30 estão ilustrados na Figura 38. 


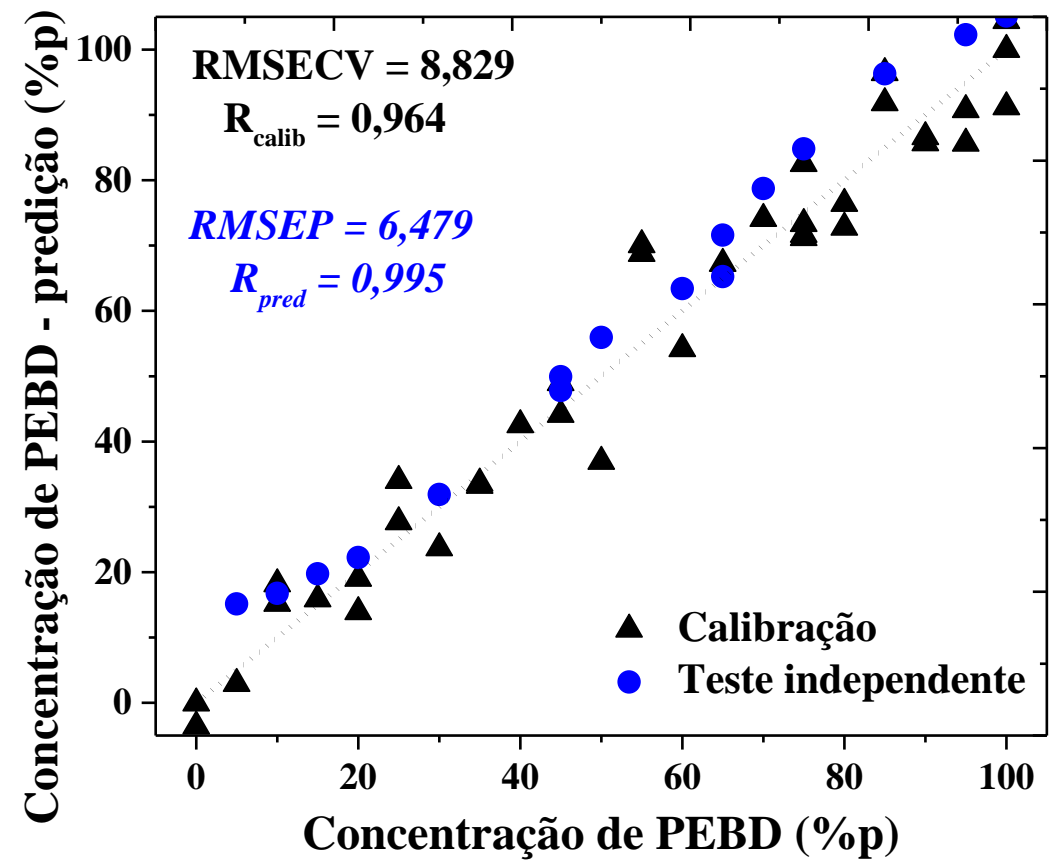

Figura 37 - Referência vs. previsão de teor de PEBD (\% p) nas blendas de PEAD/PEBD (material reciclado). Dados obtidos com o modelo iPLS30.

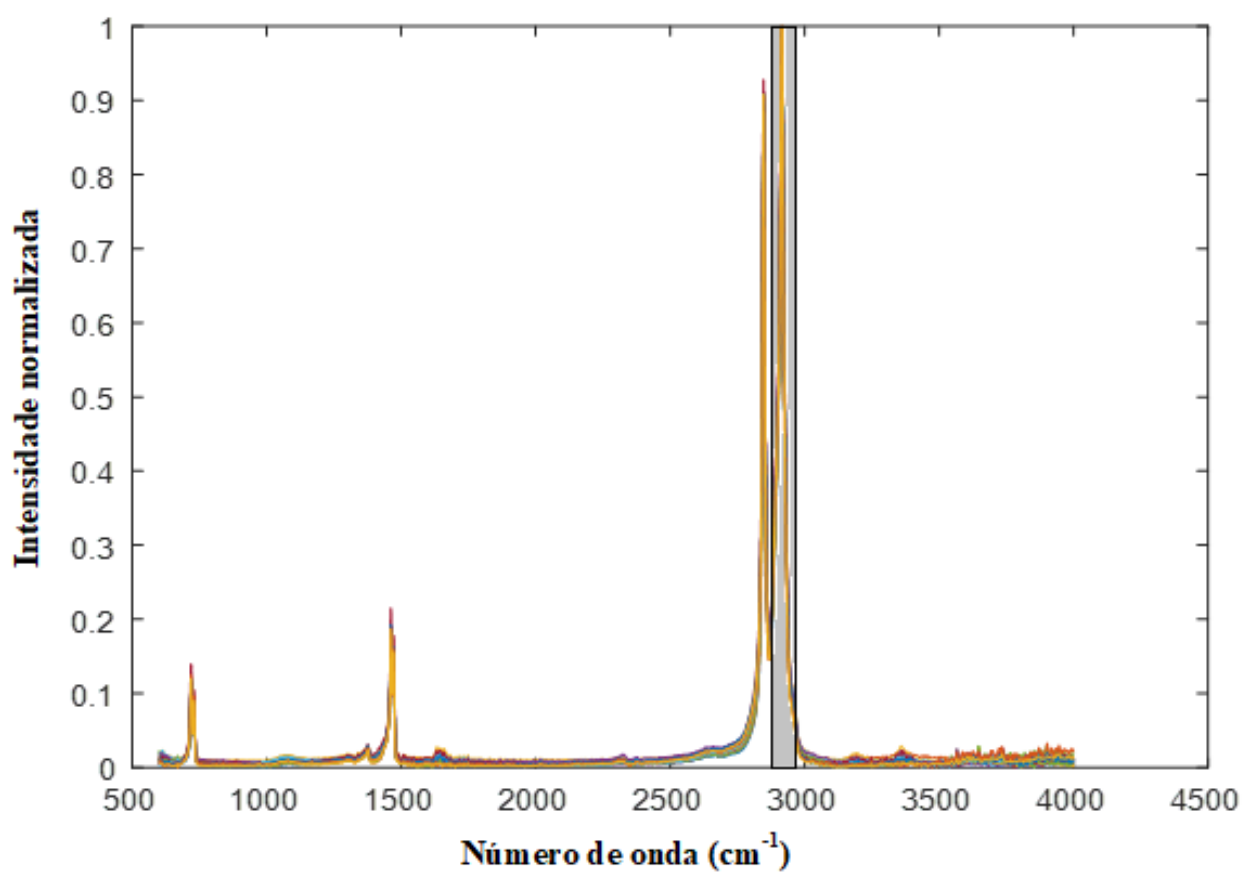

Figura 38 - Espectros ATR-FTIR das blendas de PEAD/PEBD obtidas com polímeros reciclados. A região do espectro selecionada pelo modelo iPLS30 está destacada em cinza. 


\subsubsection{Regressão CARS-PLS}

Para identificar qual o método de pré-tratamento mais adequado (centralização média, Pareto e autoescalado), foram construídos modelos de predição usando um único método e as outras variáveis da regressão CARS-PLS foram mantidas constantes. A Tabela 9 apresenta os parâmetros de desempenho dos modelos preditivos construídos com o algoritmo CARS-PLS (o número de LVs para validação cruzada, tipo de validação cruzada e número de ciclos foram mantidos constantes, como descrito na legenda da Tabela 9). Os resultados indicam que o modelo preditivo baseado na centralização média (PLS-C) melhor se ajusta ao conjunto de teste externo $($ Rpred $=0,97)$ e, também, mostra o menor erro de predição $($ RMSEP $=4,867 \%$ p de PEBD). Independentemente do método de pré-tratamento de dados, a regressão CARS-PLS tem um excelente desempenho de calibração, uma vez que os erros de calibração são extremamente baixos, menores que $0,5 \%$ de PEBD, para todos os modelos de predição.

Tabela 9 - Modelos preditivos com melhor desempenho usando regressão CARS-PLS e espectros ATR-FTIR, pré-

tratados por diferentes métodos (parâmetros constantes: número máximo de variáveis latentes para validação cruzada = 20; validação cruzada K-fold = leave-one-out; amostragem de Monte Carlo $=100$ ciclos).

\begin{tabular}{|c|c|c|c|c|c|c|}
\hline Modelo & $\begin{array}{l}\text { Pré- } \\
\text { tratamento }\end{array}$ & $\mathrm{LV}_{\text {ótimo }}$ & $\begin{array}{c}\text { RMSECV (\%p } \\
\text { de PEBD) }\end{array}$ & $\mathrm{R}_{\mathrm{calib}}$ & $\begin{array}{l}\text { RMSEP (\%p } \\
\text { de PEBD) }\end{array}$ & $\mathrm{R}_{\text {pred }}$ \\
\hline PLS & - & 19 & 0,233 & 1,000 & 6,579 & 0,945 \\
\hline PLS-C & $\begin{array}{c}\text { Centralização } \\
\text { média }\end{array}$ & 17 & 0,350 & 0,999 & 4,867 & 0,970 \\
\hline PLS-A & Autoescalado & 20 & 0,225 & 1,000 & 5,618 & 0,960 \\
\hline PLS-P & Pareto & 20 & 0,293 & 0,999 & 6,208 & 0,952 \\
\hline
\end{tabular}

A Tabela 10 contém os resultados de RMSECV e RMSEP para os modelos preditivos baseados em regressão CARS-PLS, usando vários valores de K-fold para validação cruzada. Os seus coeficientes de correlação de calibração $\left(\mathrm{R}_{\text {calib}}\right)$ e a previsão $\left(\mathrm{R}_{\text {pred}}\right)$ também foram detalhados nesta tabela.

A técnica de validação cruzada do tipo K-fold divide aleatoriamente o conjunto de dados de calibração em subconjuntos $\mathrm{K}$ mutuamente exclusivos com o mesmo tamanho, ou seja, com o mesmo número de espectros. Enquanto que os subconjuntos K-1 são utilizados como subconjunto de calibração, um subconjunto de teste é utilizado para avaliar a predição e, 
assim, calcular RMSECV e $\mathrm{R}_{\text {calib }}$ durante o treinamento do modelo preditivo. Leave-one-out é um caso específico de validação cruzada K-fold, onde K é igual ao número total de dados de espectros (N). Contudo, a validação do tipo leave-one-out é inviável quando $\mathrm{N}$ é alto porque os cálculos de erros demandam elevados custos computacionais, isto porque o erro total é estatisticamente calculado a partir do erro obtido para cada espectro no conjunto de dados.

Tabela 10 - Modelos preditivos com melhor desempenho obtidos por regressão CARS-PLS e espectros ATR-FTIR, usando diferentes valores de K-fold para validação cruzada (parâmetros constantes: pré-tratamento = centralização média; número máximo de variáveis latentes para validação cruzada = 20; amostragem de Monte Carlo = 100 ciclos).

\begin{tabular}{ccccccc}
\hline Modelo & $\begin{array}{c}\text { Validação } \\
\text { cruzada por } \\
\text { K-Fold }\end{array}$ & $\mathrm{LV}_{\text {ótimo }}$ & $\begin{array}{c}\text { RMSECV } \\
(\% \mathrm{p} \text { de } \\
\text { PEBD })\end{array}$ & $\mathrm{R}_{\text {calib }}$ & $\begin{array}{c}\text { RMSEP } \\
(\% \mathrm{p} \text { de } \\
\text { PEBD })\end{array}$ & $\mathrm{R}_{\text {pred }}$ \\
\hline PLS-C2 & 2 & 20 & 0,336 & 0,999 & 4,891 & 0,969 \\
PLS-C5 & 5 & 17 & 0,350 & 0,999 & 4,867 & 0,970 \\
\hline PLS-C15 & 15 & 16 & 0,370 & 0,999 & 4,865 & 0,970 \\
\hline PLS-C20 & 20 & 16 & 0,370 & 0,999 & 4,865 & 0,970 \\
\hline
\end{tabular}

Como pode ser verificado na Tabela 10, não há melhora na predição e desempenho de calibração dos modelos CARS-PLS usando mais de 15-fold, visto que o RMSEP dos modelos preditivos não fica menor que 4,865 \% p de PEBD. Nesta condição de K-fold, os graus de ajuste também não exibem flutuações significativas para o conjunto de dados de calibração ou de predição, uma vez que os erros $R_{\text {calib }}$ e $R_{\text {pred }}$ permanecem inalterados e iguais a 0,999 e 0,97, respectivamente.

A regressão linear PLS é baseada em um subespaço vetorial projetado, que é montado por uma relação linear entre as variáveis latentes no conjunto de dados espectrais. Assim, o número ótimo de LVs deve ser identificado para obter o melhor desempenho de calibração para o modelo PLS (ROSIPAL, 2011). Um benefício do método CARS-PLS é a possibilidade de realizar uma pesquisa automática e sofisticada para otimizar esse parâmetro, sem necessidade de buscas manuais excessivas que são, geralmente, exigidas nas regressões PLS lineares e não lineares convencionais (LI et al., 2009).

De acordo com a Tabela 11, RMSECV diminuiu e $\mathrm{R}_{\text {calib }}$ aumenta à medida que o número máximo de variáveis latentes para validação cruzada aumenta, sendo o resultado mínimo de RMSECV igual a 0,025 \% p de PEBD para o modelo PLS-40 construído com 36 
LVs. O RMSEP cai de 5,509 para 4, 994 \%p de PEBD, quando o número máximo de LVs é aumentado de 5 para 10 , respectivamente.

\begin{tabular}{|c|c|c|c|c|c|c|}
\hline Modelo & $\begin{array}{c}\text { Número de } \\
\text { LVs }\end{array}$ & $\mathrm{LV}_{\text {ótimo }}$ & $\begin{array}{c}\text { RMSECV } \\
\text { (\%p de } \\
\text { PEBD) }\end{array}$ & $\mathrm{R}_{\text {calib }}$ & $\begin{array}{l}\text { RMSEP } \\
\text { (\%p de } \\
\text { PEBD) }\end{array}$ & $\mathrm{R}_{\text {pred }}$ \\
\hline PLS-5 & 5 & 4 & 6,886 & 0,967 & 5,509 & 0,962 \\
\hline PLS-10 & 10 & 9 & 2,868 & 0,994 & 4,994 & 0,968 \\
\hline PLS-30 & 30 & 30 & 0,035 & 1,000 & 6,329 & 0,949 \\
\hline PLS-40 & 40 & 36 & 0,025 & 1,000 & 5,362 & 0,964 \\
\hline
\end{tabular}

Para investigar a influência do número de ciclos de amostragem de Monte Carlo no desempenho do modelo CARS-PLS, foram construídos modelos preditivos com 50 a 10000 corridas. Os resultados estão mostrados na forma de gráficos na Figura 39 (manteve-se constante os outros parâmetros, ou seja, tipo de validação cruzada, método de pré-tratamento e número máximo de LVs).

Todos os modelos preditivos da Figura 39 apresentam bons coeficientes de correlação para os valores previstos da concentração relativa de PEBD nas blendas de PEBD/PEAD ( $\mathrm{R}_{\text {pred }}$ superior a 0,95$)$ e excelente coeficiente de correlação para calibração $\left(R_{\text {calib }}\right.$ maior ou igual a 0,999). O erro de calibração mais alto e o menor erro de predição foram identificados para o modelo CARS-PLS construído com 100 execuções (RMSECV $=0,37 \%$ e $\operatorname{RMSEP}=4,865$ $\%$ p de PEBD). Enquanto que, o valor de erro de calibração mais baixo foi observado para o modelo construído com 500 execuções (RMSECV = 0,176 \% p de PEBD). Os resultados dos modelos CARS-PLS montados com mais de 100 ciclos de amostragem mostram, evidentemente, que a redução de RMSECV não ocasiona, necessariamente, uma melhora na capacidade preditiva dos modelos de predição baseados no algoritmo CARS-PLS (i.e., não ocasiona redução do valor de RMSEP). Além disso, todos os erros estatísticos dos modelos baseados em regressão CARS-PLS não apresentam mudanças significativas quando são utilizados 5000 ou 10000 ciclos de amostragem de Monte Carlo. 

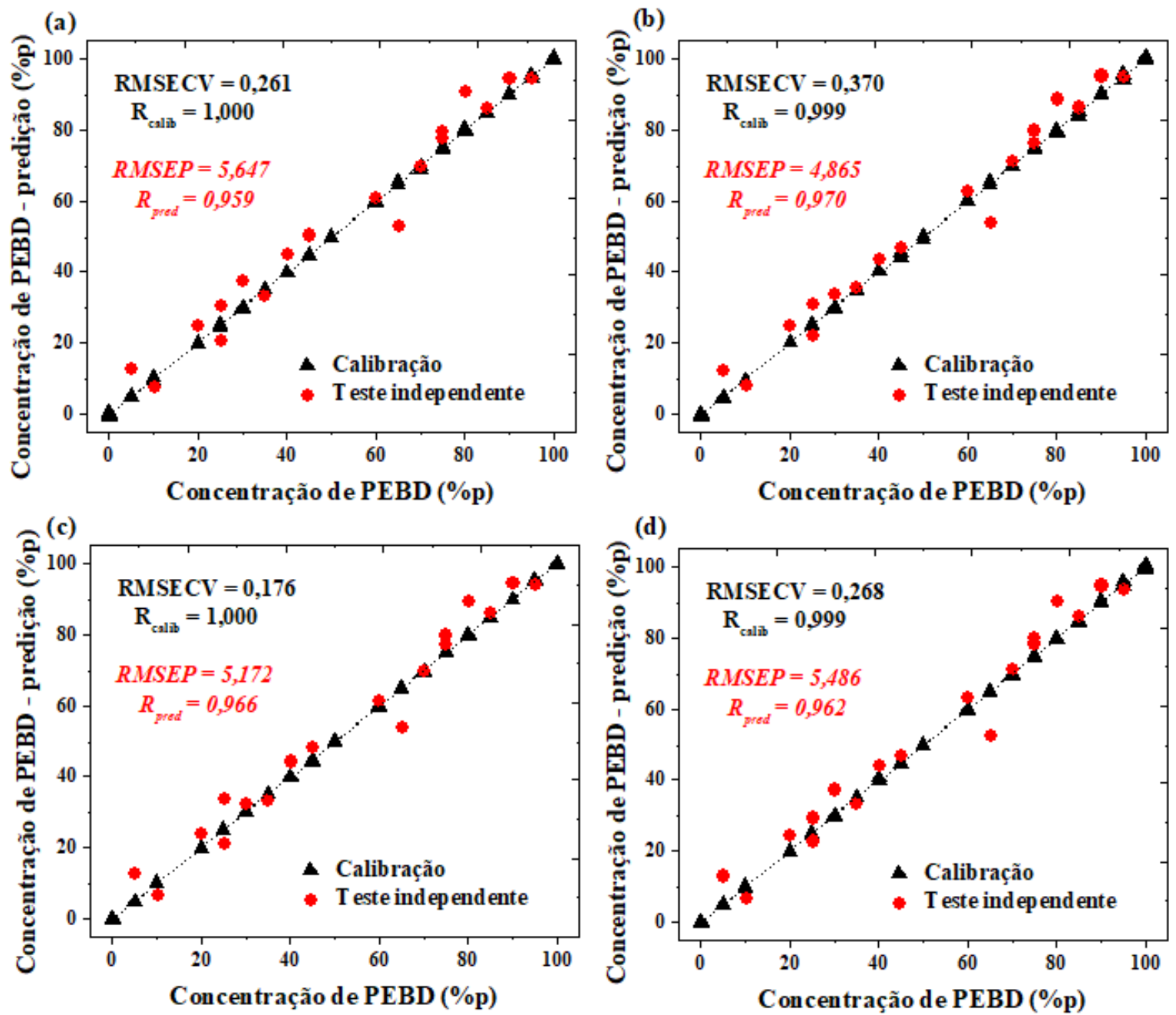

(d)
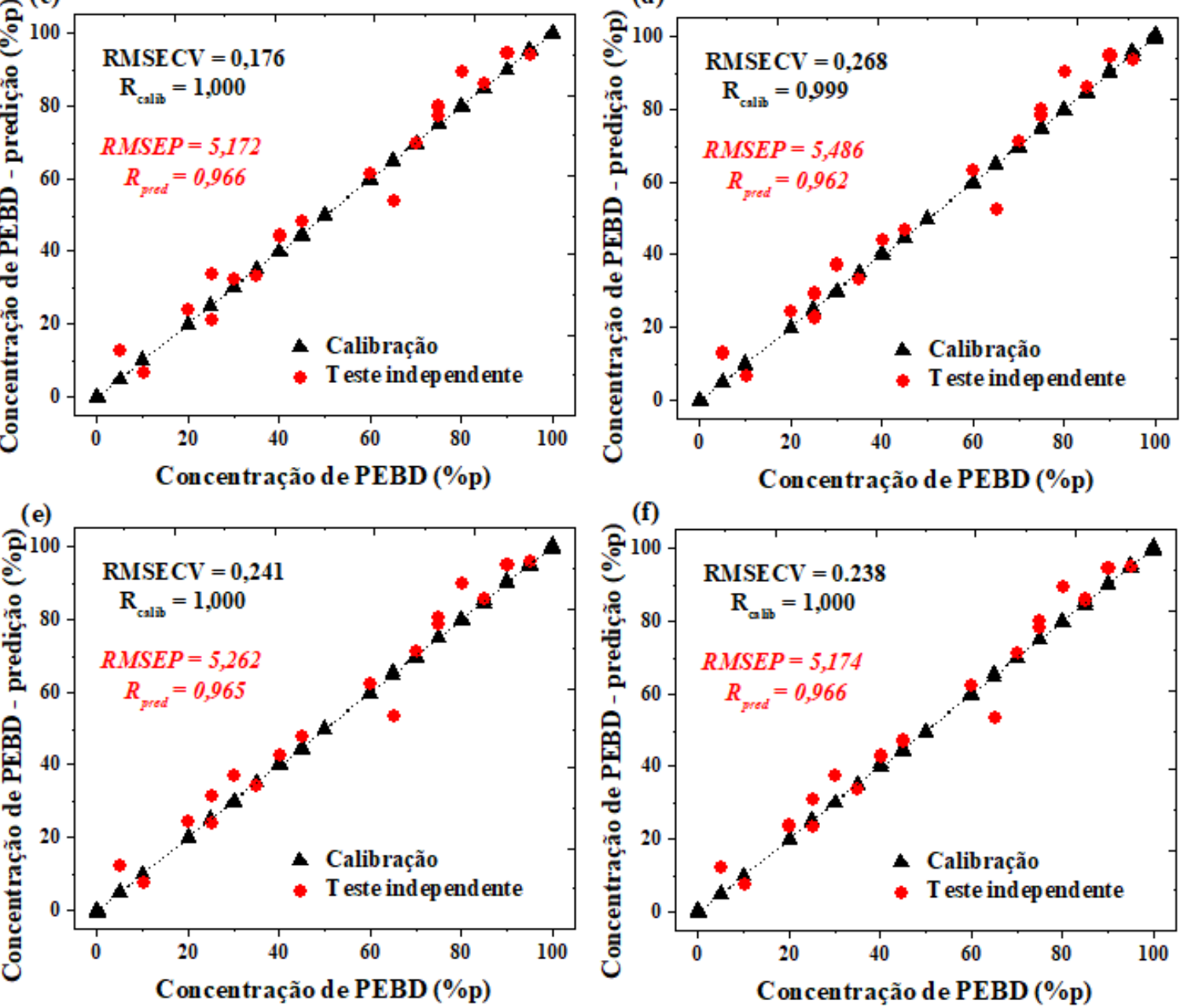

Figura 39 - Referência vs. predição do teor de PEBD (\% p) nas blendas de PEAD/PEBD (material pristino e dados ATR-FTIR). Dados obtidos por regressão CARS-PLS, usando vários números de ciclos de amostragem de Monte Carlo: (a) 50, (b) 100, (c) 500, (d) 1000, (e) 5000 e (f) 10000. (Parâmetros constantes: método de pré-tratamento = centralização média; validação cruzada K-fold = 15; número máximo de LVs = 20).

Como pode ser identificado ainda na Figura 39, os maiores desvios de predição estão localizados nas concentrações de PEBD iguais a 65 e $80 \%$ p. Isto pode ser atribuído à alta 
variação de FWHM para a banda de absorção de IR em $1460 \mathrm{~cm}^{-1}$ (Figura 23), uma vez que todos os modelos preditivos baseados em regressão CARS-PLS e espectroscopia ATR-FTIR foram construídos pela combinação dos sinais de absorção de IR em $2850 \mathrm{~cm}^{-1}$ (referente à fase amorfa e cristalina do polietileno), $2920 \mathrm{~cm}^{-1}$ e $1445 \mathrm{~cm}^{-1}$ (apenas da fase cristalina do PE), e mais outros oitenta e seis números de ondas dos espectros vibracionais de IR dos PEs e suas misturas.

No caso da regressão CARS-PLS, o modelo PLS-C20 é um dos modelos preditivos que apresentaram o melhor desempenho na predição do teor de PEBD usando os dados espectrais de ATR-FTIR. Sendo assim, foi avaliado o seu grau de generalidade fazendo um teste de predição com um conjunto de espectros IR de blendas de PEBD/PEAD obtidas com os polietilenos reciclados. Os resultados desta análise estão mostrados na Figura 40.

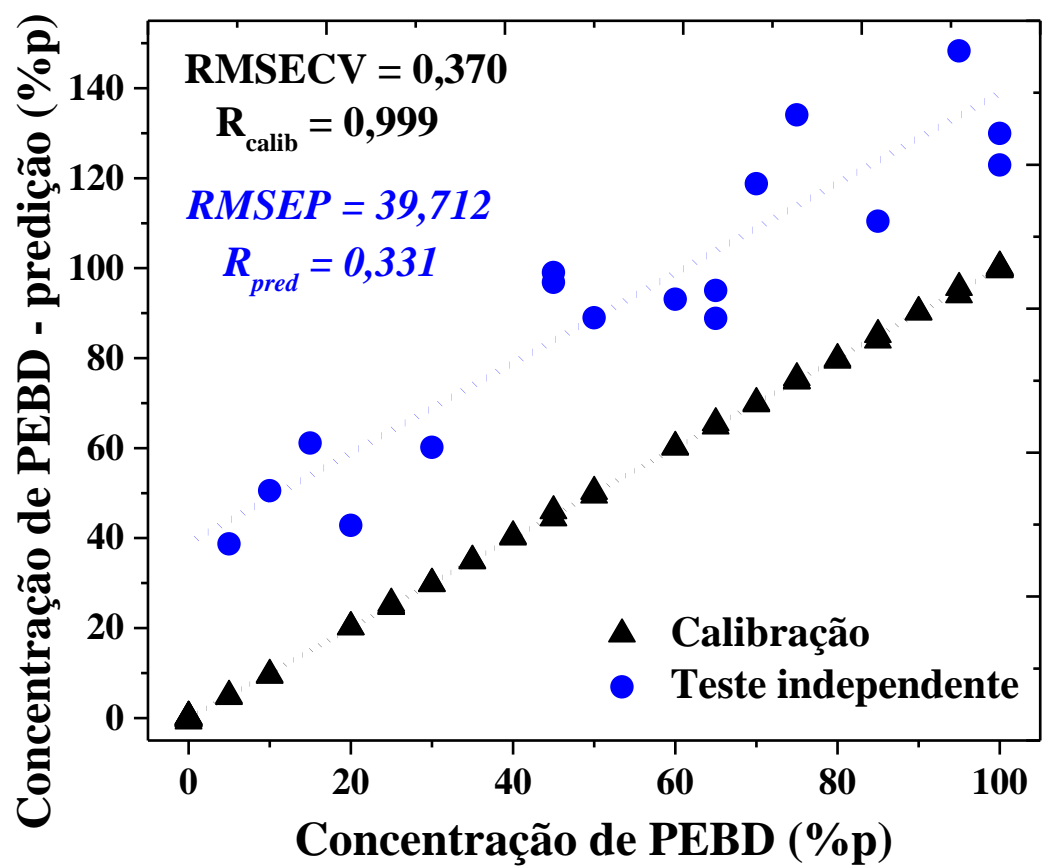

Figura 40 - Referência vs. previsão de teor de PEBD (\%p) nas blendas de PEAD/PEBD (material reciclado). Dados obtidos com o modelo PLS-C20.

Como pode ser identificado na Figura 40, o valor obtido para RMSEP é muito elevado, igual a 39,712 \% p de PEBD, e o valor de $\mathrm{R}_{\text {pred }}$ é igual a 0,331. Os resultados preditos formam uma linha reta com uma inclinação igual a 1 , porém com um coeficiente linear diferente de zero. Como se a linha de predição do modelo estivesse deslocada em um valor constante, de 40 \%p de PEBD, em relação à linha de regressão (construída na calibração multivariada do modelo de predição PLS-C20). Segundo Miller et al. (MILLER; MILLER, 2010), este tipo de não concordância entre valores de calibração e predição pode estar conectado com erros 
sistemáticos e/ou aleatórios no sinal de fundo (background) do espectrômetro. Portanto, essa elevada discrepância sugere que o modelo PLS-C20 é altamente sensível a pequenas variações nos sinais espectrais de IR, que estão relacionadas com a heterogeneidade dos polímeros reciclados.

\subsubsection{Desempenho do modelo preditivo para misturas poliméricas recicladas contendo diferentes contaminantes}

Conforme resultados apresentados nas sessões 4.2.1 e 4.2.2, o modelo preditivo iPLS30 apresenta o menor erro de predição da composição das blendas poliméricas de PEAD/PEBD obtidas com polímeros reciclados, quando são usados dados espectrais de ATRFTIR. Sendo assim, foi avaliada a capacidade deste modelo para determinar a composição de misturas poliméricas de PEAD/PEBD reciclados contendo outros materiais na sua composição.

Neste trabalho, foi optado por usar concentrações de $5 \%$ p de PP, PET, carbonato de cálcio (calcita) e sílica. PP e PET são dois dos termoplásticos mais presentes nos resíduos sólidos urbanos gerado no Brasil e no mundo. Calcita e sílica são aditivos frequentemente usados em polímeros como cargas de enchimento para reduzir o custo final do produto, visto que estes materiais cerâmicos são geralmente mais baratos que os polímeros disponíveis no mercado.

Os espectros ATR-FTIR das blendas poliméricas contaminadas estão apresentadas no Apêndice B. Conforme mostrado na Figura 41, os erros de predição aumentam significativamente quando as misturas de PEAD/PEBD apresentam esse percentual de contaminação, principalmente com a presença de PET, PP e carbonato de cálcio nas blendas poliméricas recicladas. O menor erro de predição foi obtido nos testes envolvendo as blendas poliméricas com sílica gel (RMSEP $=7,771 \%$ p de PEBD), sendo o a incerteza de predição da concentração de PEBD superior a 16 \% quando as amostras contêm os outros três contaminantes investigados neste trabalho. Além disso, estes significantes aumentos dos erros de calibração e de predição do modelo iPLS30 estão, também, associadas ao aumento da rugosidade superficial dos péletes, que são ocasionadas pela adição do contaminante nos polietilenos reciclados (Figura 42). Como discutido anteriormente, a elevação da rugosidade superficial dos péletes acarreta em maior incerteza nas medidas espectrais de ATR-FTIR. 
(a)

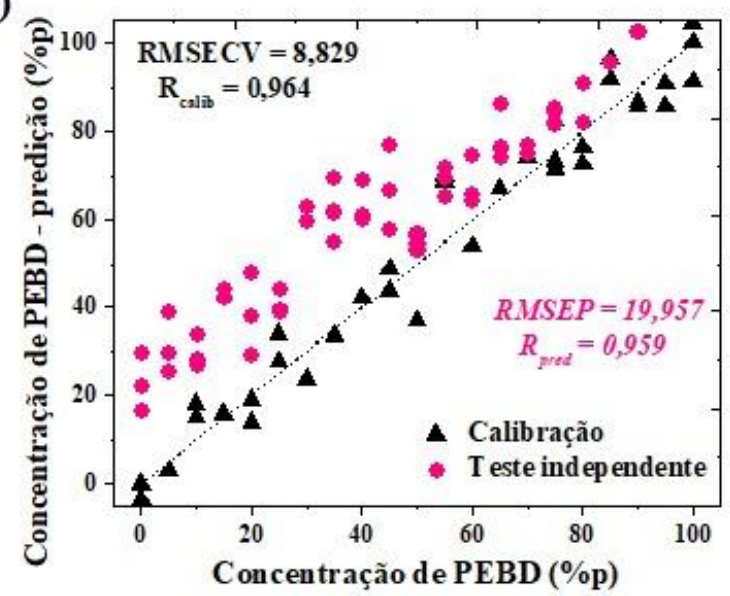

(c)

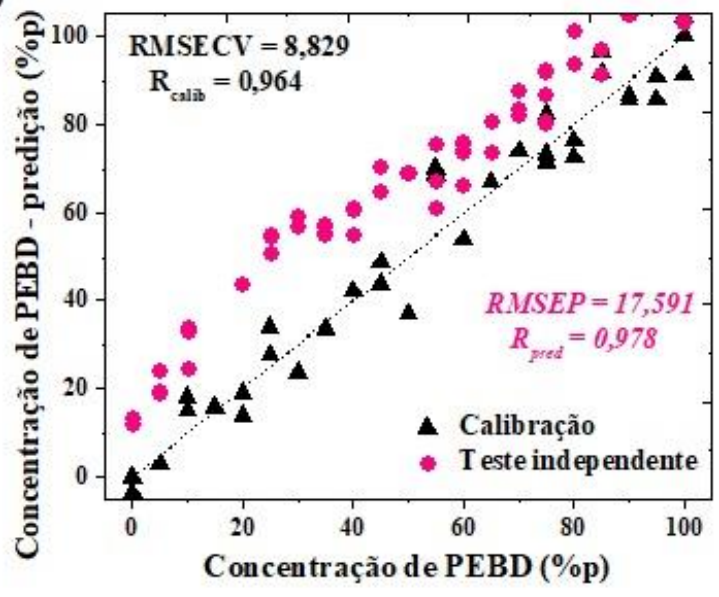

(b)

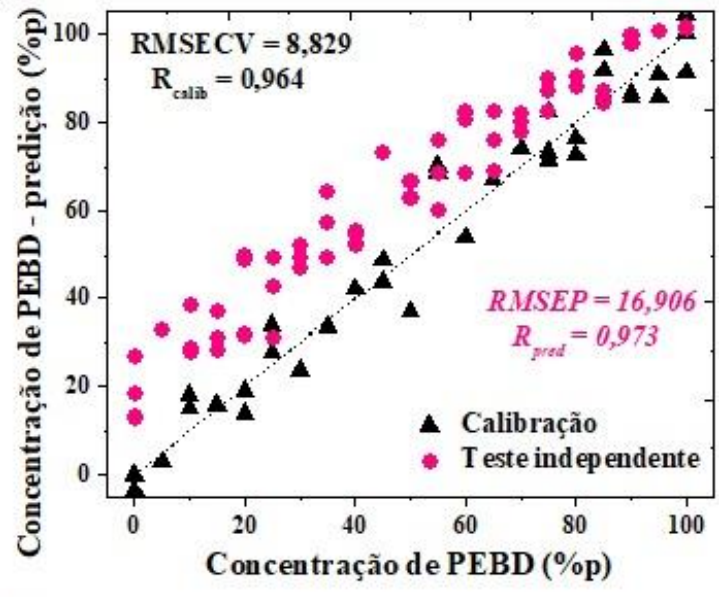

(d)

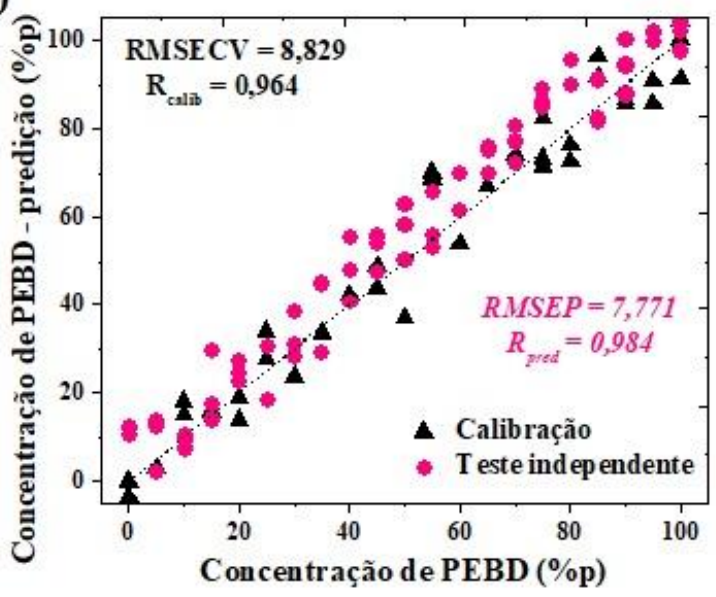

Figura 41 - Referência vs. previsão do teor de PEBD (\% p) nas blendas poliméricas de PEAD/PEBD (material reciclado). Dados obtidos com o modelo iPLS30 e dados espectrais ATR-FTIR. As misturas poliméricas recicladas contêm 5 \% p de diferentes contaminantes: (a) $\mathrm{CaCO}_{3}$, (b) PET, (c) PP e (d) sílica gel.
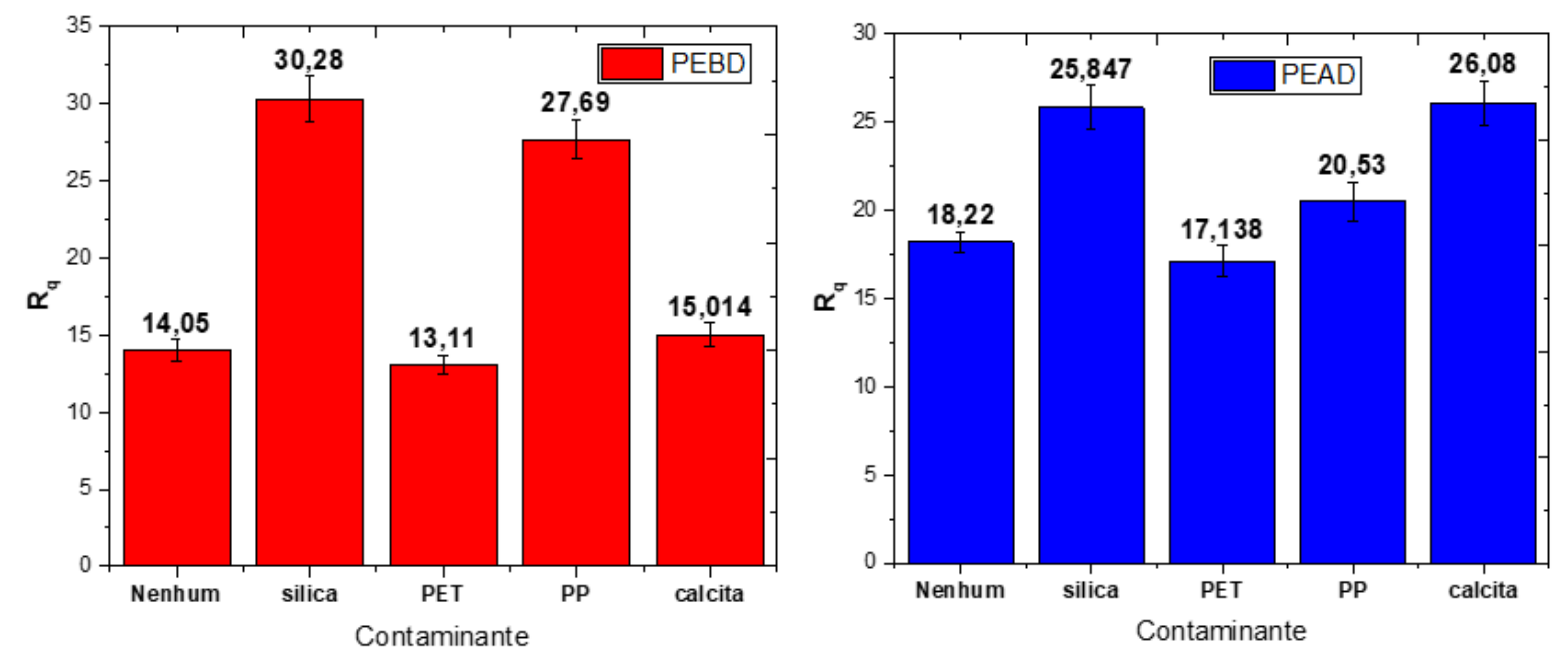

Figura 42 - Variação da rugosidade $R_{q}$ nos péletes de PEAD e PEBD reciclados devido à adição de diferentes contaminantes. 


\subsection{MODELOS DE PREDIÇÃO USANDO ESPECTROSCOPIA RAMAN CONFOCAL}

\subsubsection{Regressão PLS e iPLS}

Analogamente ao procedimento de particionamento dos espectros ATR-FTIR, os espectros Raman foram subdivididos em intervalos igualmente espaçados e a numeração do intervalo foi iniciada em $210 \mathrm{~cm}^{-1}$ (Figura 43). Avaliando a linha base dos espectros de Raman confocal, é evidente que o microscópio confocal usado nas medidas espectrais de espalhamento Raman é mais susceptível à curvatura e à rugosidade superficial dos péletes do que o espectrômetro ATR-FTIR. Além disso, a espectroscopia Raman é susceptível a efeitos de fluorescência da amostra e detecção de raios cósmicos, que também comprometem a qualidade do espectro medido.

Número do intervalo

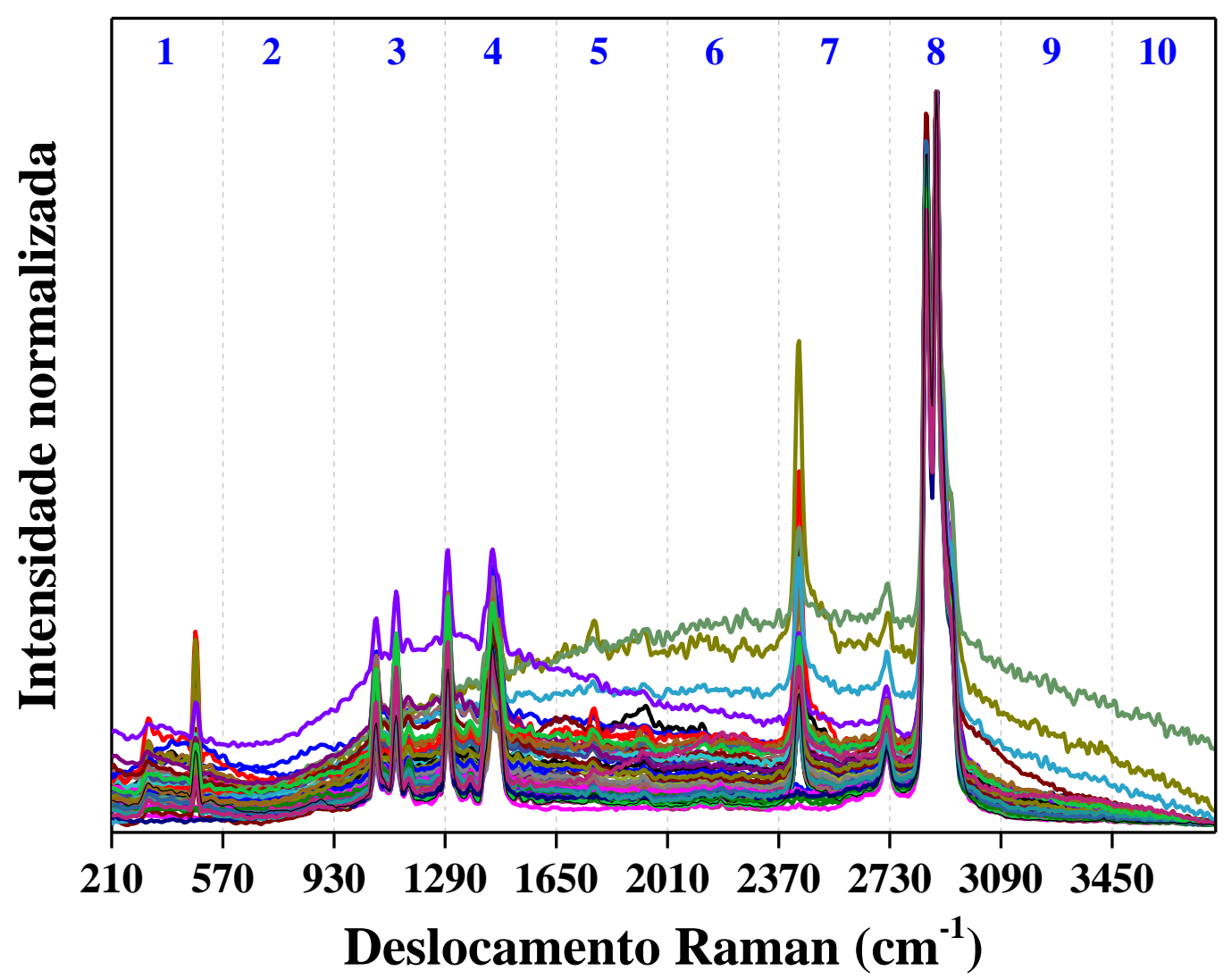

Figura 43 - Espectros Raman confocal das blendas de PEAD/PEBD (obtidas com polímeros pristinos) e sua segmentação em 10 intervalos pelo método iPLS.

Os modelos preditivos PLS e iPLS construídos com base nos espectros Raman estão mostrados na Tabela 12. O número ótimo de LVs, $R_{\text {pred }}$ e $R_{\text {calib }}$ também foram listados nesta 
tabela. Como pode ser observado, todos os modelos baseados em iPLS têm seu melhor desempenho de predição usando a faixa de espectro de $2815-2864 \mathrm{~cm}^{-1}$, o que corresponde ao estiramento assimétrico do $\mathrm{CH}_{2}$ na fase amorfa e cristalina do polietileno. Os valores RMSEP mais altos são 17,271 e 11,531 \%p de PEBD para os modelos PLSR e iPLS10R, respectivamente. O modelo iPLS40R apresentou o menor erro de calibração entre os modelos baseados nos dados espectrais Raman e algoritmos iPLS e PLS (RMSECV igual a 8,001 \%p de PEBD), mas sua capacidade de predição é igual a 9,822 \% p de PEBD.

Tabela 12 - Modelos preditivos com melhor desempenho obtidos pela regressão PLS e iPLS para a quantificação do teor de PEBD nas blendas de PEBD/PEAD (obtidas com polímeros pristinos), usando dados espectrais Raman (prétratamento $=$ centralização média).

\begin{tabular}{cccccccc}
\hline Modelo & $\begin{array}{c}\text { Número de } \\
\text { subintervalos }\end{array}$ & $\begin{array}{c}\text { Intervalo } \\
\text { selecionado }\end{array}$ & LV $_{\text {ótimo }}$ & $\begin{array}{c}\text { RMSECV } \\
(\% \mathrm{p} \mathrm{de} \\
\text { PEBD })\end{array}$ & $\mathrm{R}_{\text {calib }}$ & $\begin{array}{c}\text { RMSEP de } \\
\text { PEBD })\end{array}$ & $\mathrm{R}_{\text {pred }}$ \\
\hline PLSR & - & - & 4 & 10,104 & 0,941 & 17,271 & 0,887 \\
\hline iPLS10R & 10 & 8 & 4 & 7,039 & 0,972 & 11,531 & 0,954 \\
\hline iPLS20R & 20 & 15 & 4 & 7,702 & 0,972 & 10,528 & 0,964 \\
\hline iPLS30R & 30 & 22 & 4 & 8,085 & 0,964 & 9,355 & 0,972 \\
\hline iPLS40R & 40 & 29 & 4 & 8,001 & 0,956 & 9,822 & 0,966 \\
\hline iPLS50R & 50 & 36 & 4 & 9,594 & 0,952 & 9,883 & 0,969 \\
\hline
\end{tabular}

A determinação do valor de $\mathrm{LV}_{\text {ótimo }}$ foi feita graficamente, pela curva do erro RMSECV em função do número de variáveis latentes (Figura 44). O LV ótimo corresponde ao ponto onde o erro de calibração é mínimo, mas deve ser evitado o uso de um número elevado de variáveis latentes porque isto pode acarretar em sobre ajustes nos modelos de predição (MEDEIROS, 2009). Usando os dados espectrais Raman e o algoritmo de regressão iPLS, o modelo iPLS30R foi o que apresentou o menor valor de RMSEP (9,355 \%p de PEBD) e seu coeficiente de ajuste de predição é igual a 0,972. 


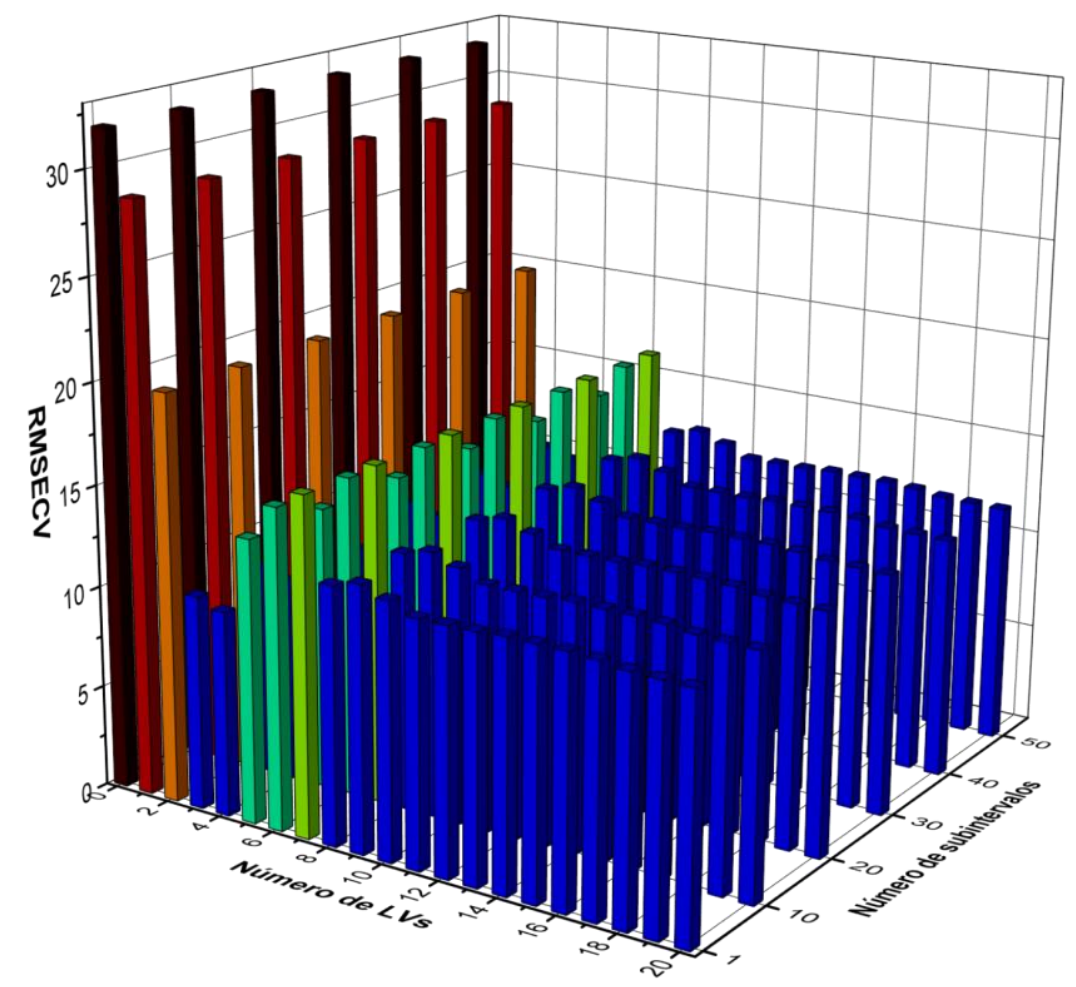

Figura 44 - Variação do RMSECV em função do número de variáveis latentes, usando diferente número de subintervalos $(1,10,20,30,40$ e 50), usando dados de espectroscopia Raman confocal. O número de subintervalo é 1 para regressão PLS e maior que 1 para regressão iPLS.

Na Figura 45, são mostrados os valores preditos do teor de PEBD nas blendas de PEAD/PEBD obtidas com polímeros pristinos. Como pode ser visto, os ajustes dos dados de calibração e predição são pobres em toda a faixa de composição da blenda, sendo o erro de predição deste modelo iPLS30R bem superior àquele observado para o modelo construído pelos dados ATR-FTIR e regressão iPLS (modelo iPLS30). Sendo isto justificado pela grande quantidade de espectros Raman com efeitos negativos de ruído, mesmo após pré-tratamento, como mencionado anteriormente e mostrado na Figura 43. Esta instabilidade do sinal presente no espectro vibracional introduz erro sistemático nos modelos de predição e, assim, afetam negativamente o desempenho dos mesmos. 


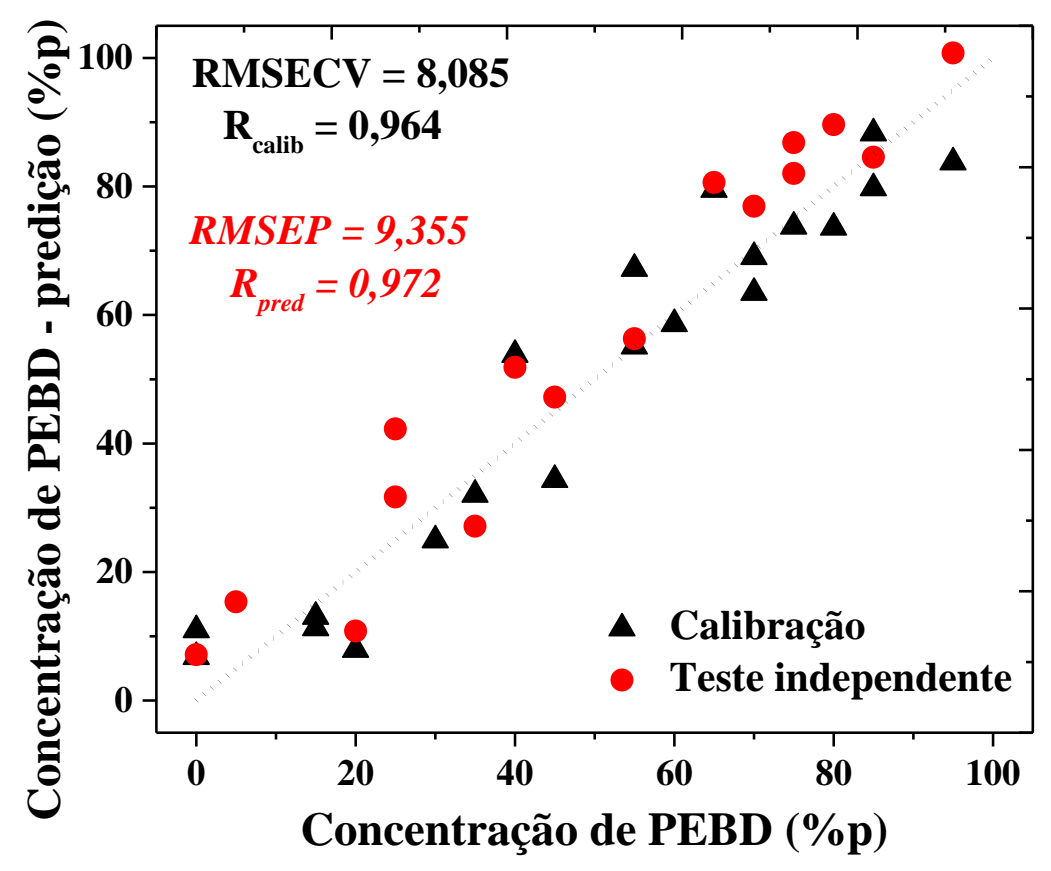

Figura 45 - Referência vs. previsão do teor de PEBD (\% p) nas blendas de PEAD/PEBD (material pristino). Dados obtidos com o modelo iPLS30R (modelo construído com o algoritmo iPLS, dados espectrais Raman subdivididos em 30 intervalos e 4 LVs).

A região selecionada pelo algoritmo de seleção iPLS para a construção do modelo iPLS30R está apresentada na Figura 46.

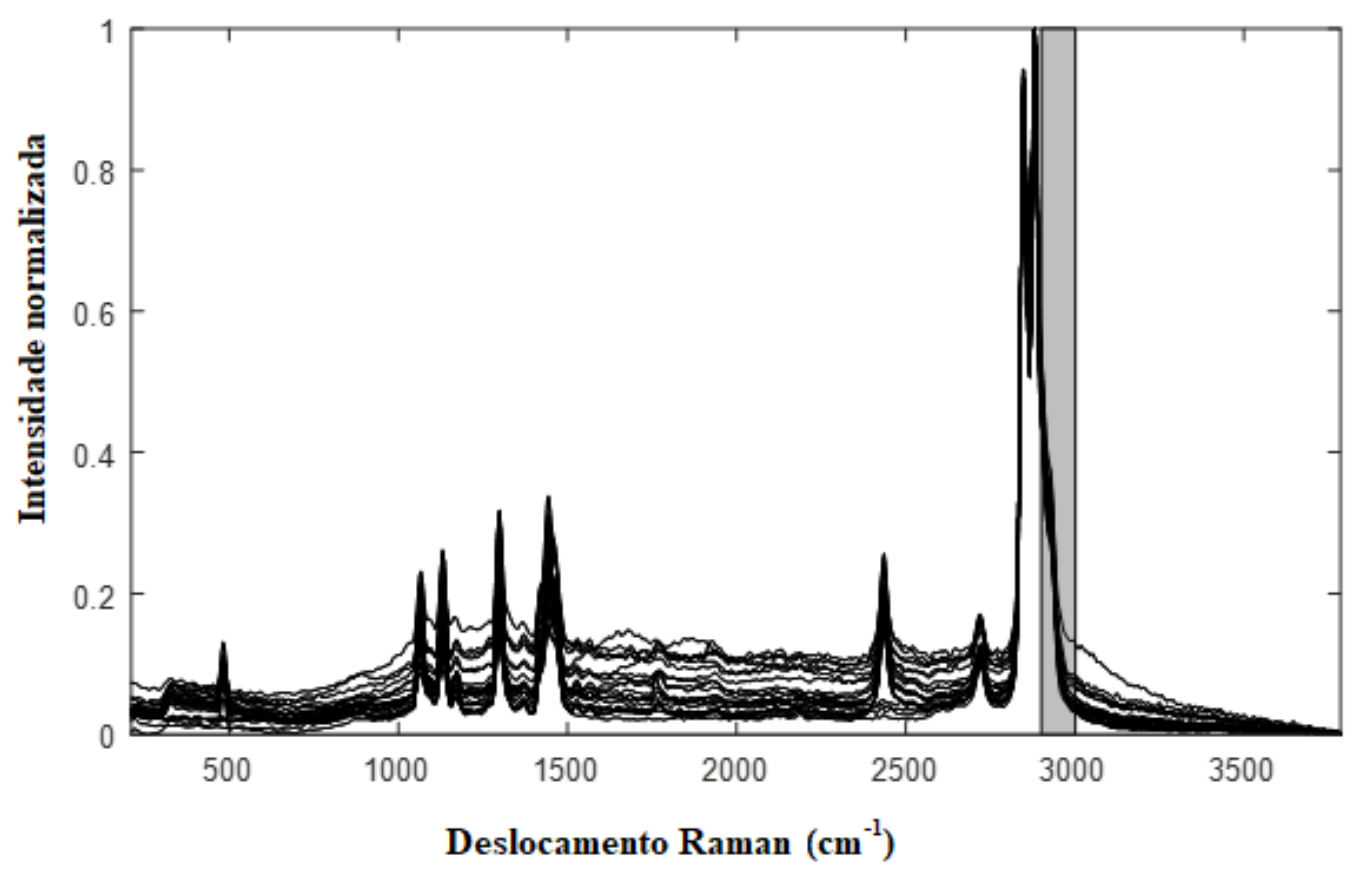

Figura 46 - Região do espectro Raman selecionada para a construção do modelo iPLS30R. 
Apesar do significante erro de calibração, o modelo iPLS30 apresenta um bom desempenho de predição do teor de PEBD em blendas obtidas com polietileno reciclados, como pode ser verificado na Figura 47. Neste caso, o erro RMSEP reduziu para 5,421\%p de PEBD e o fator de ajuste $R_{\text {pred }}$ aumentou para 0,984. Os espectros Raman das blendas recicladas e a região selecionada pelo modelo de previsão iPLS30R estão apresentados na Figura 48.

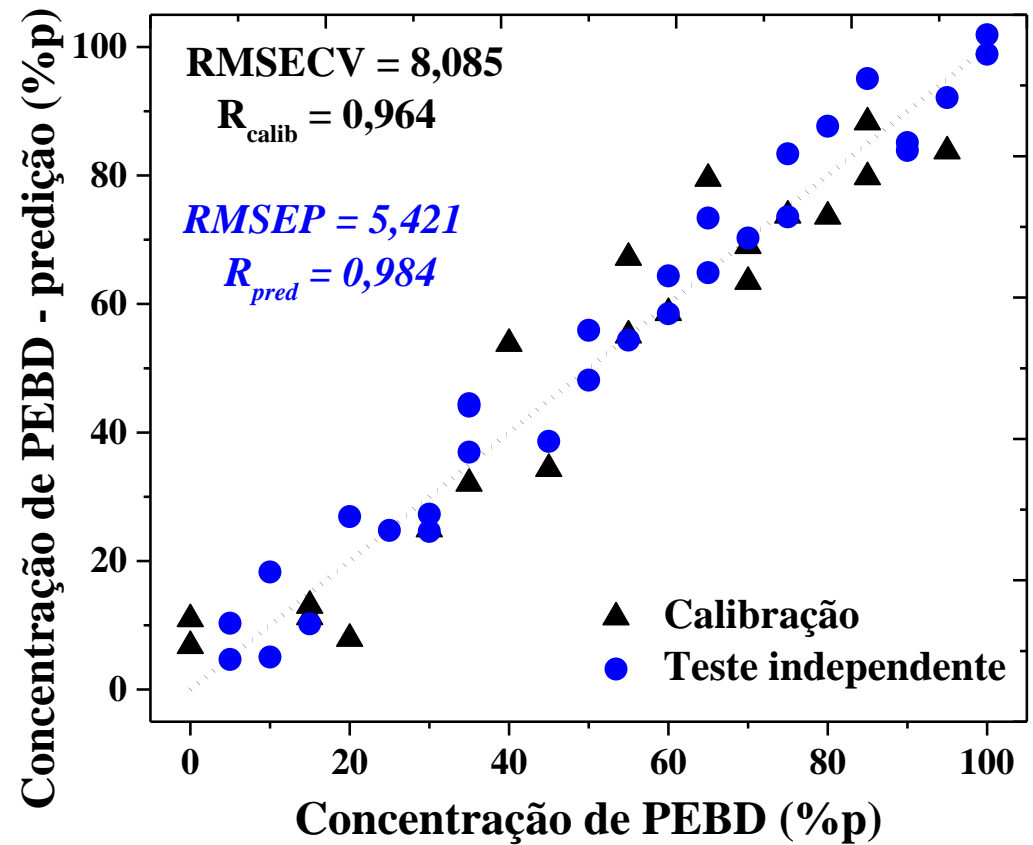

Figura 47 - Referência vs. previsão de teor de PEBD (\% p) nas blendas de PEAD/PEBD (material reciclado). Dados obtidos com o modelo iPLS30R.

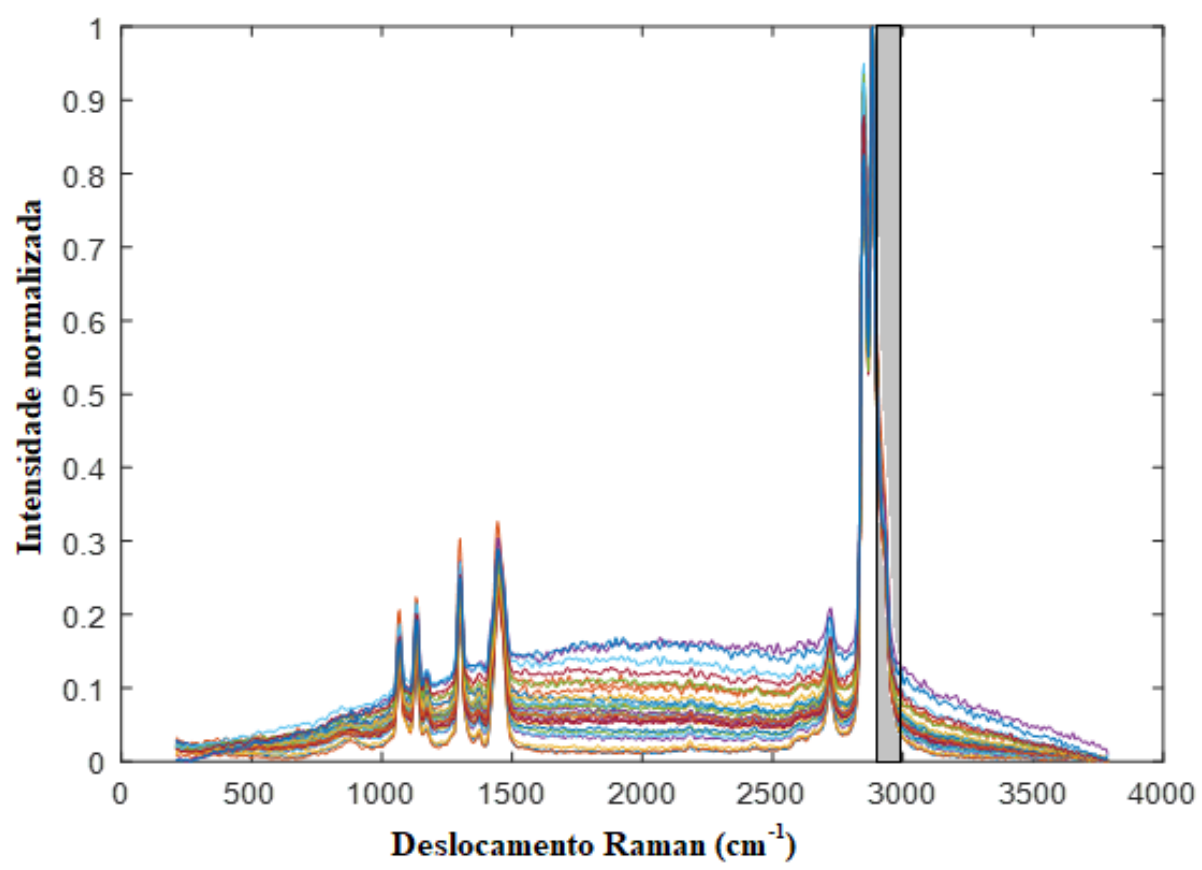

Figura 48 - Espectros Raman das blendas de PEAD/PEBD obtidas com polímeros reciclados. A região do espectro selecionada pelo modelo iPLS30R está destacada em cinza. 


\subsubsection{Regressão CARS-PLS}

De acordo com os resultados da Tabela 13, a centralização média é o método de préprocessamento mais adequado para a construção dos modelos de predição usando CARS-PLS e espectros Raman. Isto porque o modelo PLSR-C apresentou o maior valor de $R_{\text {pred }}(0,979)$ e também mostra o menor erro de predição (RMSEP $=4,062 \%$ p de PEBD) do que os modelos PLSRa, PLSR-A e PLSR-P.

Tabela 13 - Modelos preditivos com melhor desempenho usando regressão CARS-PLS e espectros Raman, préprocessados por diferentes métodos (parâmetros constantes: número máximo de variáveis latentes para validação cruzada = 20; validação cruzada K-fold = leave-one-out; amostragem de Monte Carlo = 100 ciclos).

\begin{tabular}{|c|c|c|c|c|c|c|}
\hline Modelo & $\begin{array}{c}\text { Pré- } \\
\text { tratamento }\end{array}$ & $\mathrm{LV}_{\text {ótimo }}$ & $\begin{array}{c}\text { RMSECV (\%p } \\
\text { de PEBD) }\end{array}$ & $\mathrm{R}_{\text {calib }}$ & $\begin{array}{l}\text { RMSEP } \\
\text { (\%p de } \\
\text { PEBD) }\end{array}$ & $\mathrm{R}_{\text {pred }}$ \\
\hline PLSRa & - & 20 & 0,147 & 1,000 & 6,899 & 0,939 \\
\hline PLSR-C & $\begin{array}{c}\text { Centralização } \\
\text { média }\end{array}$ & 19 & 0,329 & 0,999 & 4,062 & 0,979 \\
\hline PLSR-A & Autoescalado & 20 & 0,158 & 1,000 & 6,504 & 0,946 \\
\hline PLSR-P & Pareto & 15 & 0,765 & 0,999 & 5,146 & 0,966 \\
\hline
\end{tabular}

De acordo com a Tabela 14, não há melhora no desempenho de predição ou calibração dos modelos CARS-PLS usando mais de 5-fold, visto que o erro RMSEP é igual ao valor obtido pela validação cruzada por leave-one-out (RMSEP $=4,062 \%$ p de PEBD). Nesta condição de K-fold, os coeficientes de ajustes também não exibem variações, tanto para o conjunto de dados de calibração $\left(R_{\text {calib }}=0,999\right)$, quanto para o de predição $\left(R_{\text {pred }}=0,979\right)$. Além disso, o número ótimo de variáveis latentes fica com um valor constante, igual a 19.

Os resultados da Tabela 15 mostram que RMSECV diminui e $\mathrm{R}_{\text {calib aumenta à medida }}$ que o número máximo de variáveis latentes para validação cruzada aumenta. Sendo que, o resultado mínimo de RMSECV obtido foi 0,039 \% p de PEBD para o modelo PLSR-40 construído com 34 LVs. No entanto, os resultados de RMSEP não apresentam uma relação linear com a quantidade de LVs usada no modelo de predição. 
Tabela 14 - Modelos preditivos com melhor desempenho obtidos por regressão CARS-PLS e espectros Raman, usando diferentes valores de K-fold para validação cruzada (parâmetros constantes: pré-tratamento = centralização média; número máximo de variáveis latentes para validação cruzada = 20; amostragem de Monte Carlo = 100 ciclos).

\begin{tabular}{ccccccc}
\hline Modelo & $\begin{array}{c}\text { Validação } \\
\text { cruzada por } \\
\text { K-Fold }\end{array}$ & LV otimo $^{\text {RMSECV }}$ & $\begin{array}{c}\text { RMSEP } \\
(\% \mathrm{p} \mathrm{de} \\
\text { PEBD })\end{array}$ & $\mathrm{R}_{\text {calib }}$ & $\begin{array}{c}\text { (\%p de } \\
\text { PEBD })\end{array}$ & $\mathrm{R}_{\text {pred }}$ \\
\hline PLSR-C2 & 2 & 20 & 0,803 & 0,999 & 4,997 & 0,968 \\
PLSR-C5 & 5 & 19 & 0,329 & 0,999 & 4,062 & 0,979 \\
PLSR-C15 & 15 & 19 & 0,329 & 0,999 & 4,062 & 0,979 \\
PLSR-C20 & 20 & 19 & 0,329 & 0,999 & 4,062 & 0,979 \\
\hline
\end{tabular}

Tabela 15 - Modelos preditivos com melhor desempenho obtidos por regressão CARS-PLS e espectros Raman, usando vários valores de LVs (parâmetros constantes: pré-tratamento = centralização média; validação cruzada $\mathrm{K}$-fold = 15; amostragem de Monte Carlo = 100 ciclos).

\begin{tabular}{ccccccc}
\hline Modelo & $\begin{array}{c}\text { Número de } \\
\text { LVs }\end{array}$ & LV ótimo $^{\text {RMSECV }}$ & $\begin{array}{c}\text { RMSEP } \\
(\% \mathrm{p} \text { de } \\
\text { PEBD })\end{array}$ & $\mathrm{R}_{\text {calib }}$ & $\begin{array}{c}(\% \mathrm{p} \text { de } \\
\text { PEBD })\end{array}$ & $\mathrm{R}_{\text {pred }}$ \\
\hline PLSR-5 & 5 & 5 & 6,911 & 0,948 & 8,017 & 0,918 \\
\hline PLSR-10 & 10 & 8 & 2,951 & 0,991 & 5,521 & 0,961 \\
\hline PLSR-30 & 30 & 21 & 0,145 & 1,000 & 6,083 & 0,953 \\
\hline PLSR-40 & 40 & 34 & 0,039 & 1,000 & 6,139 & 0,952 \\
\hline
\end{tabular}

Foram construídos modelos preditivos com 50 a 10000 ciclos de amostragem Monte Carlo, os resultados obtidos estão mostrados na Figura 49. Para tanto, os outros parâmetros de regressão CARS-PLS foram mantidos constantes conforme legenda desta figura. Todos modelos preditivos mostram bons resultados para $R_{\text {pred }}$ (superior a 0,9 ) e excelentes resultados para $\mathrm{R}_{\text {calib }}(0,999)$. O maior erro de calibração e predição foi identificado para o modelo CARSPLS construído com 50 ciclos, provavelmente devido à pequena quantidade de passos para pesquisar as mudanças principais do espectro Raman e, assim, configurar um modelo preditivo com uma performance preditiva mais robusta. 
(a)

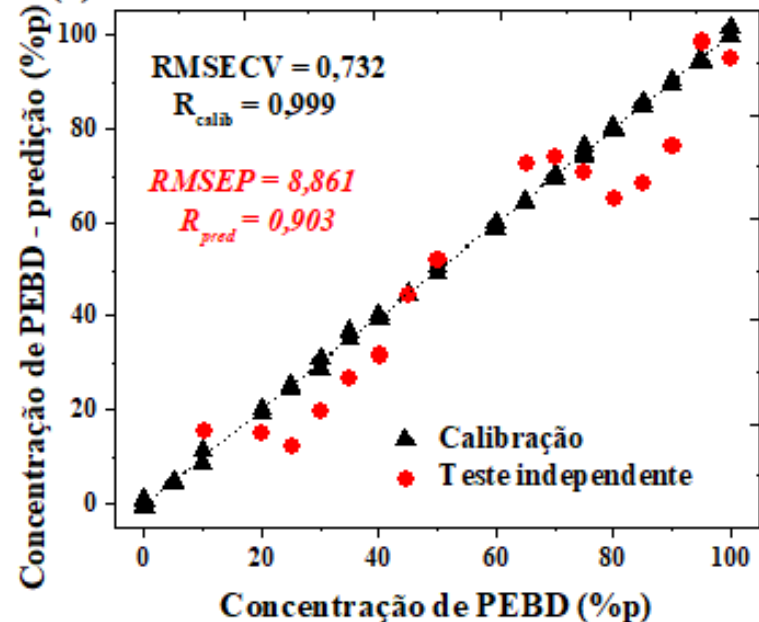

(c)
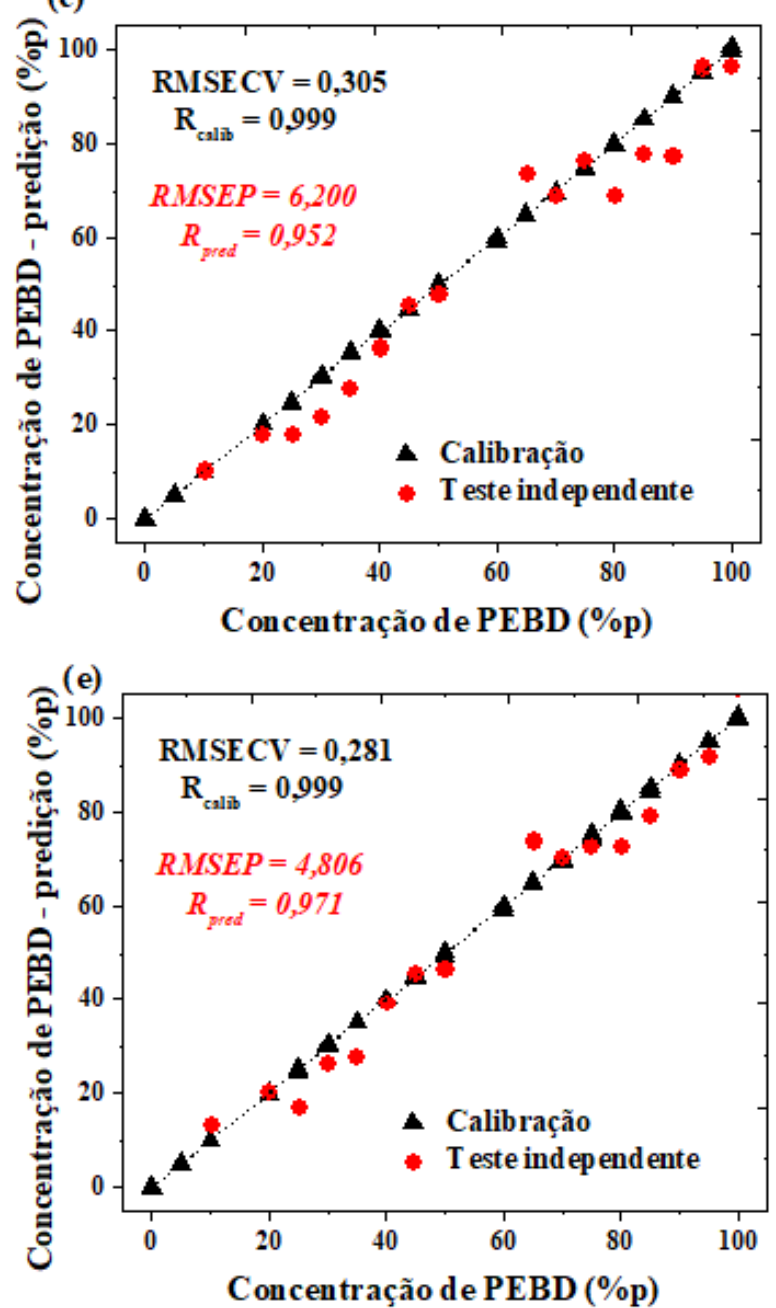

(b)
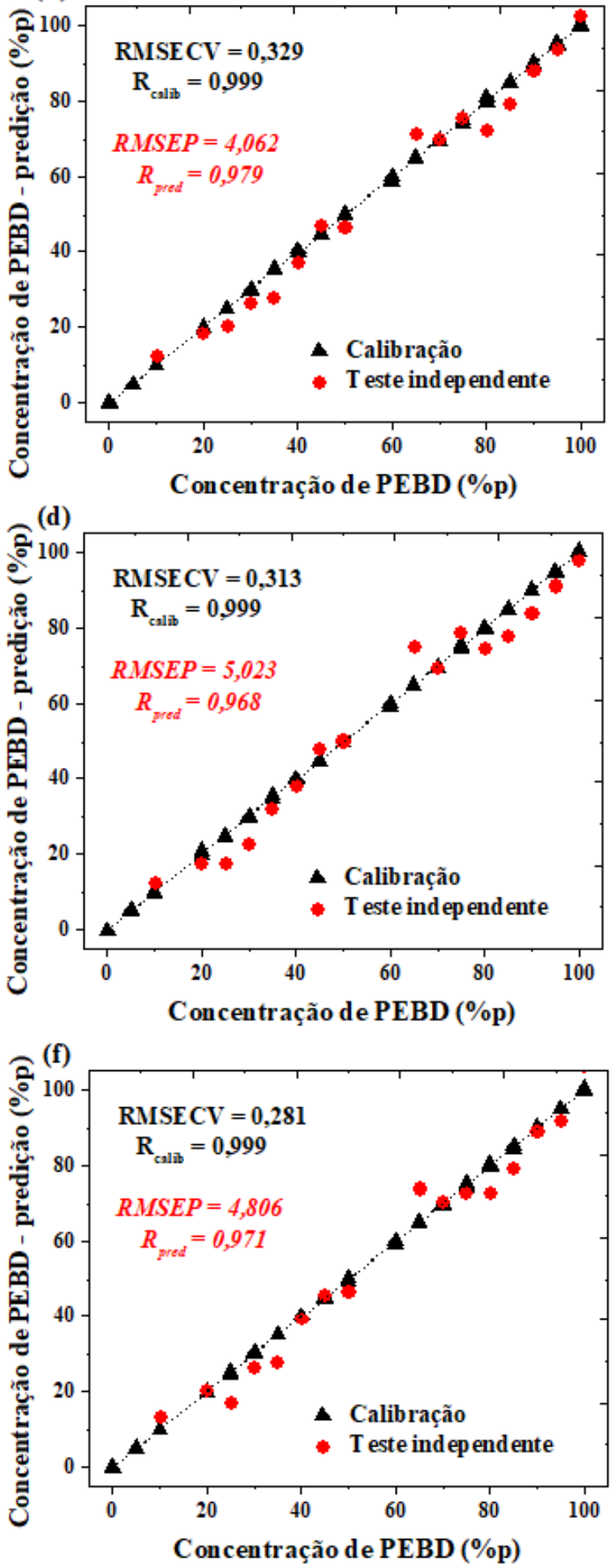

Figura 49 - Referência vs. predição do teor de PEBD (\% p) nas blendas de PEAD/PEBD (material pristino e dados de

Raman confocal). Dados obtidos com regressão CARS-PLS, usando vários números de ciclos de amostragem de Monte Carlo: (a) 50, (b) 100, (c) 500, (d) 1000, (e) 5000 e (f) 10000. (Parâmetros constantes: método de pré-tratamento = centralização média; validação cruzada K-fold = 15; número máximo de LVs = 20).

Os resultados dos modelos CARS-PLS montados com mais de 100 ciclos de amostragem (Figura 49) mostram evidentemente que a redução RMSECV não melhora 
necessariamente a capacidade preditiva do modelo de predição, isto é, não leva à redução do valor RMSEP. Além disso, todos os erros estatísticos dos modelos CARS-PLS são constantes, quando são utilizados mais de 5000 ciclos de amostragem (RMSEP = 0,281 e RMSECV = 4,806 \%p de PEBD). Todos os modelos baseados em CARS-PLS e dados espectrais Raman foram construídos com os deslocamentos Raman a $2883 \mathrm{~cm}^{-1}$ (fases de polietileno amorfo e cristalino) e $1445 \mathrm{~cm}^{-1}$ (apenas a partir da fase cristalina de PE), além de outros trinta e um pontos.

O modelo PLSR-C15 é um dos modelos de predição que apresentaram o melhor desempenho na predição do teor de PEBD, usando os dados espectrais Raman e regressão CARS-PLS. Portanto, ele foi selecionado para predizer o teor do PEBD nas blendas de PEAD/PEBD provenientes de materiais originados de resíduos pós-consumo reciclados. Os resultados desta análise estão mostrados na Figura 50, sendo o valor obtido para RMSEP superior a $29 \%$ p de PEBD e o $\mathrm{R}_{\text {pred }}$ inferior a 0,4. O desempenho é similar ao observado para o modelo PLS-C20 (construído com dados ATR-FTIR e algoritmo CARS-PLS), os resultados preditos ficaram deslocados (aproximadamente em $30 \%$ de PEBD) em relação à linha de regressão.

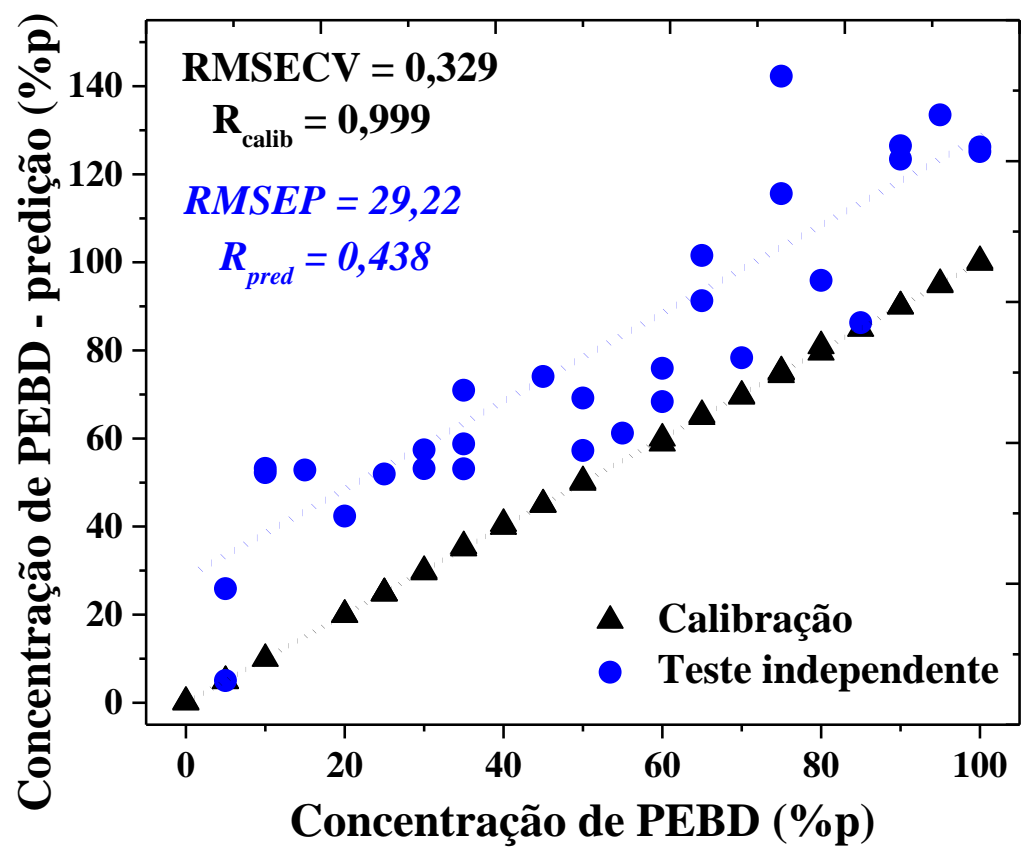

Figura 50 - Referência vs. previsão de teor de PEBD (\% p) nas blendas de PEAD/PEBD (material reciclado). Dados obtidos com o modelo PLSR-C15. 


\subsubsection{Desempenho do modelo preditivo para misturas poliméricas recicladas contendo diferentes contaminantes}

No caso da espectroscopia Raman confocal, o modelo de predição que apresentou melhor desempenho para identificar a composição das blendas recicladas de PEAD/PEBD foi o modelo iPLS30R. De acordo com a Figura 51, a incerteza da predição da composição das misturas poliméricas recicladas aumentaram em mais de 100\% quando elas estão contaminadas com calcita, PP, PET e sílica, atingindo valores de RMSEP acima de $11 \%$ p para a concentração de PEBD. Estes resultados estão relacionados com: (1) o aumento da rugosidade superficial $\mathrm{R}_{\mathrm{q}}$ dos péletes (Figura 42); (2) significativa fluorescência das amostras durante as medidas espectrais de espalhamento Raman, conforme mostrado nos espectros presentes no Apêndice C.

(a)

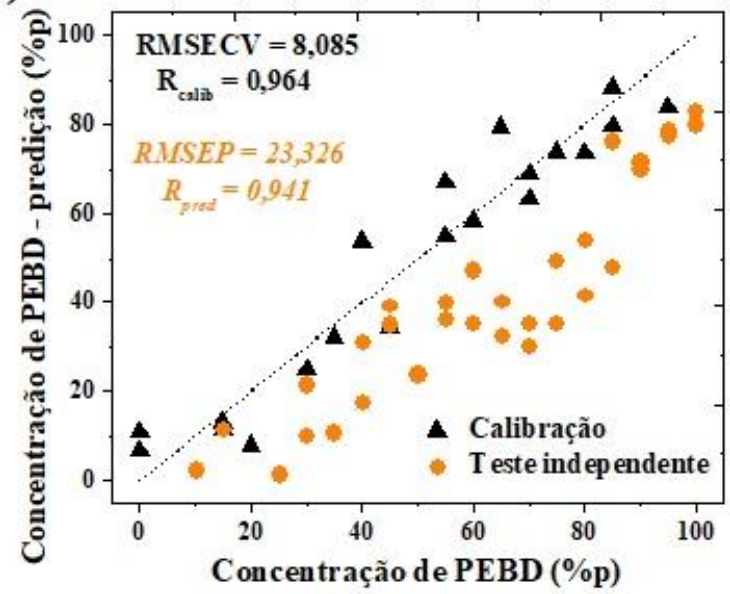

(c)

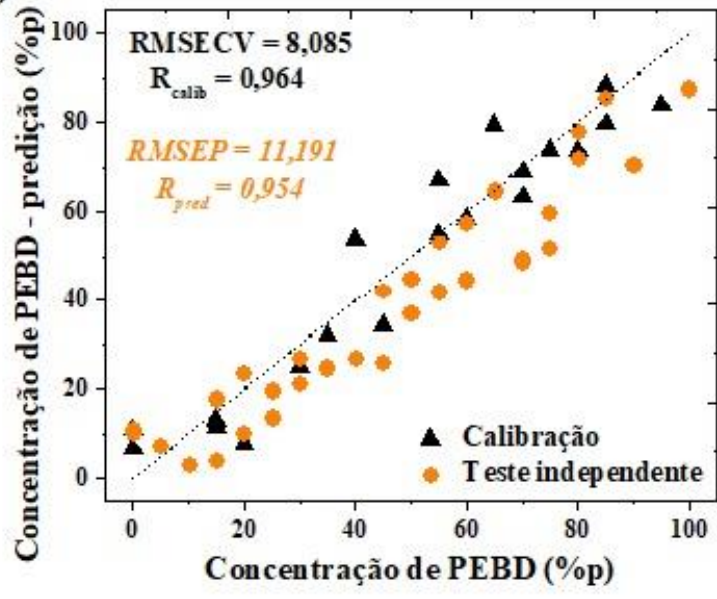

(b)

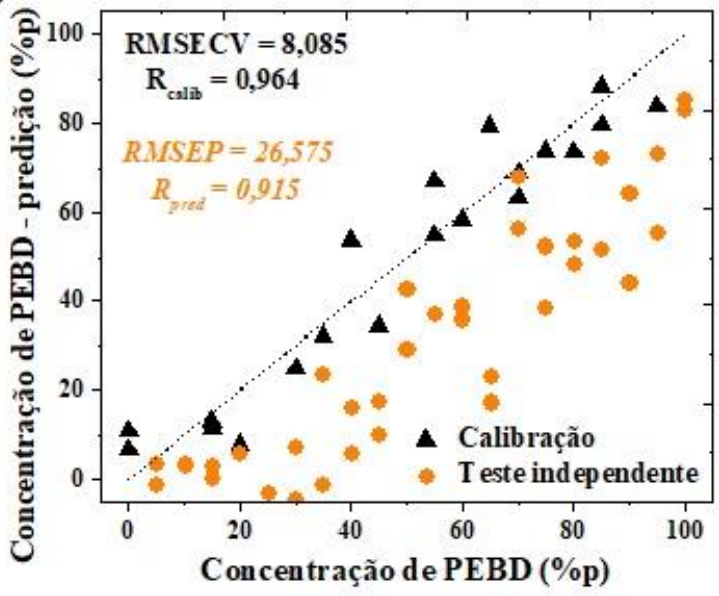

(d)

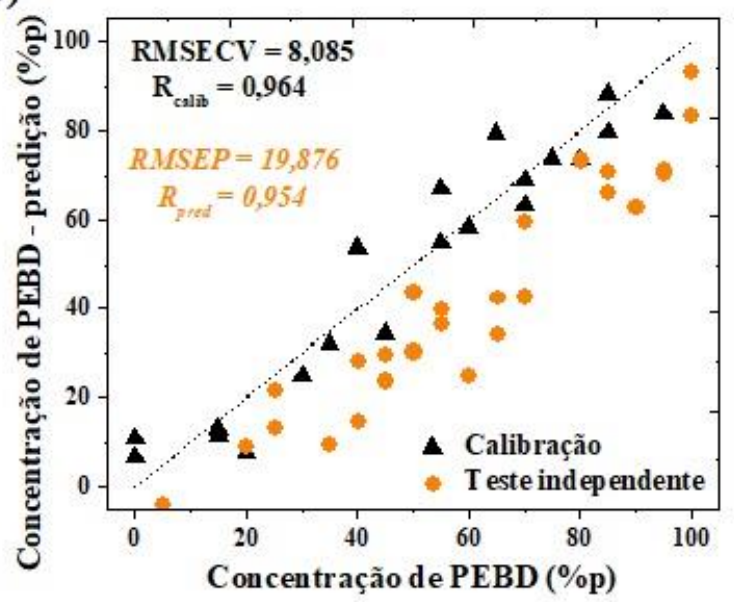

Figura 51 - Referência vs. previsão do teor de PEBD (\% p) nas blendas poliméricas de PEAD/PEBD (material reciclado). Dados obtidos com o modelo iPLS30R e dados espectrais Raman. As misturas poliméricas recicladas contêm 5 \% p de diferentes contaminante: (a) $\mathrm{CaCO}_{3}$, (b) PET, (c) PP e (d) sílica gel. 
A fluorescência é um dos principais desafios na espectroscopia de espalhamento Raman devido ao fato de que normalmente apenas 1 entre $10^{6}$ a $10^{8}$ fótons incidentes na amostra sofrem espalhamento inelástico. Desta forma, a detecção de tais sinais fracos de espalhamento Raman é frequentemente influenciada, e até mesmo impedida, pela presença de sinais de fluorescência que são mais intensos (MAZILU et al., 2010). Embora, o processo de relaxação vibracional no espalhamento é um processo que ocorre em femtossegundos $\left(10^{-15} \mathrm{~s}\right)$, enquanto que o processo de fluorescência envolve uma escala de tempo de nanossegundos $\left(10^{-9} \mathrm{~s}\right)$ (TOPORSKI, 2018).

A intensidade de fluorescência pode ser facilmente 6 ordens de magnitude superior àquela observada no espalhamento Raman. $\mathrm{O}$ fenômeno de fluorescência ocorre, majoritariamente, se o nível vibracional virtual (intermediário) da molécula se sobrepuser ao seu menor nível de energia eletrônico excitado (Regra de Kasha) (TOPORSKI, 2018). Assim, com o aumento da energia do laser (comprimentos de onda mais curtos), aumenta-se a probabilidade de fluorescência porque estes níveis energéticos (vibracional e eletrônico) ficam mais próximos.

Além destas características físico-químicas que causam fluorescência da amostra, a rugosidade superficial e as partículas contaminantes presentes nos péletes das blendas de PEBD/PEAD intensificam a fluorescência. Isto porque, a rugosidade leva à formação de outros estados vibracionais no material associados a oscilações de plasmons superficiais (SANT'ANA; CORIO; TEMPERINI, 2006), enquanto que impurezas adicionam novos níveis vibracionais tanto plasmons da própria impureza quanto de moléculas diferentes daquelas presentes na amostra pura (REJOWSKI, 2012).

Pelos dados apresentados nas Figuras 41 e 51, é evidente que os modelos preditivos iPLS30R e iPLS30 apresentam pouca eficiência de predição de composição para blendas poliméricas de PEBD/PEAD contendo contaminantes em concentrações consideravelmente elevadas. Portanto, são modelos altamente limitados para serem aplicados na caracterização e classificação de resíduos poliméricos de polietilenos presentes em RSUs, visto que os mesmos são comumente muito heterogêneos com grande quantidade de aditivos. 


\section{CONCLUSÕES}

Nesta pesquisa de doutorado foi mostrado que é possível quantificar a composição de blendas de PEAD/PEBD (em toda a sua faixa de composição. 0-100 \%p de PEAD) através de espectroscopias vibracionais Raman confocal e ATR-FTIR, usando diferentes métodos de regressão linear PLS.

O ajuste de curva da banda de absorção na região de 1340 a $1390 \mathrm{~cm}^{-1}$ do espectro ATR-FTIR, através de função Gaussiana (método não linear), mostrou-se efetiva para diferenciar PEBD, PEAD e suas misturas.

O PEAD e o PEBD reciclados apresentaram diferentes impurezas, porém em baixa concentração $(<1 \%$ p). Além disso, eles possuem grau de cristalinidade similar aos seus respectivos polietilenos pristinos.

Nos testes de validação externa usando blendas oriundas de polietilenos pristinos, os modelos preditivos construídos com regressões PLS e iPLS e dados de espectrais Raman apresentaram erro de predição (RMSEP) no intervalo de 17,3 a 9,4 \% p de PEBD, enquanto que aqueles construídos com ATR-FTIR mostraram RMSEP no intervalo de 8,3 a 5,6 \%p de PEBD.

Para ambas espectroscopias vibracionais, os modelos baseados em iPLS apresentam erros de previsão menores do que os modelos baseados em regressão PLS e, além disso, mostraram bom desempenho na predição do teor de PEBD (RMSEP entre 5 e $6 \%$ p) em blendas de PEAD/PEBD obtidas com polietilenos oriundos de resíduos pós-consumo reciclados mecanicamente.

Tanto para a espectroscopia ATR-FTIR quanto para a espectroscopia Raman confocal, os parâmetros de regressão CARS-PLS influenciam significativamente nos valores de RMSECV e RMSEP dos seus modelos preditivos. Nas condições avaliadas, o método de préprocessamento de dados autoescalado favoreceu a redução dos erros de calibração, enquanto o método de centralização média melhorou o desempenho de predição dos modelos. O aumento do valor de K-fold e do número máximo de LVs causaram uma redução dos valores de RMSEP

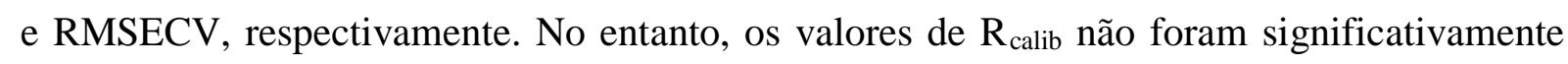
afetados por estas variáveis de regressão. O número ótimo de ciclos para amostragem de Monte Carlo foi igual a 100; acima deste valor, os modelos preditivos CARS-PLS apresentaram uma diminuição em RMSEP.

No teste de predição usando blendas obtidas com polímeros pristinos, os modelos preditivos obtidos por CARS-PLS exibiram RMSEP entre: 4,8-6,5 \%p de PEBD, para os dados de ATR-FTIR; 4,06-8,87 \%p de PEBD, para dados espectrais Raman confocal. Contudo, o 
desempenho de predição foi muito baixo para amostras recicladas mecanicamente, visto que os erros de predição são superiores a $25 \%$ p de PEBD.

Nos testes usando dados espectrais de Raman confocal e de ATR-FTIR das misturas poliméricas recicladas de PEBD/PEAD contendo $5 \%$ de PP, PET, sílica e carbonato de cálcio, os modelos preditivos baseados em regressão iPLS apresentaram erros de predição entre 11 \% e $27 \%$ de PEBD. Apenas para as amostras contento sílica, o modelo preditivo iPLS30 (construído com dados de ATR-FTIR) exibiu RMSEP próximo a 8 \%p de PEBD.

Em geral, a regressão CARS-PLS possibilita obter modelos preditivos altamente calibrados, com os menores erros de calibração, mas com baixa capacidade de prever o teor de PEBD nas misturas poliméricas de PEBD/PEAD (pristinas ou recicladas). Em contrapartida, a regressão iPLS fornece os modelos preditivos com melhor desempenho para prever a composição destas blendas pristinas, embora a regressão iPLS não apresente alta eficiência para calibração dos modelos preditivos como a regressão CARS-PLS. 


\section{REFERÊNCIAS BIBLIOGRÁFICAS}

ACHILIAS, D. S. (ED.). Material Recycling - Trends and Perspectives. Rijeka: InTech, 2012.

AL-SAEED, T. A.; KHALIL, D. A. Signal-to-noise ratio calculation in a moving-opticalwedge spectrometer. Applied Optics, v. 51, n. 30, p. 7206, 20 out. 2012.

AL-SALEM, S. M. et al. A review on thermal and catalytic pyrolysis of plastic solid waste (PSW). Journal of Environmental Management, v. 197, n. 1408, p. 177-198, jul. 2017.

AL-SALEM, S. M.; LETTIERI, P.; BAEYENS, J. Recycling and recovery routes of plastic solid waste (PSW): A review. Waste Management, v. 29, n. 10, p. 2625-2643, 2009.

AL-SALEM, S. M.; LETTIERI, P.; BAEYENS, J. The valorization of plastic solid waste (PSW) by primary to quaternary routes: From re-use to energy and chemicals. Progress in Energy and Combustion Science, v. 36, n. 1, p. 103-129, 2010.

ALLEN, V.; KALIVAS, J. H.; RODRIGUEZ, R. G. Post-Consumer Plastic Identification Using Raman Spectroscopy. Applied Spectroscopy, v. 53, n. 6, p. 672-681, 1999.

ALVES, R. B. Desenvolvimento de nanocompósito de polietileno de baixa densidade pósconsumo reciclado/bentonita (Dissertação de mestrado). Universidade Federal de Pernambuco, 2008.

ANDO, R. A. Espectroscopia Vibracional, Raman Ressonante e Eletrônica de Nitroderivados em Sistemas Conjugados (Dissertação de mestrado). Universidade de São Paulo, 2005.

ASHTON, E. G. et al. Recycling polymeric multi-material products through micronization. Journal of Cleaner Production, v. 116, p. 268-278, 2015.

BABAGHAYOU, M. I. et al. Photodegradation characterization and heterogeneity evaluation of the exposed and unexposed faces of stabilized and unstabilized LDPE films. Materials \& Design, v. 111, p. 279-290, 2016.

BANERJEE, S. et al. Scanning Electron Microscopy Measurements of the Surface Roughness of Paper. Industrial \& Engineering Chemistry Research, v. 48, n. 9, p. 4322-4325, 6 maio 2009.

BANNACH, G. et al. Efeitos da história térmica nas propriedades do polímero PET: Um experimento para ensino de análise térmica. Quimica Nova, v. 34, n. 10, p. 1825-1829, 2011. 
BARHAM, P. J. et al. Phase separation in polyethylene melts. Journal of Materials Science Letters, v. 7, n. 12, p. 1271-1275, dez. 1988.

BARROS, N. G. DE. Propriedades de material polimérico obtido da reciclagem de embalagens multicamadas (Dissertação de mestrado). Universidade Estadual de Campinas, 2013.

BENTLEY, P. .; HENDRA, P. . Polarised FT Raman studies of an ultra-high modulus polyethylene rod. Spectrochimica Acta Part A: Molecular and Biomolecular Spectroscopy, v. 51, n. 12, p. 2125-2131, nov. 1995.

BILLMEYER, F. W. Textbook of polymer science. 3. ed. New York: John Wiley \& Sons, Inc., 1984.

BORAH, J. S.; KIM, D. S. Recent development in thermoplastic/wood composites and nanocomposites: A review. Korean Journal of Chemical Engineering, v. 33, n. 11, p. 3035-3049, 19 nov. 2016.

BOROVANSKA, I. et al. Quality assessment of recycled and modified LDPE/PP blends. Journal of Elastomers \& Plastics, v. 44, n. 6, p. 479-497, 5 nov. 2012.

BRUNEEL, J. L.; LASSÈGUES, J. C.; SOURISSEAU, C. In-depth analyses by confocal Raman microspectrometry: experimental features and modeling of the refraction effects. Journal of Raman Spectroscopy, v. 33, n. 10, p. 815-828, out. 2002.

BUMBRAH, G. S.; SHARMA, R. M. Raman spectroscopy - Basic principle, instrumentation and selected applications for the characterization of drugs of abuse. Egyptian Journal of Forensic Sciences, v. 6, n. 3, p. 209-215, set. 2016.

BURNHAM, A. J.; VIVEROS, R.; MACGREGOR, J. F. Frameworks for latent variable multivariate regression. Journal of Chemometrics, v. 10, p. 31-45, 1996.

CALLISTER, W. D. J. Ciência e Engenharia dos Materiais: Uma introdução. 7. ed. Rio de Janeiro: LTC, 2008.

CANEVAROLO JR., S. V. Ciência dos polímeros: um texto básico para tecnológos e engenheiros. 2. ed. São Carlos: Artliber, 2006.

CARO, E.; COMAS, E. Polyethylene comonomer characterization by using FTIR and a multivariate classification technique. Talanta, v. 163, n. June 2016, p. 48-53, 2017.

CEMPRE. Compromisso Empresarial para Reciclagem. Review 2015. São Paulo, 2015. CHINGA, G. et al. Quantification of the 3D microstructure of SC surfaces. Journal of 
Microscopy, v. 227, n. 3, p. 254-265, set. 2007.

COLTRO, L.; DUARTE, L. C. Reciclagem de embalagens plásticas flexíveis: contribuição da identificação correta. Polímeros, v. 23, n. 1, p. 128-134, 1 fev. 2013.

COSTA, R. C. Determinação de parâmetros (sólidos solúveis, pH e acidez titulável) em ameixas intactas usando espectroscopia no infravermelho próximo e seleção de comprimento de onda (Dissertação de mestrado). Universidade Federal do Rio Grande do Norte, 2013.

COUTINHO, F. M. B.; MELLO, I. L.; SANTA MARIA, L. C. DE. Polietileno: principais tipos, propriedades e aplicações. Polímeros, v. 13, n. 1, p. 1-13, jan. 2003.

DA SILVA, D. J. et al. Polycarbonate $/ \mathrm{TiO}_{2}$ nanofibers nanocomposite: Preparation and properties. Polymer Composites, v. 39, n. S2, p. E780-E790, 21 maio 2018.

DA SILVA, D. J.; WIEBECK, H. Using PLS, iPLS and siPLS linear regressions to determine the composition of LDPE/HDPE blends: A comparison between confocal Raman and ATRFTIR spectroscopies. Vibrational Spectroscopy, v. 92, p. 259-266, 2017.

DAHLBO, H. et al. Recycling potential of post-consumer plastic packaging waste in Finland. Waste Management, v. 71, p. 52-61, jan. 2018.

DE PAIVA, L. B.; MORALES, A. R.; VALENZUELA DÍAZ, F. R. Organoclays: Properties, preparation and applications. Applied Clay Science, v. 42, n. 1-2, p. 8-24, 2008.

DE PAOLI, M.-A. Degradação e Estabilização de Polímeros. 2. ed. Chemkeys, 2008.

DENG, J. et al. Fourier Spectrometer based on a wide-range and nanometer stabilized

Michelson Interferometer. Advances in Optoelectronics and Micro/nano-optics.

Anais...Guangzhou, China: IEEE, dez. 2010

EMBER, K. J. I. et al. Raman spectroscopy and regenerative medicine: a review. npj

Regenerative Medicine, v. 2, n. 1, p. 12, 15 dez. 2017.

ESLAMIAN, M.; BAGHERI, R.; PIRCHERAGHI, G. Co-crystallization in ternary polyethylene blends: tie crystal formation and mechanical properties improvement. Polymer International, v. 65, n. 12, p. 1405-1416, 2016.

EVERALL, N. Depth Profiling With Confocal Raman Microscopy, Part I. Spectroscopy, v. 19, n. 11, p. 16-27, 2004a.

EVERALL, N. Depth Profiling With Confocal Raman Microscopy, Part II. Spectroscopy, v. 19, n. 11, p. 16-24, 2004b. 
FAN, Z. J.; WILLIAMS, M. C.; CHOI, P. A molecular dynamics study of the effects of branching characteristics of LDPE on its miscibility with HDPE. Polymer, v. 43, n. 4, p. 1497-1502, fev. 2002.

FEL, E. et al. Comparative study of gamma-irradiated PP and PE polyolefins part 2:

Properties of PP/PE blends obtained by reactive processing with radicals obtained by high shear or gamma-irradiation. Polymer, v. 82, p. 217-227, jan. 2016.

FERRÃO, M. F. et al. Simultaneous determination of quality parameters of biodiesel/diesel blends using HATR-FTIR spectra and PLS, iPLS or siPLS regressions. Fuel, v. 90, n. 2, p. 701-706, 2011.

FORD, H. D. et al. Comparative signal-to-noise analysis of fibre-optic based optical coherence tomography systems. Journal of Modern Optics, v. 52, n. 14, p. 1965-1979, 20 set. 2005 .

FREDERICCI, C. et al. Aplicação da espectroscopia Raman na identificação de minerais asbestiformes. Revista IPT - Tecnologia e Inovação, p. 13-20, 2016.

GALL, M. J. et al. The laser-Raman spectrum of polyethylene. The assignment of the spectrum to fundamental modes of vibration. Spectrochimica Acta Part A: Molecular Spectroscopy, v. 28, n. 8, p. 1485-1496, 1972.

GANDINI, A.; CHERADAME, H. Long Term Properties of Polyolefins. Berlin, Heidelberg: Springer Berlin Heidelberg, 2004. v. 169

GOMES, A. D. A. Algoritmo das Projeções Sucessivas aplicado à seleção de variáveis em regressão PLS (Dissertação de mestrado). Universidade Federal da Paraíba, 2012.

GULMine, J. V. et al. Polyethylene characterization by FTIR. Polymer Testing, v. 21, n. 5, p. 557-563, 2002.

GULMINE, J. V. et al. Degradation profile of polyethylene after artificial accelerated weathering. Polymer Degradation and Stability, v. 79, n. 3, p. 385-397, 2003.

HAGEMANN, H. et al. Quantitative infrared methods for the measurement of crystallinity and its temperature dependence: polyethylene. Macromolecules, v. 22, n. 9, p. 3600-3606, set. 1989 .

HAHLADAKIS, J. N. et al. An overview of chemical additives present in plastics: Migration, release, fate and environmental impact during their use, disposal and recycling. Journal of Hazardous Materials, v. 344, p. 179-199, fev. 2018. 
HAMAD, K.; KASEEM, M.; DERI, F. Recycling of waste from polymer materials: An overview of the recent works. Polymer Degradation and Stability, v. 98, n. 12, p. 2801$2812,2013$.

HASSEL, P. A. Nonlinear Partial Least Squares (Tese de doutorado). University of Newcastle upon Tyne, 2003.

HIND, A. R.; BHARGAVA, S. K.; MCKINNON, A. At the solid/liquid interface: FTIR/ATR — the tool of choice. Advances in Colloid and Interface Science, v. 93, n. 1-3, p. 91-114, out. 2001.

HORODYTSKA, O.; VALDÉS, F. J.; FULLANA, A. Plastic flexible films waste management - A state of art review. Waste Management, v. 77, p. 413-425, jul. 2018. HU, B. et al. Recycling-oriented characterization of polyolefin packaging waste. Waste Management, v. 33, n. 3, p. 574-584, mar. 2013.

IGNATYEV, I. A.; THIELEMANS, W.; VANDER BEKE, B. Recycling of Polymers: A Review. ChemSusChem, v. 7, n. 6, p. 1579-1593, jun. 2014.

ILYIN, S. O. et al. Phase behavior and rheology of miscible and immiscible blends of linear and hyperbranched siloxane macromolecules. Materials Today Communications, v. 22, n. November 2019, p. 100833, mar. 2020.

ISAYEV, A. I. Encyclopedia of Polymer Blends, Volume 1: Fundamentals. Weinheim, Germany: Wiley-VCH, 2010.

JASSIM, A. K. Recycling of Polyethylene Waste to Produce Plastic Cement. Procedia Manufacturing, v. 8, p. 635-642, 2017.

KAZEMI NAJAFI, S. Use of recycled plastics in wood plastic composites - A review. Waste Management, v. 33, n. 9, p. 1898-1905, set. 2013.

LACOT, E. et al. Comparative study of autodyne and heterodyne laser interferometry for imaging. Journal of the Optical Society of America A, v. 27, n. 11, p. 2450, 1 nov. 2010.

LI, H. et al. Key wavelengths screening using competitive adaptive reweighted sampling method for multivariate calibration. Analytica Chimica Acta, v. 648, n. 1, p. 77-84, ago. 2009.

LI, H.; XU, Q.; LIANG, Y. libPLS: An Integrated Library for Partial Least Squares Regression and Discriminant Analysis. PeerJ PrePrints, v. 2, p. e190v1, 2014. LIU, C.; WANG, J.; HE, J. Rheological and thermal properties of m-LLDPE blends with m- 
HDPE and LDPE. Polymer, v. 43, n. 13, p. 3811-3818, 2002.

LOPES, F. N. Espectroscopia Raman aplicada ao estudo de pigmentos em bens culturais: I - Pinturas rupestres (Dissertação de mestrado). Universidade de São Paulo, 2005.

LUIJSTERBURG, B.; GOOSSENS, H. Assessment of plastic packaging waste: Material origin, methods, properties. Resources, Conservation and Recycling, v. 85, p. 88-97, 2014. MARTÍNEZ-ROMO, A. et al. Investigating the Degradability of HDPE, LDPE, PE-BIO, and PE-OXO Films under UV-B Radiation. Journal of Spectroscopy, v. 2015, p. 1-6, 2015.

MAZILU, M. et al. Optimal algorithm for fluorescence suppression of modulated Raman spectroscopy. Optics Express, v. 18, n. 11, p. 11382, 24 maio 2010.

MEDEIROS, A. R. B. DE. Uso de ATR/FTIR e FTNIR associado a técnicas quimiométricas para quantificação de aditivos em gasolina automotiva (Dissertação de mestrado). Universidade de Brasília, 2009.

MEHMOOD, T. et al. A review of variable selection methods in Partial Least Squares Regression. Chemometrics and Intelligent Laboratory Systems, v. 118, n. August, p. 6269, ago. 2012.

MEKHZOUM, M. et al. Recent Advances in Polymer Recycling: A Short Review. Current Organic Synthesis, v. 14, n. 2, p. 171-185, 7 fev. 2017.

MILLER, C. E. Use of near-infrared spectroscopy to determine the composition of highdensity/low-density polyethylene blend films. Applied Spectroscopy, v. 47, n. 2, p. 222-228, 1993.

MILlER, J. N.; MILLER, J. C. Statistics and Chemometrics for Analytical Chemistry. 6. ed. Harlow: Pearson Education, 2010.

MITROKA, S. M. et al. Reaction mechanism for oxidation and degradation of high density polyethylene in chlorinated water. Polymer Degradation and Stability, v. 98, n. 7, p. 13691377, jul. 2013.

MOORI, T. M. Desenvolvimento e caracterização de blendas de polipropileno e polietileno modificadas por radiação gama (Dissertação de mestrado). Universidade Presbiteriana Mackenzie, 2014.

MUJICA ASCENCIO, S. et al. Confocal Raman microscopy and multivariate statistical analysis for determination of different penetration abilities of caffeine and propylene glycol applied simultaneously in a mixture on porcine skin ex vivo. European Journal of 
Pharmaceutics and Biopharmaceutics, v. 104, p. 51-58, 2016.

MUNARO, M. Desenvolvimento de blendas de polietileno com desempenho aperfeiçoado para utilização no setor elétrico (Tese de doutorado). Universidade Federal do Paraná, 2007. MUNARO, M.; AKCELRUD, L. Correlations between composition and crystallinity of LDPE/HDPE blends. Journal of Polymer Research, v. 15, n. 1, p. 83-88, 2008.

NEJABAT, G. A theoretical reasoning on why coordination catalysts supported on mesoporous supports can produce HDPE crystalline nanofibers but not iPP crystalline nanofibers. Polyolefins Journal, v. 5, n. 2, p. 153-156, 2018.

NØRGAARD, L. et al. Multivariate near-infrared and Raman spectroscopic quantifications of the crystallinity of lactose in whey permeate powder. International Dairy Journal, v. 15, n. 12, p. 1261-1270, 2005.

NWABUNMA, D.; KYU, T. Polyolefin Blends. New Jersey: John Wiley \& Sons, Inc., 2008. OLIVEIRA, M. C. B. R. DE. Gestão de resíduos plásticos pós-consumo: Perspectivas para a reciclagem no Brasil (Dissertação de mestrado). Universidade Federal do Rio de Janeiro, 2012.

PEACOCK, A. J. Handbook of Polyethylene: Structure, Properties, and Applications. New York: Marcel Dekker, Inc., 2000.

PEREIRA, K. R. DE O. Estudo, em escala de laboratório, do uso de argilas do tipo Bofe na obtenção de argilas organofílicas e ativadas (Dissertação de mestrado). Universidade de São Paulo, 2008.

PERNA, G.; LASALVIA, M.; CAPOZZI, V. Vibrational spectroscopy of synthetic and natural eumelanin. Polymer International, v. 65, n. 11, p. 1323-1330, 2016.

PERSICO, P. et al. Nanocomposite polymer films containing carvacrol for antimicrobial active packaging. Polymer Engineering \& Science, v. 49, n. 7, p. 1447-1455, jul. 2009. PLASTIVIDA. Reciclagem. Disponível em: <http://www.plastivida.org.br/ index.php/pt/conhecimento/19-reciclagem>. Acesso em: 9 fev. 2016.

POLETTO, M. Compósitos termoplásticos com madeira - uma breve revisão. Matheus Poletto, v. 2, n. 4, p. 1-7, 2017.

PONTES, I. F.; ALMEIDA, S. L. M. DE. Talco. Rochas e Minerais Industriais CETEM/2005. 2005. 
POTEKAEV, A. I. et al. The Effect of Microwave Radiation on the Supramolecular Structure of Polypropylene Fiber Materials. Russian Physics Journal, v. 58, n. 12, p. 1741-1746, 25 abr. 2016.

PUIG, C. C. On the cocrystallization phenomenon in blends of high density polyethylene and low density polyethylene. Polymer Bulletin, v. 38, p. 715-720, 1997.

RAGAERT, K.; DELVA, L.; VAN GEEM, K. Mechanical and chemical recycling of solid plastic waste. Waste Management, v. 69, p. 24-58, nov. 2017.

RAHIMI, A.; GARCÍA, J. M. Chemical recycling of waste plastics for new materials production. Nature Reviews Chemistry, v. 1, n. 6, p. 0046, 7 jun. 2017.

REJOWSKI, E. D. Caracterização e desempenho de um filme de carbono amorfo hidrogenado tipo diamante (a-C:H) dopado com Silício, aplicado em camisa de cilindro de motor à combustão interna (Dissertação de mestrado). Instituto de Pesquisas Energéticas e Nucleares, 2012.

ROCHA, F. S. Caracterização metrológica do sistema de medição de deslocamento por interferometria de um espectrômetro FTIR (Dissertação de mestrado). Universidade Federal de Minas Gerais, 2016.

ROCHA, J. T. C. et al. Sulfur Determination in Brazilian Petroleum Fractions by Midinfrared and Near-infrared Spectroscopy and Partial Least Squares Associated with Variable Selection Methods. Energy and Fuels, v. 30, n. 1, p. 698-705, 2016.

ROSIPAL, R. Nonlinear Partial Least Squares An Overview. In: LODHI, H.; YAMANISHI, Y. (Eds.). . Chemoinformatics and Advanced Machine Learning Perspectives. IGI Global, 2011. p. 169-189.

SAFINIA, S.; ALKALBANI, A. Use of Recycled Plastic Water Bottles in Concrete Blocks. Procedia Engineering, v. 164, p. 214-221, 2016.

SANT'ANA, A. C.; CORIO, P.; TEMPERINI, M. L. A. O efeito SERS na análise de traços: o papel das superfícies nanoestruturadas. Química Nova, v. 29, n. 4, p. 805-810, jul. 2006.

SATO, H. et al. Raman spectra of high-density, low-density, and linear low-density polyethylene pellets and prediction of their physical properties by multivariate data analysis. Journal of Applied Polymer Science, v. 86, n. 2, p. 443-448, 10 out. 2002.

SAVITZKY, A.; GOLAY, M. J. E. Smoothing and Differentiation of Data by Simplified Least Squares Procedures. Analytical Chemistry, v. 36, n. 8, p. 1627-1639, 1 jul. 1964. 
SERRANTI, S. et al. An innovative recycling process to obtain pure polyethylene and polypropylene from household waste. Waste Management, v. 35, p. 12-20, jan. 2015. SERRANTI, S.; GARGIULO, A.; BONIFAZI, G. Characterization of post-consumer polyolefin wastes by hyperspectral imaging for quality control in recycling processes. Waste Management, v. 31, n. 11, p. 2217-2227, nov. 2011.

SERRANTI, S.; GARGIULO, A.; BONIFAZI, G. Classification of polyolefins from building and construction waste using NIR hyperspectral imaging system. Resources, Conservation and Recycling, v. 61, p. 52-58, 2012.

SHARMA, R.; BANSAL, P. P. Use of different forms of waste plastic in concrete - a review. Journal of Cleaner Production, v. 112, p. 473-482, jan. 2016.

SHEN, X. et al. Automatic baseline correction method for the open-path Fourier transform infrared spectra by using simple iterative averaging. Optics Express, v. 26, n. 10, p. A609, 14 maio 2018a.

SHEN, X. et al. Study on baseline correction methods for the Fourier transform infrared spectra with different signal-to-noise ratios. Applied Optics, v. 57, n. 20, p. 5794, 10 jul. $2018 b$.

SILVA, D. J. DA; WIEBECK, H. Predicting LDPE/HDPE blend composition by CARS-PLS regression and confocal Raman spectroscopy. Polímeros, v. 29, n. 1, p. e2019010, 18 mar. 2019.

SILVA, F. E. B.; FLORES, É. M. M.; PARISOTTO, G. Green method by diffuse re fl ectance infrared spectroscopy and spectral region selection for the quanti fi cation of sulphamethoxazole and trimethoprim in pharmaceutical formulations. Anais da Academia Brasileira de Ciências, v. 88, p. 1-15, 2016.

SINGH, N. et al. Recycling of plastic solid waste: A state of art review and future applications. Composites Part B: Engineering, v. 115, p. 409-422, 2017.

SKOOG, D. A.; HOLLER, F. J.; CROUCH, S. R. Principles of Instrumental Analysis. 6. ed. Belmont: Thomson Brooks/Cole, 2007.

SNYDER, R. G.; KIM, Y. Conformation and low-frequency isotropic Raman spectra of the liquid n-alkanes C4-C9. The Journal of Physical Chemistry, v. 95, p. 602-610, 1991. SPINACÉ, M. A. DA S.; DE PAOLI, M. A. A tecnologia da reciclagem de polímeros. Química Nova, v. 28, n. 1, p. 65-72, fev. 2005. 
STUART, B. H. Polymer crystallinity studied using Raman spectroscopy. Vibrational Spectroscopy, v. 10, n. 2, p. 79-87, 1996.

TIWARY, C. S. et al. Electronic waste recycling via cryo-milling and nanoparticle beneficiation. Materials Today, v. 20, n. 2, p. 67-73, mar. 2017.

TOPORSKI, J. Confocal Raman Microscopy. 2. ed. Cham: Springer International Publishing, 2018. v. 66

UTRACKI, L. A.; WILKIE, C. A. Polymer Blends Handbook. 2. ed. Dordrecht: Springer Netherlands, 2014.

VAN DEN BERG, R. A. et al. Centering, scaling, and transformations: improving the biological information content of metabolomics data. BMC Genomics, v. 7, n. 142, p. 1-15, 2006.

VAN PUYVELDE, P. et al. Review on morphology development of immiscible blends in confined shear flow. Polymer, v. 49, n. 25, p. 5363-5372, nov. 2008.

VIERA, M. DE S. Qualificação e quantificação de adulterantes em misturas de biodiesel/diesel empregando espectroscopia no infravermelho por reflexão total atenuada e calibração multivariada (Dissertação de mestrado). Universidade de Santa Cruz do Sul, 2011.

WANG, C. et al. Flotation separation of waste plastics for recycling-A review. Waste Management, v. 41, p. 28-38, jul. 2015.

WANG, C.; WANG, H.; HUANG, L. A novel process for separation of polycarbonate, polyvinyl chloride and polymethyl methacrylate waste plastics by froth flotation. Waste Management, v. 65, p. 3-10, jul. 2017.

WOLD, S.; SJÖSTRÖM, M.; ERIKSSON, L. PLS-regression: A basic tool of chemometrics. Chemometrics and Intelligent Laboratory Systems, v. 58, n. 2, p. 109-130, 2001.

YOUNG, R. J.; LOVELL, P. A. Introduction to Polymers. 3. ed. New York: CRC Press, 2011.

YOUSFI, M.; LIVI, S.; DUCHET-RUMEAU, J. Ionic liquids: A new way for the compatibilization of thermoplastic blends. Chemical Engineering Journal, v. 255, p. $513-$ 524, nov. 2014.

ZARE, Y. Recent progress on preparation and properties of nanocomposites from recycled polymers: A review. Waste Management, v. 33, n. 3, p. 598-604, 2013. 
ZHANG, D.; SHEN, Y.; SOMORJAI, G. Studies of surface structures and compositions of polyethylene and polypropylene by IR+visible sum frequency vibrational spectroscopy. Chemical Physics Letters, v. 281, n. December, p. 394-400, 1997.

ZHAO, L.; CHOI, P. A Review of the Miscibility of Polyethylene Blends. Materials and Manufacturing Processes, v. 21, n. 2, p. 135-142, 1 abr. 2006.

ZUBOVA, E. A. Polymorphism and Melting in Crystalline Polyethylene and Alkanes: Molecular Dynamics Simulations. In: PALSULE, S. (Ed.). . Encyclopedia of Polymers and Composites. Berlin, Heidelberg: Springer Berlin Heidelberg, 2013. p. 1-17.

ZUO, X.; FANG, S.; LIANG, X. Synergy interval Partial Least Square (siPLS) with potentiometric titration multivariate calibration for the simultaneous determination of amino acids in mixtures. Advance Journal of Food Science and Technology, v. 6, n. 11, p. 1209$1218,2014$. 


\section{CONSIDERAÇÕES FINAIS}

\subsection{SUGESTÕES PARA TRABALHO FUTUROS}

Deixa-se como sugestões para continuar esta linha de pesquisa:

- Avaliar o desempenho dos modelos de predição em misturas poliméricas de PEAD/PEBD reciclado com outros contaminantes;

- Investigar o uso de laser com comprimento de onda maior que $600 \mathrm{~nm}$ (faixa do espectro eletromagnético no vermelho ou infravermelho) na espectroscopia Raman, reduzindo efeitos de fluorescência das misturas poliméricas de PEBD/PEAD;

- Avaliar o uso da regressão linear PLS e suas modificações para a determinação da composição de outros tipos de misturas poliméricas;

- Avaliar o desempenho de modelos preditivos baseados em métodos não lineares de regressão PLS;

- Avaliar os efeitos da rugosidade superficial das amostras e do tamanho de partículas dos contaminantes inorgânicos sobre a fluorescência das amostras durante as medidas espectroscópicas de Raman confocal.

\subsection{PRODUÇÃO TÉCNICO-CIENTÍFICA}

\subsubsection{Trabalhos publicados}

Publicações aceitas no período vigente do doutorado:

D.J. da Silva, H. Wiebeck, Predicting LDPE/HDPE blend composition by CARS-PLS regression and confocal Raman spectroscopy. Polímeros 2019, 29, e2019010. doi:10.1590/0104-1428.00218.

$\checkmark \quad$ da Silva, D. J.; Wiebeck, H. CARS-PLS Regression and ATR-FTIR Spectroscopy for Eco-Friendly and Fast Composition Analyses of LDPE/HDPE Blends. J. Polym. Res. 2018, 25 (5), 112.

da Silva, D. J.; Wiebeck, H. Using PLS, iPLS and siPLS Linear Regressions to Determine the Composition of LDPE/HDPE Blends: A Comparison between Confocal Raman and ATR-FTIR Spectroscopies. Vib. Spectrosc. 2017, 92, 259-266.

SILVA, D. J.; WIEBECK, H. Uso de espectroscopia Raman confocal e regressão por mínimos quadrados parciais (PLS) para determinar a composição de blendas recicladas de PEBD/PEAD. In: $14^{\circ}$ Congresso Brasileiro de Polímeros, 2017, Águas de Lindóia. 14 Congresso Brasileiro de Polímeros. São Carlos: ABPOL, 2017. v. 16-196. p. 1-5. 


\subsubsection{Trabalhos submetidos}

Publicações submetidas no período vigente do doutorado:

$\checkmark \quad$ Artigo intitulado: "Current options for characterization, sorting and recycling of polymeric waste”. Submissão em 2019.

\subsection{APENNDICES}

7.3.1. Apêndice A - Micrografias da superfície e imagens tridimensionais de superfície das blendas de PEBD/PEAD

As micrografias da superfície dos péletes das blendas de PEBD/PEAD (obtidas com polietilenos pristinos e reciclados) e suas respectivas imagens tridimensionais estão apresentadas nas Figuras 52 a 55.
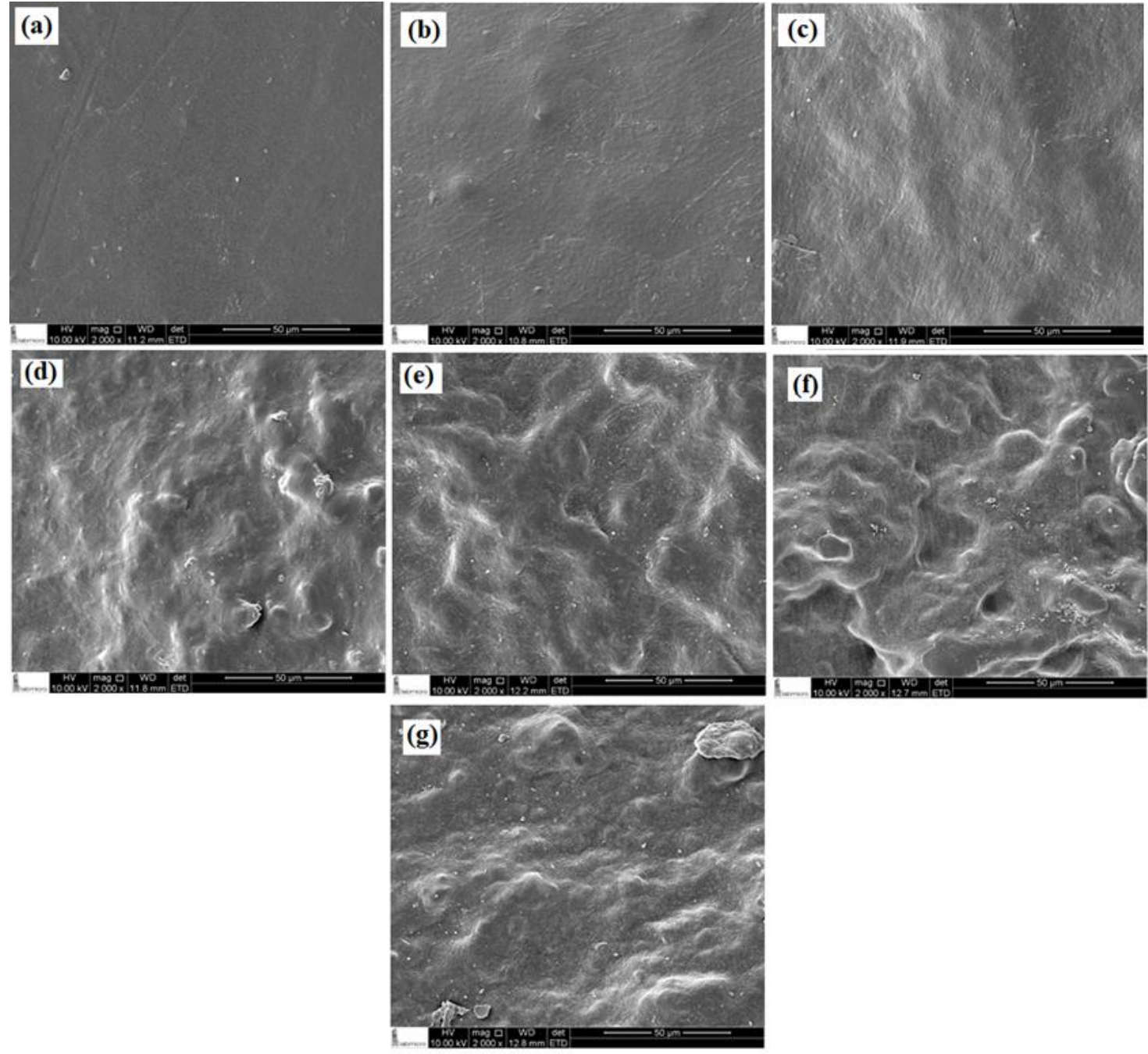

Figura 52 - Micrografias de MEV das blendas de PEBD/PEAD obtidas com polímeros pristinos, nas seguintes composições (em \% p): 100/0 (a), 90/10 (b), 70/30 (c), 50/50 (d), 30/70 (e), 10/90 (f) e 0/100 (g). Barras de escala = 50

$\mu \mathrm{m}$. 


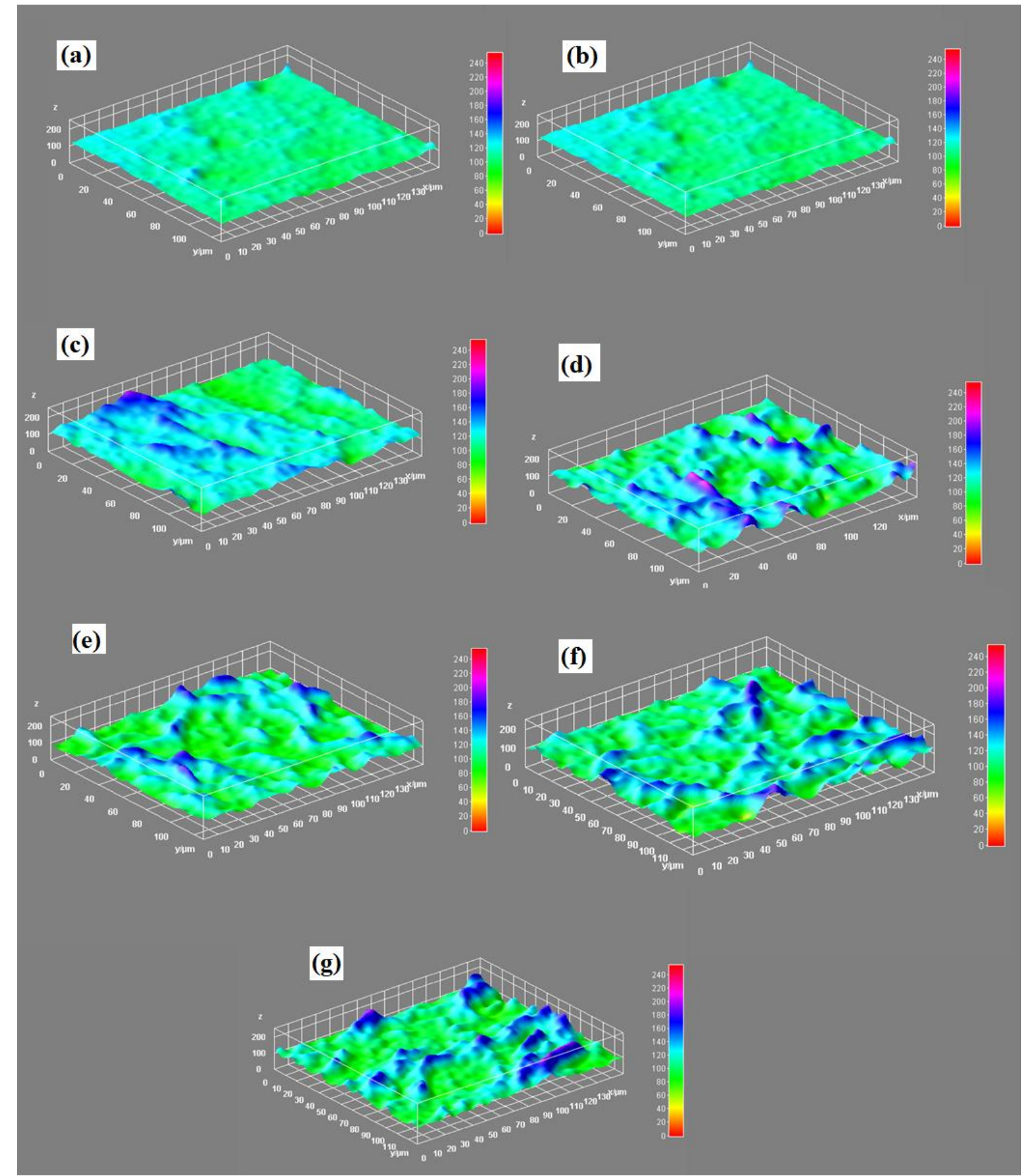

Figura 53 - Imagens superficiais 3D das blendas de PEBD/PEAD obtidas com polímeros pristinos, nas seguintes composições (em \% p): 100/0 (a), 90/10 (b), 70/30 (c), 50/50 (d), 30/70 (e), 10/90 (f) e 0/100 (g). 

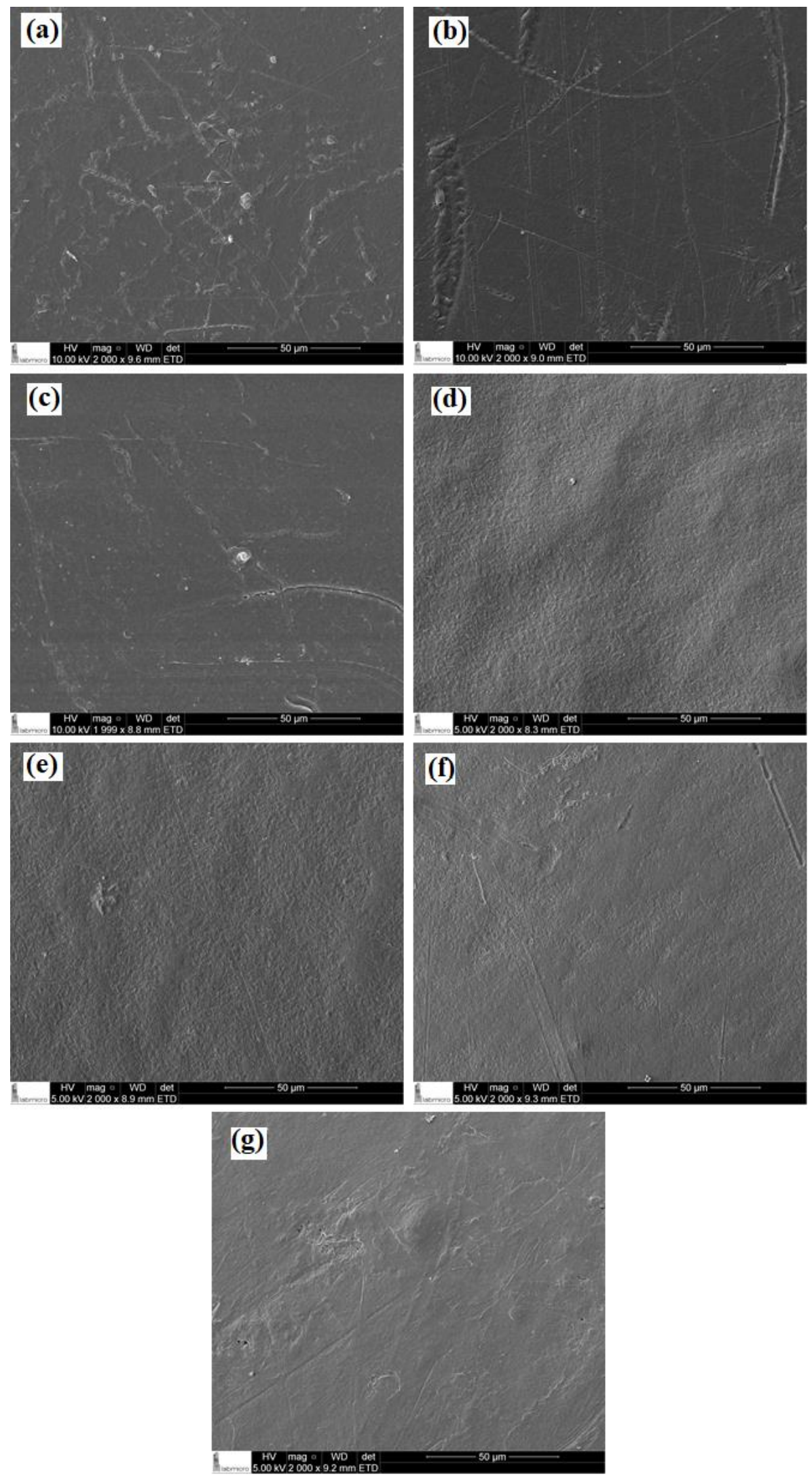

Figura 54 - Micrografias de MEV das blendas de PEBD/PEAD obtidas com polímeros reciclados, nas seguintes composições (em \% p): 100/0 (a), 90/10 (b), 70/30 (c), 50/50 (d), 30/70 (e), 10/90 (f) e 0/100 (g). Barras de escala = 50 $\mu \mathrm{m}$. 

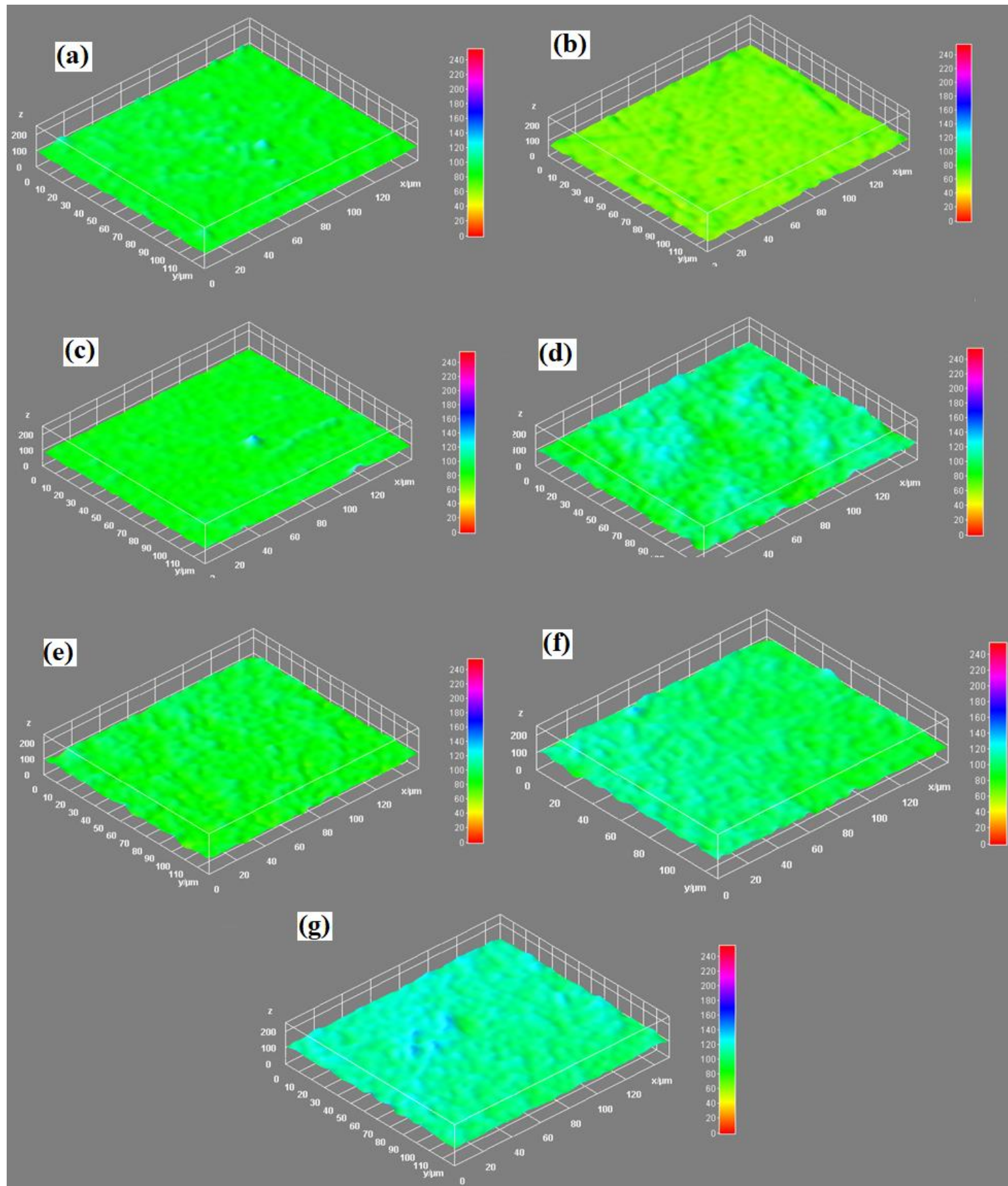

Figura 55 - Imagens superficiais 3D das blendas de das blendas de PEBD/PEAD obtidas com polímeros reciclados, nas seguintes composições (em \% p): 100/0 (a), 90/10 (b), 70/30 (c), 50/50 (d), 30/70 (e), 10/90 (f) e 0/100 (g).

7.3.2. Apêndice B - Espectros ATR-FTIR das misturas poliméricas de PEAD/PEBD recicladas com diferentes contaminantes

Os espectros ATR-FTIR das blendas poliméricas de PEAD/PEBD recicladas contendo carbonato de cálcio (calcita), PET, PP e sílica gel estão mostrados nas Figuras 56 a 59. 


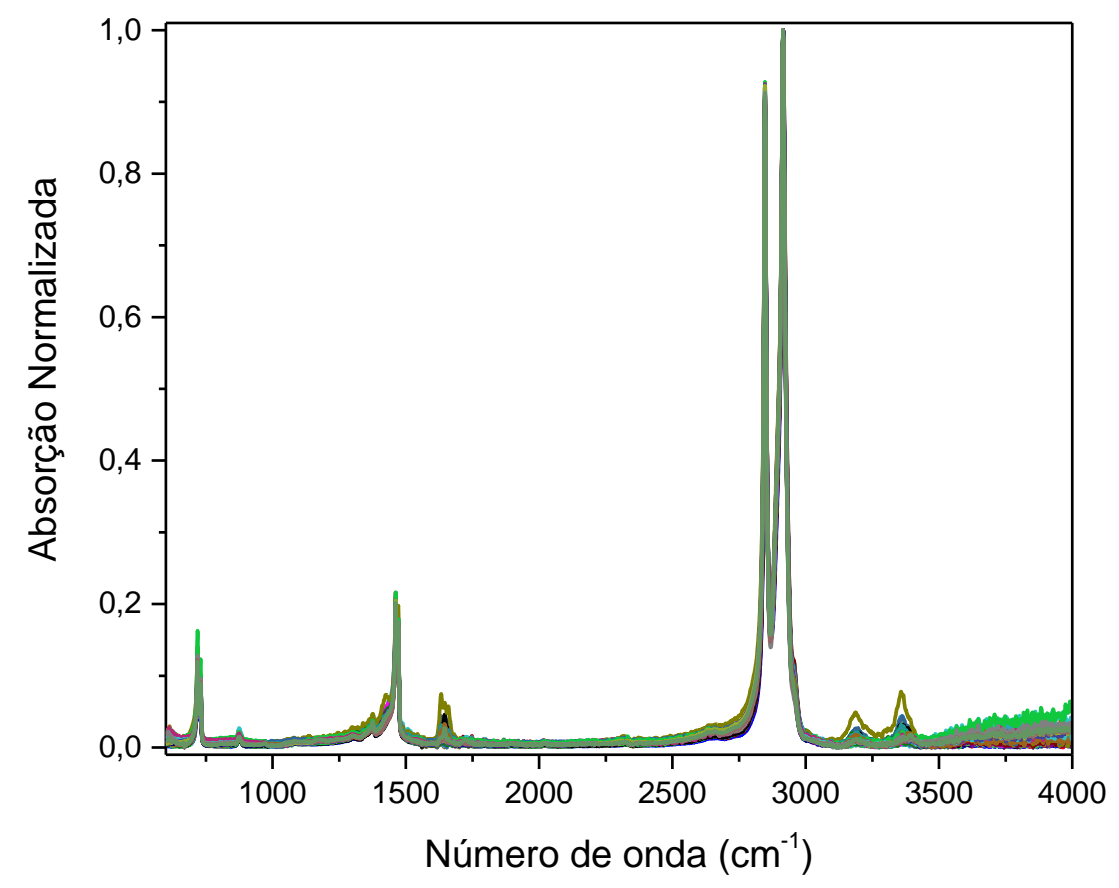

Figura 56 - Espectros ATR-FTIR das blendas de PEAD/PEBD recicladas contendo carbonato de cálcio.

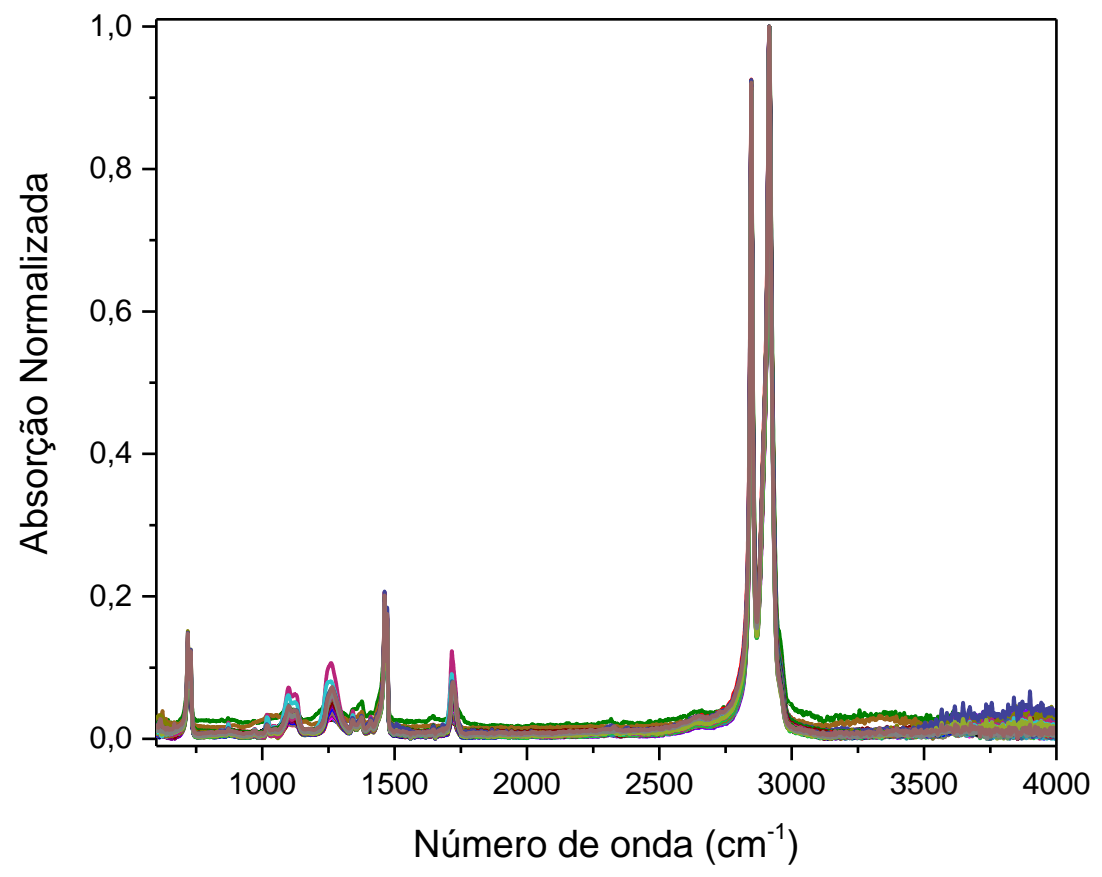

Figura 57 - Espectros ATR-FTIR das blendas de PEAD/PEBD recicladas contendo PET. 


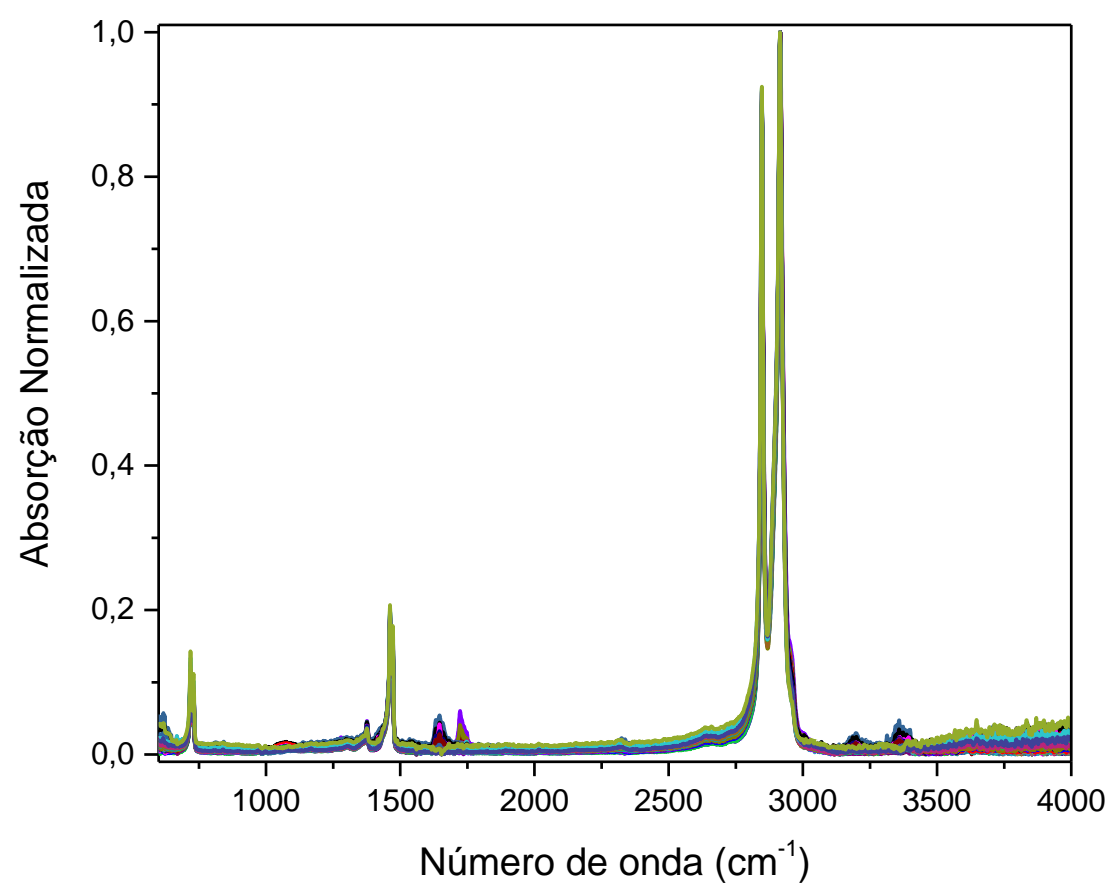

Figura 58 - Espectros ATR-FTIR das blendas de PEAD/PEBD recicladas contendo PP.

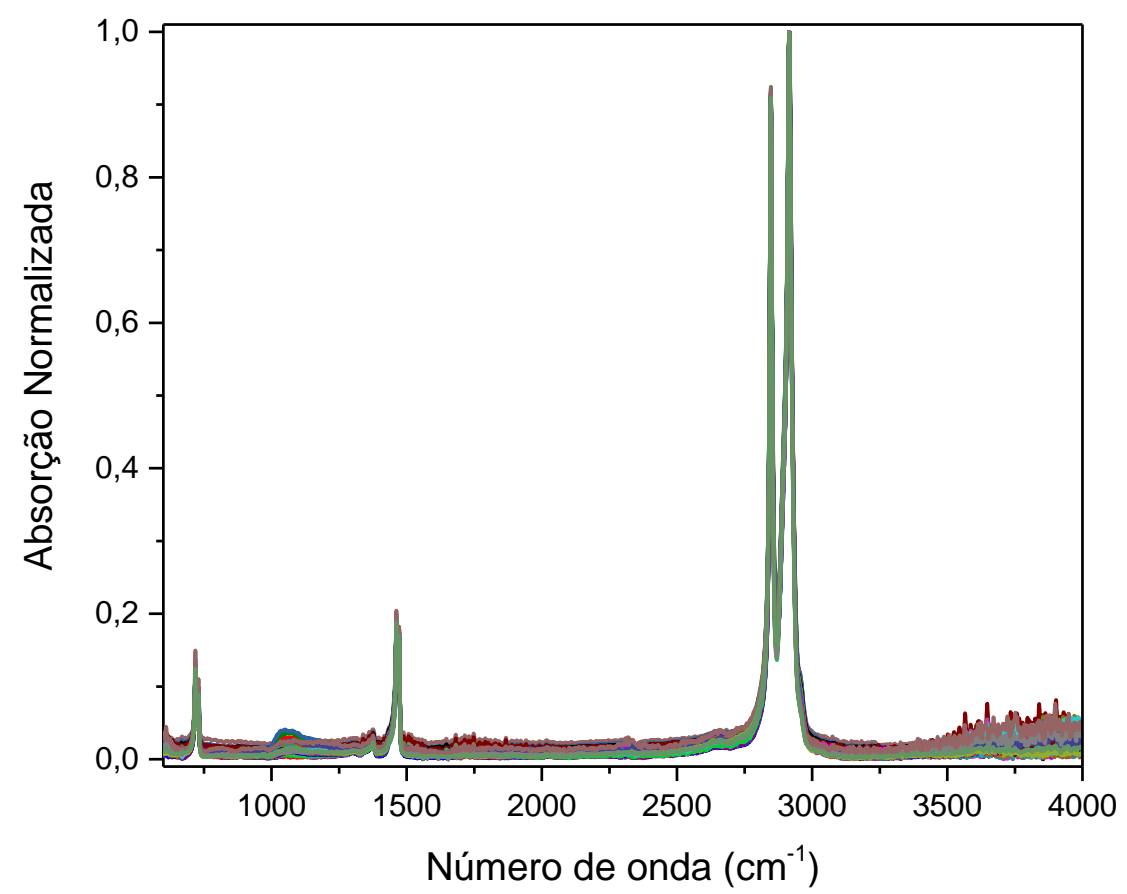

Figura 59 - Espectros ATR-FTIR das blendas de PEAD/PEBD recicladas contendo sílica gel.

7.3.3. Apêndice $C$ - Espectros de Raman confocal das misturas poliméricas de PEAD/PEBD recicladas com diferentes contaminantes

Os espectros obtidos por Raman confocal das blendas poliméricas de PEAD/PEBD recicladas contendo carbonato de cálcio (calcita), PET, PP e sílica gel estão apresentados nas Figuras 60 a 63. 


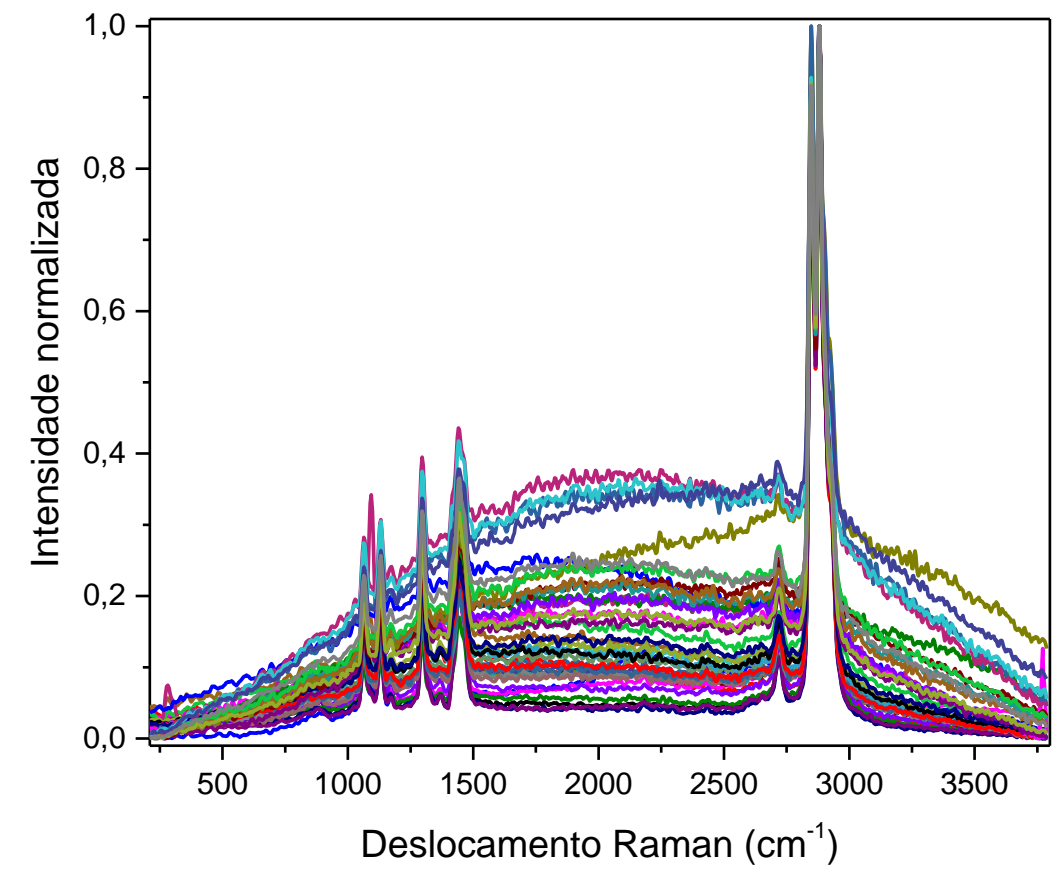

Figura 60 - Espectros de Raman confocal das blendas de PEAD/PEBD recicladas contendo carbonato de cálcio.

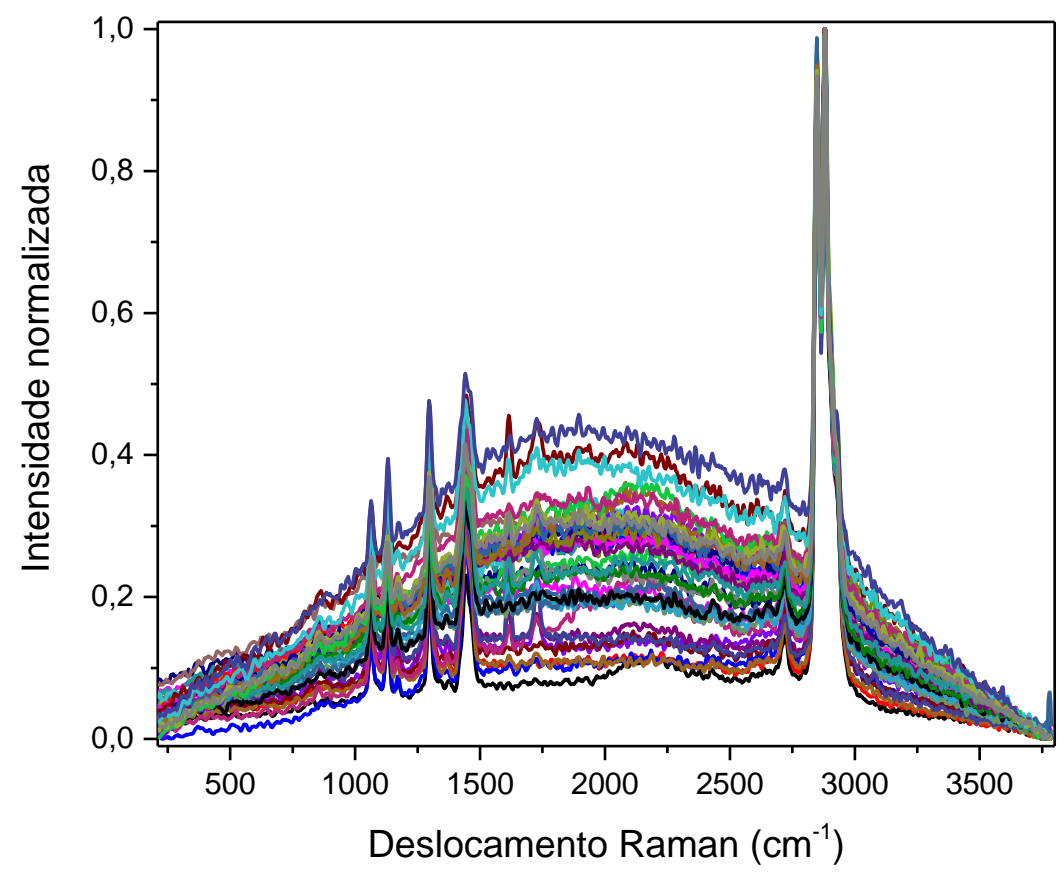

Figura 61 - Espectros de Raman confocal das blendas de PEAD/PEBD recicladas contendo PET. 


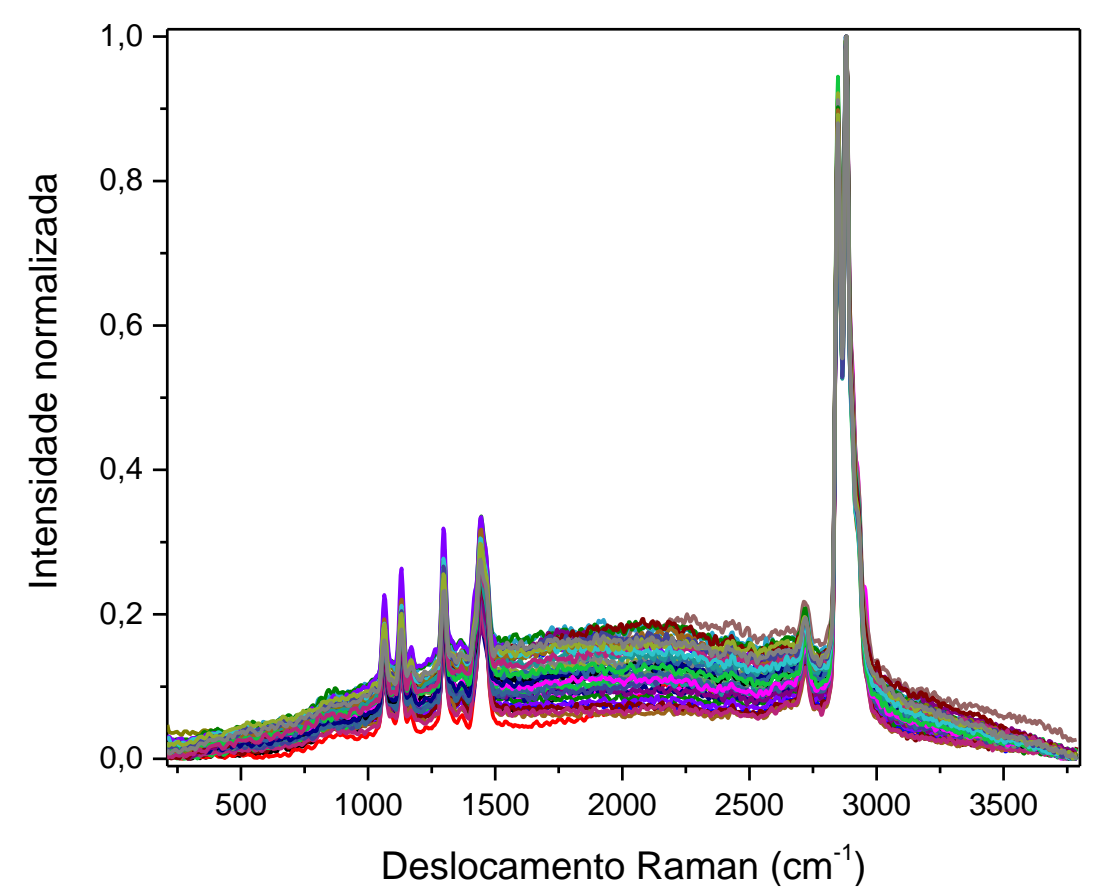

Figura 62 - Espectros de Raman confocal das blendas de PEAD/PEBD recicladas contendo PP.

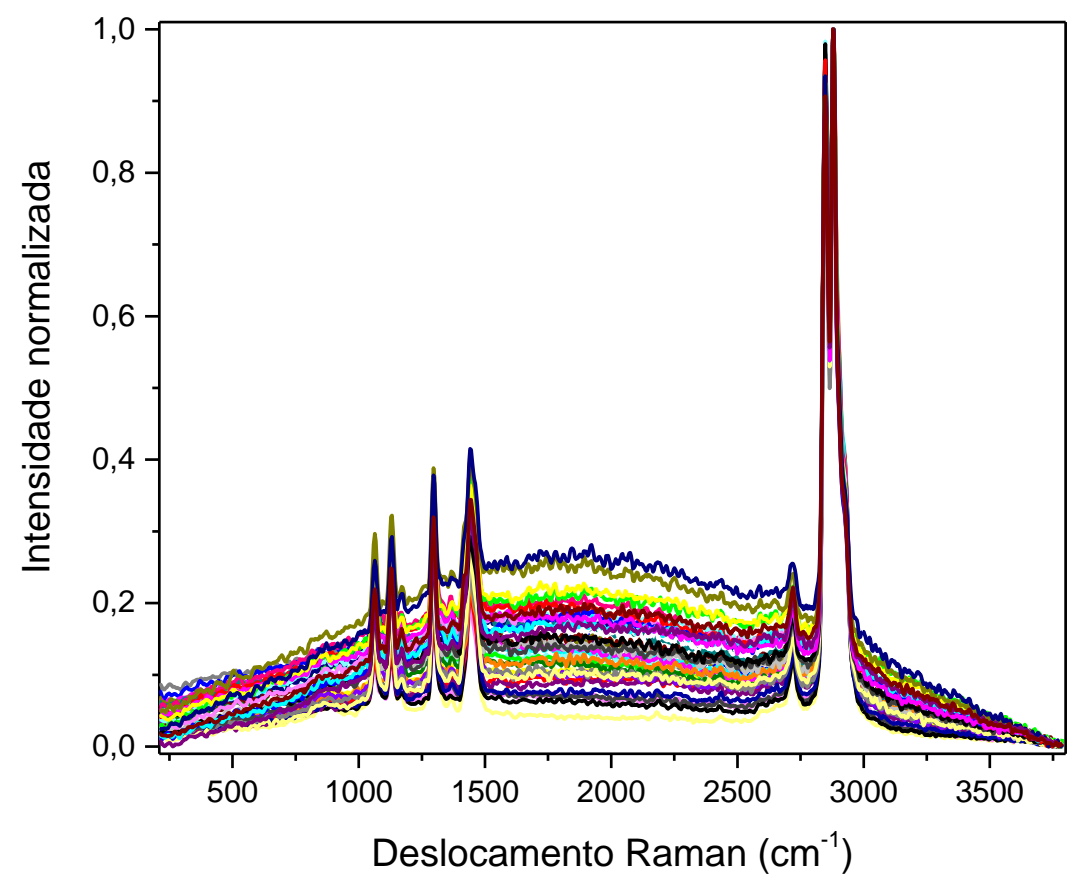

Figura 63 - Espectros de Raman confocal das blendas de PEAD/PEBD recicladas contendo sílica gel. 